\title{
Crude Power: The Foreign Policy of Oil-Producing States
}

\author{
Emma M. Ashford \\ Glasgow, United Kingdom \\ M.A., American University, 2009 \\ B.A., University of Virginia, 2007 \\ A Dissertation presented to the Graduate Faculty \\ of the University of Virginia in Candidacy for the Degree of \\ Doctor of Philosophy
}

Woodrow Wilson Department of Politics

University of Virginia

August 2014 
(c) Copyright by

Emma M. Ashford

All Rights Reserved

August 2014 


\section{ACKNOWLEDGEMENTS}

This dissertation would not have been written without the support and advice of many other people. I would like to thank my committee - Allen Lynch, Dale Copeland, David Waldner and Paul Stephan - for all their efforts throughout this process, especially their helpful comments and criticism on early drafts, which helped to make this project far better. In this dissertation, which blurs the line between international relations and comparative politics, I am particularly grateful for the differing viewpoints and theoretical background each brought to this project: Dale Copeland provided valuable insights on the best ways to structure theory and find one's own theoretical weaknesses, while David Waldner brought to bear his in-depth understanding of the issues surrounding analysis of natural resources in politics. I am particularly grateful to my chair, Allen Lynch. In addition to his wealth of knowledge on the politics of post-Soviet states, his support and advice on the dissertation process in general has been invaluable.

I am also indebted to a number of other scholars at U.Va, in particular to Todd Sescher for his extremely constructive comments on various chapters of the dissertation. I would like to thank Jeffery Jenkins and the members of the 2012 and 2013 Graduate Development Seminar, who not only provided critical comments on the project, but also provided moral support and acted as a sounding board for ideas throughout the dissertation writing process. The writing of the dissertation was made possible by funding from the Department of Politics, as well as financial support in the form of a predoctoral fellowship from the Bankard Foundation.

Last but not least, I would like to thank my family and friends, in particular, my parents and my brother, who have been extremely supportive throughout this long process. Their cheer and encouragement have been vital to the completion of this dissertation, and of the $\mathrm{PhD}$. My husband Will deserves special recognition. His love and support from beginning to end of this process has kept me sane and happy. Without him, this dissertation would never have been completed. 


\section{TABLE OF CONTENTS}

ACKNOWLEDGEMENTS ..................... . . ii

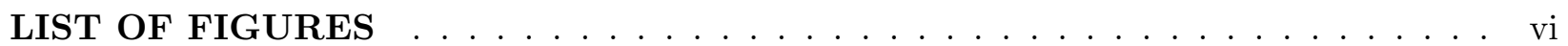

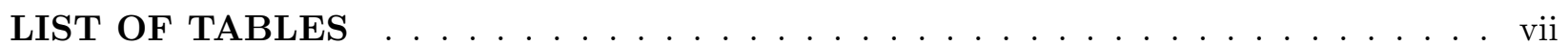

\section{CHAPTER}

I. Introduction $\ldots \ldots \ldots \ldots \ldots \ldots \ldots \ldots$

1.1 What is a 'Resource-Rich' State? . . . . . . . . . . . . . . . 5

1.2 Foreign Policy of the 'Rentier State' . . . . . . . . . . . . . . . . . . 9

1.3 Outline of the Dissertation . . . . . . . . . . . . . . . . 11

II. A Theory of Resource Abundance and Foreign Policy . . . . . . . . . . . . . 14

2.1 What Do We Know About Resource-Rich States? . . . . . . . . . . . . . . . 16

2.1.1 Domestic Political and Economic Distortions . . . . . . . . . . 16

2.1.2 International Relations and "Resource Wars" . . . . . . . . . . . . 18

2.1.3 Oil and Aggression . . . . . . . . . . . . . . . . . . . 20

2.1.4 Natural Resources: More than a Means for Conflict . . . . . . . . . 22

2.2 Oil, Natural Resources and Foreign Policy . . . . . . . . . . . . . . . . . . . 24

2.3 A Theory of Resource Abundance and Foreign Policy . . . . . . . . . . . . . 30

2.3.1 Oil Will Make You Rich . . . . . . . . . . . . . . . . . . 32

2.3.2 Resource Rents and Weak Institutions . . . . . . . . . . . . . 33

2.3.3 "Nervos Belli, Pecuniam."................. 43

2.3.4 Constraints in Government-Dominated Economies . . . . . . . . . 46

2.3.5 Theoretical Implications . . . . . . . . . . . . . . . . . . . 49

2.4 Methodological Issues . . . . . . . . . . . . . . . . . . . . . . . . . . . . . . . . . 51

2.4.1 Methodology and Case Selection . . . . . . . . . . 51

2.4 .2 Boundary Conditions . . . . . . . . . . . . . . . 55

2.4.3 Resources, Autocracy, Trade and Conflict . . . . . . . . . . 57

2.5 Conclusion . . . . . . . . . . . . . . . . . . 58

III. Resource Wealth and Aggression: A Quantitative Analysis . . . . . . . . 59

3.1 Methodology . . . . . . . . . . . . . . . . . . . 60 
3.1.1 Dependent Variables . . . . . . . . . . . . . . . . . . . . 61

3.1.2 Independent Variable, or; What is a 'Resource-Rich State'? . . . . 63

3.1.3 Control Variables . . . . . . . . . . . . . . . . . . 67

3.2 Empirical Results: Conflict Initiation and Oil . . . . . . . . . . . . . . 69

3.2.1 Regression Analysis . . . . . . . . . . . . . . . . 70

3.2 .2 Robustness Tests . . . . . . . . . . . . . . . . . 75

3.2 .3 Conflict and Oil . . . . . . . . . . . . . . . . . 81

3.3 Empirical Results: Oil, Threats and Sanctions . . . . . . . . . . . . 84

3.3.1 Logistic Regression Analysis . . . . . . . . . . . . . . . . . . . . 84

3.3.2 Robustness Tests . . . . . . . . . . . . . . . . . . . 89

3.3.3 Threat/Sanction Initiation and Oil . . . . . . . . . . . . . . . . 91

3.4 Oil vs. Natural Resources . . . . . . . . . . . . . . . . . . . . . 91

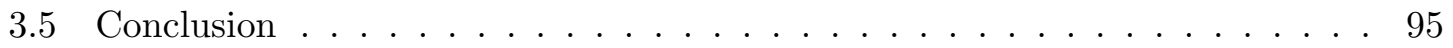

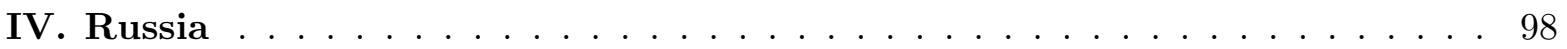

4.1 Russian Oil, Gas and Foreign Policy . . . . . . . . . . . . . . . . . 99

4.1.1 A Brief History of the Russian Petrostate . . . . . . . . . . . . . 99

4.1.2 Russian Foreign Policy Since the Soviet Collapse . . . . . . . . . . 101

4.1.3 Is Russian Foreign Policy Aggressive? . . . . . . . . . . . . . . . . . 107

4.2 From Oil to Weak Foreign Policy . . . . . . . . . . . . . . . . . . . 108

4.2.1 The Development of Russian Foreign Policy Institutions . . . . . . 108

4.2.2 Are Russian Foreign Policy Institutions Weak? . . . . . . . . . . . 113

4.2.3 Is Institutional Weakness Oil-Related? . . . . . . . . . . . . . . . . 116

4.2.4 Russian Military Spending and Focus . . . . . . . . . . . . . . 118

4.2.5 Government Constraints in Foreign Policy . . . . . . . . . . . . . . 121

4.2.6 Conclusion . . . . . . . . . . . . . . . . . . . . . . . 124

4.3 From Weak Foreign Policy Apparatus to Aggression . . . . . . . . . . . . . . 125

4.3.1 Russia and NATO in Kosovo (1999) . . . . . . . . . . . 125

4.3.2 The Second Chechen War (1999-2001) . . . . . . . . . . . . . 133

4.3 .3 The War in Georgia (2008) . . . . . . . . . . . . . . . . . 142

4.4 Conclusion . . . . . . . . . . . . . . . . . . . . . 151

4.4.1 Alternative Explanations . . . . . . . . . . . . . . 151

4.4.2 Russia: Personality-Driven Aggression . . . . . . . . . . . . . . 152

V. Saudi Arabia . . . . . . . . . . . . . . . . . . . . 154

5.1 Oil, Foreign Policy, and the Saudi State . . . . . . . . . . . . . . 155

5.1 .1 A History of Oil in the Kingdom . . . . . . . . . . . . . . . . . 155

5.1 .2 Saudi Foreign Policy: 1990-2012 . . . . . . . . . . . . . . . . 157

5.1.3 Does Saudi Foreign Policy Exhibit Aggressive Tendencies? . . . . . 162

5.2 From Oil to Weak Foreign Policy _. . . . . . . . . . . . . . . 163

5.2.1 The Development of Foreign Policy Institutions . . . . . . . . . . 163

5.2.2 Are Saudi Foreign Policy Institutions Underdeveloped? . . . . . . . 167

5.2 .3 Is Institutional Weakness Oil-Related? . . . . . . . . . . . . . . . 170 
5.2.4 Military Expenditure in the Kingdom . . . . . . . . . . . . . . . . 173

5.2.5 Government Constraints in Foreign Policy . . . . . . . . . . . . . 175

5.2 .6 Conclusion . . . . . . . . . . . . . . . . . . 178

5.3 From Weak Foreign Policy Apparatus to Aggression . . . . . . . . . . . . . . 179

5.3.1 Saudi Arabia and Yemen . . . . . . . . . . . . . . . . 179

5.3.2 Saudi Arabia and the Arab Spring . . . . . . . . . . . . . . 190

5.4 Conclusion . . . . . . . . . . . . . . . . 206

5.4 .1 Alternative Explanations . . . . . . . . . . . . . . 207

5.4.2 Saudi Arabia: Institutional Fragmentation and Aggression . . . . . 208

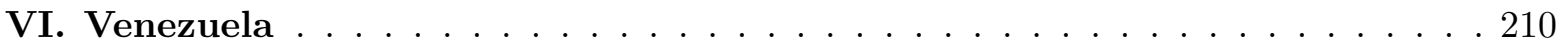

6.1 Oil and Foreign Policy in Venezuela . . . . . . . . . . . . . . . . . 211

6.1.1 A History of Oil in Venezuela . . . . . . . . . . . . . . . . . 211

6.1.2 Venezuelan Foreign Policy: 1990-2013 . . . . . . . . . . . . . . 213

6.1.3 Is Venezuelan Foreign Policy Aggressive? . . . . . . . . . . . . . . . 218

6.2 From Oil to Weak Foreign Policy . . . . . . . . . . . . . . . . . . . . . 219

6.2.1 Institutional Development and Foreign Policy . . . . . . . . . . . . 219

6.2.2 Are Venezuelan Foreign Policy Institutions Underdeveloped? . . . . 224

6.2 .3 Is Institutional Weakness Oil-Related? . . . . . . . . . . . . . . . . 227

6.2.4 Military Expenditure in Venezuela . . . . . . . . . . . . . . . . . 229

6.2.5 Government Constraints in Foreign Policy . . . . . . . . . . . . . . 232

6.2.6 Conclusion . . . . . . . . . . . . . . . . . . . . 234

6.3 From Weak Foreign Policy Apparatus to Aggression . . . . . . . . . . . . . . 235

6.3.1 Venezuela and Colombia . . . . . . . . . . . . . 235

6.3.2 Hugo Chávez: Covert and Verbal Aggression . . . . . . . . . . . . . 248

6.4 Conclusion . . . . . . . . . . . . . . . . . . . 260

6.4.1 Alternative Explanations . . . . . . . . . . . . . . . . . 260

6.4.2 Venezuela: Conflict as a Probabilistic Outcome . . . . . . . . . 261

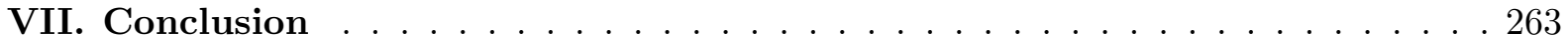

7.1 A Theory of Natural Resources and Aggression . . . . . . . . . . . . . . 263

7.2 Differing Outcomes in Oil-Rich States . . . . . . . . . . . . 265

7.2.1 A Pugnacious Petrostate: Iraq . . . . . . . . . . . . . . 265

$7.2 .2 \quad$ A Peaceful Petrostate: Kazakhstan . . . . . . . . . . . . . . . . 272

7.3 Summary of Findings . . . . . . . . . . . . . . . . . . 280

7.3.1 Theoretical Implications and Alternate Explanations . . . . . . . . 284

7.4 Key Observations . . . . . . . . . . . . . . . . . . . 285

7.5 Directions for Future Research . . . . . . . . . . . . . . . . . . 289

7.6 Policy Implications . . . . . . . . . . . . . . . . . . . . 290

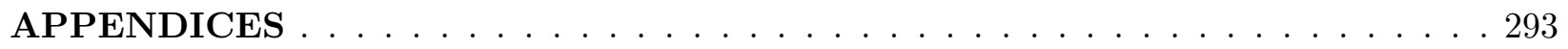

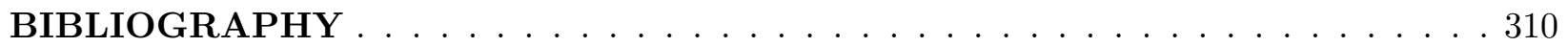




\section{LIST OF FIGURES}

\section{Figure}

$1.1 \quad$ Oil Prices $(1987-2012) \ldots \ldots \ldots \ldots \ldots \ldots$

2.1 Mean Conflicts/Threat Initiation by Level of Oil Revenue . . . . . . . . . . . . . 25

$2.2 \quad$ Causal Links between Oil, Foreign Policy Institutions and Aggression . . . . . . . . 31

2.3 The Institutional-Personalisation Mechanism . . . . . . . . . . . . . . . . 39

2.4 The Institutional-Informational Mechanism . . . . . . . . . . . . . . . . 40

2.5 Rationality: Institutions and Personality . . . . . . . . . . . . . . 56

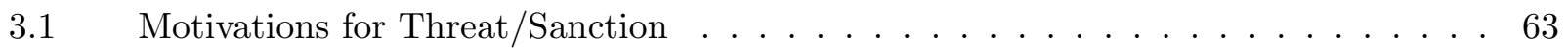

3.2 Distribution of States by Oil Revenues (as \% of GDP) . . . . . . . . . . 66

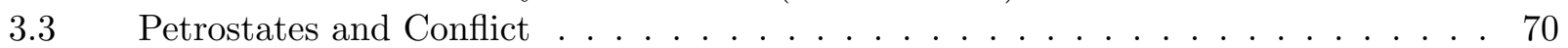

$3.4 \quad$ Predicted Probabilities of Conflict Initiation . . . . . . . . . . . . . . . . . 74

3.5 Predicted Probabilities of Conflict Initiation by Oil Revenues \& Four Key Variables: Great Power Status, Democratic Peace, Distance \& Trade Flows . . . . . . . . . . 75

3.6 Predicted Probabilities of Conflict Initiation: Two Measures of Oil Wealth . . . . . 83

$3.7 \quad$ Predicted Probabilities of Threat/Sanction . . . . . . . . . . . . . 87

3.8 Predicted Probabilities of Threat/Sanction . . . . . . . . . . . . . . 88

$4.1 \quad$ Russian Oil Rents (1991-2010) . . . . . . . . . . . . . . . . 117

4.2 Russian Oil Revenues vs. Military Expenditure (1991-2010) . . . . . . . . . . . . . 119

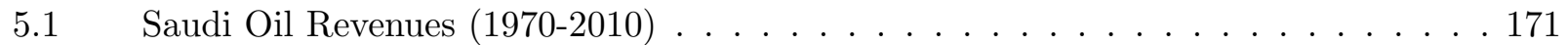

5.2 Saudi Oil Revenues vs. Military Expenditure (1991-2010) . . . . . . . . . . . . 173

6.1 Venezuelan Oil Revenues $(1970-2010) \ldots \ldots \ldots$. . . . . . . . . . . 228

6.2 Venezuelan Oil Revenues vs. Military Expenditure (1991-2010) . . . . . . . . . 230 


\section{LIST OF TABLES}

\section{$\underline{\text { Table }}$}

1.1 Types of Natural Resources . . . . . . . . . . . . . . . . . . . 6

1.2 Measurements of 'Resource-Rich': Oil . . . . . . . . . . . . . . . . . 8

$2.1 \quad$ High-Level Militarised Interstate Disputes Involving Petrostates . . . . . . . . . . 26

2.2 Oil Revenues vs. Natural Resource Revenues _ . . . . . . . . . . . . . . . . . . . . . 29

2.3 Tax Revenues vs. Natural Resource Revenues . . . . . . . . . . . . . . . . . . 35

$2.4 \quad$ Foreign Policy in Weak and Strong Institutional Environments . . . . . . . . . . 42

$3.1 \quad$ Petrostates in Dataset . . . . . . . . . . . . . . . . 65

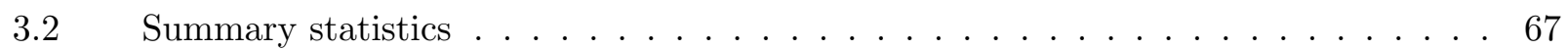

3.3 Conflict Initiation by Annual Oil Revenues . . . . . . . . . . . . . . . . . . 71

3.4 Robustness Test: Alternate Oil Measure . . . . . . . . . . . . . . . . . . 77

3.5 Haber/Menaldo Data on Conflict (1816-2002) . . . . . . . . . . . . . . 80

3.6 Revenues vs. Global Suppliers . . . . . . . . . . . . . . . . . . . . . 82

3.7 Threat/Sanction Initiation by Annual Oil Revenues . . . . . . . . . . . . . . . 85

$3.8 \quad$ Natural Resources and Conflict Initiation . . . . . . . . . . . . . . . . . 93

3.9 Natural Resources and Threat/Sanction Initiation . . . . . . . . . . . . . . . . 94

7.1 Theoretical Expectations and Findings . . . . . . . . . . . . . . . . 282

7.2 Comparison of Theoretical Explanations for Aggression in Oil-Rich States . . . . . 285

A.1 All Militarised Interstate Disputes Involving Petrostates (1965-2001) . . . . . . 295 


\author{
ABSTRACT \\ Crude Power: The Foreign Policy of Oil-Exporting States \\ by \\ Emma M. Ashford
}

As the price of oil has risen in recent years, resource-producing states have become more prominent in the international system. It is often remarked upon that these states are more prone to aggressive behavior, with cases such as Iraq, Iran and Libya commonly cited. Yet it is unclear whether there is in fact a link between oil and aggression. In addition, previous scholarly work has treated oil as an exogenous source of revenue, useful only for enabling military buildup in conflict. This approach has serious limitations, as oil has been shown to exert significant independent influence on domestic political outcomes, i.e., in democratization and economic development. This dissertation therefore sought to explore and illustrate the ways in which the organization of the domestic political economy around oil production impacts foreign policy behavior. The key mechanism by which oil impacts foreign policy is through the oil-induced weakening of foreign policy institutions. Weak institutions affect foreign policy by reducing the levels of available information for policymakers (resulting in rational miscalculations), and by making policy formation more personality-driven (i.e., made by small groups or individuals, and less consensual and cooperative). Oil can also impact foreign policy by enabling military buildup (and so making the use of force easier and more attractive to leaders), and by reducing financial constraints on leaders.

The dissertation first outlines a new theoretical framework highlighting the ways in which oil production in major oil-producing states can produce aggressive foreign policy. This is followed by a statistical study which seeks to assess the link between oil production and aggression. The study finds a strong and robust link between oil revenues and conflict initiation, as well as between oil 
revenues and threat/sanction initiation. It also finds that oil is effectively a unique natural resource, as other natural resources are not linked with aggression. The dissertation follows this with in-depth analysis of three countries (Russia, Saudi Arabia, and Venezuela), as well as two minor case studies (Iraq and Kazakhstan). In all cases, oil appears to have undermined foreign policy institutions and increased military spending, a factor which appears to have encouraged aggression in all cases except Venezuela. Oil's impact on aggression in these cases is indirect (i.e., mediated through state institutions), but is extremely influential. Ultimately, this dissertation improves our understanding of the causes of conflict by exploring the ways in which state dependence on oil production increases the likelihood of foreign policy aggression. 


\section{CHAPTER I}

\section{Introduction}

Oil, natural gas, iron, copper, zinc, cadmium, chromium and coal - these are among the many natural resources that heat our houses, run our factories and cars, and fuel our global economy. The news media frequently decries western dependence on 'foreign oil,' but citizens rarely know or care where the resources they consume come from. As only certain countries possess these resources, this creates dependencies and interdependencies among states. The US depends on imports from both friendly neighbours (i.e., Canada) and less friendly states in the Middle East and Latin America. The EU is increasingly dependent on imports of Russian and Central Asian natural gas. As a result, both scholars and policy makers seek to understand the political and economic features of resource-exporting states.

This dissertation seeks to explore one key aspect of the politics of natural resources: the link between aggressive foreign policy and oil or natural resource production. In doing so, it will seek to answer two key questions: 1) do oil-rich states indeed act more aggressively in foreign affairs than other comparable states?; and 2) if so, why? What is it about the organization of a state's political economy around oil production that alters foreign policy outcomes? The dissertation will examine three forms of aggression: physical (i.e., conflict), economic (i.e., sanctions), and verbal (i.e., threats). It will also also explore whether any relationship between aggression and resources applies to all natural resources, or whether some resources (i.e., oil) are more influential.

Despite the major role of natural resources in the global economy, the focus of previous scholarly 
research has been almost entirely on domestic affairs. Studies have shown the pernicious effects of oil on democratization, economic development and civil conflict but only within the boundaries of the state, ${ }^{1}$ while relatively little scholarly attention has been paid to the impact of oil production on relations among states. Indeed, scholarly work on the topic has not progressed substantially from the popular anecdotal assertions that resource-producing states are aggressive and belligerent, citing cases such as Iraq during the First Gulf War, Russia's attitude towards the 'near abroad', or Venezuela's belligerence towards the west since $2000 .^{2}$ It is not difficult to see why this assertion is frequently made, yet we have few explanations as to why these countries are more aggressive or conflict-prone than other states. It is also difficult to explain those resource exporters which are described as non-aggressive: Norway is the most obvious example, but others such as Saudi Arabia such as also require explanation. In 2005, Norway received more than $20 \%$ of its' GDP from oil exports, yet the country awards the Nobel Peace Prize each year. Few would accuse countries such as Trinidad and Tobago - that received 50\% of GDP from oil and gas exports in 2005 - of conducting an aggressive foreign policy. Finding out what differentiates resource-rich states and why they act more aggressively (in general) than other states, is a topic of vital importance for US foreign policy.

For many years, it was in fact believed that oil-rich states were more likely to be attacked, but we now know that this is not necessarily true. Rather, it seems that oil-rich states may instead initiate conflict more frequently than do other states. ${ }^{3}$ We do not, however, understand the causal mechanisms involved; current theories effectively attribute the empirical link between oil and conflict to other sources, such as revolutionary government. ${ }^{4}$ Natural resources are treated as merely an exogenous source of wealth for a government that would already have been conflict-prone. While oil or other natural resources certainly can increase power and influence, and permit military

\footnotetext{
${ }^{1}$ For discussion of the extensive literature on the domestic political and economic ramifications of natural resource production, see Chapter 2, Section 2.1.1.

${ }^{2}$ For examples, see Parasiliti (2003); Clem and Maingot (2011), Strouse (2009). For further discussion of the literature on natural resources in international relations, see Chapter 2, Sections 2.1.2 and 2.1.3.

${ }^{3}$ Colgan (2010) demonstrates that oil-rich states do indeed initiate more conflicts than other similar states, but argues only that oil provides the means for aggressive foreign policy.

${ }^{4}$ Colgan (2010); Colgan (2013).
} 
buildup, I argue that attributing agency to other factors (such as revolutionary government) ignores previous work on domestic politics, much of which illustrates direct links between natural resources and political outcomes. ${ }^{5}$

In addition, there has been little broader assessment of the links between natural resources and foreign policy. Previous research has focused almost entirely on conflict, particularly on the initiation of militarized interstate disputes. ${ }^{6}$ Many resource-rich states, however, exhibit aggressive behavior that does not necessarily lead to a militarized interstate dispute. For example, during the 1970s and 1980s, Muammar Gaddafi's government in Libya sponsored a number of terrorist groups, sending arms and money to insurgent groups across the Middle East and Africa, as well as Ireland, Germany and the Phillipines. In addition to the 1988 Lockerbie Bombing that killed several hundred people, the Libyan government sponsored dozens of other high profile attacks in Western Europe and the Middle East. However, an analysis of MIDs alone would reveal only one year (1986) where Libya was actually involved in conflict. Similarly, Hugo Chavez's government in Venezuela is seen as belligerent and aggressive, yet - other than his funding of the FARC in Columbia - his government has not regularly initiated conflicts. Many of the actions viewed as 'belligerent' by western powers are verbal, diplomatic or economic threats. The keypoint here is that by only studying conflict, we lose a great deal of information. If resource-rich states are aggressive in general, we can better understand the phenomenon by looking more broadly at foreign policy actions.

This dissertation's central argument is that oil production has a number of effects that, when taken together, make a state more likely to initiate conflict, and to exhibit aggressive foreign policy behavior. Firstly, oil rents undermine institutionalization in developing states, creating

\footnotetext{
${ }^{5}$ In general, the literature on the 'resource curse' posits several key problems that can arise from resource production: 1) democratic deficit (see Ross (2001); Lam and Wantchekon (2002)), 2) a lack of institutional development (Karl (1997); Chaudhry (1997); Robinson et al (2006)), 3) poor economic development (Haber and Menaldo (2011) provide the most statistically rigorous test of this hypothesis), and 4) civil war (See Ross (2004) for a good summary of the field). In all four cases, there is substantial debate about whether these effects are caused by natural resources alone, a mixture of resources and other factors, or are unrelated to natural resource production entirely. A more in-depth assessment of these literatures and debates can be found in Chapter 2, Section 2.1.1.

${ }^{6}$ Colgan (2010)(2013); Struver (2009); De Soysa, Gartzke and Li (2009). For further discussion, see Chapter 2, Section 2.1.3.
} 
a poor foreign policy bureaucracy and weak or inefficient intelligence services. This results in 'unprofessional' foreign policy decisions being made by a small group of individuals in a lowinformation environment, making bargaining more likely to break down, and conflict more likely. ${ }^{7}$ Secondly, resource rents permit governments to build up their military, buy equipment and pursue research with military applications, ensuring that the state is often better armed than its neighbors and more capable of entering a conflict quickly. This increases the likelihood that leaders will choose to use military means to resolve disputes. Finally, the government-dominated nature of the economy in these states vastly increases the size of the state, which both reduces the capitalist lobby for peace and means that leaders are less likely to suffer negative consequences from losing a war. Leaders are therefore less constrained in their ability to enter a conflict. Thus in many resourcerich states, foreign policy is produced in an unprofessional and low-information environment where government has easy access to military solutions, and the incentive to use them. I argue that this strongly increases the likelihood of aggressive foreign policy actions and of conflict initiation in these states. This theory is explored further in Chapter Two.

The question of whether resources matter for foreign policy is of increasing importance in today's world, as resource prices rise. As Figure 1.1 illustrates, the price of oil hit an all time high in 2008, with prices triple or quadruple what they were thirty years earlier. Markets saw prices fall during the global financial crisis but they have risen sharply since. This reflects both the increasing demand for fossil fuels as countries such as China undergo industrial development and the increasing difficulty of finding and extracting oil. As demand rises, and supply falls, resources such as oil become increasingly sought after. While oil is the most expensive (and price volatile) natural resource, other resources - natural gas, precious metals, etc. - are also increasing in both importance and cost. Fossil fuels in general are in great demand, and precious metals such as

\footnotetext{
${ }^{7}$ In this case, 'unprofessional foreign policy' is defined not by outcomes, but by intent. In effect, if we assume that those actors who formulate foreign policy are rational, then we would expect their output (i.e., specific foreign policies) to also be rational, that is to say, in the 'national interest.' This doesn't mean that policies produce the best outcomes, but that they are the most rational choice to serve the national interest at the time they are formulated. Thus, if we see irrational or suboptimal foreign policy decisions, they must necessarily be the result of either conflicting interests of various actors, or a deficiency in the structure of the foreign policy bureaucracy.

${ }^{8}$ Data from U.S. Energy Information Administration.
} 


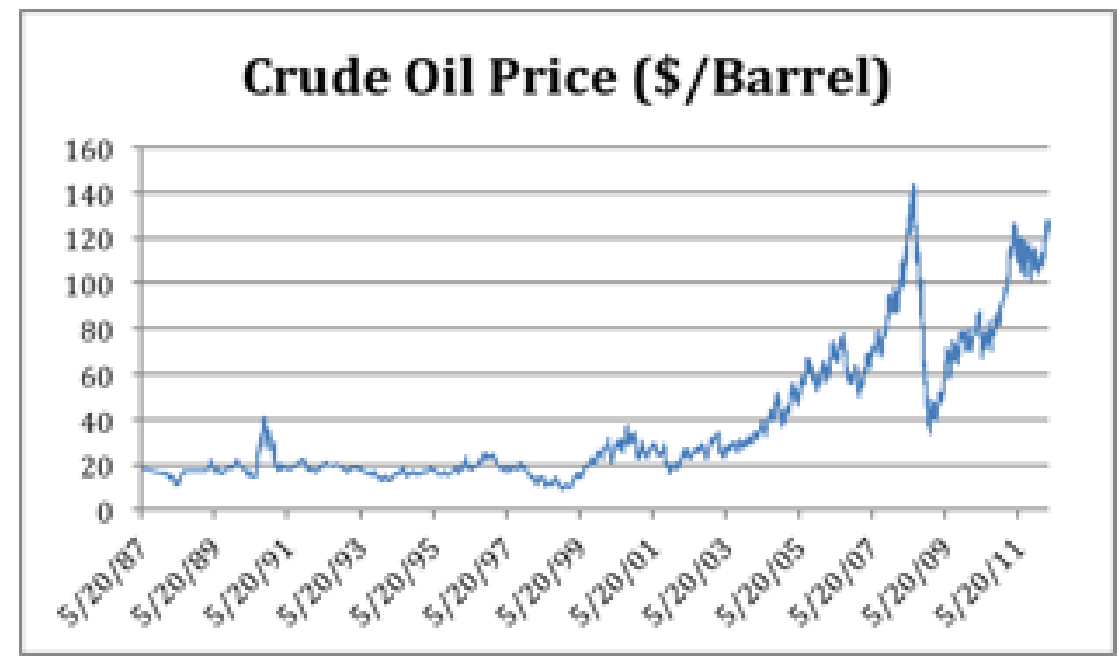

Figure 1.1: Oil Prices (1987-2012);

Brent Spot Crude Price per Barrel (inflation adjusted). ${ }^{8}$

chromium have many applications in phones, computers and other new technologies. In short, resource-rich countries are wealthy; they are becoming more so. A more thorough understanding of the ways in which these states conduct their foreign relations can only be of benefit to both academics and policymakers.

\subsection{What is a 'Resource-Rich' State?}

If one asked a layman to define 'resource-rich', his answer would likely be that Saudi Arabia, Iran, Libya and similar small non-western oil-rich states are the only ones with which we should concern ourselves. Yet, both Canada and the United States are among the world's largest producers of oil and natural gas. This confusion arises from the difficulty of defining a 'resource-rich' state. Should we measure the quantity of resources possessed by a state, or the impact of resource production on the national economy? Which resources should be included in our measurements? At what level should a state be considered 'rich' in certain resources? The answers to these questions matter a great deal, as prior research has shown that choices of definition may have substantial effects on the outcomes observed..$^{9}$

\footnotetext{
${ }^{9}$ Ross (2004) illustrates that different measurements of resource wealth in various works on natural resources and civil war in fact have major implications for study findings. It is safe to assume that this problem
} 
Table 1.1: Types of Natural Resources

\begin{tabular}{lll}
\hline \hline Hydrocarbons & Metals & Others \\
\hline Oil & Iron & Uranium \\
Natural Gas & Copper & Diamonds \\
Coal & Zinc & Salt \\
& Lead & Timber \\
& Platinum & Rare Earth Elements \\
& Lithium & Slate \\
& Gold & Quartz \\
& Silver & \\
& Copper & \\
\hline \hline
\end{tabular}

What counts as a natural resource? Practically anything, from renewable resources like timber, wind, or water, to nonrenewable fossil fuels. Yet most works on resource rich states tend to focus primarily on lucrative or rare resources, as these are the most likely to have a substantive effect on political and economic structures. Higher levels of resource rents will necessarily impact the economy and government finances more than lower levels of rents, and larger proportions of world supply bring more political leverage than small ones, meaning that rare or lucrative resources are likely to have larger effects on a nation. Table 1.1 illustrates some of the more common natural resources, which include hydrocarbons/energy resources, precious metals and gems, stone and rare elements. There are few countries which possess no natural resources at all, but resources vary wildly in terms of rarity and earnings potential. Lead ore, for example, is cheap and produced by many countries, while crude oil is produced by fewer countries and is extremely lucrative. This explains in part why so much of the previous work on resource states has focused on oil. The ease of obtaining data on oil is also a factor, as clear pricing, a uniform end product and global markets make data much easier to obtain on oil than on other resources such as natural gas, where pricing varies and global markets are fragmented.

Since the list of natural resources is virtually inexhaustible, this dissertation will adopt a shorter, more manageable list of natural resources as defined by the World Bank; this is defined as the "production of oil, natural gas, coal, minerals (i.e., precious metals and gems) and timber." 10 may apply to the general study of natural resources and political economy.

${ }^{10}$ World Development Indicators, The World Bank (2012). 
However, prior studies have shown that there may be a difference between oil and other natural resources. ${ }^{11}$ Authors disagree on why this is so, although it is strongly suspected that the high price of oil as opposed to other resources is to blame. Colgan (2010), for example, shows that oil-rich states are more prone to conflict, but does not assess any broader definition of natural resources. Therefore, one important question that this dissertation will seek to answer is whether any relationship between natural resources and foreign policy holds true for natural resources in general, or whether oil is in some way unique. The theory outlined in Chapter Two strongly suggests that more lucrative resources should have a more pronounced effect on state aggression.

Measurement of natural resource wealth also poses a problem. Each resource can be measured in four potential ways: 1) quantities extracted; 2) quantities exported; 3) stocks in the ground (in effect, future extraction potential); or 4) government rents received from extraction and sale. The first and second of these are purely measures of quantity, while the third represents the potential quantities for future extraction. The fourth measure, however, is more a way of assessing the impact of resource rents on the national economy, in particular on government finances. For many domestic theories of the resource curse, it is this link between resources and revenue that leads to such negative outcomes. In effect, it matters less if a country is a large global producer, than if resource production dominates the domestic economy and government finances.

For this reason, in this dissertation, oil production will be analysed using both a measure of revenues generated and a measure of production quantity. Indeed, as Table 1.2 shows, using different metrics to measure natural resources does in fact yield slightly different sample sets. The first column shows those countries that receive more than 10\% of GDP in resource revenues, while the second column instead shows those countries that produce over $1 \%$ of global oil production. The grey box indicates those countries that fall into both categories. Although there is a sizable overlap in the two groups of countries, there is enough difference to perhaps produce different results. It is likely that any distinction between the two measures may also help us understand the potential

\footnotetext{
${ }^{11}$ Collier and Hoeffler (2002), for example, include all primary commodities in their well-known study on civil war and natural resources, but point out that there is a statistically significant difference between the effects of oil and all other natural resources; although this has no substantive effect on their specific findings, it is clearly an important distinction.
} 
Table 1.2: Measurements of 'Resource-Rich': Oil

\begin{tabular}{|c|c|}
\hline $\begin{array}{l}\text { Oil Revenues } \\
(10 \% \text { of GDP })\end{array}$ & $\begin{array}{c}\text { Oil Exports } \\
\text { (Greater than 1\% of Global Supply) }\end{array}$ \\
\hline $\begin{array}{c}\text { Algeria } \\
\text { China } \\
\text { Egypt } \\
\text { Indonesia } \\
\text { Iran } \\
\text { Iraq } \\
\text { Kuwait } \\
\text { Libya } \\
\text { Malaysia } \\
\text { Mexico } \\
\text { Nigeria } \\
\text { Norway } \\
\text { Oman } \\
\text { Russia } \\
\text { Saudi Arabia } \\
\text { United Arab Emirates } \\
\text { Venezuela }\end{array}$ & $\begin{array}{c}\text { Algeria } \\
\text { China } \\
\text { Egypt } \\
\text { Indonesia } \\
\text { Iran } \\
\text { Iraq } \\
\text { Kuwait } \\
\text { Libya } \\
\text { Malaysia } \\
\text { Mexico } \\
\text { Nigeria } \\
\text { Norway } \\
\text { Oman } \\
\text { Russia } \\
\text { Saudi Arabia } \\
\text { United Arab Emirates } \\
\text { Venezuela }\end{array}$ \\
\hline $\begin{array}{c}\text { Angola } \\
\text { Azerbaijan } \\
\text { Bahrain } \\
\text { Brunei } \\
\text { Cameroon } \\
\text { Congo } \\
\text { Ecuador } \\
\text { Equatorial Guinea } \\
\text { Gabon } \\
\text { Kazakhstan } \\
\text { Papua New Guinea } \\
\text { Peru } \\
\text { Qatar } \\
\text { Sudan } \\
\text { Suriname } \\
\text { Syria } \\
\text { Trinidad \& Tobago } \\
\text { Tunisia } \\
\text { Turkmenistan } \\
\text { Yemen }\end{array}$ & $\begin{array}{c}\text { Argentina } \\
\text { Australia } \\
\text { Brazil } \\
\text { Canada } \\
\text { Colombia } \\
\text { India } \\
\text { United Kingdom } \\
\text { USA }\end{array}$ \\
\hline
\end{tabular}

NB: Countries were recorded as being in category for at least one year during the period 1965-2001. Grey area indicates overlap between categories. Data from World Bank, US Energy Information Administration and BP Statistical Index. For further information on sources and methods used in construction of the dataset, see Chapter Three, Section 1. 
causal links between resource extraction and foreign policy; for example, if we see that resource revenues are linked to conflict but the quantity of global production is not, this would indicate that a focus on those countries that receive high resource revenues may be warranted and that revenue itself may be an intervening variable linking natural resources with foreign policy behavior.

\subsection{Foreign Policy of the 'Rentier State'}

Most of the academic attention given to resource-rich states has focused on domestic politics and political economy, and on the perception of these states as 'rentier' states. The term was popularized by Mahdavy and Belwabi in the 1970s, and is typically used to describe any state that earns substantial rents from external sources, such as the export of a natural resource. These states are often viewed as corrupt, undemocratic, and economically underdeveloped. Research since the 1970s has continued to focus on these aspects, yet even as our understanding of the role that resources may play in domestic affairs has become more nuanced, ${ }^{12}$ the focus has remained narrowly domestic. Despite the overabundance of studies on domestic politics, we have little to no understanding of how these states conduct their foreign affairs. ${ }^{13}$ The focus in the media tends to be on energy security, that is to say, on the ramifications of dependence for many western states on imports of foreign resources, particularly oil and natural gas. Popular works on energy security and policy provide in-depth studies of the dependency links between different states, and formulate strategies for how western countries may insulate themselves from energy shocks. ${ }^{14}$ Although these works carry an unwritten assertion - that resource-rich states are not trustworthy partners for many western states - there is no real explanation of why this should be the case.

In more narrow, country-based studies, we see a more nuanced approach to the link between natural resources and foreign policy. In certain cases, scholars attribute belligerent state behavior to

\footnotetext{
${ }^{12}$ See Haber \& Monaldo (2011).

${ }^{13}$ Foreign policy is itself somewhat difficult to define. Foreign policies are essentially those actions taken by a state towards other states. This includes conflict, but also economic and diplomatic interactions. Comparative foreign policy analysis - the cross-national study of foreign policy using the comparative method - is particularly well suited to this project (Rosenau (1974), Kegley (1987)).

${ }^{14}$ For example, Yergin (1993) and (2011)
} 
oil wealth, or to the oil price cycle. Indeed, the hypotheses of these studies have been so well explored in certain regions that one scholar even states that "understandings of Russian energy diplomacy often focus on its position as an 'energy superpower," and devotes an article to attempting to debunk this claim. ${ }^{15}$ These studies tend to focus on the Middle East or Russia. ${ }^{16}$ Regardless, we see no clear general hypothesis about any link between foreign policy and resource wealth. The country studies are also frequently guilty of selecting on the dependent variable: One suspects that oil is cited as an important factor primarily because these states are large oil exporters.

Given the focus of the energy security literature on mistrust, it is baffling that the standard assumption among IR scholars has for many years been that resource-rich states are in fact more likely to be the victims of aggression than its perpetrators. This assumption is theoretical in nature, and implies that states will attack other states to obtain scarce resources when necessary. There have indeed been wars over resources (although they tend to be civil wars rather than intrastate ones), but there is no broad based evidence that resource-rich states are attacked more frequently than other states. Indeed, in the only study to statistically assess the relationship between conflict and oil, Colgan finds no clear link between resources and being the target of aggression. ${ }^{17}$ In contrast, he finds a strong link between oil and conflict initiation.

In summation, we know little about the foreign policy of resource-rich states, other than that they do appear to be more prone to initiate conflict. This is particularly perplexing, as one would expect any rational state that is heavily dependent on outside trade and rents to avoid conflict, as conflict is likely to disrupt trade arrangements. ${ }^{18}$ The dissertation will therefore seek to explore the links between oil and foreign policy actions more broadly.

\footnotetext{
${ }^{15}$ Monaghan (2007): 5 .

${ }^{16}$ See Strouse (2009); Parasiliti (2003); Clem and Maingot (2011).

${ }^{17}$ Colgan (2010).

${ }^{18}$ It is generally accepted that trade is beneficial to states and that conflict is less likely between trading partners since it reduces the potential for future trade (Rosecrance (1986)), although this relationship may be affected by various factors such as regime type (Oneal and Russett (2001)), or by expectations of future trade (or lack thereof) (Copeland (1996)).
} 


\subsection{Outline of the Dissertation}

Chapter Two picks up many of the themes touched upon in this introduction, and lays out the dissertation's central questions and theoretical framework. The chapter begins by outlining the extant literature on resource-rich states, both in comparative politics and international relations. It then lays out the dissertation's key questions and the central argument of the dissertation: that the pernicious effects of natural resource rents on the development of state institutions, combined with the impact of resource rents on military spending, and the negative effects of domestic economic dominance by the state is likely to create a less-constrained state with high-levels of military spending, and poorly formulated or unprofessional foreign policy, increasing the likelihood of conflictual foreign policy behavior. Chapter Two then lays out the testable hypotheses and theoretical expectations arising from this theory, and discusses various methodological issues.

Chapter Three tests statistically whether resource-rich states are more aggressive than states with similar characteristics which are not resource-producers using a newly created dataset that contains directed-dyad year observations for states between the years 1965 and 2001. First, the chapter discusses data sources, variables and the statistical methodology used. Next, the statistical analysis focuses on two key dependent variables (conflict and threats/sanctions), and two key independent variables (oil revenues and natural resource revenues). The findings indicate that states with higher levels of oil revenues do indeed initiate more conflicts, and initiate more threats and sanctions than other comparable states. This finding also holds true for those states with fewer resource revenues but which produce a large proportion of world supply. Following this, the chapter

examines whether the relationship between natural resources and conflict/threats is comparable to that between oil and conflict/threats, and finds that there is no clear relationship, indicating that oil may indeed be a unique natural resource.

Chapters Four through Six focus on individual resource-rich states, seeking to explore the causal mechanisms behind the relationship between oil revenues and aggressive foreign policy through indepth case studies. Each country is assessed in two specific ways: a broad survey of major foreign policy decisions during the period 1945-2010, and an in-depth analysis of several specific instances 
of foreign policy decision-making. In these sub-cases, the focus will be on process tracing and on assessing whether we can identify any of the effects predicted by the theory in Chapter Two. Chapter Four focuses on Russia, a major resource producer and a great power. Many observers have noted that Russian foreign policy during the last decade has seemed particularly aggressive, a fact that is often attributed (without explanation) to the rising price of oil and natural gas. ${ }^{19}$ The Russian case meets many of our theoretical expectations, with confused and unprofessional foreign policy making, and a strong reliance on military solutions to solve problems. The case illustrates how these factors contributed to conflict in three specific conflicts: Russia's involvement in Kosovo, the Second Chechen War, and the 2008 War in Georgia.

Chapter Five focuses on Saudi Arabia. While many observers describe Saudi Arabia as a peaceful oil-rich state, largely due to its strong and friendly relationship with the United States, this case illustrates that Saudi foreign policy is in fact quite aggressive, but relies heavily on covert action, and on the funding of third party actors to achieve its goals. Saudi foreign policy also meets many of our theoretical expectations, in particular, extreme personalization of foreign policymaking, and major institutional weakness. This case then explores how these factors impacted foreign policy formation in Saudi policy on Yemen, as well as the Kingdom's responses to the Arab Spring. Oil-induced institutional weakness and military spending are shown to be key in producing aggressive outcomes in these cases.

Venezuela, a country which has been a major producer of oil since the 19th century, is the subject of Chapter Six. Venezuela's recent aggressive behavior under the government of Hugo Chávez is well-known, but it was not so aggressive under the Punto Fijo period of pacted democracy which preceded Chávez's regime. Despite this, Venezuela did indeed meet several of our theoretical expectations during both periods, in particular a weak institutional framework for foreign policy, and high military spending. As such, the Venezuelan case provides an interesting case in which to assess our theory; this chapter explores Venezuelan engagement with Colombia, its relationship with the U.S., and Hugo Chávez's verbal aggression. Ultimately, the Venezuelan case provides an

\footnotetext{
${ }^{19}$ Also of particular note is the fact that the only current comprehensive study of oil and conflict (Colgan (2010)) describes Russia as an abnormality and an inexplicable case.
} 
illustration of the probabilistic nature of the theory (i.e., oil does not necessarily always produce conflict), and of the impact that other factors, such as informal institutions, can have on foreign policy formation.

Chapter Seven concludes the dissertation, discussing overall findings and contribution to future research. This chapter also includes brief case studies of two additional petrostates (Kazakhstan and Iraq), as well as a comparison of the explanatory power of the dissertation's theory with that several other key theories. Finally, the chapter discusses the policy implications of the dissertation's findings. 


\section{CHAPTER II}

\section{A Theory of Resource Abundance and Foreign Policy}

As discussed in Chapter One, this dissertation seeks to show that oil is not merely a means for state aggressiveness, and instead explores the factors that may explain the link between aggression and oil. The key questions are therefore: 1) As previous research suggests, are resource-rich states more aggressive than others? Does this apply to all foreign policy actions, or only to conflict initiation?; 2) If so, what is it that links oil and aggressive foreign policy behavior? and 3) Is oil unique, or do other natural resources have the same effects? In this chapter, I will argue that natural resources and foreign policy are linked in three key ways, although all rely on the lucrative, 'no-strings attached' nature of resource income for a government. The distortions of the polity which result from resource production can produce many unhealthy side effects, including profoundly impacting the incentives and preferences of policymakers as they make foreign policy decisions. I argue that these distortions have the potential to explain the propensity to aggression of many of these states.

First, there is a well-documented relationship between oil and weak institutionalization, as the ready stream of resource revenue diminishes the state's need for taxation and undermines the development of state capacity (especially in underdeveloped states). ${ }^{1}$ I argue that this is also likely to produce a weak foreign service and intelligence community. Leaders in resource-rich states are therefore operating in a low information environment when formulating foreign policy: they are not

\footnotetext{
${ }^{1}$ Karl (1997); Chaudhry (1997), among others, make this point.
} 
receiving advice from a professional foreign service, and may have limited sources of information, resulting in foreign policy that is less consensual, less informed and more personality-driven. Second, there is indeed truth to the idea that oil provides the means for conflict. States with high levels of resource rents have excess money that can be used to purchase military materiel, to support a large standing army, or to fund military research and technology, which does not need to be obtained through taxation. This not only provides the means for aggression, but increases the likelihood that politicians will resort to military action. Finally, an economy that is heavily reliant on natural resource production tends to be state dominated. Many scholars have argued that private ownership creates a lobby for peace (as peace increases profits) and increases constraints on a government's ability to enter a conflict. ${ }^{2}$ It follows therefore that a resource-rich economy is one in which the government faces fewer constraints on foreign policy.

This chapter will therefore focus both on the ways in which oil production can lead to our three mediating variables (weak institutions, military expenditure, and low government constraints), and on how these intervening variables can each increase the likelihood of conflict initiation and state aggression in a resource-rich state. It is laid out as follows: first, a brief discussion of prior literature on resource rich states outlines work on the domestic political ramifications of resource extraction, and highlights the limitations of our knowledge on the topic of foreign policy. Next, some key statistics illustrate the relationship between natural resources and foreign policy actions. Following this, the theory is outlined in more detail, and the resulting testable hypotheses are discussed. The chapter concludes with a discussion of research design, case selection, and several cross-cutting methodological issues.

\footnotetext{
${ }^{2}$ McDonald (2009); Gartzke (2001).
} 


\subsection{What Do We Know About Resource-Rich States?}

\subsubsection{Domestic Political and Economic Distortions}

Resource-rich states can suffer from many domestic political and economic problems. Although these vary widely in severity and impact, they are often collectively and popularly referred to as the 'resource curse.' Various scholars from the comparative politics tradition have illustrated that resource-rich states are likely to experience lower levels of democratization, economic development and even higher levels of civil conflict as a result of depending so heavily on natural resource extraction and rents, while others dispute some of these findings. Yet the evidence does tend to support the idea that being a resource exporter has substantive, often negative effects on a country, even if the magnitude of the effect varies.

The earliest studies on oil-rich states argued that the possession or production of natural resources can corrupt regimes and undermine democracy. During the 1970s and 1980s, a number of scholars noted the empirical regularity that many oil exporters were non-democratic, producing single-country case studies of the potential for authoritarianism in states with large quantities of resource rents, an idea later popularized as 'rentier state' theory. Most of this research focused heavily on the oil states of the Middle East (Iran in particular), ${ }^{3}$ but cross-national analysis was limited, as "theories of the rentier state far outstrip[ped] detailed empirical analysis of actual cases." ${ }^{4}$ In response to this criticism, Michael Ross provided the first major cross-national statistical study illustrating a correlation between authoritarianism and resource production, ${ }^{5}$ and the period following saw broader statistical work that - with a few key exceptions - tended to support the rentier state hypothesis. Lam and Wantchekon, for example, find a similar statistical relationship, but argue that resource rents simply reinforce elite authority. ${ }^{6}$ Others argue that static models are the problem, as resource wealth does in fact increase the survival rate of already existing autocracies,

\footnotetext{
${ }^{3}$ Mahdavy (1970); Skocpol (1982), among others

${ }^{4}$ Chaudhry (1997): 287.

${ }^{5}$ Ross (2001).

${ }^{6}$ Lam and Wantchekon (2002).
} 
but cannot create autocracy by itself. ${ }^{7}$

Resource wealth has also been studied as a potential reason for weak state structures, and limited state capacity. ${ }^{8}$ Recent studies have tended to take a more nuanced approach, with resource wealth perhaps not the cause of weak institutionalization, but instead merely a reason why poor institutions do not improve. ${ }^{9}$ Recent research has also highlighted the importance of whether a state had strong institutions prior to discovering natural resource wealth, as the quality of state institutions is effectively a pre-existing factor. In this way, resource wealth can inhibit the development of good institutions in undeveloped states, retard the growth of further institutional capacity in somewhat developed states, but have little effect on institutions in an already developed state. ${ }^{10}$ This has the potential to explain why Norway, for example, has strong state institutions, while Yemen does not. ${ }^{11}$

More controversial is the link between natural resources and economic development. This is also probably the largest single school of thought on the 'resource curse.' Numerous anecdotal and single country studies have come to the conclusion that resource producers are unlikely to become successful developmental states. ${ }^{12}$ Sachs and Warner produced the first major statistical study on the topic, in which they drew a clear correlation between resource abundance and lower levels of economic growth. ${ }^{13}$ However, later work sheds doubt on this conclusion; more sophisticated statistical analyses often show little evidence of an economic resource curse, and even some evidence that those states with abundant resources may do better than others. ${ }^{14}$

\footnotetext{
${ }^{7}$ Ulfelder (2007).

${ }^{8}$ Chaudhry (1997); Karl (1997).

${ }^{9}$ Waldner and Smith (2012) make this argument.

${ }^{10}$ See Acemoglu and Robinson (2006); Mehlum et al (2006); and Brunnschweiler and Bulte (2008).

${ }^{11}$ Alexeev and Conrad (2009) conclude that resource wealth does not inhibit growth, but that a state's starting point (at the time of oil discovery) is key: resource wealth does not encourage institutionalisation, but it cannot undo the past. In effect, Saudi Arabia's institutions and development without oil would not resemble Sweden, but rather Yemen.

${ }^{12}$ Auty (2001).

${ }^{13}$ Sachs and Warner (1995) focus primarily on the phenomenon known as 'Dutch Disease,' the idea that a profitable resource sector encourages capital and labour to flee all other productive sectors, resulting in an underdeveloped economy heavily reliance on extractive industries.

${ }^{14}$ Haber and Menaldo (2011) subject the economic ramifications of the resource curse to extensive analysis and find no clear link between resources and poor economic performance, even using a variety of different measures for resources and control variables. It should be noted, however, that while this study makes a
} 
Mixed results are common in studies of the resource-curse; for example, although a number of studies have shown that when factors such as corruption and investment (for example) are included in statistical regressions, resources have no effect on economic growth, it can also be argued that these factors are not true omitted variables, but are instead 'transmission methods' for natural resources. ${ }^{15}$ There are also theoretical limitations and endogeneity problems in many of these works. ${ }^{16}$ Causal mechanisms are also unclear, as explanations range from weak institutions, to corruption, ${ }^{17}$ to politicians' incentives to make poor decisions due to short time-horizons. ${ }^{18}$ In possibly the most contentious debate on the 'resource curse' - the link between resource wealth and civil war - the literature is characterized by mixed statistical results and broad confusion about potential mechanisms. The idea that resources promote greed and conflict seems logically intuitive, yet studies indicate that natural resources increase the likelihood of civil conflict, ${ }^{19}$ or may even increase its' duration, ${ }^{20}$ while several others have found no significant link between the two. ${ }^{21}$ Although many of these debates continue, there is no denying that natural resources are an important domestic factor that merits further study.

\subsubsection{International Relations and "Resource Wars"}

Given this extended debate on the domestic features of resource-rich states, it is surprising how little attention has been paid to these states by scholars of international relations. Traditional realist accounts of state behavior tended to ignore natural resources (as indeed they ignored all domestic political and economic factors). In these accounts, the national interest - ie, state survival - is the key

convincing case against an economic resource curse, it doesn't address institutional or democratic effects.

${ }^{15}$ Papyrakis and Gerlagh (2004) argue that when this causal chain is accounted for, the negative effects of resources on growth still far outweigh any positive effects.

${ }^{16}$ Studies often test hypotheses using a measure of oil exports as a percentage of GDP for the independent variable, and GDP growth itself as the dependent variable. Since these measures are linked, this poses substantial measurement problems.

${ }^{17}$ Williams (2011).

${ }^{18}$ Acemoglu and Robinson (2006).

${ }^{19}$ See Collier and Hoeffler (2002); Fearon and Laitin (2003), among others.

${ }^{20}$ Fearon (2003).

${ }^{21}$ Humphreys (2003); De Soysa (2002). 
(and often only) factor guiding state behavior in the international system. ${ }^{22}$ Unlike other domestic factors, however, natural resources do in fact matter to neorealist theories of international relations as one piece of an 'elements of national power' approach, ${ }^{23}$ providing a key source of matériel and military power for a state.

However, despite this, there has been little analysis of how natural resources augment state power, and only limited discussion of the fungibility of natural resources for military purposes. ${ }^{24}$ In part, this is a reflection of the fact that power is notoriously difficult to measure - something that often leads to tautological arguments. Thus, although natural resources are one key element of state power, ${ }^{25}$ both neorealist and neoliberal scholars have tended to ignore natural resources, merely asserting that possession of these resources will grant states increased power and influence. One key work that highlights this problem is Keohane and Nye's Power and Interdependence, which analyzes how interdependence can alter power relationships. ${ }^{26}$ Although the book's central example of vulnerability is natural resource dependence, the authors do not make any attempt to analyze which resources may be important, or in which ways they increase power and influence.

Second image theories - those that focus on domestic imperatives and foreign policy creation - have also been largely silent on the subject of natural resources. Even works (such as those on capitalist peace theory) that typically analyze domestic political economic factors have almost entirely ignored the potential for natural resources to affect foreign policy, perhaps due to the framing of such arguments in contrast to work on the 'democratic peace.' ${ }^{27}$ This is merely one example, yet despite numerous studies on regime type, lobbying, institutional structure and other

\footnotetext{
${ }^{22}$ The national interest is itself an extremely 'fuzzy' concept, as societal needs can often conflict with the interests of the governing elites (Knorr (1975)).

${ }^{23}$ Berenskoetter and Williams (2007).

${ }^{24}$ Baldwin (1989).

${ }^{25}$ Waltz (1979).

${ }^{26}$ They posit that some countries are 'sensitive' to these effects, i.e., would experience short-term problems, while others are 'vulnerable,' because it would not be easy to recover even in the long-term (Keohane and Nye (2000)).

${ }^{27}$ Since there is a clear statistical relationship between economic interdependence and conflict (Gartzke, $\mathrm{Li}$ and Boehmer (2001); Mansfield and Milner (2000)), most works on the links between political economy and conflict focus on mechanisms (Rosecrance (1986); Russett and Oneal (2001); Copeland (1996)). Unfortunately for our area of study, these works focus largely on developed western democracies, and are more concerned with trade in goods than in primary commodities.
} 
domestic factors, there has been little exploration of the issue of natural resources, with Colgan (2010) the only major exception.

As a result of the focus on resources as power, policy debates have focused heavily on the politics of dependence and conflict. Even the academic literature on the topic has focused on factors such as US energy strategy, or upon the potential for wars over scarce natural resources such as oil. This literature also clusters temporally, with many pieces written in the mid-to-late-1970s on the political ramifications of the 1973 oil shock. ${ }^{28}$ Some policy studies - particularly during the late 1970s and 1980s - focused on the study of cartel formation and operation (i.e., the politics of OPEC) and either tended to discuss the internal politics of the cartel, ${ }^{29}$ or provided histories of the development of the oil and natural gas extraction industries. ${ }^{30}$ Some policy and academic papers have focused on the military applications of resources, in particular predicting conflict or "resource wars" over scarce natural resources. ${ }^{31}$ Despite this, the limited works on the topic have illustrated that this is only likely in certain situations, such as when states share disputed borders, and/or when natural resources are close to border areas. ${ }^{32}$ In other situations, it seems that states do not conflict over natural resources, and that natural resource producers are in fact less likely to suffer attacks or invasions than other similar states. ${ }^{33}$

\subsubsection{Oil and Aggression}

In contrast to the works discussed above - where resource rich states are the target of aggression - this dissertation focuses on the role of natural resources in creating aggressive foreign policy by oil producing states. Few studies have discussed this, and those which do tend to perpetuate the idea of natural resources as nothing more than a source of power or influence, despite often finding evidence for the aggressiveness of resource-rich states.

\footnotetext{
${ }^{28}$ In fact, there have been few books written on this topic since the $1980 \mathrm{~s}$.

${ }^{29}$ Maull (1975); Pachauri (1985).

${ }^{30}$ Hamilton (1986); Walton (1977).

${ }^{31}$ Klare (2002, 2007); Conant (1982); Lieber (1983); and Westing (1986), among others.

${ }^{32}$ Caselli, Morelli and Rohner (2012) show that conflict is indeed more likely when states share a disputed source of natural resources.

${ }^{33}$ De Soysa, Gartzke and Li (2009).
} 
In one unpublished paper, for example, De Soysa, Gartzke and Li test three potential models for conflict among oil-rich states: 1) a 'blood oil' model where states attack in order to obtain resources; 2) a 'liberal oil' hypothesis, where trade imperatives prevent conflict with oil-rich states; and 3) a 'strategic oil' model, where the possession of oil permits oil-rich states to be more aggressive abroad. They find some support for the third hypothesis, but do not provide any reason for aggressiveness on the part of petrostates, focusing instead on why they find no evidence of 'resource wars. 34 Similarily, Struver describes a typology of four possible resource-based conflicts, assessing whether states fight in order to gain resources, or because they have resources. His analysis is primarily based on simple bivariate statistics, but concludes that resource-rich states are surprisingly likely to initiate conflicts. Again, however, he simply assumes that this is because oil wealth provides military power, providing no actual causal mechanism. ${ }^{35}$

Colgan provides the most nuanced and statistically complex analysis to date of the relationship between oil and conflict. In his 2010 article and followup book, he illustrates, as previous studies suggested, that oil exporters do initiate more MIDs than other similar states. ${ }^{36}$ However, his findings rely statistically (and theoretically) on the inclusion of a variable for 'revolutionary government' in his analysis, which shows that it is only when oil and revolutionary government come into contact that states initiate more conflicts. Theoretically, therefore, his argument hews to the classic understanding of natural resources: they are at best a source of power, wealth or leverage, and it takes revolutionary government to provide the agentic power which leads to increased conflict. While this is the most comprehensive study of natural resources and conflict to date, it nonetheless has several key limitations. In particular, the author does little to assess the potential endogeneity that may link oil wealth and revolution itself, presenting only a few simple statistics to support his contention that there is no link. If oil wealth is indeed partly endogenous to revolutionary government, as some prior theories have suggested, then this would be a major concern for these statistical results. Since he does not test any model where oil wealth is not in-

\footnotetext{
${ }^{34}$ De Soysa, Gartzke and Li (2009).

${ }^{35}$ Struver (2010).

${ }^{36}$ Colgan (2010); (2013).
} 
teracted with revolutionary government, it is unclear whether there is a relationship between oil and conflict independent of revolutionary governance. Colgan also briefly addresses the difference between natural resources in general and oil in particular, and finds that natural resources seem to have no clear relationship with conflict.

These three works, although they begin to address the potential links between oil and foreign policy, all suffer from the two key limitations: Firstly, all these works focus on oil primarily as a means for conflict, rather than as a mechanism. In each case, the argument is effectively that oil provides military might or influence, and thus a means for states already predisposed to conflict to achieve it with fewer costs. These arguments have little explanatory power, as they rely on exogenous factors to explain conflict initiation itself. These studies also ignore potential international mechanisms that may link oil production and conflictual behavior, such as involvement in international institutions. ${ }^{37}$ All of this implies that there may be additional reasons why oil-rich states initiate conflicts. Secondly, they focus almost entirely on armed conflict, at the expense of considering aggressive foreign policy behaviour more broadly. If natural resource production does increase the likelihood of conflict, it is also likely that it shapes a state's foreign policy in general.

\subsubsection{Natural Resources: More than a Means for Conflict}

This dissertation therefore seeks to explore the relationship between natural resources and foreign policy, drawing on the literature on the domestic political and economic ramifications of resource extraction. While there is evidence that natural resources (in particular, oil) are linked to aggressive foreign policy, we have little understanding of why this is the case. In contrast to Colgan's work on oil and conflict, this dissertation seeks to focus on oil not only as a means for conflict (i.e., through military expenditure), but as a potential mechanism, linking work on the domestic effects of the 'resource curse' with the propensity to aggressive foreign policy seen among many resource states. Thus it examines the ways in which oil production distorts the foreign policy

\footnotetext{
${ }^{37}$ One recent unpublished paper argues that oil-rich states are extremely unusual in that they are extremely economically globalized, while remaining outside the scope of many humanitarian and societal international organizations (Ross and Voeten (2011)). This has the potential to impact foreign policy behavior in a major way.
} 
process, particularly through weak institutionalization.

Although this dissertation does not seek to add to the major theoretical debates in international relations, it nonetheless seeks to situate its analysis within the neoclassical realist paradigm. Neoclassical realism strives to integrate the best qualities of third-image and second-image theories of international relations in order to produce coherent theories of foreign policy. ${ }^{38}$ The key limitation of neorealist theory is that its parsimony strongly reduces its explanatory power. In this way, it is more a theory of international relations than it is a theory of foreign policy. ${ }^{39}$ Similarly, secondimage domestic theories tend to ignore international variables, placing all explanatory power for outcomes in the domestic sphere and ignoring systemic pressures. Instead, authors in the neoclassical realist school acknowledge that the ways in which states react in international relations, while primarily shaped by the rational systemic impulses produced by the overall distribution of power, are also filtered through the state structure. In effect, we can view "domestic interests and institutions as an imperfect transmission belt that can frequently ignore or distort objective international circumstances, thereby affecting national policy." 40 While this approach is sometimes criticized by neorealist scholars as reductionist, ${ }^{41}$ neorealism and neoclassical realism are in fact seeking to explain different outcomes: the former is focused on broad patterns in international relations, while the latter seeks to explain specific foreign policy outcomes. ${ }^{42}$

This dissertation, which seeks to explore how one key domestic variable - natural resource production - impacts foreign policy formation, and in particular, the proclivity of states to pursue aggressive foreign policy, fits well within the neoclassical realist research program. Our theory does not posit that oil production entirely shapes a state's foreign policy choices, but rather that oil production is one domestic factor which has the potential to undermine rational policy choices by leaders, and to increase the probability of aggression. Leaders in oil-rich states are indeed rational security maximizers, ${ }^{43}$ but natural resource production - in particular, its role in weakening foreign

\footnotetext{
${ }^{38}$ For a more thorough description of the paradigm, see Taliaferro, Lobell and Ripsman (2009).

${ }^{39}$ Waltz (1979).

${ }^{40}$ Fordham, in Taliaferro, Lobell and Ripsman (2009): 251.

${ }^{41}$ Walt, in Katznelson and Milner (2002).

${ }^{42}$ Taliaferro, Lobell and Ripsman (2009).

${ }^{43}$ The debate between defensive and offensive realists focuses primarily on the causes of conflict, with the
} 
policy institutions - has the potential to distort foreign policymaking, resulting instead in boundedly rational outcomes. These theoretical assumptions provide the basis for our analysis going forward.

\subsection{Oil, Natural Resources and Foreign Policy}

A few empirical details may help to shed some light on the relationships between oil and foreign policy. Table 2.1 provides a listing of conflicts initiated by oil-rich states from this dissertation's own dataset. ${ }^{44}$ For each conflict in this table, the initiator was a petrostate, drawing more than $10 \%$ of government revenue from oil production. The overall dataset covers the years 1965-2001 and includes 1130 militarized interstate disputes, of which 201 were initiated by petrostates. Table 2.1 lists a subset of these conflicts: all MIDs initiated by a petrostate that involved fatalities. ${ }^{45}$ This table provides a picture of these conflicts; they cluster in Africa and the Middle East, and certain countries - Iran, Iraq, Nigeria - appear repeatedly. Many of these were territorial disputes. This supports the idea that resource-rich states may simply be more likely to initiate conflicts that were already somewhat likely.

former focusing on the misperceptions and the security dilemma, and the latter on anarchy. In contrast to defensive realists (i.e., Jervis or Walt), who argue that states have an incentive to expand only when threatened, offensive realists (i.e., Mearsheimer or Gilpin) hold that anarchy provides strong incentives for states to maximize their power and territory. For an excellent summary of this debate see Walt's Enduring Relevance of Political Realism (2002). Again, this dissertation does not endeavor to engage this debate. Throughout the dissertation, as with many other neoclassical realist works, we simply accept the defensive realist assumption that states prioritise security maximization. In doing so, the dissertation is more concerned with explaining the factors which may raise this probability of aggression (see Brooks (1997)).

${ }^{44}$ Data from a variety of sources; for further information on sources and methods used in construction of the dataset, see Chapter Three, Section 3.1.

${ }^{45}$ The complete table including all petrostate-MIDs can be found in Appendix A. 

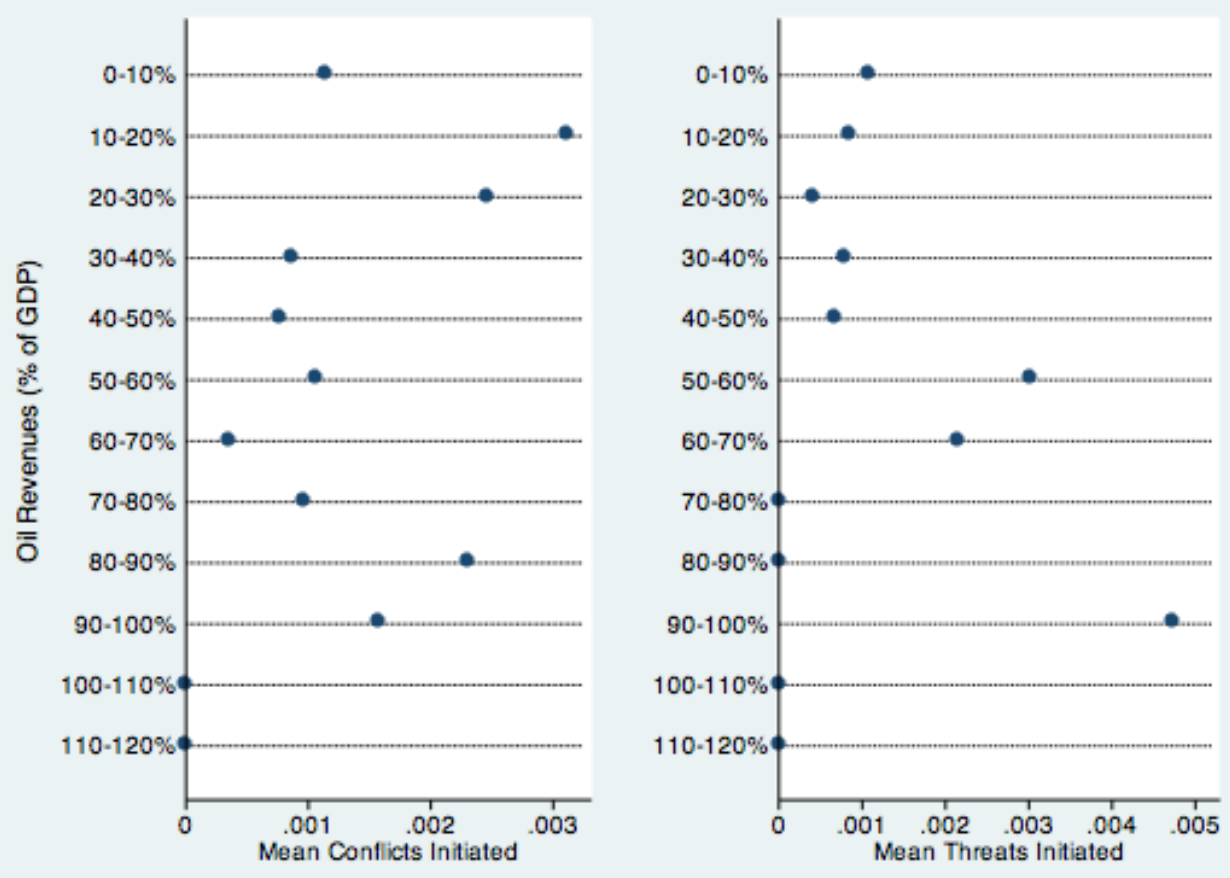

Figure 2.1: Mean Conflicts/Threat Initiation by Level of Oil Revenue 
Table 2.1: High-Level Militarised Interstate Disputes Involving Petrostates

\begin{tabular}{|c|c|c|c|c|c|}
\hline $\begin{array}{c}\text { State A } \\
\text { (Initiator) }\end{array}$ & $\begin{array}{c}\text { State B } \\
\text { (Recipient) }\end{array}$ & Year & $\begin{array}{l}\text { Level of } \\
\text { Dispute }\end{array}$ & $\begin{array}{c}\text { Name of } \\
\text { Dispute (if any) }\end{array}$ & $\begin{array}{c}\text { Number of } \\
\text { Fatalities }\end{array}$ \\
\hline $\begin{array}{l}\text { Saudi Arabia } \\
\text { Iran } \\
\text { Iraq } \\
\text { Iran } \\
\text { Iraq } \\
\text { Angola } \\
\text { Egypt } \\
\text { Ecuador } \\
\text { Egypt } \\
\text { Iran } \\
\text { Algeria } \\
\text { Syria } \\
\text { USSR } \\
\text { Syria } \\
\text { Saudi Arabia } \\
\text { Iraq } \\
\text { USSR } \\
\text { Cameroon } \\
\text { Nigeria } \\
\text { Iran } \\
\text { Syria } \\
\text { Egypt } \\
\text { Syria } \\
\text { Iran } \\
\text { Iraq } \\
\text { Iraq } \\
\text { Iraq } \\
\text { Iraq } \\
\text { Turkmenistan }\end{array}$ & $\begin{array}{c}\text { Israel } \\
\text { Iraq } \\
\text { Kuwait } \\
\text { Iraq } \\
\text { Iran } \\
\text { DR Congo } \\
\text { Libya } \\
\text { Peru } \\
\text { Cyprus } \\
\text { USSR } \\
\text { Morocco } \\
\text { Israel } \\
\text { China } \\
\text { Israel } \\
\text { Yemen Arab Republic } \\
\text { Iran } \\
\text { China } \\
\text { Nigeria } \\
\text { Cameroon } \\
\text { Turkey } \\
\text { Israel } \\
\text { Cyprus } \\
\text { USA } \\
\text { Turkey } \\
\text { USA } \\
\text { Iran } \\
\text { Kuwait } \\
\text { Kuwait } \\
\text { Afghanistan }\end{array}$ & $\begin{array}{l}1967 \\
1971 \\
1972 \\
1973 \\
1974 \\
1977 \\
1977 \\
1977 \\
1978 \\
1978 \\
1979 \\
1979 \\
1979 \\
1980 \\
1980 \\
1980 \\
1980 \\
1981 \\
1981 \\
1981 \\
1982 \\
1983 \\
1983 \\
1987 \\
1987 \\
1989 \\
1990 \\
1992 \\
1993\end{array}$ & $\begin{array}{l}\text { Use of Force } \\
\text { Use of Force } \\
\text { Use of Force } \\
\text { Use of Force } \\
\text { Use of Force } \\
\text { Use of Force } \\
\text { Use of Force } \\
\text { Use of Force } \\
\text { Use of Force } \\
\text { Use of Force } \\
\text { Use of Force } \\
\text { Use of Force } \\
\text { Use of Force } \\
\text { Use of Force } \\
\text { Use of Force } \\
\text { War } \\
\text { Use of Force } \\
\text { Use of Force } \\
\text { Use of Force } \\
\text { Use of Force } \\
\text { War } \\
\text { Use of Force } \\
\text { Use of Force } \\
\text { Use of Force } \\
\text { Use of Force } \\
\text { Use of Force } \\
\text { War } \\
\text { Use of Force } \\
\text { Display of Force }\end{array}$ & $\begin{array}{c}\text { Six Day War } \\
\text { Occupation of Abu Musa } \\
\text { Badrah Clash } \\
\text { Egypt-Libya Clashes } \\
\text { Rio Cenepa VI } \\
\text { Lacarna Airport Raid } \\
\text { Iranian Chinook Shootdown } \\
\text { Western Sahara War } \\
\\
\text { Iran-Iraq War } \\
\text { Cameroon-Nigeria Clash } \\
\text { Cameroon-Nigeria Clash } \\
\text { Lebanon War } \\
\text { Larnaca Airport Dispute } \\
\text { Lebanon Clashes } \\
\text { USS Stark Incident } \\
\text { First Gulf War }\end{array}$ & $\begin{array}{c}1000+ \\
1-25 \\
1-25 \\
26-100 \\
26-100 \\
251-500 \\
101-250 \\
1-25 \\
1-25 \\
1-25 \\
\text { Unknown } \\
1-25 \\
1-25 \\
1-25 \\
1-25 \\
1000+ \\
1-25 \\
1-25 \\
1-25 \\
1-25 \\
1000+ \\
1-25 \\
\text { Unknown } \\
1-25 \\
26-100 \\
1-25 \\
1000+ \\
1-25 \\
26-100\end{array}$ \\
\hline
\end{tabular}


Continued from previous page

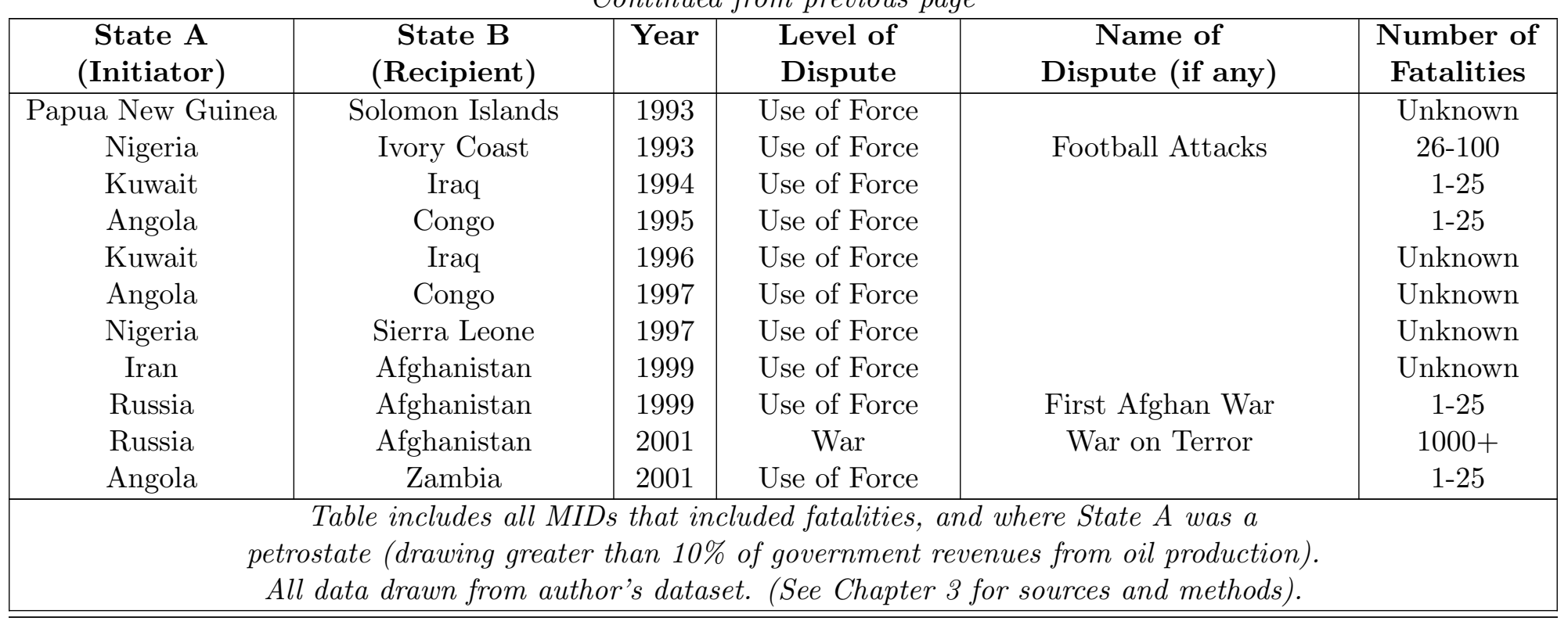


Simple bivariate statistics can tell us more about these relationships. Figure 2.1 illustrates the relationship between oil revenues and two key indicators of aggression: initiating conflict and issuing threats/sanctions. Oil revenue is broken down by $10 \%$ increments, although in reality few countries fall into the higher percentage ranges. $86.4 \%$ of states receive less than $10 \%$ of government revenues from oil, while around 5\% receive 10-20\% of government revenue, and around $3.5 \%$ of states receive $20-30 \%$. $2 \%$ of states receive $30-40 \%$ of revenue, and $1.5 \%$ receive around 40-50\%. The remaining categories cover less than $2 \%$ of all states, and the distribution is therefore extremely skewed. Thus we are primarily interested in the $11 \%$ (or so) of states that draw more than $10 \%$ of government revenue from oil. Figure 2.1 does show a slight upward trend in likelihood for conflict, particularly among those states in the 10-20\% category. We also see a slight upward trend for threats. Ultimately, it is difficult to draw any conclusions from these bivariate graphs, as conflict initiation is also dependent on many other factors. However, these figures do provide some indication that resource-rich states not only initiate more conflicts, but also may issue more threats.

We can also use basic empirics to look at the differences between natural resources and oil. There is a strong correlation between oil and resource revenues, indicating that most states with high levels of natural resource revenues also have high levels of oil revenues. Only a few states have substantial levels of natural resource revenues without oil production. Table 2.2 provides a list of those states that received more than $10 \%$ of GDP in natural resource revenues at some point between 1965-2001, and whether at least half this revenue came from oil. Since resource revenues are generally less lucrative than oil revenues, this indicates that there may indeed be a difference. However, this also indicates that the large overlap between oil-rich and resource-rich states may make it difficult to draw conclusions on this topic. In conclusion, although there is some empirical evidence to support the idea that oil-rich states are more likely to initiate conflicts, data is more problematic in determining the link between all natural resources and aggression. 
Table 2.2: Oil Revenues vs. Natural Resource Revenues

\begin{tabular}{|c|c|}
\hline \multicolumn{2}{|c|}{$\begin{array}{l}\text { States with Natural Resource Revenues } \\
\text { in Excess of } 10 \% \text { of GDP }\end{array}$} \\
\hline Revenue Primarily from Oil & Revenue Not Primarily from Oil \\
\hline $\begin{array}{l}\text { Albania } \\
\text { Algeria } \\
\text { Bolivia } \\
\text { Cameroon } \\
\text { Canada } \\
\text { China } \\
\text { Congo } \\
\text { Ecuador } \\
\text { Egypt } \\
\text { Equatorial Guinea Indonesia } \\
\text { Kazakhstan } \\
\text { Malaysia } \\
\text { Monaco } \\
\text { Nigeria } \\
\text { Norway } \\
\text { Papua New Guinea } \\
\text { Peru } \\
\text { Russia } \\
\text { Suriname } \\
\text { Syria } \\
\text { Tunisia } \\
\text { Trinidad and Tobago } \\
\text { Uzbekistan } \\
\text { Vietnam }\end{array}$ & $\begin{array}{l}\text { Bhutan } \\
\text { Burundi } \\
\text { Cambodia } \\
\text { DR Congo } \\
\text { Ethiopia } \\
\text { Guinea } \\
\text { Guinea-Bissau } \\
\text { Guyana } \\
\text { Honduras } \\
\text { Jamaica } \\
\text { Laos } \\
\text { Liberia } \\
\text { Mauritania } \\
\text { Mongolia } \\
\text { Morocco } \\
\text { Mozambique } \\
\text { Namibia } \\
\text { Nepal } \\
\text { Nicaragua } \\
\text { Sierra Leona } \\
\text { South Africa } \\
\text { Swaziland } \\
\text { Togo } \\
\text { Uganda } \\
\text { Zambia }\end{array}$ \\
\hline \multicolumn{2}{|c|}{$\begin{array}{l}\text { Table includes all countries (1965-2001) that drew more than } 10 \% \text { of government revenue } \\
\text { in GDP from natural resource exports, but did not reach the } 10 \% \text { threshold from oil alone. } \\
\text { Those in left-hand column drew revenues of more than } 5 \% \text { of GDP from oil, } \\
\text { while those on the right drew revenues of less than } 5 \% \text { from oil production. All data } \\
\text { drawn from author's dataset (See Chapter } 3 \text { for sources and methods). }\end{array}$} \\
\hline
\end{tabular}




\subsection{A Theory of Resource Abundance and Foreign Policy}

The core argument of this dissertation is that resource production has a number of effects that, when taken together, make a state more likely to initiate conflict, or to exhibit aggressive foreign policy behavior. ${ }^{46}$ I argue that while there is some truth to the assertion that resource exporters possess greater power and leverage, the organization of the domestic political economy around resource production can also have significant independent effects on foreign policy outcomes. It must also be noted that the theory focuses on explaining state behavior, not on outcomes; in effect, we seek to explain aggressive state behavior, not whether this leads to bilateral exchange of hostilities through interaction with other states.

This dissertation's central argument is that high levels of resource rents undermine institutionalization in developing states, leading to a poor foreign policy bureaucracy, and ensuring that foreign policy decisions are often made with limited information, through a personalistic process. There are also several other ways in which natural resource production may encourage conflictual foreign policy. Firstly, resource rents allow states to build up their military, buy equipment and pursue research with military applications, ensuring that the state is often better armed than its neighbors and more capable of entering a conflict quickly. This is likely to encourage leaders to focus on military options when making decisions. Secondly, the government-dominated nature of the economy in these states vastly increases the size of the state, reducing constraints on the government in foreign policy, and making conflict less costly for leaders. Figure 2.2 illustrates in brief the links between natural resource production and aggressive foreign policy, by focusing on these three specific mediating variables: weak institutions, military expenditure and focus, and low government constraints. This section will outline these links in more detail.

\footnotetext{
${ }^{46}$ Throughout this section, analysis discusses the probability/ likelihood of 'conflict' and of 'aggressive foreign policy' interchangeably. In effect, both mean a state's propensity to undertake aggressive or conflictual foreign policy actions, including, but not limited to initiation of conflict.
} 


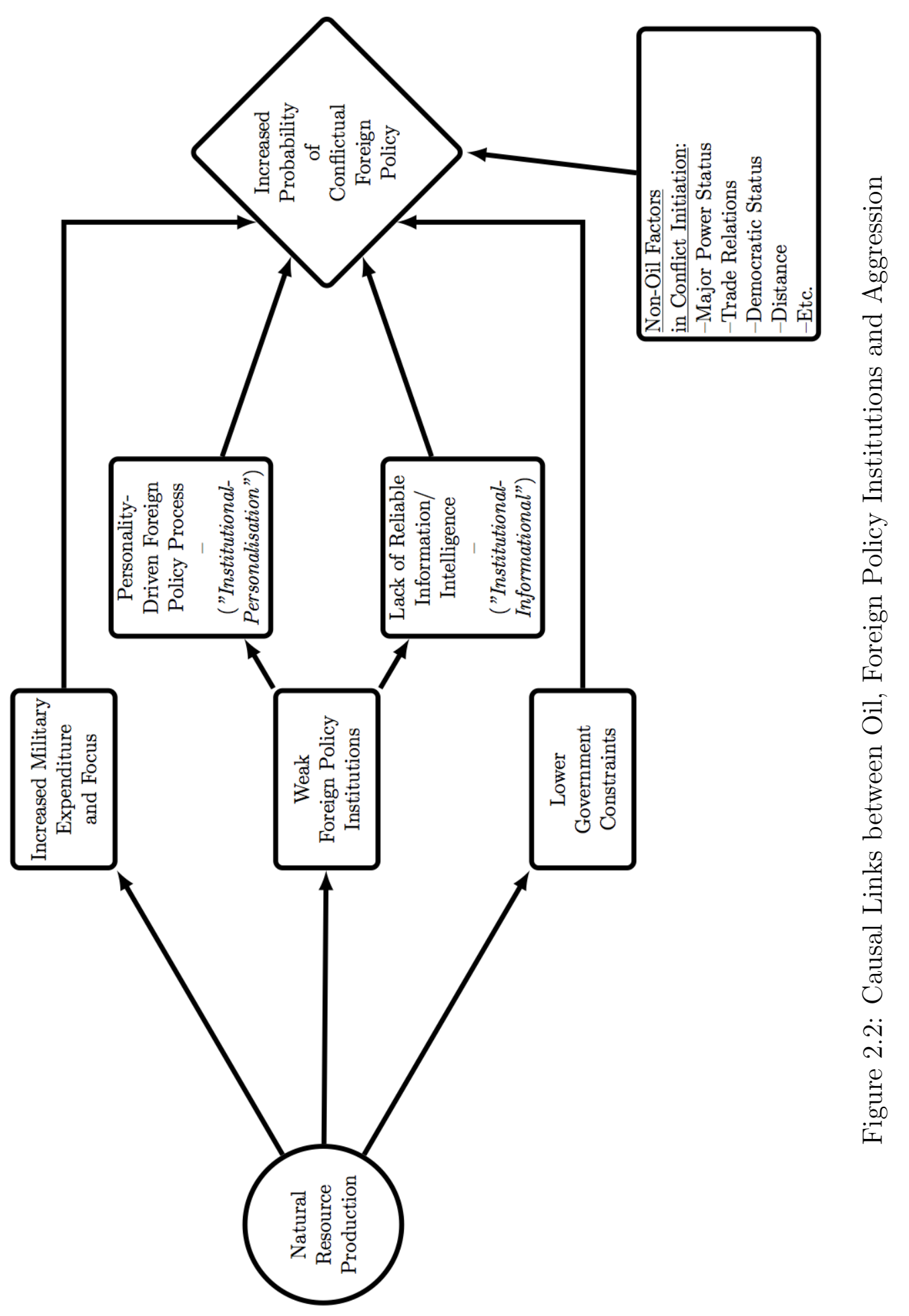




\subsubsection{Oil Will Make You Rich}

Before discussing the links between natural resources and foreign policy, we will briefly discuss the relationship of resource production and export with government revenue, as this is key to all three mechanisms. As the title of this section implies, natural resources are frequently a source of copious income for companies and for states. The resources discussed in academic literature tend to be lucrative - oil, natural gas, diamonds - and we rarely focus on other resources such as timber or wind power. This is largely because there is a substantive, qualitative difference between a cheap, renewable resource like timber and a scarce, nonrenewable resource like oil or coal. Oil is typtically the most profitable natural resource for a country to produce, with prices around $\$ 100 /$ barrel for the last several years. ${ }^{47}$ Natural gas is also lucrative, although the ratio of oil price to natural gas price has climbed from $6: 1$ to $33: 1$ in the last five years. ${ }^{48}$ Oil is thus outstripping even other profitable resources in its earnings potential.

This enriches both companies and states. Exxon Mobil, the world's largest privately-owned oil producer, handles only around $3 \%$ of global oil production, yet had earnings of $\$ 383$ billion in 2010. States in particular receive much of the value from their natural resources, even if they do not extract the resources themselves. Large oil and natural gas exporters often have state-owned monopolies on gas production, while others contract with large multinationals to extract their resources. In either case, states can expect to receive a sizable chunk of the retail price of each barrel of oil. ${ }^{49}$ For example, in 2012, Russia produced around 10 million barrels of oil per day,

\footnotetext{
${ }^{47}$ The profitability of a natural resource to a producing state is necessarily a function of the cost of exploration and production $(\mathrm{E}+\mathrm{P})$, as well as global market prices. This will vary by country: for example, Saudi Arabia, with one of the world's lowest $\mathrm{E}+\mathrm{P}$ costs, takes $95 \%$ of the per barrel price as profit, while Norway, which has to extract most of its oil through expensive off-shore drilling, realizes much less of the per barrel price as profit. Nonetheless, oil is - to all producing states - extremely lucrative, as oil is a rare, highly in-demand resource. Oil is far more remunerative to produce than other natural resources, which command lower market prices in general.

48 "Oil and Natural Gas Prices Get Divorced," http://www.forbes.com/sites/energysource/2012/01/10/oiland-natural-gas-prices-get-divorced (2012).

${ }^{49}$ Although this dissertation focuses only on government revenues, it is worth noting that these revenues also have the potential to create personal enrichment among leaders. For example, though there is no concrete evidence of corruption at the highest levels of the Russian government, several scholarly analyses suggest that as much as $\$ 300$ billion of Russian assets are held abroad in tax havens (Shelley (2003)). These tax havens also receive between $10 \%$ and $16 \%$ of Russia's oil and gas exports, far more than would be expected, implying that exports are used to mask capital transactions into offshore accounts (Tabata (2003)).
} 
with a total value of up to $\$ 408.8$ billion. While extraction, refining and transit infrastructure is expensive, the Russian government still pockets a sizable segment of that income; Gaddy and Ickes estimate that in 2005 alone, resource revenues (i.e., pure profit for the state) were worth almost $25 \%$ of GDP, ${ }^{50}$ while Kuboniwa et al estimate around $24 \%$ of GDP. ${ }^{51}$ Following the global financial crisis, this is now estimated to be closer to $52 \%$ of GDP. ${ }^{52}$

This income is the reason why resource-rich states are often described as 'rentier states.' Although a rentier state can be any state that relies heavily on foreign - rather than domestic - sources of income (i.e., foreign aid), petrostates are particularly prone to falling into this category. High levels of resource rents mean that governments have easy sources of income other than taxation. Government spending choices carry few political costs, and money can be more freely spread around without increasing the burden on citizens. Petrostates are also prone to debt, as spending levels are inelastic while oil pricing is highly volatile. ${ }^{53}$ In Oman, for example, the government collected revenues of around $2.4 \%$ of GDP from taxation in 2008. The same year, the government of Oman received oil rents of $40.4 \%$ of GDP, making oil wealth around twenty times more valuable to the government than basic taxation. ${ }^{54}$ This highlights the vast difference in budget an energy-rich state can have when compared to a near neighbor with no resources. Resources, particularly hydrocarbons, provide a free source of income for a state, reducing political constraints on spending, increasing the size of the state, and decreasing government reliance on citizenry for income (i.e., taxation). This has major implications for all state functions, including foreign policy formation.

\subsubsection{Resource Rents and Weak Institutions}

Although there are various ways in which resource wealth can encourage aggression, the primary mechanism discussed here involves oil's effects in weakening or preventing the development of strong state capacity, including those institutions for foreign policy formation and implementation.

\footnotetext{
${ }^{50}$ Gaddy and Ickes (2005): 559-583.

${ }^{51}$ Kuboniwa, Tabata and Ustinova (2005): 68-76.

${ }^{52}$ EIA Russia Country Study (2014); Available from http://www.eia.gov/countries/cab.cfm?fips=RS.

${ }^{53}$ For further discussion of the links between debt and oil production, see Terry Lynn Karl (1997).

${ }^{54}$ Data from World Bank; Available from http://data.worldbank.org.
} 
Scholars used to describe state capacity as only the ability to tax, but many authors have since expanded their definition to include "the wider range of competencies that the state acquires in the development process." ${ }^{55}$ State capacity can therefore include several related dimensions, including "1) the embeddedness [of the state] with non-state actors, 2) the organizational competence of state agencies, and 3) the territorial reach of state institutions." 56 It is this second quality - organizational competence - that is of particular importance to the foreign policy process, and thus of interest to our study.

Resource rents are generally agreed to have an adverse effect on the development of state institutional capacity, although the degree to which this occurs varies widely based on the level of state development prior to the discovery of oil. ${ }^{57}$ The basic mechanism focuses on the fact that state development is widely accepted to be linked to the development of property rights, effective taxation and bureaucracy. ${ }^{58}$ It is theorized that state capacity can be undermined by resource rents, as governments have a free source of income, meaning they do not need to tax their citizens extensively and do not develop efficient tax collection institutions. The lack of a tax apparatus is particularly common in resource-rich states, where regimes get their wealth from non-tax sources, diminishing much of the political pressure to reform or improve institutional capacity. ${ }^{59}$ While

\footnotetext{
${ }^{55}$ Besley and Persson (2010): 1.

${ }^{56}$ Vom Hau (2012): 5.

${ }^{57}$ While most examples of this path dependence tend to focus on African states, the case of the Soviet Union can also be a good illustration of this process. Oil production had already begun in Russia at the time of the revolution, but the blockade of oil exports by Western countries during and immediately following the Civil War meant that oil was not particularly profitable for the state in the early Soviet period, although some oil was sold clandestinely to western companies (Alexperov (2011): 111-112). By 1926, oil exports to Europe and America had resumed, but the modernization of the Soviet economy during the five-year plans meant most oil production was destined to fill domestic need, not international exports. As a result, oil production, although it provided much-needed foreign capital during this period, did not dominate the USSR's economy or government revenues. Instead, oil was primarily used as a tool to drive further Soviet industrialization (Alexperov(2011): 130-131), and to economically support nearby communist states. During this period, the regime's main sources of income were instead exports of heavy machinery and weapons to developing states (Library of Congress (1989)). Thus, during the crucial period of institutional development (prior to WWII), the Soviet Union could not truly be classed as a 'petrostate.' It was not until the 1970s and 1980s that the USSR began to rely heavily on oil exports as its key source of foreign currency, and this had little impact on institutions, which were solid and well-developed by this period.

${ }^{58}$ See Tilly (1990); Levi (1988). They, among many others, discuss the development of European states, focusing on the necessity of developing efficient taxation in order to wage war effectively.

${ }^{59}$ For an excellent summary of the state capacity/taxation debate, see Brautigam (2008) in Eds. Brautigam, Fjeldstad and Moore (2008).
} 
Table 2.3: Tax Revenues vs. Natural Resource Revenues

\begin{tabular}{l|c|c}
\hline \hline State & $\begin{array}{c}\text { Tax Revenues } \\
\text { as of GDP (2005) }\end{array}$ & $\begin{array}{c}\text { Natural Resource Revenues } \\
\text { as \% of GDP (2005) }\end{array}$ \\
\hline Bahrain & $1.4 \%$ & $24.0 \%$ \\
DR Congo & $9.9 \%$ & $22.4 \%$ \\
Iran & $7.9 \%$ & $51.6 \%$ \\
Kazakhstan & $17.1 \%$ & $52.2 \%$ \\
Nigeria & $0.2 \%$ & $43.4 \%$ \\
Oman & $2.0 \%$ & $57.4 \%$ \\
Russia & $16.6 \%$ & $38.4 \%$ \\
Venezuela & $15.5 \%$ & $47.9 \%$ \\
\hline \multicolumn{2}{c}{ All data from World Bank; Available from data.worldbank.org. } \\
\hline
\end{tabular}

there are limited situations in which resource-rich states have the incentive to build strong tax and development institutions - i.e. majority private ownership of the resource extraction industry - these conditions are rarely found in developing states. ${ }^{60}$ The problem can be illustrated briefly by Table 2.3, which contrasts tax revenues and natural resource revenues in several well-known petrostates in 2005. As the table clearly shows, these states are not dependent on taxation. For most, oil or natural resources provide double, triple or higher the revenue that taxation does. For some, i.e. Nigeria, it is clear that taxation is considered unimportant and is simply not collected, as the paltry $0.2 \%$ tax rate shows. Instead, these states rely heavily on oil revenues, reducing the need for strong institutions as a method of interaction with the population.

In addition, resource rents also tend to inhibit the development of a meritocratic bureaucracy. Dixit highlights this logic through formal modeling; in effect, all bureaucrats are agents, providing services (such as improving economic efficiency) in exchange for payment by the regime. In systems with high levels of taxation, particularly in democracies, this is paid for through broad transfers from citizens. In rent-dependent states (especially those which are autocracies), however, these costs are borne directly by the regime. The leader must weigh the benefit of the bureaucrat against the loss of rents. ${ }^{61}$ Leaders in resource-rich states therefore only have an incentive to develop bureaucracy which will further enrich them. As Besley and Persson note, resource rents thus strongly "diminish

\footnotetext{
${ }^{60}$ Jones Luong and Weinthal (2006): 242.
}

${ }^{61}$ Dixit (2009): 2-3. 
the incentive to invest in state capacity." ${ }^{62}$ Interestingly, this relationship is not only linked to oil wealth, but also to any major influx of outside no-strings revenue such as foreign aid. As with any form of unearned income, "there is little incentive to establish an efficient civil service." 63

It must be noted that a key factor affecting the relationship between resources and institutions is the quality of pre-existing institutional structures. In effect, the level of state capacity and development at the time of initial resource discovery and exploitation is extremely important. ${ }^{64}$ Those states with well-developed institutions - for example, Norway, which discovered oil only in the 1970s - will likely be unaffected by this relationship. States with middling levels of institutional development will likely experience little future development in state capacity, but will not dip below current levels of institutionalization, ${ }^{65}$ while underdeveloped states are unlikely to successfully achieve substantial institutional development after the initial exploitation of resources. ${ }^{66}$ Contrast two oil-rich states: Jordan, and Saudi Arabia. In Jordan, oil was not discovered until 1984, meaning that the country had thirty years following independence (1946) in which to develop institutions before the discovery of oil. Jordan is considered one of the more advanced countries in the region by the World Bank and OECD. In contrast, oil was mass produced in Saudi Arabia as early as the 1940s, meaning that the state never fully developed solid institutions. ${ }^{67}$ The level of development at the time of first oil production is therefore extremely important.

Much of the work on bureaucratic development has focused heavily on institutions as the drivers of economic development. Similarly, most literature on institutions and the 'resource curse' have used institutions as the intervening variable which undermines economic development. ${ }^{68}$ Thus there has been little study of whether other state institutions are impacted by resource wealth. Some authors criticize the idea that all institutions and bureaucratic structures are evenly impacted by resource wealth. Hertog, for example, argues that theories of the rentier state are painted

\footnotetext{
${ }^{62}$ Besley and Persson (2010): 13.

${ }^{63}$ Moore (2007); Morrison (2009).

${ }^{64}$ See Acemoglu and Robinson (2006); Alexeev and Conrad (2009); Waldner and Smith (2012); Brunnschweiler and Bulte (2008).

${ }^{65}$ Alexeev and Conrad (2009): 587.

${ }^{66}$ Mehlum et al (2006).

${ }^{67}$ Thieme, "The Petroleum Dataset" (2007).

68i.e., Chaudhry (1997) among others.
} 
too broadly and argues that specific factors within each state may alter which institutions are successful and which are not. Nonetheless, his study of Saudi Arabia, although illustrating a few small 'pockets of efficiency,' demonstrates the same basic problem outlined above: the Saudi state is non-responsive to its citizens and has had little incentive to develop sturdy institutions. ${ }^{69}$ In his work on the developmental state, Peter Evans attempts to show that states can range in terms of efficiency and graft, and argues that most states will have internally varying levels of institutionalization. ${ }^{70}$ Similarly, other authors have argued that there are often 'pockets of efficiency' within the bureaucracy, even if it is generally poor. ${ }^{71}$

While these works suggest that it is not impossible for efficiency and inefficiency to coexist in different sectors of the bureaucracy, the 'pockets of efficiency' approach can also have major downsides. Piecemeal efficiency strongly undermines 'organizational coherence,' for example, and even efficient institutions will likely be personalistic and dependent on individuals if they are constantly surrounded by clientelism. ${ }^{72}$ As a result, any efficient institution in a resource-rich state is more likely to be the exception than the norm, including in foreign policy. In addition, the foreign policy bureaucracy typically does not increase rent income, and is therefore likely to be a low priority for resource-rich leaders. Thus we would expect foreign policy institutions in resource-rich states to lack a good, meritocratic bureaucracy and solid institutional structures. ${ }^{73}$ As in the case of economic institutions, while these problems may afflict all resource-rich states to some extent, those that are underdeveloped in general are more likely to suffer severe problems. Thus, we would expect to see a less developed foreign policy apparatus in Yemen than in Norway.

\footnotetext{
${ }^{69}$ According to Hertog (2010), in the Saudi case, the few well-developed institutions are that way only because those in charge (various members of the royal family) sought change and development. Outcomes are therefore entirely agentic.

${ }^{70}$ Evans (1989): 577.

${ }^{71}$ Ibid.

${ }^{72}$ Evans (1989): 578.

${ }^{73}$ It is also likely that attempts to reform such bureaucracy may fail; resource-rich states often have to pour increasing sums of money into the bureaucracy to keep them functioning at even a basic level. As such, it is important to note that money does not necessarily increase efficiency if the institutions are already underdeveloped and no real political will or necessity for reform exists.
} 


\subsubsection{Foreign Policy in a Weak Institutional Environment}

Weak foreign policy institutions have a number of consequences for the formation of pragmatic, rational foreign policy. Weak institutions are likely to make foreign policy decisions less deliberative, less cooperative and less informed, resulting in personalistic decisions, and poorly formulated, boundedly rational or 'unprofessional' outcomes. For the purposes of this dissertation, 'unprofessional' foreign policy is defined not by outcome, but by intent. In effect, if we assume that actors who formulate foreign policy are rational, then we would expect their output (i.e., specific foreign policies) to also be rational (in the 'national interest'). ${ }^{74}$ This doesn't mean that these policies necessarily produce the best outcomes, merely that they are the most logical choice to serve the national interest at the time they were formulated. ${ }^{75}$ The focus of this section is therefore on the ways in which oil-induced weak institutions can undermine these rational impulses, in particular with regards to aggression.

I argue that weak institutionalization of the foreign policy and intelligence apparatus as a result of oil revenues has two specific consequences which can increase the likelihood of state aggression: an "institutional-personalization" mechanism (i.e., the ways in which weak institutionalization can result in the personalization of foreign policy), and an "institutional-informational" mechanism (i.e., the ways in which weak institutionalization can deprive policymakers of key information). These are illustrated in Figures 2.3 and 2.4, which demonstrate in more depth the relationship between the theory's key mediating variable - weak institutionalization - and aggressive foreign policy.

Figure 2.3 illustrates the "institutional-personalization" mechanism. As many pervious studies

\footnotetext{
${ }^{74}$ For neorealist scholars, rationality or the national interest is merely the need for state survival. In contrast, some theories point out that the national interest can instead be conceptualised as the interests of society at large (Knorr (1975)). This creates a problem, as societal needs can often conflict with the interests of the governing elites. For the purposes of this dissertation, the "national interest" is assumed to be the well-being of the whole society.

${ }^{75}$ In fact, as scholars of bureaucratic politics have long argued, a foreign policy system may 'work' well, and yet produce poor outcomes, due to constraints on policymakers or other factors (Gelb and Betts (1979)). Thus only if poorly formulated foreign policy which doesn't serve the national interest occurs frequently (and cannot easily be attributed to conflicting domestic interest groups), can we conclude that foreign policy-making within the state is to some extent 'unprofessional.'
} 




Figure 2.3: The Institutional-Personalisation Mechanism

have shown, good foreign policymaking relies heavily on the inputs of many actors, working together in a deliberative process. The bureaucracy often acts as a check on foreign policy decisions made by leaders, ensuring that it is well thought-out and debated. ${ }^{76}$ If foreign policy institutions are inefficient, it is likely that decisions will be made by either a small group within the bureaucracy, by a small group within the regime or even by an individual leader. This can be incredibly detrimental to the production of rational foreign policy that supports the "national interest." 77 Hermann argues that personality traits of individual leaders matter to varying degrees in foreign policy; in particular, they matter more when there is no debate or foreign policy bureaucracy to provide an alternate viewpoint. ${ }^{78}$ Thus foreign policy will be more affected by the individual personality traits of leaders (such as nationalism or distrust of others) when there are no solid foreign policy institutions.

The lack of strong institutions can also make foreign policy less cooperative. Previous studies have shown that when multiple autonomous actors are involved in the foreign policymaking process,

\footnotetext{
${ }^{76}$ Katzenstein (1977).

${ }^{77}$ It should also be noted that bureaucracies do not necessarily always produce the best outcome, if the inputs (i.e., public opinion) are in some way flawed. The debate over the Vietnam war in the US is one such example - as Gelb and Betts (1979) illustrate, the presumption that the US had to enter the war to fight communism was fundamentally flawed, but this did not arise from any flaw in the foreign policy decision-making process itself.

${ }^{78}$ Hermann (1980).
} 


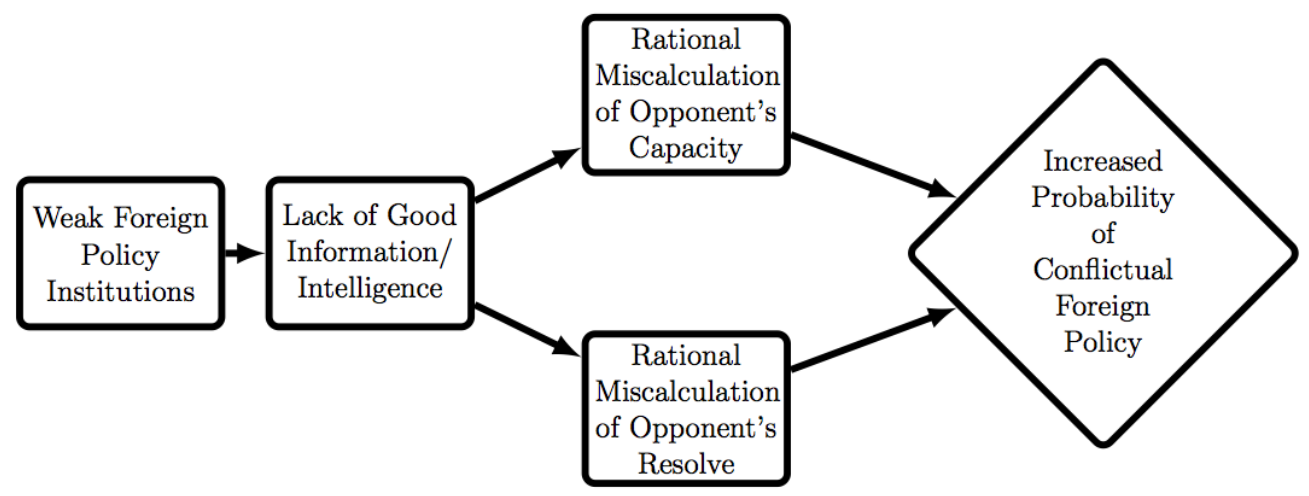

Figure 2.4: The Institutional-Informational Mechanism

it tends to be more cooperative, less confrontational and more rational than either a single leader or a small group. ${ }^{79}$ Additionally, bureaucracies are much more likely to absorb learning from prior foreign policy experiences. While individuals can indeed participate in such a process, research indicates that their thinking may be colored by a single past incident, while a group is much more likely to consider multiple past events. ${ }^{80}$ For example, Russian military involvement in the Kosovo crisis of 1999 was significantly complicated by the lack of impartial advice from a bureaucracy. Instead, the decisions were largely made by individual military chiefs, who personally persuaded President Yeltsin that military involvement was a good option. Military leaders were largely driven by their fear of NATO and cold war mindset, and they neither considered alternative options, nor conducted any debate. Trade and Foreign Ministries were not consulted, and thus no alternative viewpoints to this militaristic mindset were considered. The incident turned out to be an utter fiasco, with Russian troops reduced to begging nearby NATO forces for food and water after reinforcements and supply lines could not be solidified. ${ }^{81}$ Thus, weak institutions can result in foreign policy made by small groups or individuals, making it less cooperative and more personality-driven, increasing the potential for conflict.

Figure 2.4 illustrates what we can term the "institutional-informational" mechanism. A lack of strong state institutions - in particular, the foreign policy bureaucracy and intelligence services -

\footnotetext{
${ }^{79}$ Hermann et al (1989); Hudson and Vore (1995).

${ }^{80}$ Levy (1994); Khong (1992).

${ }^{81}$ Norris (2005).
} 
results in a lack of information about other states and about the consequences of potential decisions. Most models of foreign policy decision-making tend to assume a perfect Weberian bureaucracy, ${ }^{82}$ resulting in perfect information flow. However, weak institutions undermine this assumption, and tend to produce poor or imperfect information. This is particularly problematic as leaders receive most of their information on foreign policy and economic issues from bureaucratic institutions. ${ }^{83}$ International relations literature is replete with theories and examples of how foreign policy decisions are distorted by a low-information environment; bargaining failures, treaty problems and conflict have all been attributed to a lack of information available to policymakers.

The link between informational failures and conflict is clearly outlined by the work on the Bargaining Theory of War, ${ }^{84}$ which focuses on the puzzle that "wars are costly, but nonetheless wars recur." 85 Fearon argues that typical explanations of war do not adequately explain why rational leaders would choose to enter conflict and instead focuses on three potential explanations: commitment problems, indivisible issues or informational imperfections. ${ }^{86}$ It is this latter that concerns us: informational imperfections can lead to conflict as leaders rationally miscalculate an opponent's military capacity or resolve. Fearon's formal model mostly focuses on the combination of private information and rational incentive to misrepresent it as the key cause of conflict, but his arguments assume that policymakers receive perfect information. ${ }^{87}$ In an oil-rich state with weak institutions, this assumption does not hold. Policymakers are likely to be receiving incomplete or inaccurate information, and as such are more likely to rationally miscalculate an opponent's strength or resolve.

Thus, with weak institutions, foreign policy is substantially less informed, and states are more likely to enter a conflict, or to fail to achieve other goals. For example, when Saddam Hussein invaded Kuwait in 1991, he firmly believed that there was no chance the US would intervene.

\footnotetext{
${ }^{82}$ Dixit (2009): 2.

${ }^{83}$ Milner (1997).

${ }^{84}$ Reiter (2003) in particular highlights the fact that intelligence failures can lead to distorted assessments of opponents.

${ }^{85}$ Fearon (1995): 379.

${ }^{86}$ Ibid., 381.

${ }^{87}$ Ibid.
} 
Table 2.4: Foreign Policy in Weak and Strong Institutional Environments

\begin{tabular}{|c|c|c|}
\hline Decision Criteria & $\begin{array}{l}\text { Strong Institutions } \\
\text { (Non-Petrostate) }\end{array}$ & $\begin{array}{l}\text { Weak Institutions } \\
\text { (Petrostate) }\end{array}$ \\
\hline Who makes decisions? & Leaders & Leaders \\
\hline Who advises on decisions? & $\begin{array}{l}\text { Foreign policy bureaucracy, } \\
\text { personal advisors }\end{array}$ & $\begin{array}{l}\text { Personal advisors, } \\
\text { 'inner circle' }\end{array}$ \\
\hline $\begin{array}{l}\text { Where does information } \\
\text { come from? }\end{array}$ & $\begin{array}{l}\text { Intelligence services, } \\
\text { expert foreign policy } \\
\text { bureaucracy, learning from } \\
\text { prior experiences }\end{array}$ & $\begin{array}{l}\text { Personal sources and } \\
\text { opinions, media, } \\
\text { non-expert bureaucracy }\end{array}$ \\
\hline Policy debate present? & $\begin{array}{l}\text { Yes, in bureaucracy (options } \\
\text { presented to leader) }\end{array}$ & $\begin{array}{l}\text { Maybe, in small group, } \\
\text { 'inner circle' }\end{array}$ \\
\hline
\end{tabular}

In part, this was the result of poor intelligence work, which gave him "a general ignorance of his adversaries will and capabilities," and in part because he was surrounded by advisors who refused to contradict his opinions. ${ }^{88}$ He therefore initiated the conflict relying on entirely incorrect information, and only narrowly avoided a coalition invasion of Iraq to remove him from power at that time. In this way, without strong institutions to provide information, many resource-rich states are likely to be making foreign policy decisions without necessary information, increasing the likelihood of conflict.

\subsubsection{Natural Resources, Weak Institutions and Foreign Policy}

In conclusion, there are two distinct ways in which weak institutions can undermine foreign policy, and lead to conflictual foreign policy: increased personalization, and a lack of information. When combined, we can see that decision-making in a weak institutional environment can differ substantially from decision-making in a well institutionalized system; these differences are outlined briefly in Table 2.4. Strong foreign policy institutions, and a competent bureaucracy, are key to informed, rational and cooperative foreign policy; the likelihood that these institutions are weak in resource-rich states therefore has the potential to undermine foreign policy decisions, and produce

\footnotetext{
${ }^{88}$ Record (2007): 1. Also see Post (1991).
} 
sub-optimal outcomes such as aggression.

\subsubsection{Oil's Other Enabling Effects: "Nervos Belli, Pecuniam." 89}

In addition to weak institutions, there are two other ways in which oil production can undermine foreign policy and lead to aggressive foreign policy and conflict. These can best be thought of as conflict-enabling factors. This section discusses and builds upon the only previously-posited link between oil and conflict: money as a source of military might. Resource rents enable military buildup and research, and provide the means to buy military equipment from technologically advanced allies. One only has to look at the list of customers for US supplied armaments to see that many of the customers are resource-rich states like Saudi Arabia and Kuwait. Military buildups in resource states have been long considered a fact, and the few previous works that deal with the links between oil and conflict - whether civil or intrastate - have focused on this. These arguments have relied on oil as a means for conflict, relying instead on other factors to provide the impetus for conflict. ${ }^{90}$ However, I argue that not only does oil wealth provide the means to carry out aggressive foreign policy, but the military buildup permitted by excessive oil rents can in fact encourage aggression by leaders by increasing the perception that they are likely to win.

Resource exporting states have always used their bounties of natural resources to improve military capability; indeed, this is why realist scholarship includes natural resources as one element of state power. In the post-war world, this relationship has shifted from the use of metals in producing tanks and guns to the use of resource rents more broadly to buy military equipment and supplies from other nations. This has been commonly noted by academics studying the politics of military expenditure. In particular, those scholars studying developing countries note that resource-rich states are particularly likely to hugely expand military capacity and technology, since there are no political costs or tradeoffs involved. In contrast, other developing states must often

choose between military spending and development spending. ${ }^{91}$ Venezuela under Hugo Chavez, for

\footnotetext{
${ }^{89} \mathrm{Tr}$ : "Endless Money Forms the Sinews of War" (Cicero).

${ }^{90}$ Colgan (2010); Struver (2010); and De Soysa et al (2009).

${ }^{91}$ Deger (1986); Basedau and Lay (2009); and Dunne and Perlo-Freeman (2003).
} 
example, spent billions on social programs (i.e., education, food, and housing subsidies) in addition to large purchases of military materiel from Russia and China. Military spending also does not typically decrease when resource prices do, and is instead somewhat inelastic. Countries may delay large capital expenditures, but rarely reduce general funding or downsize the military during periods of lower resource prices. ${ }^{92}$ Instead, these countries tend to borrow to finance continued military development.

For resource-rich states, therefore, money can be used to bolster military capabilities in a number of ways. The size of the standing military can be increased, as extra wages no longer pose a huge burden. Research on military technology can be more easily funded. Some states choose to funnel money into illicit nuclear, chemical or biological weapons programs, such as Iraq under Saddam Hussein, which produced a chemical weapons program described in one CIA report as "the largest in the third world," along with "an advanced biological warfare program [which] was the most advanced in the Arab world." 93 Other oil-rich states such as Libya and Syria are also well-known for their development of illicit weapons. However, many states simply use oil revenues to bolster their military by purchasing arms and armaments from developed country producers, increasing the technological superiority of the state's military. Between 2010 and 2013, for example, Saudi Arabia spent in excess of $\$ 30$ billion on purchases of arms from the US, including 154 F-15 fighter jets, over 100 helicopters of different types, and 126 armed personnel carriers. ${ }^{94}$ This pattern also applies outside the Middle East, as countries in Africa, Asia and Latin America purchase arms. Venezuela, one of Latin America's richest oil states is currently undergoing a rearmament program, and has purchased armored vehicles, small arms, tanks, artillery and other weapons from Russia, China and Spain (among others) in just the last four years. ${ }^{95}$

The Stockholm International Peace Research Institute's analysis of military expenditures indicate that military spending has increased by almost $50 \%$ in the last decade, and that much of

\footnotetext{
${ }^{92}$ Chun (2010).

${ }^{93}$ CIA, "Prewar Status of Iraq's Weapons of Mass Destruction" (2002).

${ }^{94}$ Defense Industry Daily (July 18, 2013); Available from http://www.defenseindustrydaily.com/a-2010saudi-shopping-spree-06520/

${ }^{95}$ SIPRI, "Trends in International Arms Transfers" (2013).
} 
this increase stems from rising commodity prices, as resource exporting states increase their military spending in line with increasing resource prices. ${ }^{96}$ In 2011, the 15 countries with the highest military expenditures (as a \% of GDP) included eleven petrostates, ten of whom would be considered developing or undeveloped countries by the World Bank. ${ }^{97}$ It should be noted that this does not necessarily mean that the military is better trained, or organized, merely that it is better funded. ${ }^{98}$ In comparison to non-resource states, however, oil-rich states often have a larger and better equipped military.

Theoretically, having a strong military undoubtedly increases the attraction of military options to leaders. As many theorists have described, when deciding whether to enter (or continue) a conflict, leaders must weigh the potential risks of losing against the possible benefits of winning. Since waging wars are costly, and losing even more so, this decision includes various factors, allowing leaders to generate an assessment of the likelihood of winning or losing before they enter the conflict, considering such factors as available resources, public (or private support) for a war, and perceptions about opponents strength and resolve. ${ }^{99}$ Domestic political factors (such as the likelihood of losing or retaining office in certain regime types if the war goes badly) are also extremely important. ${ }^{100}$

Previous arguments of this type have focused on regime type and coalitions in the decisionmaking process, yet the comparison of one's own military to the enemy's forces is also key to a leader's assessment of the likelihood of winning. Simply put, a leader is more likely to enter a conflict if he perceives his military to be superior. ${ }^{101}$ In 1980, for example, Saddam Hussein chose to initiate a war against Iran because he believed his military would triumph. Although Iran was also a resource-rich state, oil revenues had been disrupted by the revolution, and the army was in disarray. Hussein's attack sought to take advantage of temporary weakness with his strong military, equipped with weapons purchased from the US. Hussein genuinely believed that his forces would

\footnotetext{
${ }^{96}$ SIPRI Yearbook (2010).

${ }^{97}$ SIPRI Yearbook (2011).

${ }^{98}$ Hertog (2011) argues that these militaries are often less efficient, largely because of the distorting and corrupting effects of resource rents. In fact, we might therefore expect to see resource-rich states initiate more conflicts, but losing many of them. See also Brooks (1997).

${ }^{99}$ Bueno de Mesquita, Morrow, Siverson and Smith (2004).

${ }^{100}$ Goemans (2000).

${ }^{101}$ Bueno de Mesquita, Morrow, Siverson and Smith (2004).
} 
triumph quickly, but the bloody conflict lasted eight years. In this, he sincerely misjudged the likely outcome of the conflict, based largely on a misunderstanding of military tactics and a presumption of his own military's superiority. Thus, this dissertation argues that not only does oil wealth allow for increased military spending, and the means to wage war, but simply possessing this enlarged and technologically superior military is likely to encourage state aggression.

\subsubsection{Constraints in Government-Dominated Economies}

The final way in which oil can undermine foreign policy formulation and result in conflict or aggressive foreign policy behavior relates to constraints on policymakers. Resource revenues do have a clear link with government constraints, as resource rents often permit leaders greater control of the domestic media market than other states, allowing them shape public opinion. Resource rents can be used to purchase media outlets, and to subsidize government-friendly newspapers and channels. ${ }^{102}$ By doing so, the government can shape public opinion through friendly coverage, and through limiting information. As Stein notes, "press restrictions force citizens to form their opinion based on the limited information media provide[s]." 103 Thus, resource revenues may help to free governments from some of the constraints of public opinion. Governments may not be able to shape the opinion of small groups of more informed individuals, such as business people or elites. ${ }^{104}$

However, natural resource production also allows for freedom from economic constraints for leaders. Unlike previously discussed mechanisms, this results not only from resource rents, but instead from the distorted nature of the economy in many resource producing states. While it is debatable whether resource-wealth actually retards growth, the sectoral shifts and distorted labour market commonly known as the 'Dutch Disease' is a very real problem for many oil and resource wealthy states. Again, like the institutional theories discussed in Section 3.2, this problem is somewhat more likely to affect underdeveloped states than those that are already prosperous or developed when oil is discovered. In these states, natural resource production is the most lucrative

\footnotetext{
${ }^{102}$ This relationship between press and state is similar to that found in most autocracies; thus this relationship is further complicated by the potential link between natural resources and autocracy itself.

${ }^{103}$ Stein (2012): 2 .

${ }^{104}$ Weeks (2008): 38.
} 
industry, and labour flees other productive sectors seeking jobs in the resource extraction industry, raising wages in general. This reduces productivity in manufacturing sectors, creating economic weakness. More problematic, however, is the relative overvaluation of the native currency, caused by the value inherent in resource exports. As the currency appreciates, exports become expensive and imports become cheaper; this decreases returns in the manufacturing sector, as neither exports nor the local market are now profitable. This ensures that the economy and labour market are dominated by natural resource extraction. ${ }^{105}$

In most oil-rich states, governments rely heavily on state-owned enterprises for management of the resource sector. Thanks to the peculiar economic distortions caused by resource extraction, the result is government dominance of the economy. Many of the world's best known oil and gas producers are SOEs, such as Saudi Arabia's Aramco, Russia's Gazprom, or Malaysia's Petronas. In 2012, 17 of the world's top 25 oil companies were majority owned by the state, with two more Brazil's Petrobras and Norway's Statoil - being semi-public. ${ }^{106}$ Governments draw many benefits from letting a SOE handle extraction; profit does not have to be shared with a multinational corporation, and control is easier. Many of these SOEs in fact operate most extraction operations in joint ventures with multinationals, allowing for increased profit while benefitting from advanced extraction technology and expertise. Thus, in those resource-rich states - typically less developed states - where resource extraction does dominate the economy, the public sector tends to dominate the economy.

The public-private balance of the economy can have major consequences for foreign policy, in particular for conflict initiation, on which most prior research on the subject has focused (i.e., the 'capitalist peace.'). This argument focuses on one facet of this relationship: a strong public section reduces the constraints a government has on foreign policy. McDonald draws on Bueno de

\footnotetext{
${ }^{105}$ Sachs and Warner (1997); Payrakis and Gerlagh (2004).

${ }^{106}$ The top 25 are: Saudi Aramco (Saudi Arabia), Gazprom (Russia), National Iranian Oil (Iran), Exxonmobil, Petrochina (China), BP, Royal Dutch Shell, Pemex (Mexico), Chevron, Kuwait National Petroleum Co. (Kuwait), Abu Dhabi National Oil Co. (UAE), Sonatrach (Algeria), Total, Petrobras (Brazil), Rosneft (Russia), Iraqi Oil Ministry (Iraq), Qatar Petroleum (Qatar), Lukoil (Russia), ENI, Statoil (Norway), ConocoPhillips, Petroleas de Venezuela (Venezuela), Sinopec (China), Nigerian National Oil Company (Nigeria) and Petronas (Malaysia). List calculated by Wood MacKenzie consulting firm for Forbes magazine (2012).
} 
Mesquita's selectorate theory to argue that a strong private sector has three impacts which can reduce conflict. ${ }^{107}$ Firstly, states with a strong private sector have greater constraints on their ability to initiate a conflict, as they must rely on taxation in order to fund war. Secondly, since businesses typically profit from peace, the private sector itself is a source of lobbying against conflict. The larger the private sector in a state, the larger the anti-conflict lobby will be. In both cases, a large private sector acts against state aggression. Finally, states with large private sectors are more able to credibly signal their intentions to other states, as it is obvious that they face major constraints on initiating a conflict. In response, opponents are less likely to seek preventative war, as they can more easily trust that the first state will keep its word. ${ }^{108}$ This is less relevant for this dissertation as we are focusing on conflicts initiated by petrostates, but may go some way towards explaining why oil-rich states are also attacked more often than others. ${ }^{109}$

As McDonald notes, without the lobby for peace and financial constraints of taxation, "governments gain a relatively free hand in foreign policy... when they possess large quantities of public property." 110 For example, between 1978 and 1987, Libya attacked neighboring Chad several times, in addition to funding and arming native Chadian rebels. There was little to be gained from this conflict, other than control of the Aouzou strip, a small sector of Chad, and the potential for a more pro-Libyan government in Chad. In addition, France and US were intervening on the side of the Chadian government, leading to several major defeats for Libya. Despite this, Libya initiated at least four distinct bouts of conflict, as the Gaddafi government had few constraints at home. During this period, the Libyan government controlled around $70 \%$ of its oil output, and was earning $30.2 \%$ of its GDP from oil exports (or around $\$ 800$ million per year). ${ }^{111}$ Thus, the Gaddafi regime didn't have to increase taxes to initiate conflict, was not constrained by a business lobby, and was free to initiate four effectively worthless conflicts.

We can see from a typical interaction between two states (one oil-rich, one not) how the differ-

\footnotetext{
${ }^{107}$ McDonald (2009); Bueno de Mesquita (2003).

${ }^{108} \mathrm{McD}$ Donald (2009). This latter is also the argument outlined in Gartzke, Li and Boehmer (2001).

${ }^{109}$ See also Fearon (1995).

${ }^{110}$ McDonald (2009): 54.

${ }^{111}$ Data from World Bank; Available from http://data.worldbank.org
} 
ences in economic makeup can alter bargaining and incentives for leaders. State A is a petrostate, drawing most of its revenue from oil exports, and little from tax on individuals or businesses. State $\mathrm{B}$ is a non-petrostate, reliant on taxation for government revenue. Both are autocratic. ${ }^{112}$ These two states are engaged in heated dispute over a strip of land claimed by both sides; as the issue is effectively indivisible, negotiations have previously failed. In State B, the president consults with her advisors, who inform her that a war cannot be paid for out of the treasury. She also receives lobbies from the two major business associations in her state, informing her that war is unwise, and would greatly reduce trade and investment, hurting profits and reducing the government's tax take. Reluctantly, she decides that war is infeasible, and returns to the bargaining table. In State A, the leadership also consults with his advisors, who advises that there is limited money in the treasury to pay for a war. However, money can be transferred from the state-owned enterprise (responsible for almost $40 \%$ of State A's GDP) in charge of oil production and used to fund the conflict. Like State B, State A's leader receives visits from pro-peace businessmen, but dismisses them. Even if he does lose, it is unlikely that there will be substantial impact on the economy, as trade of non-resource goods is only a minor part of the economy. He decides to initiate the conflict. Although simplistic, this scenario does highlight the difference between the incentives for leaders in public-sector vs. private-sector dominated economies. Thus, this dissertation argues that in an oil-rich state with government dominated economy, there are simply far fewer constraints on leaders, increasing the likelihood of aggressive foreign policy. ${ }^{113}$

\subsubsection{Theoretical Implications}

In Section Three, I have argued that the organization of the political economy around resource production has a number of different impacts, each of which increases the likelihood of aggressive foreign policy by a small, but significant amount. These effects are primarily indirect, meaning that

\footnotetext{
${ }^{112}$ Democracy is also known to place considerable constraints on conflict initiation, and so this example will focus on two non-democracies. For further discussion of the ways in which oil and autocracy may be related, and the impact on this argument, see Section 4.3.

${ }^{113}$ It must be noted that the tangled causal relationship between public opinion and lobbying, resource rents, media control and government constraints may make this hypothesis extremely difficult to test in practice.
} 
oil production leads to certain intervening variables (weak institutions, military expenditure and focus, and low government constraints), which then drive aggressive foreign policy. This dissertation's primary focus is on the two institutional mechanisms laid out in Section 3.2, which illustrate how oil-related institutional weakness can result in informational inefficiencies and personality-driven foreign policy, increasing the probability of conflictual behavior. However, the dissertation also seeks to examine two enabling factors: oil-enabled military expenditure and focus, and oil's ability to reduce constraints on government. Figure 2.2 illustrates these various mechanisms. This theory gives rise to several research hypotheses, which will be tested using both statistical analysis and qualitative case studies in the following chapters. We do expect resource-rich states to act more aggressively than others, in particular those with substantial levels of resource rents. The first two research hypotheses are therefore:

Hypothesis 1. All else equal, resource-rich states are more likely to exhibit aggressive foreign policy than other comparable states.

Hypothesis 2. These effects will be present only in states with significant income from natural resources. States that export oil will be more prone to aggression than those states that export other, less lucrative natural resources.

As described above, resource rents tend to produce weak institutions, which means that foreign policy may be produced without the aid of a professional foreign service or intelligence agencies, resulting in personalistic foreign policy produced in a low-information environment. Resource rents also increase military spending, and encourage the use of military means to resolve disputes. Finally, the government-dominated nature of the economy in oil-rich states reduces constraints on governments in making foreign policy decisions. This gives rise to the remaining three research hypotheses:

Hypothesis 3. Resource-rich states will have underdeveloped foreign policy institutions. The decision-making process will be dominated by a small group or an individual, and characterized by disagreements. Available information will be confused or lacking. 
Hypothesis 4. All else equal, resource-rich states will exhibit higher levels of military spending and readiness than other comparable states, and a tendency to ignore or avoid diplomatic or other alternatives to military action.

Hypothesis 5. Governments in oil-rich states face fewer constraints on foreign policy; governments do not have to seek broad public coalitions in order to enter conflict.

Hypotheses One and Two will be tested statistically in Chapter Three, while Hypotheses Three, Four and Five will be tested using process tracing in three qualitative case studies of resource-rich states: Russia, Venezuela and Saudi Arabia. The focus will be on assessing whether the key variables suggested by the theory are indeed present in resource-rich states, and whether they are linked to foreign policy outcomes, in particular, an increase in state aggressiveness. While it is unlikely that analysis will find all these factors present in every country, it seems likely that some combination will be present in a sizable segment of resource-rich states, thus explaining, at least in part, the propensity of resource-rich states to aggression.

\subsection{Methodological Issues}

\subsubsection{Methodology and Case Selection}

The hypotheses outlined above will be tested using a combination of quantitative and qualitative methods, as it would be difficult to examine both empirical regularities and potential causal mechanisms without both. The strengths and weaknesses of large-n and case-study research have the potential to complement each other in analysis, as large-n work tends towards 'thin' conceptions of variables and no real ability to discern causal mechanisms. Small-n case studies, in contrast provide much greater leverage to examine micro causal factors, but lack generalizability. By using both methods, we can ameliorate some of these limitations. ${ }^{114}$ The study will involve two discrete elements: 1) a statistical study; and 2) three qualitative case studies of Russia, Venezuela and Saudi Arabia.

\footnotetext{
${ }^{114}$ Coppedge (1999).
} 
The first element of the study is statistical analysis using a new directed-dyad database which covers the years 1945-2001. Aggressive foreign policy is operationalized as issuing more threats/sanctions, or initiating more conflicts. The primary independent variable is Oil Revenues (\% of GDP). The secondary independent variable tested is Natural Resource Revenues (\% of GDP), which includes revenues from production of oil, natural gas, coal, minerals and timber. The relationship between oil and aggressiveness is also tested using an alternate measure of oil wealth, Oil Production (\% of World Supply). The key dependent variables are both binary measures: Conflict Initiation and Threat/Sanction Initiation. A variety of control variables are also used, including major power status, alliance similarity, capabilities ratio, democratic status, distance, regional dummy variables, peace years and trade between dyad members, largely based on prior studies of threats, sanctions and conflict. All variables are assessed using a logit model, and both fixed effects and rare events logit models are also tested for comparison purposes. Various robustness tests are also included, as well as a brief test of the theory over a broader time period (1816-2002).

The second section of the dissertation will take the form of three in-depth case studies of Russia, Venezuela and Saudi Arabia during the period 1991-2013. While statistical analysis will focus on whether resource-rich states are more aggressive, the case studies will primarily focus on the potential causal chain between natural resource production, our intervening variables, and foreign policy outcomes. ${ }^{115}$ Case study selection is always tricky, as we must be careful to avoid selecting on the dependent variable. These cases have been chosen as they represent variety in foreign policy behavior and size, and form a good cross-section of resource-rich states. Russia is a major exporter and great power, popularly considered to be extremely aggressive. Venezuela under Hugo Chavez is a small, but quite aggressive petrostate, although it was less aggressive during the latter half of the twentieth century. Finally, Saudi Arabia is the world's largest oil exporter, but is remarkable for its strong diplomacy and lack of overt aggression, providing a potential negative case for the theory.

Each chapter will begin with an overview of foreign policy from 1991-2013 to situate the reader.

${ }^{115}$ Gerring (2008). 
Next, we will seek to assess the links between natural resources and our theory's mediating variables: weak institutionalization, military expenditure and focus, and low government constraints. Analysis will seek to evaluate the theorized links between oil and these mediating variables. This is key, as oil does not directly influence aggressive foreign policy, but instead influences foreign policy formation indirectly through these mediating factors. Next, each chapter will focus on several sub-cases (specific instances of foreign policy making), to examine the links between our mediating variables and aggressive foreign policy. Information from memoirs, quotes or interviews from leaders and news sources will be of particular value, as the goal here is to examine more closely the factors that affect the decision-making process. Thus, each chapter will attempt to determine through process tracing whether natural resource production helps to drive these outcomes, either alone or through interaction with other factors. Although variables are often treated merely as 'probability raisers' in the study of causality, one must consider both whether variables are broadly applicable to many cases (i.e., population-level) or whether they are interlinked with other factors in specific cases (i.e., sample-level) in order to produce the relevant outcome. ${ }^{116}$ It is important to remember that resource wealth is just one of a 'bundle of factors' that may alter foreign policy outcomes, with different combinations of factors producing similar outcomes at different times. Thus, we expect to find cases in which oil-driven factors are key in driving aggression, and others where they are less important.

In making assessments, it is important to note that this dissertation does not seek to assess the quality of foreign policy per se, nor whether outcomes are good or bad, but rather whether the process of foreign policy making itself is distorted in the ways suggested by the theory. Literature on bureaucratic politics has long addressed this issue: understanding how policy is made does not imply a judgement about the policy or its outcomes. If we focus only on 'bad outcomes' or on high stakes issues, it is extremely difficult to understand how the system works in other cases. ${ }^{117}$ This can even lead to tautological conclusions, as a negative policy is assumed to arise only from a broken system. In fact, as scholars have argued, a foreign policy system may 'work' well, and yet produce

\footnotetext{
${ }^{116}$ Mahoney (2008).

${ }^{117}$ Anderson (1983).
} 
a negative outcome, due to constraints on policymakers or other factors. Therefore, within each sub-case, the dissertation will attempt to assess not the outcomes themselves, but whether these outcomes and the process through which decisions were reached correspond to our theory-based expectations.

The theory of natural resources and aggression outlined in Chapter Two has several key observable implications, primarily related to our mediating variables, which we can assess in the case studies. Firstly, each case study will assess the links between oil production and our theory's mediating variables, focusing on these observable implications. Secondly, each case study chapter will focus on whether these factors are in fact linked to aggressive foreign policy behavior in specific cases of foreign policy decision making. The observable hypotheses are listed below, along with their theoretical basis:

\section{Weak Institutional Environment for Foreign Policy}

(a) Foreign policy is personalized and primarily made by individuals or small groups.

(b) Available information is confused or lacking, and important factors are unknown or unclear.

(c) Foreign policy is characterized by disagreements and jockeying for influence.

\section{High Levels of Military Readiness and Focus}

(a) Comparatively high levels of military spending.

(b) A tendency to ignore or avoid diplomatic or other alternatives to military action.

\section{Public Sector Dominated-Economy Lacks Constraints on Government}

(a) Public opinion is opposed to policy, or is treated as unimportant by leaders.

(b) Government does not seek broad public coalitions to support policy.

These expectations will be the focus of process tracing within the case studies. It is important to note that we should not necessarily expect to see all of these factors in any given case, rather we should expect to see different combinations in different cases, with each acting as a slight 'probability raiser' for aggressive foreign policy. ${ }^{118}$ However, in order to support the theory, we should expect to find several of these factors at work in each case.

\footnotetext{
${ }^{118}$ Mahoney (2008).
} 


\subsubsection{Boundary Conditions}

The key boundary condition is that the study only covers the period from 1960-2001 (statistical) and 1991-2010 (qualitative). While it would likely provide fascinating insights to study resourcerich states in earlier periods, a combination of data restrictions and the curious organizational structure of the pre-war resource extraction industry make this extremely difficult. Firstly, severe data restrictions on energy production prior to 1960 make the extension of the dataset to earlier time periods exceedingly difficult. No general source of such statistics exists, and many countries did not keep adequate records. Comprehensive data is available only for the US and UK prior to this date. None of the central sources for energy data - the US Energy Information Administration, the World Bank/IMF and oil company databases - cover any period prior to 1960. The data problem is further complicated by the nature of oil extraction in the interwar period. Many western countries were heavily involved in, or colonised oil-rich states, primarily to extract those resources (e.g., Iraq or Iran). The states themselves benefitted only infrequently; while quantities of resources extracted would be listed for each state, in fact the profit typically went to the intervening power. Some states were effectively divided between western nations by density of oilfields. In Chapter Three, however, the use of replication data from Haber and Menaldo (2011) allows us to conduct robustness tests over a longer time frame (1816-2002). This data is extremely limited, with a small sample set (primarily large countries are included), and substantial quantities of missing data. In addition, it does not account for the distorted colonial extraction structure discussed above, and as such, is not suitable for use in our central analysis. Despite this, it can be used as a robustness test, and results from this analysis do support the findings of the main analysis, that oil-rich states initiate more conflicts and threats/sanctions than other states. It is hoped that the use of this data can ameliorate the problems of using a shorter time frame for the central study.

Another major boundary condition is that this dissertation does not seek to add to major theoretical debates in international relations, but seeks to situate itself within the broad paradigm of neorealist (and in particular, neoclassical realist) thought. Our theory shares with this paradigm the understanding that leaders are rational in their behavior, and are primarily motivated by the 


\section{Psychological}

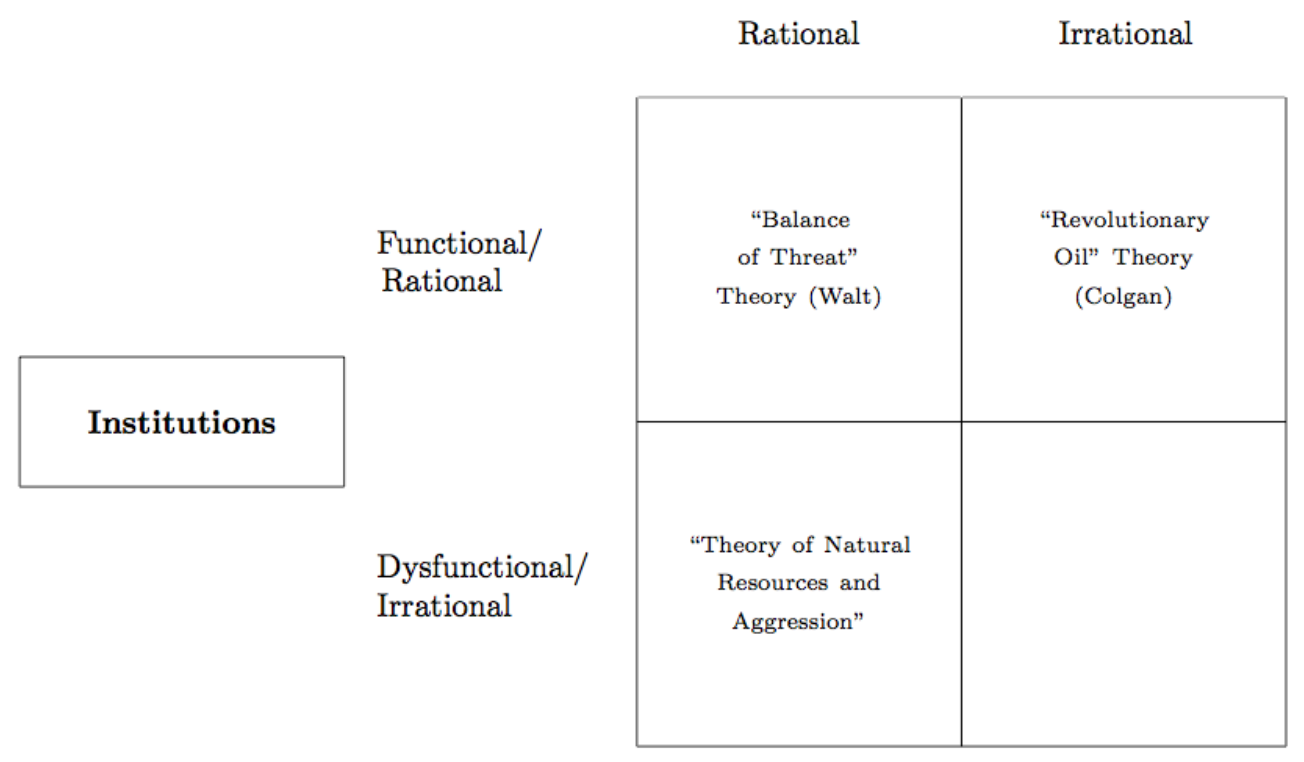

Figure 2.5: Rationality: Institutions and Personality 
'national interest.' The main difference between this dissertation's theory, and standard neorealist explanations of conflict is in one key assumption: the perfect or imperfect functionality of institutional structures for foreign policy. While most neorealist accounts of conflict initiation (i.e., Fearon) assume that institutions are perfectly functional, this dissertation relaxes this assumption, illustrating how the presence of a factor (oil) which undermines institutionalization can cause boundedly rational or even irrational foreign policy outcomes. Thus, this dissertation's theory does not undermine neorealist theories of conflict, but seeks to further explore how relaxing one key assumption can impact conflict initiation within such a framework. Figure 2.5 shows several key theories of conflict initiation in the context of individual rationality and institutional functionality, including this dissertation's theory, balance of threat theory, ${ }^{119}$ and revolutionary war theory, ${ }^{120}$ the main alternative theory linking conflict and oil. ${ }^{121}$ Thus this dissertation explores conflict initiation from within the neoclassical realist framework, accepting the assertion that leaders are rational security-maximisers.

\subsubsection{Resources, Autocracy, Trade and Conflict}

Another concern that must be addressed is the possibility that any connection between natural resources and aggressive foreign policy (especially conflict) is essentially spurious in nature. Firstly, there is a documented relationship between regime type and foreign policy outcomes. The democratic peace literature highlights the empirical regularity that regime type seems to alter the propensity of a state to conflict, although authors have more trouble explaining the causal mechanisms involved with explanations ranging from purely normative, to liberal institutions, or domestic audience costs. ${ }^{122}$ Evidence also shows that although autocracies are more war prone than democracies, there are substantive differences within the subset of authoritarian regimes. ${ }^{123}$

\footnotetext{
${ }^{119}$ Balance of Threat theory posits that states seek to maximize their security, largely by balancing against perceived threats (Walt (1984)).

${ }^{120}$ See Section 2.1.3 for further discussion of Colgan's argument.

${ }^{121}$ Each of these alternate theories will be additionally discussed in the case studies, with a specific focus on whether they can better explain observable outcomes than this dissertation's theory.

${ }^{122}$ Owen (1994); Fearon (1994).

${ }^{123}$ Weeks (2011).
} 
Colgan (2010) argues that it is revolutionary government which creates conflict, with oil being purely the means to aggressive ends. However, there is also evidence of a documented relationship between resource wealth and regime type. It is postulated by many authors that oil either inhibits democratization or increases the survival rate of autocracies, since resource rents reinforce elite authority, and allow governments to respond to the needs of their citizens without burdening them. ${ }^{124}$ Since oil has been linked to regime type, and regime type linked to conflict, great care must be taken to ensure that resource wealth is not merely a spurious factor in this relationship. A similar concern applies to the potential link between trade and conflict. However, in both cases, careful use of control variables for regime type within the statistical model - combined with attention to state structures in case study analysis - should go some way to ameliorating this problem.

\subsection{Conclusion}

This chapter has presented theoretical foundations for the dissertation, arguing that existing explanations for the high-levels of conflict initiation among resource-exporters are insufficient. I argue instead that the organization of the domestic economy around resource production and export produces a number of distortions and effects that, when taken together, significantly increase the likelihood of conflictual foreign policy. I argue firstly that resource rents tend to lead to weak foreign policy institutions, resulting in foreign policy being made in a personalistic fashion and a low-information environment. Secondly, resource rents permit military buildup and technological superiority, increasing the likelihood of military actions. Finally, resource exporters tend to have a government-dominated economy, making them less constrained than other governments, again increasing the likelihood of conflict.

${ }^{124}$ Mahdavy (1970); Ross (2001); Wantchekon (2002); and Ulfelder (2007). 


\section{CHAPTER III}

\section{Resource Wealth and Aggression: A Quantitative Analysis}

The theory laid out in Chapter Two suggests a number of hypotheses concerning the link between natural resources and aggression. This chapter seeks to assess two of these hypotheses statistically. These are:

Hypothesis 1. All else equal, resource-rich states are more likely to exhibit aggressive foreign policy than other comparable states.

Hypothesis 2. These effects will be present only in states with significant income from natural resources. States that export oil will be more prone to aggression than those states that export other, less lucrative natural resources.

The chapter will focus in particular on the first of these hypotheses, using two key measures which may indicate foreign policy aggression: 1) the propensity of a state to initiate conflict, and 2) the propensity of a state to issue threats or sanctions against other states. The quantitative analysis presented in this chapter finds strong evidence that both of these measures are linked to the production of oil, although there seems to be no systematic relationship between aggression and the production of all other natural resources.

The chapter is organized as follows: Section 3.1 describes variables, data sources and statistical methodology. Sections 3.2 and 2.3 focus on Hypothesis One: Section 3.2 presents empirical results 
for analysis of Conflict as the dependent variable, while Section 3.3 presents empirical results for Threats/Sanctions as the dependent variable. Section 3.4 focuses on Hypothesis Two, and examines whether natural resources exhibit similar or different characteristics than oil in the propensity of states to instigate conflict or threats/sanctions. Section 3.5 concludes with a discussion of the empirical results and their implications for the dissertation's theory.

\subsection{Methodology}

As this topic has been previously understudied, analysis relies on a new dataset drawing data from a variety of different sources, including conflict data from the Correlates of War project; data on sanctions from the Threat and Imposition of Sanctions (TIES) project; energy data from the World Bank, BP and Energy Information Administration' and governance data from the POLITY project. This data has been combined to create a directed-dyad dataset for the years 1960-2001, where each pair of countries has two 'directed' observations for each year in the dataset. Although this involves an extremely large number of observations, it allows for analysis of which state initiated a conflict or threat/sanction, as well as simultaneous analysis of the key characteristics of both states. ${ }^{1}$ Unfortunately, severe data restrictions on oil production prior to 1960 make the extension of the dataset to earlier time periods difficult, ${ }^{2}$ although a robustness test on a more limited set of data covering the years 1816-2002 is included in Section 3.2.2.

As both primary variables are binary in nature (i.e., conflict/no conflict), this analysis will primarily use logit models to assess relationships between key variables of interest. As both Conflict and Threat are 'rare events,' models will also be tested using the conditional log-log link function, and a rare events logit ${ }^{3}$. Both are designed to ameliorate some of the problems which occur when

\footnotetext{
${ }^{1}$ The list of dyads was generated using EUGene, the expected utility generator created by Bennett and Stam (2008).

${ }^{2}$ The central sources for energy data are the US Energy Information Administration, the World Bank/IMF and oil company databases, all of which only cover the post-World War II period.

${ }^{3}$ Tomz, King and Zeng (2001) argue that standard logit models are inappropriate to analyze rare events, as they tend to severely underestimate the probability of a positive outcome. Their statistical package ReLogit is designed to use within dataset sampling in order to avoid these concerns and produce more accurate results in cases where the dependent variable is unbalanced.
} 
analyzing rare events, and to ensure that results are not skewed by the unbalanced dataset. In addition, fixed effects will also be estimated, to see whether there are dyad-specific omitted variables which may alter the results. Although the primary dependent variables of interest (conflict and threat) tend to be relatively time invariant for many dyads, Chamberlain's estimators allows us to calculate fixed effects over this subset of cases. ${ }^{4}$ As the dataset is time-series cross-sectional data (i.e., each country or dyad is listed many times in the dataset), standard errors will be clustered by dyad, and a measure of peace years and a three-knot spline will be included in each regression to account for time dependence within the dataset. ${ }^{5}$

\subsubsection{Dependent Variables}

The key outcome which this study seeks to explain - aggressiveness of a state - will be operationalized using two different measures, conflict initiation, and threat/sanction initiation. Both are binary measures. The first dependent variable - Conflict Initiation - is drawn from the Correlates of War Project, widely used by scholars studying the causes of war. Conflict is therefore simply a binary measure of whether state A initiated any militarized interstate dispute against state B in the given year or not. Although there are cases where state A initiated multiple conflicts against state $\mathrm{B}$ in the same year, this is uncommon. Theoretically, it is also likely that multiple conflicts initiated by one state against another in the same year are related to the same factors, and therefore provide us no additional analytical leverage. For this reason, analysis using a binary response model such as logit or probit seems better suited to the question at hand than a poisson (count) model of total number of conflicts.

The conflict variable therefore measures whether or not a militarized interstate dispute (MID)

\footnotetext{
${ }^{4}$ As Baltagi, Bresson and Pirotte (2003) illustrate, although fixed effects tend to produce the most efficient estimator, panel data with time invariant parameters cannot be estimated using fixed effects without bias. Many dyads in this dataset experience no conflict at all over the time period, and are therefore dropped from any fixed effects analysis. Beck and Katz (2000) argue that fixed effects are never suitable for dyadic data analysis, precisely because of this problem. Chamberlain's estimators (see Baltagi (2009) allow us to estimate fixed effects even with these restrictions, but the results may suffer some bias.

${ }^{5}$ Beck, Katz and Tucker (2007) illustrate the problems of serial autocorrelation within cross-sectional time-series datasets, particularly in analyses of topics such as conflict, where length of time since the last conflict is an important variable. They suggest the use of a variable for peace years and a three-knot spline of peace years in order to smooth the curve and avoid these problems.
} 
was initiated by state A in the given year. A MID is defined as a situation in which a state "threatens, displays or uses military force against the government, representatives or territory of another state." ${ }^{6}$ Although a broader definition of conflict than war, the use of the MID classification has been widely accepted in the literature as one of the best ways to understand dispute onset among states. The conflict variable only includes threats involving the imminent use of force, and does not include sanctions at all; thus overlap with the second area of analysis (threats/sanctions) is minimal. Conflict is a rare event, with only 1,253 MIDs occurring in the 476,295 possible dyadyears. Therefore, although the models will be tested using standard logit and fixed effects logit models, the data will also be tested using complementary log-log and rare events logit models to correct for the relative paucity of positive cases in the dataset.

The second dependent variable under study is Threat/Sanction Initiation, a binary variable drawn from the Threat and Imposition of Sanctions (TIES) dataset. This variable therefore measures whether or not state A threatened to, or did in fact limit/end "their economic relations with [State B] in an effort to persuade that country to change its policies." 7 This could be through a variety of means, including tariffs, export controls, embargoes, import bans, travel bans, freezing assets, or cutting aid. Similar to conflict, it is uncommon for multiple sanctions to exist within the same dyad-year, and those which do occur are generally related. Sanctions can also relate to a number of issues, ranging from human rights to economic policies; as Figure 3.1 indicates, trade practices are the most common reason for threats or sanctions, followed by human rights issues and alliance/alignment politics. Threat is also a rare event, with only 789 instances of threat occurring in 476,295 potential dyad-years. This again suggests that a rare events logit or complementary loglog may be a better model for analysis than the conventional logit. These two metrics will be used as the key dependent variables in the study, allowing for analysis of two different potential avenues for aggressive foreign policy: Threat will capture verbal or economic measures of antagonism, while Conflict is more likely to capture physical aggression.

\footnotetext{
${ }^{6}$ Ghosn, Palmer \& Bremmer (2004).

${ }^{7}$ Morgan, Krustev \& Bapat (2006).
} 


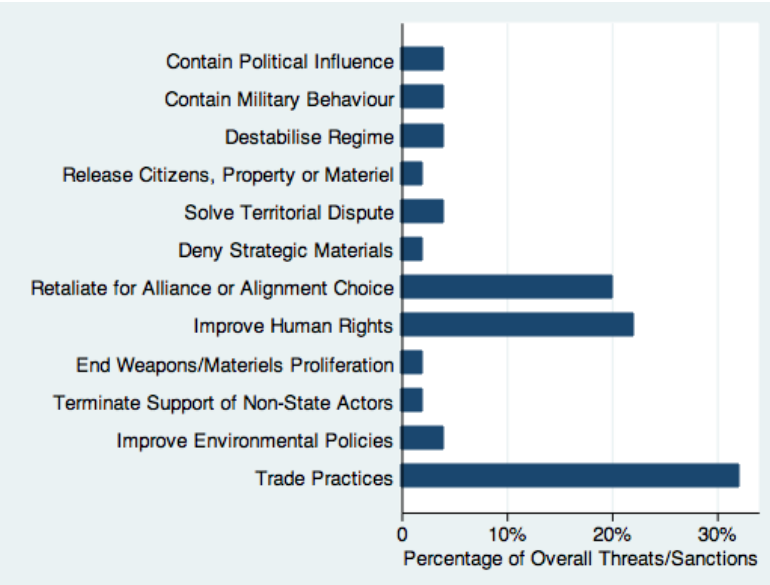

Figure 3.1: Motivations for Threat/Sanction

\subsubsection{Independent Variable, or; What is a 'Resource-Rich State'?}

The primary independent variable(s) for the study are various measures of oil and natural resources for individual countries. As discussed in Chapter One, the question of what defines a 'resource-rich' state and how to measure such a distinction is complex. Although a broad definition of resource-rich is straightforward - it is simply a state where economic production is to a greater or lesser extent focused on the production and export of raw materials - measurement is a more complex problem. Since almost every state produces some form of natural resource, and natural resources can include everything from hydrocarbon resources to precious stones and metals to even items like timber or agricultural goods, the key decision of which states count as resource-rich can be problematic. In studies dealing with natural resources, the researcher must choose first which resources to assess, and then how to best measure their importance to a state. These choices can have huge ramifications, as evidence suggests differing measurements may have a large impact on eventual results. ${ }^{8}$

Given the theoretical focus of this dissertation on resource revenues as the mechanism through which aggressive foreign policy is created, this study will focus primarily on measures of revenue

\footnotetext{
${ }^{8}$ Ross (2004) illustrates that different measurements of resource wealth in various works on natural resources and civil war in fact have major implications for study findings. In general, those studies which use oil reserves (ie, stocks in the ground) find no statistical links, while those which look at exports or government income find more links.
} 
from natural resources, rather than on absolute measures of resource production. The study therefore has two key independent variables: a measure of oil revenue, and a measure of natural resource revenue. The primary independent variable will be Oil Revenues, as a percentage of GDP, a measure of how much revenue State A (the initiating state in each dyad) earned from oil exporting in a given year. This variable was coded using data from three different sources. Primary data on oil revenues comes from the World Bank, which produces a figure (based on country statistics) of oil revenue as a percentage of GDP. ${ }^{9}$ However, this measure had large quantities of missing data, providing data for barely half the countries in the sample. Additional information on oil export and prices was therefore obtained from the BP Statistical Index and the Energy Information Administration (EIA) and used to fill in many of the missing figures. ${ }^{10}$ This yields a single continuous measure of Oil Revenues as a percentage of GDP, allowing us to measure the impact of oil exporting on the national economy in each state. ${ }^{11}$ Figure 3.2 shows the distribution of oil revenues (as a percentage of GDP) across the states in the study, with a normal curve overlaid for reference. The distribution is decidedly skewed, with the vast majority of states receiving little or no revenue from oil production.

The secondary independent variable tested will be Natural Resource Revenues (State A), again as a percentage of GDP. This data comes from the World Bank, and includes revenues from production of oil, natural gas, coal, minerals (i.e., precious metals and gems) and timber. ${ }^{12}$ This is an extremely broad measure, but given the difficulty of obtaining data on the export of many of these raw materials, this variable is the best available which allows for the analysis of a variety of natural resources. In addition to these two primary measures, robustness tests will also be carried out using several alternate measures of revenue. Firstly, Oil Revenues will be recoded into two dummy variables, Petrostate (10\%) for those states which receive revenues equivalent to $10 \%$ of

\footnotetext{
${ }^{9}$ World Development Indicators, The World Bank (2012).

${ }^{10}$ Energy Information Administration (2012) \& BP Statistical Index (2011).

${ }^{11}$ When observations in both samples are assessed, the World Bank and EIA data are correlated at the 97\% level, and World Bank and BP data are correlated at the 99\% level. Thus, although they come from different initial sources, it seems appropriate to use these different measures to create a more representative variable.

${ }^{12}$ World Development Indicators, The World Bank (2012).
} 
Table 3.1: Petrostates in Dataset

\begin{tabular}{l|c|c}
\hline \hline State & $\begin{array}{c}\text { Oil Revenues } \\
\text { (10\% of GDP) }\end{array}$ & $\begin{array}{c}\text { Oil Revenues } \\
\text { (20\% of GDP) }\end{array}$ \\
\hline Algeria & $1973-2001$ & $1974-1981$ \\
Angola & $1985-2001$ & $1985-2001$ \\
Azerbaijan & $1991-2001$ & $1992-2001$ \\
Bahrain & $1980-2001$ & $1980-2000$ \\
Brunei & $1985-2001$ & $1984-2001$ \\
Cameroon & $1980-2000$ & 1984 \\
China & $1979-1982$ & - \\
Congo & $1974-2001$ & $1974-2001$ \\
Ecuador & $1974-2001$ & $1979-2000$ \\
Egypt & $1976-1992$ & $1979-1985$ \\
Equatorial Guinea & $1993-2000$ & $1995-2001$ \\
Gabon & $1971-2001$ & $1973-2001$ \\
Indonesia & $1974-1985$ & $1979-1980$ \\
Iran & $1971-2001$ & $1973-2001$ \\
Iraq & 19712001 & $1971-2001$ \\
Kazakhstan & $1991-2001$ & $2000-2001$ \\
Kuwait & $1971-2001$ & $1971-2001$ \\
Libya & $1990-2001$ & $1990-2001$ \\
Malaysia & $1979-1990$ & - \\
Mexico & $1979-1987$ & - \\
Nigeria & $1973-2001$ & $1974-2001$ \\
Norway & $1996-2001$ & - \\
Oman & $1971-2001$ & $1971-2001$ \\
Papua New Guinea & $1990-2001$ & $1990-1993$ \\
Peru & $1979-1980$ & - \\
Qatar & $1971-2001$ & $1971-2000$ \\
Russia & $1990-2001$ & - \\
Saudi Arabia & $1971-2001$ & $1971-2001$ \\
Sudan & $2000-2001$ & - \\
Suriname & $1998-2000$ & - \\
Syria & $1975-2001$ & $1990-2000$ \\
Trinidad \& Tobago & $1973-2000$ & $1974-1990$ \\
Tunisia & $1979-1985$ & - \\
Turkmenistan & $1991-2001$ & $1997-2001$ \\
United Arab Emirates & $1975-2001$ & $1975-1992$ \\
Venezuela & $1971-2001$ & $1974-2000$ \\
Yemen & $1990-2001$ & $1990-2001$ \\
\hline \hline
\end{tabular}




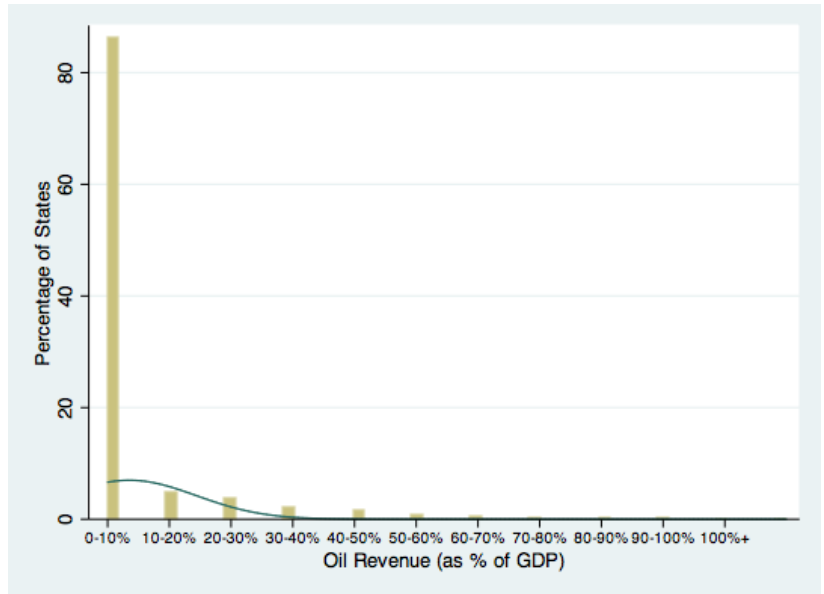

Figure 3.2: Distribution of States by Oil Revenues (as \% of GDP)

GDP (or more) from oil exports, and Petrostate(20\%) for those with $20 \%$ of GDP (or higher) revenues from oil. These cutoffs have been common in previous work, and will allow us to test whether the relationship between oil and aggression holds constant when we consider states as two broad groups: petrostates and non-petrostates. Table 3.1 provides a list of those states which fall into each category, and the years in which they did so.

Secondly, some authors have argued that the use of GDP in measures of oil production introduces an endogeneity problem into our statistical analysis, as GDP itself may be affected by the production of oil exports. ${ }^{13}$ In addition, prior literature in international relations suggests that being a large global producer of oil does in fact create leverage, and may increase aggressiveness of a state, independent of revenue. Thus, while our primary theoretical focus is on oil revenues, robustness tests will also be carried out using a metric which does not involve GDP, and which instead measures a country's impact on global resource markets. A measure of Oil Exports as a percentage of world supply has been created using BP and EIA data, both of which provide total production figures for both national and global production. This variable is therefore a measure of how much of the world's oil supply any given country produces. Since this variable is independent of GDP and a state's economic performance, these robustness tests should hopefully mitigate en-

\footnotetext{
${ }^{13}$ A number of studies (including Brunnschweiler and Bulte (2004) \& Stevens and Dietsche (2008)) highlight this endogeneity problem, which is particularly pronounced in studies of economic development, where GDPbased measures can feature in both dependent and independent variables.
} 
dogeneity problems found in the measure of oil revenues as a percentage of GDP, as well as provide an idea of how important the 'leverage' aspect of oil production may be to state aggressiveness.

\subsubsection{Control Variables}

Table 3.2: Summary statistics

\begin{tabular}{lccccc}
\hline \hline \multicolumn{1}{c}{ Variable } & Mean & Std. Dev. & Min. & Max. & N \\
\hline Conflict Initiation & 0.001 & 0.036 & 0 & 1 & 955082 \\
Threat Initiation & 0.001 & 0.029 & 0 & 1 & 955074 \\
Oil Revenues (as \% of GDP) & 4.723 & 11.992 & 0 & 113.397 & 705835 \\
Natural Resource Revenues (as \% of GDP) & 8.053 & 14.094 & 0 & 214.492 & 737703 \\
Oil Exports (as \% of World Supply) & 0.007 & 0.023 & 0 & 0.283 & 667198 \\
Major Power (State A) & 0.037 & 0.188 & 0 & 1 & 955082 \\
Major Power (State B) & 0.037 & 0.188 & 0 & 1 & 955082 \\
Alliance Similarity & 0.024 & 0.256 & -0.367 & 1 & 920036 \\
Capabilities Ratio & 126.472 & 1574.969 & 0 & 158539 & 954710 \\
Polity Score (State A) & 2.261 & 0.908 & 1 & 3 & 955082 \\
Democratic Peace & 0.441 & 0.496 & 0 & 1 & 955082 \\
Distance & 5.875 & 0.735 & 1 & 6 & 955082 \\
Trade Flow (A-to-B) & 71.820 & 1266.421 & 0 & 229191 & 919986 \\
Trade Flow(B-to-A) & 71.820 & 1266.421 & 0 & 229191 & 919986 \\
Peace Years & 16.341 & 11.535 & 0 & 41 & 955082 \\
\hline \hline
\end{tabular}

In addition to our central variables, a number of relevant control variables (as indicated by prior studies on conflict and sanctions) will be included in the analysis. It should be noted that slightly different combinations of control variables will be used in the analysis of threat than those used to analyze conflict. This is because prior work has indicated that different factors influence a country's decision to issue a sanction than those which influence the decision to initiate conflict. Using the same variables for each analysis would therefore bias the results. Instead, control variables are included only when they are relevant (as indicated by prior research). Table 3.2 presents summary statistics for key variables.

The first set of control variables come from the Correlates of War project, and are all commonly used as control variables in analyses of conflict. ${ }^{14}$ Major Power represents two dummy variables,

\footnotetext{
${ }^{14}$ All Correlates of War variables taken from Ghosn, Palmer \& Bremer(2004).
} 
the first indicating whether State A is a major power or not, and the second indicating the same for State B in each dyad. This variable comes from the Correlates of War data; and indicates both military capability and prestige within the international system. This variable is included in analyses of Conflict and Threat, as previous studies indicate that major powers initiate both conflicts and threats/sanctions at a substantially higher rate than other states. Alliance Similarity also comes from the COW project, and is the Tau-b global alliance score of each dyad. This is a measure of how similar two states' alliance portfolios are to each other; similarity in alliance portfolios has been shown to reduce conflict. This variable will only be included when analyzing conflict, as previous studies have shown no significant link between threats/sanctions and alliance similarity.

Capabilities Ratio also comes from Correlates of War, and is the ratio of the CINC Capabilities score of States A and B. The CINC score is an index of six indicators of national power - military expenditure, military personnel, energy consumption, iron/steel production, urban population, and total population. Although energy production has typically been treated as one facet of state power, the CINC score includes no statistics on production of energy, so collinearity with oil data is unlikely to be a problem. The capabilities ratio is effectively a measure of the comparative power of States $\mathrm{A}$ and $\mathrm{B}$, and how effectively they are able to wage war against each other. The final variable to come from the Correlates of War project is Distance, an ordinal variable which measures how far apart each dyad is. It ranges from 0 (contiguous states) to 6 (those which are more than 400 miles apart). This variable is only included in analysis of conflict, as it has previously been shown to be important in studies of conflict, but has rarely featured in prior analyses of threats/sanctions.

Two additional variables, Polity Score and Democratic Peace come from the POLITY-IV project. ${ }^{15}$ Polity Score is a trichotomous measure of State A's polity score, ${ }^{16}$ indicating whether the state is a democracy, anocracy or autocracy. State A's polity score is included as prior studies have indicated a relationship between oil revenues and autocratic governance, as well as the fact

\footnotetext{
${ }^{15}$ Marshall and Jaggers(2010).

${ }^{16}$ Coding guidelines for the trichotomous indicator is taken from the Polity-IV codebook, where the authors suggest using an ordinal variable to put states in three broad groups depending on democratic status.
} 
that autocratic states may be more aggressive than democracies; the polity score is therefore included to preclude the possibility that oil is merely a spurious variable. State B's polity score is not included in analyses of Conflict, as there is no theoretical reason to do so. However it is included in the analysis of Threat, as autocracies are typically more likely to receive sanctions. The second variable, Democratic Peace is included in analyses of Conflict instead of state B's polity score, and measures whether the two states within the dyad are both democracies or not. This corresponds to the standard democratic peace argument that two democracies are unlikely to enter conflict.

Trade Flow again represents two variables: a one-year lagged measure of State A's exports to State B (in current US \$millions), and vice versa. This data comes from Russett and Oneal's Triangulating Peace dataset. ${ }^{17}$ They, among many others, have argued that increased trade tends to decrease the likelihood of conflict. These variables are also included in the analysis of Threat, as increased trade likely reduces the propensity of states to issue economic sanctions. The measurement of trade flows is lagged one year in order to avoid potential endogeneity problems caused by the fact that conflict typically reduces trade while it is ongoing. In addition, Peace Years (a measure of time since last conflict within this dyad) and a three-knot spline are included in the analysis of both threat and conflict. This method allows us to mitigate problems of temporal dependence within cross-sectional panel series data. ${ }^{18}$ Finally, dummy variables for region of each state, as well as a dummy variable (Cold War) for whether the year took place during the cold war are included.

\subsection{Empirical Results: Conflict Initiation and Oil}

In this section, the relationship between oil wealth and physical aggression by states (i.e., conflict initiation) will be tested. Figure 3.3 shows the breakdown of initiated conflicts by three groups of states, those which are non-petrostates (oil revenues of less than $10 \%$ of GDP), those which are moderate petrostates (revenues of 10-20\% of GDP) and those which are high petrostates (revenues greater than $20 \%$ of GDP). Note that both groups of petrostates constitute a larger portion of

\footnotetext{
${ }^{17}$ Russett and Oneal (2001).

${ }^{18}$ Beck, Katz and Tucker (1997).
} 


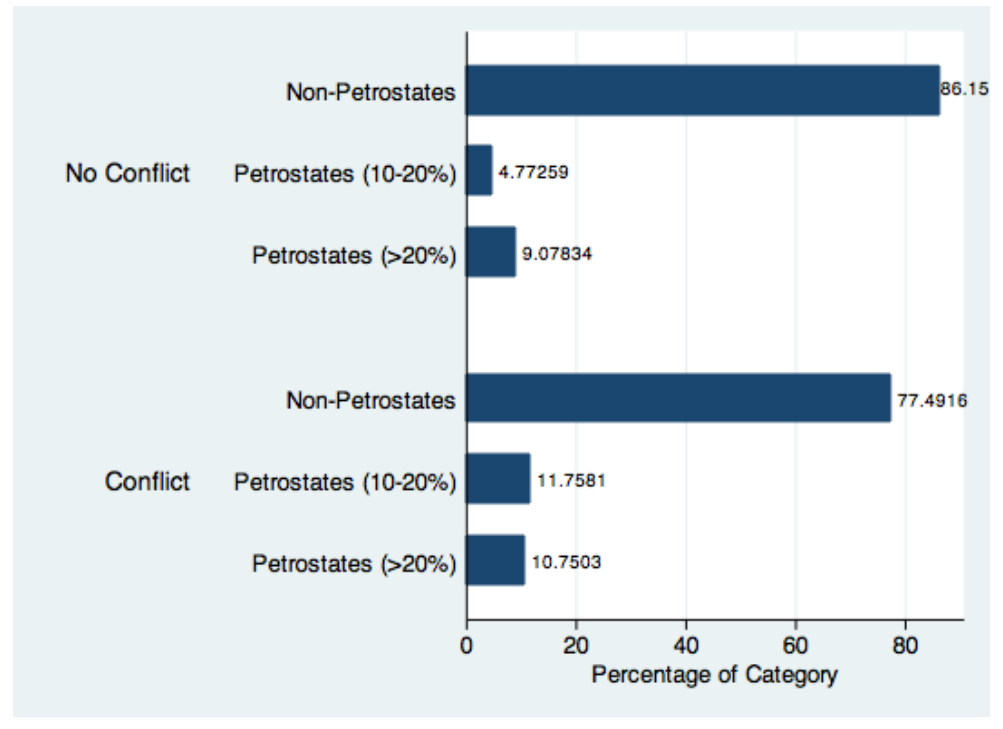

Figure 3.3: Petrostates and Conflict

those states which initiated conflict than of those which did not. This is suggestive of the fact that petrostates may indeed be more prone to conflict. However, in order to draw any more robust conclusions, we must examine this relationship within a multinomial framework.

\subsubsection{Regression Analysis}

Table 3.3 presents results from these multinomial regressions, and provides strong evidence that oil-rich states are indeed more prone to initiate conflict than other states. Model 1.1 is simply a base logit model without oil, in order to verify that factors shown to be important in prior scholarly studies are still of interest within this dataset. Most factors are signed as expected and positive; the only key exception is Democracy (State A) which has been previously shown to have no effect on conflict and is only included to mitigate the potential effects of the democratic 'Resource Curse'. Model 1.2 incorporates our key variable of interest, Oil Revenues, in the regression, and shows strong support for Hypothesis One. Since this is a logit regression, the coefficients cannot be directly interpreted, but the key variable is signed as expected, and is highly positive; As countries obtain greater levels of oil revenue (as a \% of GDP), they do initiate more conflicts.

Most other variables are also signed as expected. If either State A or State B is a major power, 
Table 3.3: Conflict Initiation by Annual Oil Revenues

\begin{tabular}{|c|c|c|c|c|c|}
\hline $\begin{array}{l}\text { Dependent Variable: } \\
\text { Conflict Initiation }\end{array}$ & $\begin{array}{l}\text { Model } 1.1 \\
\text { Base Logit }\end{array}$ & $\begin{array}{l}\text { Model 1.2 } \\
\text { Oil Logit }\end{array}$ & $\begin{array}{l}\text { Model } 1.3 \\
\text { C-Log-Log }\end{array}$ & $\begin{array}{c}\text { Model } \mathbf{1 . 4} \\
\text { Rare Events } \\
\text { Logit }\end{array}$ & $\begin{array}{c}\text { Model } \mathbf{1 . 5} \\
\text { Fixed Effects } \\
\text { Logit }\end{array}$ \\
\hline $\begin{array}{l}\text { Annual Oil Revenues } \\
\text { (as \% of GDP) }\end{array}$ & & $\begin{array}{c}0.009^{* * *} \\
(0.00)\end{array}$ & $\begin{array}{c}0.008^{* *} \\
(0.00)\end{array}$ & $\begin{array}{c}0.009^{* * *} \\
(0.00)\end{array}$ & $\begin{array}{l}0.007^{*} \\
(0.00)\end{array}$ \\
\hline Major Power (State A) & $\begin{array}{l}1.646^{* * *} \\
(0.21)\end{array}$ & $\begin{array}{c}1.745^{* * *} \\
(0.21)\end{array}$ & $\begin{array}{c}1.583^{* * *} \\
(0.19)\end{array}$ & $\begin{array}{c}1.740^{* * *} \\
(0.21)\end{array}$ & $\begin{array}{c}2.280^{* * *} \\
(0.23)\end{array}$ \\
\hline Major Power (State B) & $\begin{array}{c}1.294^{* * *} \\
(0.21)\end{array}$ & $\begin{array}{c}1.260^{* * *} \\
(0.21)\end{array}$ & $\begin{array}{c}1.123^{* * *} \\
(0.21)\end{array}$ & $\begin{array}{c}1.263^{* * *} \\
(0.21)\end{array}$ & $\begin{array}{c}1.667^{* * *} \\
(0.23)\end{array}$ \\
\hline Alliance Similarity & $\begin{array}{l}-0.223 \\
(0.15)\end{array}$ & $\begin{array}{l}-0.163 \\
(0.16)\end{array}$ & $\begin{array}{l}-0.144 \\
(0.16)\end{array}$ & $\begin{array}{l}-0.160 \\
(0.16)\end{array}$ & $\begin{array}{l}0.563^{*} \\
(0.24)\end{array}$ \\
\hline Capabilities Ratio & $\begin{array}{c}-0.001^{*} \\
(0.00)\end{array}$ & $\begin{array}{c}-0.002^{* *} \\
(0.00)\end{array}$ & $\begin{array}{c}-0.002^{* *} \\
(0.00)\end{array}$ & $\begin{array}{c}-0.002^{* *} \\
(0.00)\end{array}$ & $\begin{array}{c}-0.001^{*} \\
(0.00)\end{array}$ \\
\hline Democracy (State A) & $\begin{array}{l}0.020 \\
(0.07)\end{array}$ & $\begin{array}{l}0.056 \\
(0.07)\end{array}$ & $\begin{array}{l}0.064 \\
(0.07)\end{array}$ & $\begin{array}{l}0.057 \\
(0.07)\end{array}$ & $\begin{array}{c}-0.126^{*} \\
(0.06)\end{array}$ \\
\hline Cold War & $\begin{array}{l}0.071 \\
(0.10)\end{array}$ & $\begin{array}{c}0.416^{* * *} \\
(0.12)\end{array}$ & $\begin{array}{c}0.413^{* * *} \\
(0.12)\end{array}$ & $\begin{array}{c}0.414^{* * *} \\
(0.12)\end{array}$ & $\begin{array}{c}0.327^{* *} \\
(0.12)\end{array}$ \\
\hline Democratic Peace & $\begin{array}{c}-0.435^{*} \\
(0.18)\end{array}$ & $\begin{array}{c}-0.496^{*} \\
(0.19)\end{array}$ & $\begin{array}{c}-0.470^{*} \\
(0.19)\end{array}$ & $\begin{array}{c}-0.494^{*} \\
(0.19)\end{array}$ & $\begin{array}{c}-0.693^{* * *} \\
(0.18)\end{array}$ \\
\hline Distance & $\begin{array}{c}-0.843^{* * *} \\
(0.03)\end{array}$ & $\begin{array}{c}-0.781^{* * *} \\
(0.04)\end{array}$ & $\begin{array}{c}-0.768^{* * *} \\
(0.04)\end{array}$ & $\begin{array}{c}-0.781^{* * *} \\
(0.04)\end{array}$ & $\begin{array}{c}-0.852^{* * *} \\
(0.05)\end{array}$ \\
\hline Lagged Trade (A-to-B) & $\begin{array}{c}-0.000^{*} \\
(0.00)\end{array}$ & $\begin{array}{c}-0.000^{*} \\
(0.00)\end{array}$ & $\begin{array}{c}-0.000^{* *} \\
(0.00)\end{array}$ & $\begin{array}{c}-0.000^{* *} \\
(0.00)\end{array}$ & $\begin{array}{l}-0.000 \\
(0.00)\end{array}$ \\
\hline Lagged Trade (B-toA) & $\begin{array}{l}0.000^{*} \\
(0.00)\end{array}$ & $\begin{array}{l}0.000 \\
(0.00)\end{array}$ & $\begin{array}{l}0.000^{*} \\
(0.00)\end{array}$ & $\begin{array}{l}0.000^{*} \\
(0.00)\end{array}$ & $\begin{array}{l}0.000 \\
(0.00)\end{array}$ \\
\hline Constant & $\begin{array}{l}-0.214 \\
(0.22)\end{array}$ & $\begin{array}{c}-0.691^{* *} \\
(0.25)\end{array}$ & $\begin{array}{c}-0.980^{* * *} \\
(0.24)\end{array}$ & $\begin{array}{c}-0.690^{* *} \\
(0.25)\end{array}$ & \\
\hline $\mathrm{N}$ & 702648 & 522061 & 522061 & 522061 & 121023 \\
\hline Log-Likelihood & -4995.83 & -3719.44 & -3735.25 & -3719.4419 & -2662.81 \\
\hline $\mathrm{AIC}^{*} \mathrm{n}$ & 10029.660 & 7478.884 & 7510.493 & 7478.884 & 5363.621 \\
\hline
\end{tabular}


the likelihood of conflict increases; this result is highly significant. Alliance Similarity is also signed as expected - similarity in alliance portfolios decreases the likelihood of conflict, however, this result is statistically insignificant. ${ }^{19}$ Capabilities Ratio is negatively signed, and significant. The greater State A's preponderance of power over State B, therefore, the greater the chance of conflict initiation. Democracy (State A) is positively signed, but highly insignificant. The coefficient for Democratic Peace is also significant, and indicates that conflict initiation is less likely when both states are democracies. Cold War is positive, and is significant. Distance is also highly significant, and, as expected, indicates that countries which are closer together are much more likely to conflict. Finally, trade seems to play a role for State A, as increased trade flows to B are correlated with lower levels of conflict initiation. Trade from B-to-A is insignificant, a result which is perhaps not unexpected in this directed-dyad format where State A's motives are the primary concern.

Model 1.3 presents the same regression, but uses a complementary log-log link function instead of the more standard logit. The complementary log-log is similar to the logit function, but is asymmetrical, allowing for more precise analysis when the probability of the result (i.e., conflict/no conflict) is very small or large. In this case, where conflict is an exceedingly rare event, the complementary log-log may provide more accurate results. Model 1.3 presents no major differences in sign or significance of key coefficients, except that the trade variable for State B becomes barely significant. As the coefficients for trade are extremely small, this is not a major change. Model 1.4 uses a Rare Events Logit, as developed by Tomz, King and Zeng. This model uses a sampling technique to prevent underestimation of positive outcomes when the outcome of interest (conflict) is a rare event. ${ }^{20}$ Again, Model 1.4 presents no major differences in coefficients of interest from Model 1.2 in terms of sign or significance, indicating that the rarity of conflict within the dataset has not skewed results.

Model 1.5 adds Fixed Effects estimators. This allows us to control for potentially omitted dyad-

\footnotetext{
${ }^{19}$ This perhaps mirrors criticism by Signorinio and Ritter (2002), who argue that although measures of alliance portfolio similarity have become standard control variables in the literature, little is understood about how they influence conflict. They illustrate that different measures of alliance similarities can produce different results, and argue that we cannot necessarily infer state interests solely from their alliances.

${ }^{20}$ Tomz, King and Zeng (2001).
} 
specific variables. Using a fixed effects logit does not alter the result on most variables, and our key variable of interest, Oil Revenues is unchanged from Model 1.2. The only major change in this model is that Democracy (State A) becomes negative and significant, indicating that democracy in State A decreases the likelihood of conflict. Even in this model, however, oil revenues remain positive and significant, indicating an effect of oil over and above that of autocracy in creating conflict. $^{21}$ Despite this difference, Model 1.5 continues to show a clear, significant relationship between Oil Revenues and Conflict Initiation.

Given similar models and coefficients, there are several key criteria we can use to judge which best fits the data. The Akaike Information Criterion (AIC) allows us to directly compare models; Model 1.2 has an AIC of 0.014, as do models 1.3 and 1.4. Model 1.5 has a lower AIC of 0.13, indicating that it performs slightly better with fewer parameters. However, AIC cannot show how well the model fits the data. When we compare pseudo- $R^{2}$, we find that Model 1.2 has an $R^{2}$ of 0.314 , while model 1.3 is a worse fit, with a lower pseudo- $R^{2}$ value of 0.311 ; this statistic cannot be calculated for the Rare-Events Logit, as it would be biased. Model 1.5 has a pseudo- $R^{2}$ value of only 0.137 , indicating that it is a substantially poorer fit for the data, despite the slightly improved AIC. This is unsurprising considering the large number of dropped observations. For this reason, further analysis and robustness tests will focus on Model 1.2, the standard logit model.

Predicted probabilities allow us to better understand the magnitude of the relationship between oil revenues and conflict initiation. Figure 3.4 presents the predicted probability of conflict initiation for an 'average' state by level of resource revenue received. This graph illustrates the likelihood of conflict initiation by State A against a state with which it shares a border, the most common type of conflict. All other values are held at their mean or median, as appropriate. As the graph shows, a state which exports no resources has approximately a $0.14 \%$ likelihood of initiating a conflict against a contiguous state in any year, while a petrostate (at the $10 \%$ level) has a $0.15 \%$ likelihood, a petrostate (with revenues of $30 \%$ of GDP) has a likelihood of almost $0.16 \%$, and a state at the $50 \%$ level has a $0.17 \%$ chance of initiating a conflict against a bordering country. This

\footnotetext{
${ }^{21}$ Interacting Oil Revenues with Democracy (State A) also produces an insignificant result.
} 


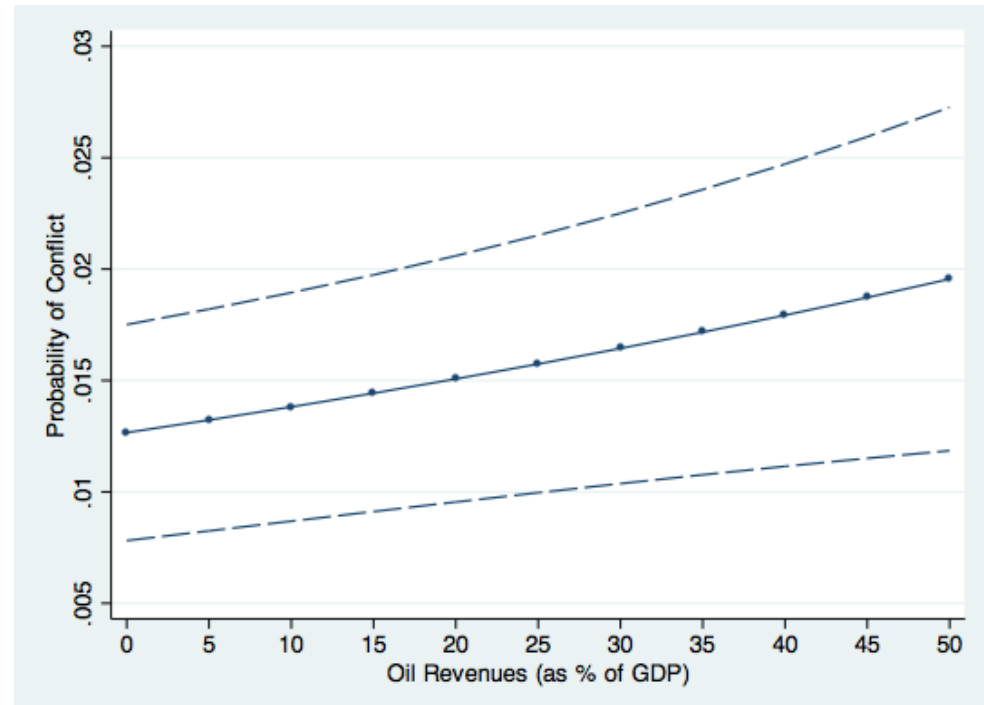

Figure 3.4: Predicted Probabilities of Conflict Initiation

is not an unrealistic scenario, as a number of states have at various points earned over $50 \%$ of their GDP from oil (including Trinidad and Tobago, Venezuela, Azerbaijan, Nigeria, Congo and Saudi Arabia, among others). Thus a state with $50 \%$ resource revenues has a $21 \%$ greater chance than a non-exporter of initiating a conflict in a given year.

It is worth noting that oil is not more important than a number of other factors previously shown to be important in understanding why conflicts occur, merely that when holding other factors constant, oil does appear to be strongly linked to conflict initiation. Figure 3.5 illustrates this graphically, presenting the relationship between oil and conflict as influenced by four key factors which have been previously shown to influence conflict. In the upper left, major powers with or without oil are more likely to initiate conflicts than other states, but major powers with increased revenues from oil are more likely to initiate conflicts than other major powers. The democratic peace hypothesis is also borne out by these results; the upper right chart shows that pairs of democracies are less likely to fight than dyads which contain one or two non-democracies. In both cases, increased oil revenues lead to a greater likelihood of conflict initiation.

In the lower left, we can see that the logical assumption that states which share a border are more likely to conflict is borne out, while those far apart are less likely to do so. Although the 

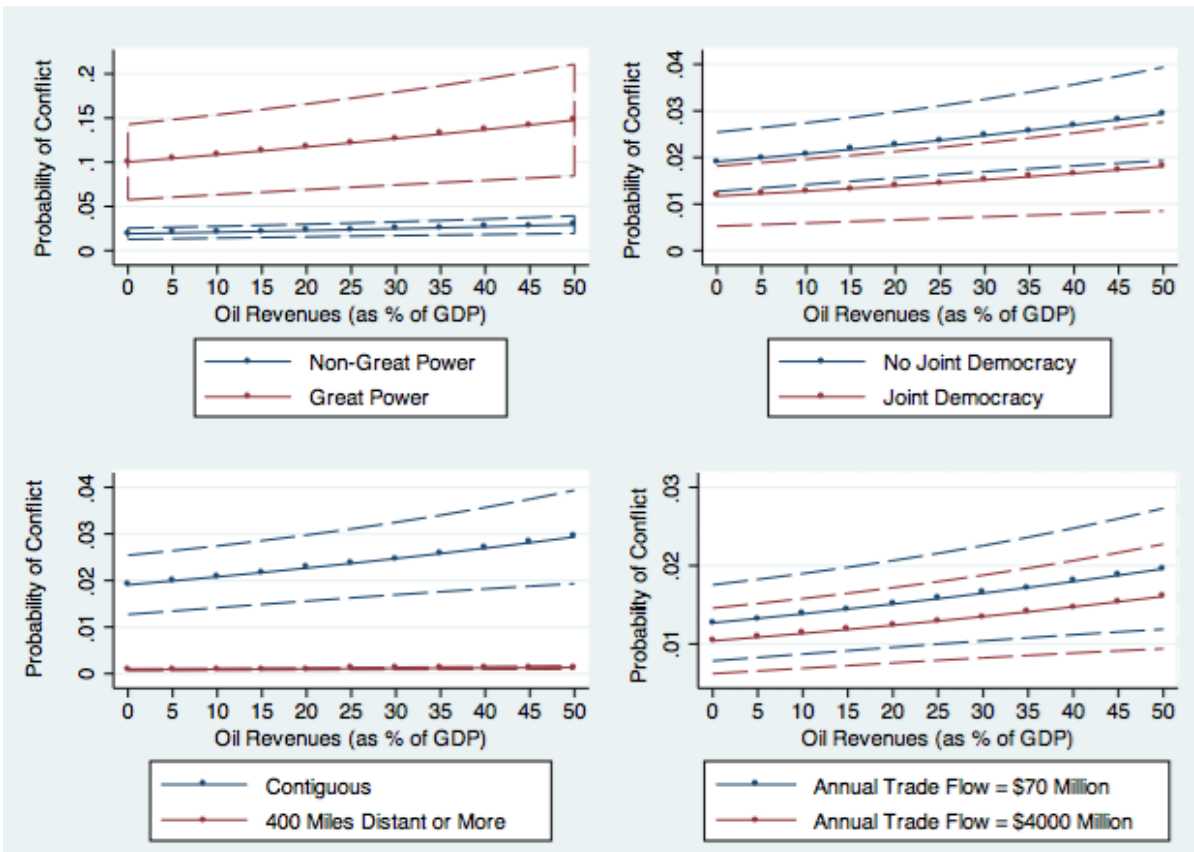

Figure 3.5: Predicted Probabilities of Conflict Initiation by Oil Revenues \& Four Key Variables: Great Power Status, Democratic Peace, Distance \& Trade Flows

relationship between oil and conflict initiation is strong for contiguous states, it is much weaker for distant ones, with a shallow slope. ${ }^{22}$ Finally, in the lower right, trade is shown to impact conflict, with trade flows of around $\$ 4000$ million (two standard deviations above the mean) leading to a lower likelihood of conflict than at the mean ( $\$ 71$ million). In both cases, however, the slope is similar, implying that increased oil revenues have some effect regardless of the level of trade. Oil revenues therefore seem to be a significant factor in conflict initiation, although this effect is obviously also dependent on other key factors.

\subsubsection{Robustness Tests}

These results were subjected to a number of robustness tests and diagnostics. Firstly, collinearity diagnostics were run, to assess whether there are collinearity problems between oil revenues and

\footnotetext{
${ }^{22}$ This is the only case where slope seems to differ as the result of a control variable, leading to the conclusion that oil production as a factor seems to matter more in cases where a dyad is contiguous. This model was retested creating an interaction term for distance and oil, in order to test this hypothesis. The interaction term was insignificant, indicating that distance doesn't substantially alter the slope of the line.
} 
military capabilities or democracy. Mean VIF for all key variables was 1.94, with no VIF higher than 2.5, indicating little to no collinearity between variables. Secondly, points of high leverage were estimated using Pregibon's Delta-Beta statistic; this diagnostic allows us to assess whether or not certain key cases are have too much influence and may be biasing regression results. For Model 1.2, only one observation (the dyad Canada-USA in 1997) seems influential, with a D-Beta value of 0.8. An additional four observations, three of which involve the USA are moderately influential, with D-Beta values between 0.2 and 0.4. These five observations were excluded and the regression run again; results were effectively identical. Thus, we can conclude that no particular observation is exercising too much influence in Model 1.2.

These results suggest a strong link between oil production and conflict initiation. However, as various scholars have noted, the choice of how to measure resources can strongly influence the results of an analysis. For this reason, robustness tests were conducted using several alternate measures of natural resources. Oil Revenues were used to create a dichotomous variable, with those states with more than $10 \%$ revenue from oil in a given year classified as 'petrostates.' Substituting this measure into Model 1.2 resulted in no change in sign, significance or magnitude of the coefficients. In particular, the coefficient for Petrostate(10\%) was identical to that for the continuous measure of Oil Revenues. The same test was then performed categorizing states into those with $20 \%$ (or higher) revenues from GDP as petrostates. The sign and significance of coefficients remained unchanged, although the magnitude of the coefficient on Petrostate(20\%) became somewhat smaller. However, the relationship still appears strong and significant.

There is also concern that oil revenues may be to some extent linked to conflict. In particular, a large oil exporter going to war may artificially inflate oil prices and increase revenues. If oil revenues are partially endogenous to conflict in this way, it would undermine our conclusions. To test for this problem, oil revenues were lagged by one year (so that oil revenues are tested against conflict in the following calendar year) and retested. The results show no change in sign, significance or magnitude of the coefficients, indicating that price endogeneity is not a problem for this analysis. This result is consistent in both standard logistic regression, and fixed effects logistic regression. 
Table 3.4: Robustness Test: Alternate Oil Measure

\begin{tabular}{lcc}
\hline \hline Dependent Variable: & $\begin{array}{c}\text { Model 1.6 } \\
\text { Logit }\end{array}$ & $\begin{array}{c}\text { Model 1.7 } \\
\text { Fixed Effects Logit }\end{array}$ \\
& & \\
\hline Oil Exports(as \% of World Supply) & $8.985^{* * *}$ & $7.862^{* * *}$ \\
& $(1.30)$ & $(1.43)$ \\
Major Power (State A) & $1.066^{* * *}$ & $1.810^{* * *}$ \\
& $(0.21)$ & $(0.25)$ \\
Major Power (State B) & $1.229^{* * *}$ & $1.796^{* * *}$ \\
& $(0.21)$ & $(0.24)$ \\
Alliance Similarity & -0.109 & $0.584^{*}$ \\
& $(0.15)$ & $(0.24)$ \\
Capabilities Ratio & $-0.002^{* *}$ & $-0.002^{*}$ \\
& $(0.00)$ & $(0.00)$ \\
Democracy (State A) & -0.003 & $-0.146^{*}$ \\
& $(0.08)$ & $(0.06)$ \\
Cold War & $0.367^{* *}$ & $0.300^{*}$ \\
& $(0.12)$ & $(0.12)$ \\
Democratic Peace & $-0.448^{*}$ & $-0.676^{* * *}$ \\
& $(0.20)$ & $(0.19)$ \\
Distance & $-0.774^{* * *}$ & $-0.866^{* * *}$ \\
& $(0.04)$ & $(0.05)$ \\
Lagged Trade (A-to-B) & $-0.000^{* *}$ & $-0.000^{*}$ \\
& $(0.00)$ & $(0.00)$ \\
Lagged Trade (B-to-A) & $0.000^{*}$ & $0.000^{*}$ \\
& $(0.00)$ & $(0.00)$ \\
Constant & $-0.662^{* *}$ & \\
& $(0.22)$ & \\
\hline N & 485634 & -2460.19 \\
Log-Likelihood & -3461.50 & 4958.383 \\
AIC & 6963.005 & \\
\hline Notes: Standard errors are robust and clustered by dyad (in parentheses). \\
Peace years and a 3-knot spline are included in the regression, but not \\
$\quad$ shown. Regional dummies also included, but not shown. \\
$*=p<0.05, * *=p<0.01, * * *=p<0.001$ \\
\hline \hline
\end{tabular}


Another common concern in the literature is that measures of oil revenues (as a \% of GDP) are flawed because they rely on GDP, which may itself be linked to conflict or to oil production. While our primary theoretical focus is on the impact of oil revenues on a state's behavior, oil may also have significant leverage effects in the international arena. To address this concern, the variable Oil Exports (as a proportion of world supply) is tested. This measure does not rely on measures of national economic performance, or take account of the size of a state. Instead, it is simply a measure of the state's contribution to total global oil supply. This measure may also provide us a way to assess a central theoretical question: do oil-rich states enter conflict for domestic reasons (i.e., structure of government, lack of institutionalization, etc), or merely because resources convey upon these states increased leverage and power? The results are shown in Table 3.4, and are similar to those of prior models, indicating that this relationship is robust to this different measure of export. The coefficient on Oil Exports remains positive and highly significant. This is interesting, as it implies that in addition to the effect of oil revenues on a state domestically, there may be an international leverage effect created by being a large global oil producer.

An additional series of robustness tests was conducted using only a sample of 'politically relevant dyads.' Many recent analyses have used only a sample of politically relevant dyads - that is, only those dyads which are contiguous or are major powers - in the study of conflict; the reasoning is that it is unlikely that states outside this sample of countries will conflict. However, Benson argues that by testing only politically relevant dyads, scholars bias their results towards major powers, and do not adequately study those factors which can lead smaller states to trade or fight with each other. ${ }^{23}$ Since most major powers are not oil exporters, the use of politically relevant dyads is likely to bias results in this analysis, and models presented here instead use a more representative selection of dyads. For robustness, however, these variables are retested using only those observations which are deemed to include 'politically relevant dyads.' The results are similar to those presented in the analysis above, although there is minor variation depending on the measure used. Oil Revenues (as a \% of GDP) remain positive, although they become barely insignificant (that is, significant at

\footnotetext{
${ }^{23}$ Benson (2005) shows that sample choice can seriously alter the results of analyses of trade and conflict.
} 
the $p<0.06$ level). When tested as a binary variable, Petrostate(10\%) is signed and significant as before, with little difference in coefficients. Finally, when testing Oil Exports (as proportion of world supply), the variable remains positive and significant as before. The results therefore stay broadly similar despite losing most small oil-exporting states from the sample. Since there are good theoretical reasons to doubt the validity of using only politically relevant dyads in this case, these results are broadly supportive of the central findings.

Finally, one concern is that the dataset only covers a short time-frame (1960-2001), as data availability in earlier periods is patchy at best. This may lead us to miss important insights from the prewar period. In order to combat this shortcoming, analysis was conducted using replication data from Haber and Menaldo (2011). ${ }^{24}$ This data covers a much longer period (1816-2002), but has substantial missing data, and tends only to cover major powers and large oil-producing countries, making it unsuitable for our full analysis. The key variable of interest is State Fiscal Reliance on Oil Revenues, a measure of how reliant a state is on oil revenues to function. While not exactly the same as our central variable, this is a similar measure which also provides a picture of state dependence on oil revenues. Table 3.5 presents the results of analysis using a standard logit model. ${ }^{25}$ Due to the limited selection of countries in this dataset, the two Major Power variables have been omitted, as they are collinear with other key variables. Our central variable of interest, State Fiscal Reliance on Oil is signed and significant as expected, and other control variables are signed as expected, although several (especially trade variables) are insignificant. Distance and Democratic Peace are signed and significant as expected. In general, although these results are less reliable due to the small sample size, they provide a good robustness test of our earlier results over a longer time frame, indicating that the relationship between oil and state aggressiveness is not only confined to the period after 1945 .

\footnotetext{
${ }^{24}$ Replication data used with permission; Haber and Menaldo (2011).

${ }^{25}$ The data is insufficient to conduct a fixed effects analysis.
} 
Table 3.5: Haber/Menaldo Data on Conflict (1816-2002)

\begin{tabular}{lc}
\hline \hline Dependent Variable: & $\begin{array}{c}\text { Model 4.1 } \\
\text { Logit }\end{array}$ \\
Conflict Initiation & $0.012^{*}$ \\
State Fiscal Reliance & $(0.01)$ \\
on Oil Revenues & Omitted \\
& \\
Major Power (State A) & Omitted \\
Major Power (State B) & 0.510 \\
& $(0.70)$ \\
Alliance Similarity & -0.014 \\
& $(0.01)$ \\
Capabilities Ratio & -0.242 \\
& $(0.28)$ \\
Democracy (State A) & $-0.862^{*}$ \\
& $(0.36)$ \\
Cold War & $-0.005^{*}$ \\
& $(0.44)$ \\
Democratic Peace & $-0.448^{* * *}$ \\
& $(0.07)$ \\
Distance & -0.001 \\
Trade (A-to-B) & $(0.00)$ \\
Trade (B-to-A) & 0.000 \\
Constant & $(0.00)$ \\
Negional dummies, peace years and a 3-knot spline are included in the regression \\
N
\end{tabular}




\subsubsection{Conflict and Oil}

In general, the results of robustness tests confirm the central finding of the regression analysis; states which are large oil exporters do initiate more conflicts. The results also highlight two additional factors. Firstly, the importance of other key factors, such as major power status and distance, cannot be understated. States which have oil are indeed more likely to enter conflict, but we should expect to see such conflicts primarily in specific situations. For example, for a small state which is an oil exporter, we would expect that the conflicts initiated would primarily be border disputes. This is simply to point out that this analysis therefore fits within the broader variety of factors which influence conflict.

The second interesting finding is that the analysis of Oil Exports (as a proportion of world supply) has a substantially larger coefficient, which suggests stronger results than when we assess the effect of Oil Revenues (as a \% of GDP). Using predicted probabilities, we can assess whether the magnitude of Oil Exports (as a \% of world supply) is comparable to that of Oil Revenues (as a $\%$ of GDP). While the two metrics are not easily comparable (for example, a $1 \%$ increase in revenues may be only a fraction of a percent of world supply), we can see in Figure 3.6 that the slopes of the two equations (holding other factors at their mean or median) are very different. As we move from minimum to maximum on each indicator, the slope for Oil Exports (as a proportion of world supply) is much steeper. For example, a state which receives $50 \%$ (the modal value) of its' GDP in oil revenues each year has around a $2.6 \%$ percent chance of initiating a conflict in a given year. In contrast, a state which supplies approximately 14\% (again, the modal value) of the world's supply has a $6 \%$ chance of initiating a conflict. The effect becomes more pronounced as we move towards the maximum, although it should be noted that there are very few states which export more than $6 \%$ of global supply. This comparison implies strongly that the the marginal effect of supplying more of the world's oil supply (perhaps in power terms) is greater than the marginal domestic effect of increased revenue from oil wealth in influencing conflict.

This comparison is also interesting when we consider the sample itself; the set of states which are large global suppliers of oil are not necessarily the same set of states which draw high levels 
Table 3.6: Revenues vs. Global Suppliers

\begin{tabular}{|c|c|c|}
\hline $\begin{array}{l}\text { Oil Revenues } \\
(10 \% \text { of GDP })\end{array}$ & $\begin{array}{c}\text { Oil Exports } \\
\text { (Greater than 1\% } \\
\text { of Global Supply) }\end{array}$ & $\begin{array}{c}\text { Both } \\
\text { (\% represents } \\
\text { World Supply) }\end{array}$ \\
\hline Group 1 & Group 2 & Group 3 \\
\hline Angola & Argentina (1\%) & Algeria $(2 \%)$ \\
\hline Azerbaijan & Australia (1\%) & China $(1-4 \%)$ \\
\hline Bahrain & Brazil (1\%) & Egypt $(1 \%)$ \\
\hline Brunei & Canada $(3 \%)$ & Indonesia $(1-2 \%)$ \\
\hline Cameroon & Colombia (1\%) & $\operatorname{Iran}(5-6 \%)$ \\
\hline Congo & India $(1 \%)$ & $\operatorname{Iraq}(3-4 \%)$ \\
\hline Ecuador & United Kingdom (1-4\%) & Kuwait $(4-7 \%)$ \\
\hline Equatorial Guinea & USA $(9-28 \%)$ & Libya $(2-4 \%)$ \\
\hline Gabon & & Malaysia $(1-1.5 \%)$ \\
\hline Kazakhstan & & Mexico $(1-5 \%)$ \\
\hline Papua New Guinea & & Nigeria $(1-3 \%)$ \\
\hline Peru & & Norway (1-5\%) \\
\hline Qatar & & Oman $(1 \%)$ \\
\hline Sudan & & Russia $(9-18 \%)$ \\
\hline Suriname & & Saudi Arabia (7-12\%) \\
\hline Syria & & United Arab Emirates (2-3\%) \\
\hline Trinidad \& Tobago & & Venezuela (4-11\%) \\
\hline Tunisia & & \\
\hline Turkmenistan & & \\
\hline Yemen & & \\
\hline
\end{tabular}




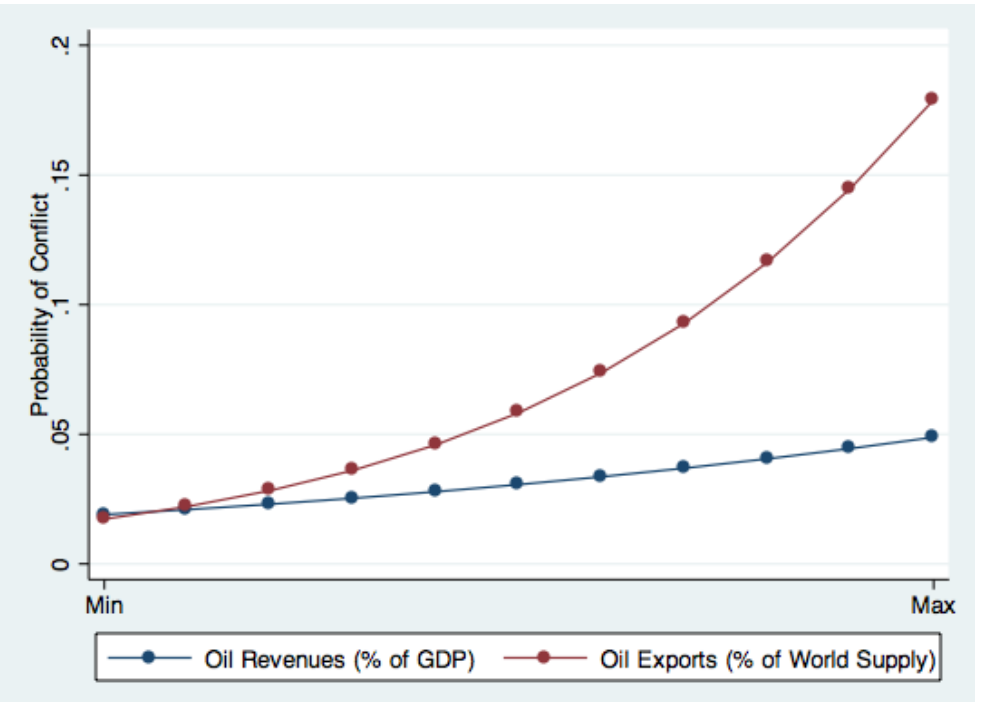

Figure 3.6: Predicted Probabilities of Conflict Initiation: Two Measures of Oil Wealth

of revenue from oil exporting. Table 3.6 illustrates the three different groups: states which draw more than $10 \%$ revenue from oil exports (i.e., 'petrostates'), states which supply more than $1 \%$ of global oil production, and those states which belong to both categories. As we can see, there is a substantial difference, with limited overlap between the two categories. Those states which supply large quantities of oil, but for whom revenues do not constitute a substantial portion of GDP are typically large developed economies (UK, Canada, etc). In contrast, those which receive only high revenues tend to be small, poorly developed states. This indicates that our analysis of Oil Exports (as proportion of world supply) should perhaps be treated as less of a robustness test (although it certainly supports the central finding), and more as an independent finding. While it in no way undermines this dissertation's theory about the domestic effect of oil production on aggression, it suggests that oil production may in fact impact relations between states in multiple ways. In order to test this, Model 1.2 was rerun excluding those states in Group 2. The results were unchanged in sign, significance and magnitude of the coefficients, indicating that there is some relationship between oil and conflict aside from mere power considerations. Next, Model 1.6 was rerun, excluding those states in Group 1. Again, the results were unchanged from the previous results. These findings indicate that there may indeed be two distinct ways in which oil alters 
foreign policy outcomes.

\subsection{Empirical Results: Oil, Threats and Sanctions}

The relationship between oil and conflict therefore seems strong and robust to the inclusion of a variety of different factors. Oil-rich states, even when defined in differing ways, do initiate more conflicts than other similar states, and can therefore be described as more physically aggressive. In this section, therefore, we move on to examine Hypothesis One from a different angle, asking whether oil-rich states are also more aggressive in other ways. Are these states more prone to issue threats? Do they issue more economic sanctions? These types of actions by states fall in a grey area: they certainly do not constitute violence or conflict, but they are nonetheless often interpreted as aggressive or belligerent.

\subsubsection{Logistic Regression Analysis}

Table 3.7 presents the results of the analysis of Threat Initiation. As with conflict, we first test Oil Revenues (as a \% of GDP) as our key independent variable. Model 2.1 presents a base model for comparison to previous studies, and offers results generally in line with previous studies. As noted earlier in the chapter, the control variables used for the analysis of Threat are slightly different than those for Conflict, as previous work has indicated that different factors seem to be responsible for threat and sanction initiation. The primary differences are: 1) regional dummies are dropped, as these are typically not included in analyses of sanctions, 2) a control variable indicating if there was a conflict in the year was added, 3) the variable for Distance was dropped, as this is less important for threat than it is for conflict, and 4) a democracy variable was added for State B (the receiving state) - while autocracies are no more likely to be attacked than other states, they are certainly more likely to be sanctioned. All other variables remain the same.

Model 2.2 presents the full logit model with Oil Revenues included as a variable. Oil Revenues is signed as expected, and is highly significant. The higher the level of oil revenues (as a \% of GDP) that a state receives, the more it is likely to issue threats or sanctions, a finding which supports the 
Table 3.7: Threat/Sanction Initiation by Annual Oil Revenues

\begin{tabular}{|c|c|c|c|c|c|}
\hline $\begin{array}{l}\text { Dependent Variable: } \\
\text { Threat/Sanction Initiation }\end{array}$ & $\begin{array}{c}\text { Model 2.1 } \\
\text { Base Logit }\end{array}$ & $\begin{array}{l}\text { Model } \mathbf{2 . 2} \\
\text { Oil Logit }\end{array}$ & $\begin{array}{l}\text { Model } 2.3 \\
\text { C-Log-Log }\end{array}$ & $\begin{array}{c}\text { Model } 2.4 \\
\text { Rare Events } \\
\text { Logit }\end{array}$ & $\begin{array}{c}\text { Model 2.5 } \\
\text { Fixed Effects } \\
\text { Logit }\end{array}$ \\
\hline $\begin{array}{l}\text { Annual Oil Revenues } \\
\text { (as \% of GDP) }\end{array}$ & & $\begin{array}{c}0.033^{* * *} \\
(0.00)\end{array}$ & $\begin{array}{c}0.032^{* * *} \\
(0.00)\end{array}$ & $\begin{array}{c}0.033^{* * *} \\
(0.00)\end{array}$ & $\begin{array}{c}0.032^{* * *} \\
(0.00)\end{array}$ \\
\hline Democracy (State A) & $\begin{array}{c}0.551^{* * *} \\
(0.06)\end{array}$ & $\begin{array}{c}0.776^{* * *} \\
(0.07)\end{array}$ & $\begin{array}{c}0.780^{* * *} \\
(0.07)\end{array}$ & $\begin{array}{c}0.774^{* * *} \\
(0.07)\end{array}$ & $\begin{array}{c}0.561^{* * *} \\
(0.07)\end{array}$ \\
\hline Democracy (State B) & $\begin{array}{c}0.391^{* * *} \\
(0.06)\end{array}$ & $\begin{array}{c}0.336^{* * *} \\
(0.06)\end{array}$ & $\begin{array}{c}0.331^{* * *} \\
(0.06)\end{array}$ & $\begin{array}{c}0.336^{* * *} \\
(0.06)\end{array}$ & $\begin{array}{c}0.183^{* *} \\
(0.07)\end{array}$ \\
\hline Major Power (State A) & $\begin{array}{c}3.084^{* * *} \\
(0.12)\end{array}$ & $\begin{array}{c}3.130^{* * *} \\
(0.13)\end{array}$ & $\begin{array}{c}3.133^{* * *} \\
(0.13)\end{array}$ & $\begin{array}{c}3.127^{* * *} \\
(0.13)\end{array}$ & $\begin{array}{c}2.921^{* * *} \\
(0.14)\end{array}$ \\
\hline Major Power (State B) & $\begin{array}{c}1.508^{* * *} \\
(0.16)\end{array}$ & $\begin{array}{c}1.456^{* * *} \\
(0.17)\end{array}$ & $\begin{array}{c}1.445^{* * *} \\
(0.16)\end{array}$ & $\begin{array}{c}1.461^{* * *} \\
(0.17)\end{array}$ & $\begin{array}{c}1.525^{* * *} \\
(0.18)\end{array}$ \\
\hline Conflict in Year & $\begin{array}{c}1.964^{* * *} \\
(0.25)\end{array}$ & $\begin{array}{c}1.760^{* * *} \\
(0.26)\end{array}$ & $\begin{array}{c}1.575^{* * *} \\
(0.24)\end{array}$ & $\begin{array}{c}1.768^{* * *} \\
(0.26)\end{array}$ & $\begin{array}{c}1.133^{* * *} \\
(0.14)\end{array}$ \\
\hline Cold War & $\begin{array}{l}0.080 \\
(0.10)\end{array}$ & $\begin{array}{c}0.251^{*} \\
(0.11)\end{array}$ & $\begin{array}{c}0.258^{*} \\
(0.11)\end{array}$ & $\begin{array}{c}0.251^{*} \\
(0.11)\end{array}$ & $\begin{array}{l}-0.171 \\
(0.14)\end{array}$ \\
\hline Capabilities Ratio & $\begin{array}{c}-0.001^{*} \\
(0.00)\end{array}$ & $\begin{array}{c}-0.001^{*} \\
(0.00)\end{array}$ & $\begin{array}{c}-0.001^{*} \\
(0.00)\end{array}$ & $\begin{array}{c}-0.001^{*} \\
(0.00)\end{array}$ & $\begin{array}{r}-0.001 \\
(0.00)\end{array}$ \\
\hline Lagged Trade (A-to-B) & $\begin{array}{c}0.000^{* * *} \\
(0.00)\end{array}$ & $\begin{array}{c}0.000^{* * *} \\
(0.00)\end{array}$ & $\begin{array}{c}0.000^{* * *} \\
(0.00)\end{array}$ & $\begin{array}{c}0.000^{* * *} \\
(0.00)\end{array}$ & $\begin{array}{c}0.000^{*} \\
(0.00)\end{array}$ \\
\hline Lagged Trade (B-to-A) & $\begin{array}{l}-0.000 \\
(0.00)\end{array}$ & $\begin{array}{l}-0.000 \\
(0.00)\end{array}$ & $\begin{array}{l}0.000 \\
(0.00)\end{array}$ & $\begin{array}{l}-0.000 \\
(0.00)\end{array}$ & $\begin{array}{l}-0.000 \\
(0.00)\end{array}$ \\
\hline Constant & $\begin{array}{c}-9.752^{* * *} \\
(0.39) \\
\end{array}$ & $\begin{array}{c}-10.459^{* * *} \\
(0.43) \\
\end{array}$ & $\begin{array}{c}-10.449^{* * *} \\
(0.40) \\
\end{array}$ & $\begin{array}{c}-10.411^{* * *} \\
(0.43) \\
\end{array}$ & \\
\hline $\mathrm{N}$ & 726820 & 545613 & 545613 & 545613 & 162733 \\
\hline Log-Likelihood & -4465.37 & -4126.92 & -4146.73 & & -2991.28 \\
\hline $\mathrm{AIC}$ & 8958.734 & 8283.841 & 8323.454 & & 6010.556 \\
\hline
\end{tabular}


main hypotheses of the study. Most other variables are also signed as expected, and did not change sign or significance from Model 2.1. Democracies tend to both issue and receive more threats and sanctions; this correlation is highly significant, and matches the results of prior studies. Similarly, major powers issue and receive more threats. More threats and sanctions are also likely if there is a conflict in the year. More sanctions were issued during the Cold War, although this is insignificant in Models 2.1 and 2.5. The coefficient on Capabilities Ratio illustrates that states are less likely to threaten/sanction a state which is more powerful than themselves, although this is insignificant in Model 2.5. All other variables are statistically signed as indicated in the table. Trade from A-to-B is significant and positively signed, indicating that increased flows of trade increase the likelihood of threats or sanctions; this is likely because of trade disagreements between states. However, the coefficient is extremely small. Trade flows from B-to-A, in contrast, seem to have little effect; the coefficient varies in sign, and is highly insignificant. ${ }^{26}$

As with analysis of conflict, threats and sanctions are considered 'rare events,' which may lead standard binary choice models to be misleading. Therefore, several models better suited to the analysis of rare outcomes were tested. Model 2.3 shows the results of a complementary log-log model; there are no changes in sign or significance of any variables and coefficients remained similar. Model 2.4 presents the results of a Rare Events Logit, better suited to the analysis of extremely rare events like conflict or sanctions. These results are also effectively identical to those in Model 2.2 , the standard logit model. The results of these two models serve to illustrate that despite the unbalanced nature of the dependent variable, the standard logit model does a good job of assessing the data.

Model 2.5 uses a fixed effects logit to check for dyad-specific omitted variable bias. The coefficient for Oil Revenues remains unchanged in terms of sign, significance and magnitude, as do coefficients for democracy (both states), major power status (both states), conflict in year, and trade (both states). Cold War and Capabilities Ratio both become insignificant. Given strong similarities between models, we can compare measures of Goodness-of-Fit to allow us to assess

\footnotetext{
${ }^{26} \mathrm{As}$ with conflict, this is likely due to minor collinearity between trade flows between the two states; it is unusual for trade to flow only one-way in a dyad.
} 


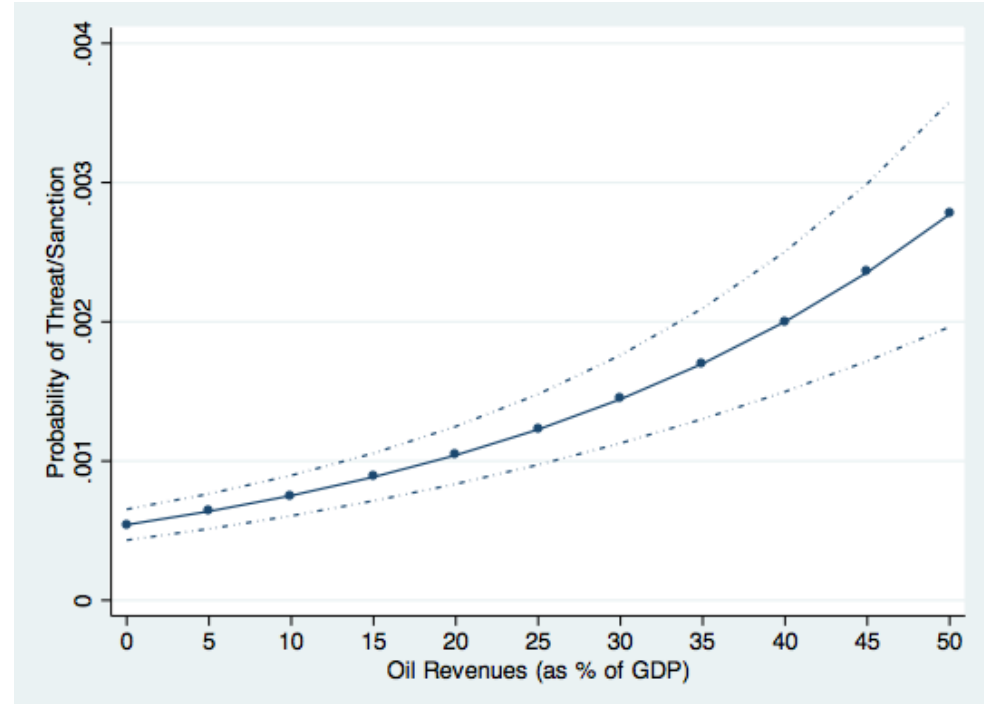

Figure 3.7: Predicted Probabilities of Threat/Sanction

which model best fits the data. The AIC for both Model 2.2 and 2.5 is 0.015 , indicating that they are roughly equivalent in terms of information. $R^{2}$ for Model 2.2 is 0.232 , while the $R^{2}$ for Model 2.5 is 0.187 , indicating that Model 2.2 is a better fit for the data. Further analysis and robustness tests will therefore be based on Model 2.2.

Figure 3.7 presents predicted probabilities for Model 2.2, allowing us to see the magnitude of the effect of Oil Revenues on Threat, holding all other variables at their mean or median value. The graph shows a steady upward relationship, with reasonably small confidence intervals. The model predicts that a state with no revenue from oil exports has a likelihood of $0.05 \%$ of initiating a threat or sanction within a given year. Those states with $10 \%$ of GDP in oil revenues have a $0.075 \%$ likelihood of initiating a threat, while those petrostates with $20 \%$ of GDP in oil revenues have a $0.1 \%$ likelihood of initiating a threat. Those states with relatively extreme levels of resource revenues (50\% of GDP) have a $0.25 \%$ likelihood of initiating a threat or sanction. An increase from $0 \%$ to $50 \%$ of GDP in revenues from oil therefore represents a $400 \%$ increase in likelihood of threat/sanction initiation. The effect of oil exporting on the initiation of threats and sanctions thus seems reasonably substantial, not merely statistically significant.

As with conflict, the effect of oil exporting on threat and sanction initiation is obviously de- 

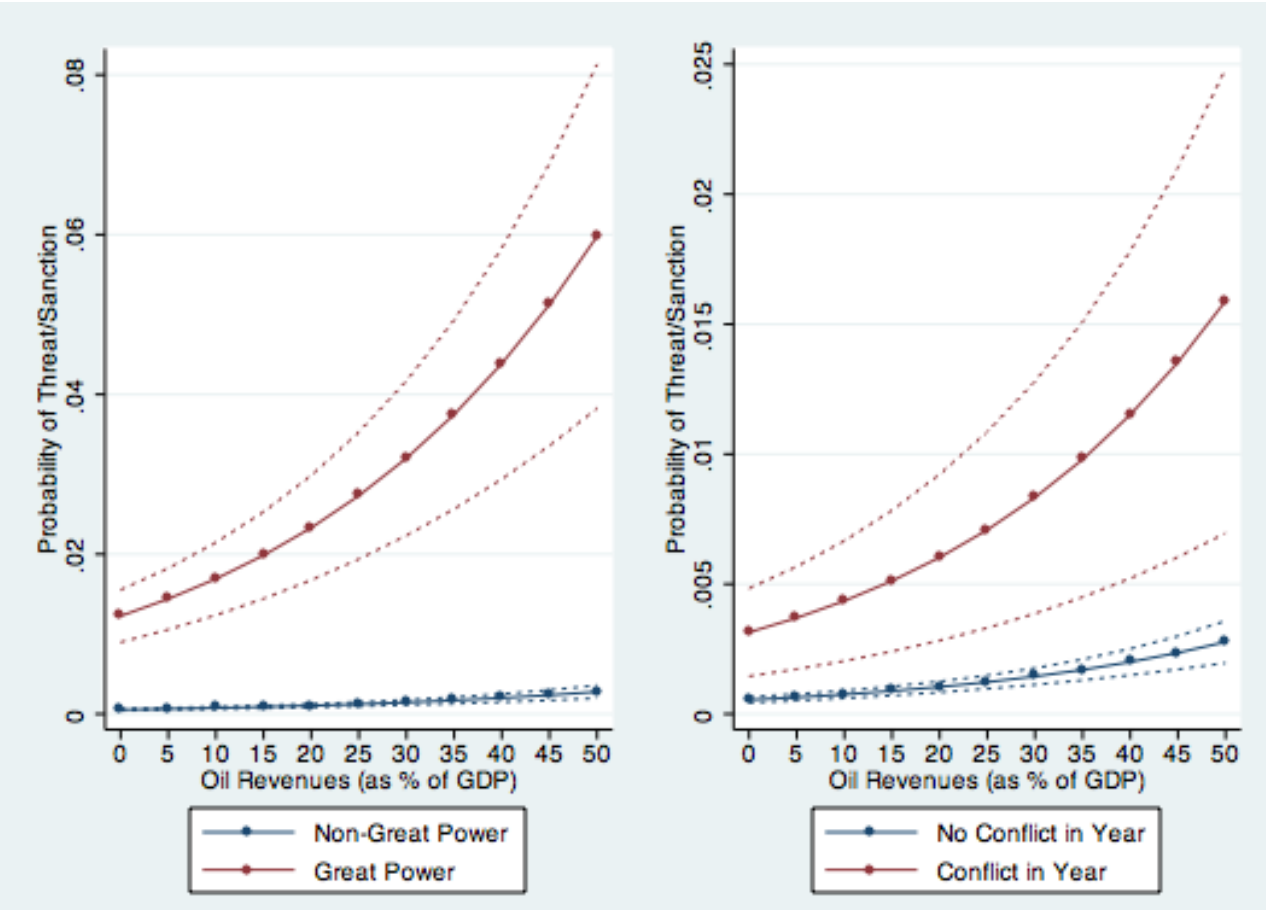

Figure 3.8: Predicted Probabilities of Threat/Sanction

pendent on other key factors. Figure 3.8 illustrates two of these relationships. On the left, we can see that great powers initiate more threats in general than other states. In addition, the slope for great powers is substantially steeper, indicating that oil revenues have a drastically increased effect on great powers. One should be wary, however, as the extremely large confidence intervals for great powers are indicative of the relative paucity of great powers which are also oil exporters in the sample set. On the right, we can see the relationship between oil revenues, threats/sanctions and the presence or absence of conflict in the year. Conflict in Year greatly increases the chance for a threat/sanction, and although confidence intervals are again wide, both lines (conflict and no conflict) indicate a clear upward trend. Thus, the relationship between oil revenues and threats/sanctions is clear, although (like conflict) its magnitude varies with other key factors. 


\subsubsection{Robustness Tests}

As with our analysis of conflict, the results of our analysis of threat were subjected to a number of robustness tests. Firstly, several basic tests were conducted. Mean Variance Inflation Factor for Model 2.2 is 2.07, and most variables had a VIF of less than 2. Both variables for trade flow had a

slightly higher VIF of around 6, indicating that they may be correlated (although this is still well below a VIF of 10, typically considered as the level where collinearity is a serious concern). Model 2.2 was rerun, first without either trade variable, second with State A's Trade alone, and third with State B's Trade alone. State A's trade remained significant and negatively signed when included alone, and State B's trade remained positively signed, but became significant when included alone. Thus, this minor collinearity is likely the reason for the insignificance of this variable in the original model. Despite this, however, no other variable saw any change in sign, significance or magnitude of the coefficient in any of the three modified models. Since this minor collinearity poses no problem to our central variables of interest, both trade variables have been left as part of the model. Low VIF scores for other variables indicate no other problems with multicollinearity.

Pregibon's Delta-Beta statistic was calculated to test for points of high leverage; this statistic allows us to identify specific observations which are particularly influential in our analysis. These observations may skew overall results. Only one observation has a D-Beta score of greater than 2, the typical point of concern. Another three observations have a D-Beta score of higher than 1, with five more greater than 0.5. Delta-Beta scores for all other observations are lower and well clustered. All nine of the potential points of high leverage are dyads containing the USA and another major power (Japan, China, Canada), and all but one are during the time period 1999-2001. In order to test for potential bias caused by these observations, Model 2.2 was rerun excluding all nine observations. Results did not change either substantively or substantially for any variable in the analysis.

Second, a series of robustness tests were conducted using different measures for oil. Model 2.2 was retested using two binary indicators of oil revenues (as a \% of GDP): (Petrostate(10\%) and Petrostate(20\%)). Oil remains highly significant and positively signed in both cases, and all other 
variables remain effectively unchanged. The model was then reassessed using our alternate measure of oil, Oil Exports (as a proportion of world supply). As discussed in Section 2.2, this metric avoids many of the problems inherent in using a GDP indicator of resource wealth. It also tests the relationship between oil and threats using a somewhat different group of 'oil rich' states - in this case, those that contribute a substantial amount of oil to world supply. Oil Exports (as a proportion of world supply) is positive and highly significant, again indicating a strong relationship between oil production and threats/sanctions. Other variables largely remain signed and significant as in Model 2.2, with the exception of Trade, which becomes insignificant for both State A and State B. Again, collinearity is a slight problem here for our trade variables, and both become significant when included in the regression separately. However, this does not alter sign, significance or size of coefficient on any other variable. The results for the analysis of threat therefore seem to be reasonably robust to different ways of measuring whether a state is 'resource-rich' .

Finally, the analysis was rerun, using only those dyads deemed to be 'politically relevant.' As before, this reduced set of states includes only major powers and contiguous states. This distinction is even more problematic than it is for conflict, as threats/sanctions may be initiated by countries many thousands of miles apart. Indeed, economic policy is for many states decidedly more global than military policy; for this reason, politically relevant dyads seem even less 'relevant.' Again, variables indicating major power status were dropped because of collinearity problems. Both Oil Revenues (as \% of GDP) and Oil Exports (as a proportion of world supply) were tested, both remained significant and positively signed. Oil Revenues became slightly less significant, while Oil Exports became more significant. This is likely because the set of observations which are "politically relevant' includes more large states and excludes many smaller oil exporters. Even when using this extremely restricted set of observations, however, the relationship between Oil Revenues and Threat Initiation remains robust. Since the data on threats and sanctions only goes back to the early 1970s, we cannot use Haber and Menaldo's (2011) oil data to assess this relationship over a longer time-period, and thus this robustness test is not included in our analysis of Threat. 


\subsubsection{Threat/Sanction Initiation and Oil}

The robustness tests support the original analysis, and indicate strongly that oil production is indeed is an important factor for states in making threats or sanctions against other states. Unlike conflict, however, threats/sanctions are not necessarily intrinsically aggressive, making this result less clear cut than that of the previous section. Countries may initiate a sanction or threat for a variety of reasons, including improving human rights, or preventing nuclear proliferation. ${ }^{27}$ Since our variable for threat/sanction may include such cases, a final test was done, recoding the variable Threat Initiation to include only those cases where the threat/sanction was obviously militaristic or economic in nature. Thus, threats issued against human rights violators, nuclear proliferators, and those related to environmental issues, or state support of non-state actors such as terrorists were dropped from the indicator. It should be noted (as seen in Figure 3.1) that human rights is the only one of these categories which is sizable; the majority of threats are trade or alignment based. The model was then rerun using this limited version of the threat variable; the results were unchanged, with oil still positive and highly significant. With the more altruistic forms of threat removed from the sample, we can see that a state with high levels of oil production still tend to issue more threats and sanctions than other comparable states. While this metric is necessarily more vague than conflict, it is still a strong indicator than those countries with increased levels of oil production are not merely more physically aggressive, but also more aggressive verbally and economically. This provides strong support for Hypothesis One.

\subsection{Oil vs. Natural Resources}

This section will focus on Hypothesis Two, seeking to assess the potential effects of all natural resources on foreign policy. Although many talk about 'natural resource wealth' as if all resources are equivalent, the truth is that many studies which focus on natural resources tend to focus on oil, rather than other resources. This is largely because oil is (by far) the most lucrative natural

\footnotetext{
${ }^{27}$ The Threat and Imposition of Sanctions database includes twelve types of sanction, of which four can be construed as uniformly positive and eight as either negative or sometimes negative.
} 
resource in the world, and one of the most sought after, as it has limited sources and is a necessary commodity for transportation and manufacturing. Thus, when arguing that resources revenues create political outcomes, oil is the logical resource to focus on. In the theory laid out in Chapter Two, I argue that the impact of resource production on state aggression is mediated by the level of revenue a state receives from that resource, suggesting strongly that oil may in fact have a larger impact than other resources. This section therefore seeks to assess whether this is the case, or whether oil and other natural resources are functionally interchangeable.

Table 3.7 presents the results of Model 3.1, which uses Natural Resource Revenues (as a \% of GDP) as the key independent variable. This measure, created by the World Bank, includes a wide variety of natural resources in the statistic, include gas, oil, minerals, metals and even timber exports. ${ }^{28}$ The coefficient for natural resource revenues, although positive, is highly insignificant. Most other variables are signed as expected and significant. The results remain the same when complementary log-log and rare events logit models are used instead of the standard logit. This implies no real link between natural resources (in general) and conflict initiation. The table also includes Model 3.2, which uses a fixed effects logit, with no major difference in results. Thus our results for natural resources differ from the strong relationship which seems to exist between oil and aggressiveness. Our theory expects that this is because oil provides greater revenues than other natural resources. Model 3.1 was therefore reassessed, adding an additional variable, Petrostate(10\%). This variable records whether or not a state received $10 \%$ of its revenue from oil exports. When controlling for this factor, oil was highly significant and positively signed (as in previous results), but natural resource revenues became negatively signed and significant. This supports the idea that oil wealth may produce different results than natural resource wealth.

Table 3.8 presents the results of Models 3.3 and 3.4, using the same natural resource indicator to analyze threat initiation. In both models, threat is both positively signed and significant, a result which is the same as that presented earlier for oil. This result is also borne out by using different link functions (complementary log-log and rare events) to analyze these variables. The

\footnotetext{
${ }^{28}$ World Development Indicators, The World Bank (2012).
} 
Table 3.8: Natural Resources and Conflict Initiation

\begin{tabular}{lcc}
\hline \hline $\begin{array}{l}\text { Dependent Variable: } \\
\text { Conflict Initiation }\end{array}$ & Model 3.1 & Model 3.2 \\
& Logit & Fixed Effects \\
Logit
\end{tabular}


Table 3.9: Natural Resources and Threat/Sanction Initiation

\begin{tabular}{|c|c|c|}
\hline $\begin{array}{l}\text { Dependent Variable: } \\
\text { Threat/Sanction Initiation }\end{array}$ & $\begin{array}{l}\text { Model 3.3 } \\
\text { Logit }\end{array}$ & $\begin{array}{c}\text { Model 3.4 } \\
\text { Fixed Effects } \\
\text { Logit }\end{array}$ \\
\hline $\begin{array}{l}\text { Natural Resource Revenues } \\
\text { (as \% of GDP) }\end{array}$ & $\begin{array}{c}0.017^{* * *} \\
(0.00)\end{array}$ & $\begin{array}{c}0.018^{* * *} \\
(0.00)\end{array}$ \\
\hline Democracy (State A) & $\begin{array}{c}0.648^{* * *} \\
(0.06)\end{array}$ & $\begin{array}{c}0.448^{* * *} \\
(0.07)\end{array}$ \\
\hline Democracy (State B) & $\begin{array}{c}0.335 * * * \\
(0.06)\end{array}$ & $\begin{array}{c}0.214^{* *} \\
(0.07)\end{array}$ \\
\hline Major Power (State A) & $\begin{array}{c}3.127^{* * * *} \\
(0.12)\end{array}$ & $\begin{array}{c}2.932^{* * * *} \\
(0.14)\end{array}$ \\
\hline Major Power (State B) & $\begin{array}{c}1.531^{* * *} \\
(0.16)\end{array}$ & $\begin{array}{c}1.609^{* * *} \\
(0.17)\end{array}$ \\
\hline Conflict in Year & $\begin{array}{c}1.794^{* * *} \\
(0.26)\end{array}$ & $\begin{array}{c}1.185^{* * *} \\
(0.28)\end{array}$ \\
\hline Cold War & $\begin{array}{c}0.406^{* * *} \\
(0.11)\end{array}$ & $\begin{array}{r}-0.008 \\
(0.14)\end{array}$ \\
\hline Capabilities Ratio & $\begin{array}{r}-0.001 \\
(0.00)\end{array}$ & $\begin{array}{l}-0.001 \\
(0.00)\end{array}$ \\
\hline Lagged Trade (A-to-B) & $\begin{array}{c}0.000^{* * *} \\
(0.00)\end{array}$ & $\begin{array}{l}0.000^{*} \\
(0.00)\end{array}$ \\
\hline Lagged Trade (B-to-A) & $\begin{array}{l}-0.000 \\
(0.00)\end{array}$ & $\begin{array}{r}-0.000 \\
(0.00)\end{array}$ \\
\hline Constant & $\begin{array}{c}-10.163^{* * *} \\
(0.42)\end{array}$ & \\
\hline $\mathrm{N}$ & 562044 & 170192 \\
\hline Log-Likelihood & -4251.07 & -3088.15 \\
\hline $\mathrm{AIC}^{*} \mathrm{n}$ & 8532.137 & 6204.302 \\
\hline $\begin{array}{l}\text { Notes: Standard errors ar } \\
\text { Peace years and a } 3 \text {-knot } \\
\qquad *=p<\end{array}$ & $\begin{array}{l}\text { ustered by } d y \\
\text { ne are inclu } \\
* *=p<0.0\end{array}$ & $\begin{array}{l}\text { entheses), and } \\
\text { regression but r } \\
0.001\end{array}$ \\
\hline
\end{tabular}


coefficients are smaller, but predicted probabilities show that the effect of natural resource revenues appears to be roughly equivalent to that of oil revenues. Natural resources therefore do seem to be correlated with threats, but not with conflict. Natural Resource Revenues also remain significant and positively signed in Model 3.2 with the addition of the Petrostate(10\%) control variable; threats increase with both oil revenues and natural resource revenues.

In conclusion, the relationship between natural resources and conflict seems substantially more tenuous than that of oil and conflict, while oil seems to be broadly comparable to other natural resources in terms of threat initiation. These mixed results suggest that further research is needed, perhaps using more clearly defined variables (the World Bank metric is exceedingly broad in its definition of natural resources). Therefore, while we can conclude from this analysis that a reasonably robust relationship exists between oil and aggression, we cannot make the same assertion about general natural resources. This provides support for Hypothesis Two, indicating that the level of income generated by a resource may be important to the development of aggressive foreign policy.

\subsection{Conclusion}

This chapter sought to examine whether resource-rich states are truly more aggressive, in particular by analyzing whether these states issue more conflicts, threats and sanctions. The results provide clear support for Hypothesis One: increased oil revenues are strongly linked to increased levels of conflict initiation, especially in cases (such as border disputes) where conflict was already somewhat likely. This relationship is robust to the use of different measures of oil wealth and other tests. Holding other factors constant, those states with oil revenues of $20 \%$ of GDP have a $14 \%$ greater likelihood of initiating a conflict than those with no oil revenues. While we are primarily interested in the domestic effects of oil production in this analysis, it is interesting to note that this effect is even more pronounced when considering oil exports as a proportion of world supply: a large global oil supplier (5\% of global oil supply) has a $59 \%$ greater likelihood of initiating a conflict than a non-petrostate. 
Increased oil revenues are also strongly linked to the initiation of threats and sanctions. Although threats and sanctions are less obviously aggressive than conflict (e.g., there are positive types of sanction), this relationship is robust even when only negative sanctions are tested. Those states with oil revenues of $20 \%$ of GDP have a $100 \%$ greater likelihood of initiating a threat or sanction than a non-oil producing state. This relationship is also robust to the use of different measures of oil wealth and other tests and becomes more pronounced when considering levels of oil export instead. In short, oil-rich states are shown to be more aggressive: physically, verbally and economically.

While we cannot draw causal inferences from this analysis, several factors are of interest. Firstly, the relationship between oil and conflict is not affected by the inclusion of democracy indicators, or the interaction of autocracy and oil. Scholars have argued both that oil wealth leads to autocracy, and that autocracies tend to be more aggressive. However, the relationship between oil and conflict is robust even when democracy indicators are included, indicating that oil production is indeed an independent factor with the potential to alter foreign policy outcomes. Secondly, it should be noted that this evidence is primarily based on oil-exporting states, rather than on all natural resources, for which results are more mixed. There is no clear relationship between all resource revenues and Conflict, although the relationship between all resource revenues and Threat appears to be similar to our analysis of oil. In addition, there is cause to be concerned about the nature of the independent variable, as the World Bank measure of natural resources is extremely broad. For this reason, we should be cautious about drawing conclusions about the relationship between natural resources and foreign policy. This analysis will continue to focus on the foreign policy of oil-rich states.

Finally, those states which are large global suppliers are not the same as those states which receive high levels of revenue from oil. When assessed separately, both groups exhibit the same relationship: increased oil wealth is strongly correlated with increased conflicts and threats. This provides some evidence that there may indeed be both a 'power-based' explanation (i.e., that states with greater levels of oil export possess more power and leverage as a result), and a domestic 
explanation (i.e., that the domestic political economy of oil exporting influences foreign policy choices). Thus while previous studies have focused on the former explanation, this study seeks to shed light on the ways in which oil is linked with aggression through its effects on a state's domestic economic and political institutions.

In conclusion, this chapter has found broad support for both Hypothesis One and Hypothesis Two, finding that the evidence for a link between oil and aggressive foreign policy is strong. Chapters 4-6 will now focus on the why of this relationship, in effect, what it is about the organization of a state's political economy around oil production that leads states to be more aggressive in foreign policy. In doing so, we will seek to assess the dissertation's central theory: that resource rents reduce constraints on governments, reduce the strength of foreign policy institutions and increase the attractiveness and availability of military options, and in doing so, increase the likelihood of state aggression. 


\section{CHAPTER IV}

\section{Russia}

Russia is today one of the world's best known petrostates, with natural resource production often cited as both a possible cause of its aggression, as well as a potential 'weapon.' ${ }^{1}$ Russia has shown itself willing to use energy issues to gain the upper hand in diplomacy, yet there has been little study of the links between resource production and Russian foreign policy. ${ }^{2}$ This case study does not seek to show a direct causal link between oil and aggression, but rather how oil shapes the intermediate outcomes, such as weak institutionalization, which undermine effective foreign policy and act as a 'probability raiser' for conflict initiation. This chapter is organized into three parts.

In Section 4.1, we describe the relationship between the Russian state and natural resources, then provide a broad overview of foreign policy since 1991. Section 4.2 assesses the causal links between oil revenues and the theory's mediating variables: weak institutionalization, reliance on military force, and government freedom from constraints. Following this analysis, Section 4.3

\footnotetext{
${ }^{1}$ Monaghan (2007).

${ }^{2}$ It is important to note that this case does not examine the foreign policy outcomes of the Soviet Union, but only those of Russia itself post-1991. This is for several key reasons. Firstly, data on oil exports and information on institutions and decision-making during the Soviet period is necessarily more limited, making research on these topics extremely difficult. Secondly, this dissertation's theory effectively assumes a broadly capitalist system; it is possible that oil production may produce different distortions in a communist system. In particular, the difficulties of assessing market pricing for oil provided Finally, and most important, it is not clear that the USSR was in fact a 'petrostate' during its early development. Early embargoes on Soviet oil, followed by the intensive use of oil production for internal industrialization, limited oil revenues to the regime prior to the 1940s. Thus, during its key period of institutionalization, the USSR was not a petrostate. For these reasons, this cases focuses instead on Russia post-1991, where the Soviet collapse created an institutional vacuum at the same time as oil production was high.
} 
focuses on how these mediating variables undermine effective foreign policymaking, in particular, how they contribute to aggression, by analyzing several specific cases of foreign policy formation and implementation - Kosovo, the Second Chechen War, and the War in Georgia. Analysis indicates that Russian foreign policy institutions in part have been weakened by oil production, and that this has both undermined the foreign policy process and contributed to the initiation of conflict.

\subsection{Russian Oil, Gas and Foreign Policy}

\subsubsection{A Brief History of the Russian Petrostate}

The relationship of the Russian state with oil and natural gas extends as far back as the early 19th century, with some of the world's earliest experiments in refining taking place in refineries near Baku in 1837. The industry has been a major component of the Russian economy during the Tsarist, Soviet and post-Soviet periods, with all three governments heavily reliant on natural resource revenues for support. As early as 1910, Russia produced 10.77 million tones oil per year, providing a major source of revenue to the tsarist regime. ${ }^{3}$ By 1927, the industry was effectively recovered from the Revolution, and by 1932, the Soviet oil industry was producing around 23 million tones of oil per year, double the level of pre-war production. So quick was the development of the industry that by 1930, Stalin was able to report to the 16th Congress of the CPSU that:

"...under the Five-Year Plan, the oil industry was to produce 977 million rubles worth of products by 1932-33. But, in 1929-30, it is already producing 809 million rubles in products, that is, $83 \%$ of the amount projected in the Five-Year Plan for 1932-33. That means we are fulfilling the Five-Year Plan for the oil industry in some two-and-a-half years." 4

During this period, the majority of oil and natural gas was exported (as little domestic demand existed), and resource revenues were used to boost communist industrial development in other sectors.

\footnotetext{
${ }^{3}$ Alekperov (2011).

${ }^{4}$ Stalin (1954), cited in Alekperov (2011): 128.
} 
Oil and gas revenues were a major driver of Soviet industrial capacity both during and after World War II. Production reached an all time high of 550 million tones of oil per year by $1985 .{ }^{5}$ Much of this extra capacity was absorbed by the Soviet Union's fraternal communist states, many of whom received subsidized imports of oil and natural gas. These supplies were critical to the economic health of the communist bloc as a whole. ${ }^{6}$ As the Soviet economy stagnated in the late 1970s and 1980s, exports remained a key source of hard currency for the regime; one estimate shows that $39 \%$ of the USSR's revenues came from oil and gas exports in $1985 .^{7}$ However, this period also saw a precipitous fall in oil and gas production, caused by a lack of planning and investment in the increasingly rigid Soviet economy. The result was a shortfall in supply precisely as the regime most needed resource revenues. Many argue that the oil shocks of the late 1980s were pivotal in leading to the collapse of the Soviet Union. When Saudi Arabia radically restructured its oil production in 1985, causing world oil prices to collapse, this meant the loss of up to $\$ 20$ billion per year in oil revenue for the USSR, a budget gap which the Soviet leadership could only fill with debt. ${ }^{8}$ Combined with the fall of global oil prices during this period, the result was catastrophic.

The 1990s saw a radical reorganization of the natural resource extraction industry in newly capitalist Russia. Foreign investment poured into the country, and companies were sold at a knockdown price to businessmen known as the 'Oligarchs.' By 1998, the resource industry was the major driver of Russian economic growth, acting as the catalyst for the Russian economic crash - a direct result of the East Asian Crisis - and as the major factor which allowed the Russian economy to recover. Even in the post-Soviet era, subsidies still place a strain on energy companies. Gazprom's own figures show that in 2007, the average price for a Russian citizen per $1000 \mathrm{~m}^{3}$ was 1301 Rubles, while the average price in the European Union was 5181 Rubles, almost four times the amount. There are also continued subsidies to the CIS: the average purchaser of gas in a CIS country still pays only half the price of a West European consumer. ${ }^{9}$ Finally, Gazprom in particular

\footnotetext{
${ }^{5}$ BP Statistical Index (2010), available from www.bp.com/statisticalreview.

${ }^{6}$ Vatansever (2010).

${ }^{7}$ Vatansever (2010).

${ }^{8}$ Gaidar (2007).

${ }^{9}$ Gazprom Annual Financial Report (2009), available from http://www.gazprom.com/investors/reports/2009/.
} 
is often forced by the government to subsidize towns in inhospitable places, a legacy of the Soviet era, by providing them with extremely cheap heat during cold Siberian winters. ${ }^{10}$

Meanwhile, the Russian state has never been richer. In one study, Gaddy and Ickes estimated that in 2005 alone, resource rents amounted to almost $25 \%$ of GDP. ${ }^{11}$ The government is highly dependent on natural resources, and taxes resources at a high level.Prior to the financial crisis, taxation of these two industries was thought to make up between 20 and $25 \%$ of the total budget of the Russian Federation, ${ }^{12}$ with oil taxed through export duties and gas through excise duties. Russia takes a much higher cut of profits in taxes than most other petrostates, in effect taxing energy production twice: once at the point of extraction and again at the point of export. The marginal tax rate on exports can be as high as $65 \% .{ }^{13}$ This money has been widely used to develop Russia, but money has also been stored in a stabilization fund. This money was instrumental in allowing Russia to weather the 2008 financial crisis. Since the financial crisis, Russian oil revenues have risen even faster as a proportion of state revenue. In one off-the-cuff remark at the 2012 Valdai Discussion Club meeting in St. Petersburg, Vladimir Putin noted:

"...of course, 50 percent of our budget revenue comes from oil and gas sales." 14

Similarly, the U.S. Energy Information Administration estimated in 2013 that oil and gas exports accounted for $52 \%$ of government revenues, and more than $70 \%$ of Russian exports. ${ }^{15}$ These figures reveal the extreme dependence of the Russian state on resource revenues.

\subsubsection{Russian Foreign Policy Since the Soviet Collapse}

Russian foreign policy between 1991 and 2012 can roughly be grouped into two eras: the immediate post-Soviet Yeltsin era (1991-1999), and the period following Vladimir Putin's appointment as Prime Minister in 1999. The Yeltsin period can best be viewed as a transition from the Soviet

\footnotetext{
${ }^{10}$ Ahrend and Tompson (2005).

${ }^{11}$ Gaddy and Ickes (2005); see also Kuboniwa, Tabata and Ustinova (2005).

${ }^{12}$ Tabata (2002).

${ }^{13}$ Alexeev and Conrad (2009).

${ }^{14}$ Putin, speech at the Valdai Discussion Club (2012). Available from: http://eng.kremlin.ru/news/4564.

${ }^{15}$ U.S. EIA Country Report Russia (2013).
} 
era, in which major initiatives to build new relations with countries around the world had widely varying results. As Kotkin notes, "analysts who generalized about Russia's foreign policy from the peculiar circumstances of the 1990s now look silly." 16 The period began in a cooperative fashion, as Yeltsin's government sought strong ties with the West. By 1995, however, this early promise was dashed, and the government turned towards anti-Western policies. After 1999, although the issues involved remained similar, foreign policy instead rejected the weakness of the Yeltsin era, with efforts made by Russian policymakers to reassert some level of Great Power status, and reestablish Russia's role as a major player in global affairs. The two periods share strong similarities in both foreign policy problems and goals. In both periods, Russia tended to pursue an 'inchoate foreign policy,' defined more by immediate issues than by long-term planning. ${ }^{17}$

Foreign policy was muddled in the immediate post-Soviet period, as states sought to find new solutions for foreign policy outside the Soviet umbrella. This had two main ramifications: Firstly, border disputes had been unimportant when all states were part of the USSR. Now, nebulous postSoviet borders resulted in many conflicts, which were often dealt with inconsistently: Chechnya, for example, has typically been treated as a domestic insurgency, while Crimea has been treated as a border dispute, although both were originally part of the Russian Empire. Secondly, it had been assumed that other republics would continue to take foreign policy direction from Moscow; instead, other states actively sought engagement with the West, or with China, leading to a sense of betrayal among Russian leaders, who saw Western states interfering in their 'sphere of influence.'

Border disputes with other post-Soviet states were rife during the Yeltsin period, as the tendency of the Kremlin to support ethnic Russian secessionists often inflamed tensions. The Yeltsin government provided weapons and support to pro-Russian secessionists in conflicts such as the War in Abkhazia (1992-3), the Moldovan Civil War (1991-2) and the Tajik Civil War (1992). Although formally neutral, Russian peacekeepers in these conflicts in reality often provided military support, such as the 1993 Russian bombing of Sukhimi, Georgia. Although the Kremlin denied involvement, UN reports explicitly noted the involvement of Russian forces. As one writer put it, "the notion

\footnotetext{
${ }^{16}$ Kotkin (2004): 1.

${ }^{17}$ Legvold (2007).
} 
of Abkhazian tanks and Abkhazian air force is as absurd as the idea of a Mongolian navy." ${ }^{18}$ The 1990s also saw tensions over the Kuril Islands, a tiny area in the Russian Far East. Boris Yeltsin took a hard line towards Japan, with "any thought of territorial accommodation... abandoned amidst strident nationalist posturing." 19 In contrast, long-running border disputes with China were resolved much more peaceably, culminating in the 1998 Sino-Russian Border Demarcation Pact.

The First Chechen War (1994-6) was Russia's major conflict during the 1990s, a short and bloody war marred by ethnic cleansing and war crimes. The region had been de facto independent, but war crimes escalated, and by late 1994, the Yeltsin government felt compelled to intervene. They launched a massive military offensive, including a huge aerial bombardment of Grozny similar in scope to the Dresden bombings of WWII. ${ }^{20}$ Approximately 5,500 Russian troops perished in the fighting, while the civilian death toll was likely between 50,000 and 100,000. ${ }^{21}$ The mounting death toll and morale problems caused by continual failures to achieve military objectives created a groundswell of opposition to the war in Russia, ${ }^{22}$ and it finally ended in the Khasav-Yurt Accord in 1996.

Conflicts often served to distract from Russia's main foreign policy concern: influence over the states of the 'near abroad.' In 1991, as the USSR collapsed, Russian elites sought to create a new, similar structure in the form of the CIS, and Russia's 1993 Foreign Policy Concept called for a "unified military strategic space" within the CIS. ${ }^{23}$ However, the assumption that Moscow would continue to control the region's foreign policy was broadly challenged, in particular by Ukraine. ${ }^{24}$ Many post-Soviet states argued that Russian diplomats were condescending in their

\footnotetext{
${ }^{18}$ Kubicek (2000): 563 .

${ }^{19}$ Marantz (1997): 347.

${ }^{20}$ Sakwa (2005).

${ }^{21}$ The figure of 5500 Russian deaths is an official statistic, with other sources (such as the Committee of Soldiers Mothers) claiming a much higher death toll, perhaps as high as 14000 deaths. In addition, there are no clear casualty numbers for Chechen fighters, many of whom are included in the civilian death toll.

${ }^{22}$ Medvedev (2004).

${ }^{23}$ Foreign Policy Concept of the Russian Federation (1993), available from http://www.mid.ru/nsosndoc.nsf/osnddeng.

${ }^{24}$ During the 1990s, Russia also failed to promote membership of a number of related organizations such as the CIS Free Trade Area (CISFTA), the Eurasian Economic Community (EurAsEc), and the Collective
} 
dealings; Ukrainian President Leonid Kuchma even commented that "in Russia they pretend that Ukraine as a sovereign, independent state does not exist." ${ }^{25}$ By the mid-2000s, the CIS was treated by many states as little more than "an instrument for a civilized divorce" from the Soviet Union. ${ }^{26}$ Instead, western-leaning states like Georgia and Ukraine chose to form GU(U)AM, which seeks cooperation with NATO. ${ }^{27}$

Russia's relationship with the West has also been fraught. In the immediate aftermath of the Soviet collapse, foreign aid flowed into the country, including a $\$ 1.6$ billion aid package from the US. A sizable subset of Russian elites (the 'Westernizers') sought to reform Russia domestically along Western lines. ${ }^{28}$ However, good relations were quickly undermined by disagreements. Indeed, "many Russians still see NATO through an historic lens of suspicion and consider the alliance's activities as directed against their country," ${ }^{29}$ as seen in the incendiary Russian responses to NATO bombings in Yugoslavia (1994-1995). ${ }^{30}$ The biggest problem was NATO expansion, to which Russia strongly objected. Mikhail Gorbachev had assented to the reunification of Germany only on the understanding that NATO would not "move one inch east." 31 Russia's earliest draft Foreign Policy Concept also stated explicitly that that former members of the Warsaw Pact could join NATO only if Russia were also invited to join. Yet by 1999, three such states had become NATO members. By 1998-9, Yeltsin's early rapprochement with the West had ended, with over $70 \%$ of Russians describing themselves as anti-American in polls. ${ }^{32}$

Russian influence was extremely limited between 1991 and 1999, as the Yeltsin administration lurched from crisis to crisis, creating ad hoc foreign policy with no clear consensus on any issue. ${ }^{33}$ Yeltsin personally bears a substantial amount of blame for this; his opinions were often arbitrary and

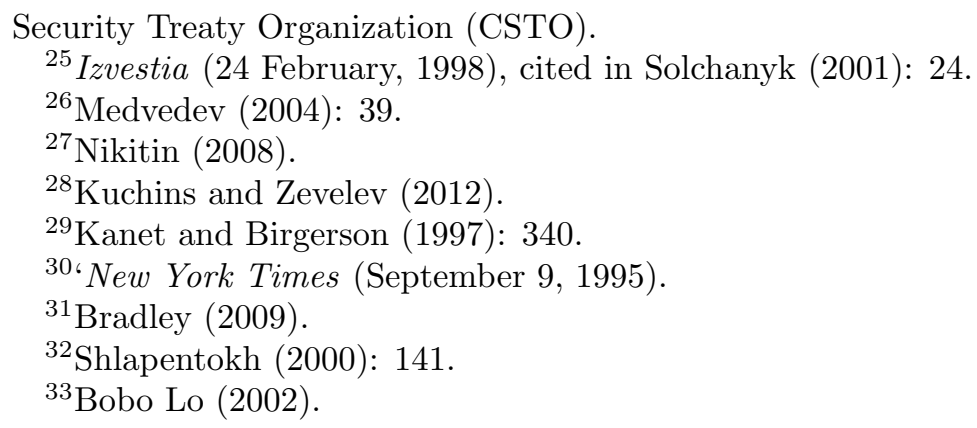


he was known to verbally abuse staff and ministers. ${ }^{34}$ The Putin period in Russian foreign affairs beginning with his accession to Prime Minister in August 1999 - is best considered as a response to this weakness. The period from 1999 onwards saw many changes in foreign policy priorities, with some arguing that foreign policy was largely set by which approach was most 'persuasive' to the President, and by whom it was proposed. ${ }^{35}$

Putin's decade in power saw two major conflicts, both more serious than those of the Yeltsin period: the Second Chechen War (initiated in 1999), and the 2008 Georgia War. ${ }^{36}$ While other territorial disputes did not escalate to full conflict, several did become heightened, in particular "the deliberate escalation of the old quarrel with Japan over the South Kuril Islands." 37 This dispute flared up in 2010, with the visit of President Medvedev to the region, and his announcement of increased military patrols on the islands. During one such patrol in 2013, Japanese officials claim that Russian jets violated Japanese airspace above Rishiri island in Hokkaido, but the dispute has not escalated since. ${ }^{38}$

The period also saw a number of diplomatic and espionage-related disputes with countries of the 'near abroad.' In particular, Moscow sought to prevent and discredit the wave of 'color revolutions' which swept the region in 2003-6. It is strongly suspected that the 2004 dioxin poisoning of pro-Western presidential candidate Viktor Yuschenko in Ukraine can be attributed to Russian agents. In addition, "in July 2009 Kyiv expelled two Russian diplomats from the Crimea, not for spying... [but for] trying to incite the population against the Ukrainian government." 39 The Kremlin also sought to sanction these states economically; for example, in 2006, 2008 and 2010, Russia cut gas supplies to Ukraine in mid-winter. Each cutoff followed on the heels of a major political disagreement between Ukraine and Russia. The election of pro-Moscow politician Viktor Yanukovich to the presidency of Ukraine in 2010 was quickly followed by the signing of an attractive

\footnotetext{
${ }^{34}$ Shlapentokh (2000).

${ }^{35}$ Spechler (2010): 39.

${ }^{36}$ Both conflicts are covered in more depth in Section 4.3 of this chapter.

${ }^{37}$ Baev (2012): 16.

${ }^{38}$ The Diplomat (February 8, 2013), available from http://thediplomat.com/flashpointsblog/2013/02/08/did-russian-jets-violate-japanese-airspace.

${ }^{39}$ Blank (2012): 67.
} 
gas pricing deal for Ukraine. Russia has also continued to push further integration within the CIS and other regional bodies, but has met with little success, as it seems that "common Soviet origin is no longer a dominating, integrating factor of the group of newly independent states." ${ }^{40}$ Analysts note that "the CIS clings to a kind of half-life, useful as a forum for certain kinds of interaction and association but painfully short of dynamism," 41 while "the CSTO remains a talk shop." 42

Relations with the West since 1999 have varied widely. Following the 9/11 attacks, Russia pledged to assist the US in its War on Terror, drawing parallels with muslim extremism in Chechnya, and supporting the US invasion of Afghanistan. However, relations quickly soured, and the 2003 Russian Military Strategic Document cited US troops in Central Asian states as Russia's major strategic concern. ${ }^{43}$ By 2005, the Putin administration had successfully pressured Uzbekistan to terminate the US lease on several of its airfields. ${ }^{44}$ Although the Obama administration sought a 'reset' of relations in 2008, tensions were increased in 2010 by the FBI discovery of a large illegal Russian spy ring, in 2012 by the expulsion of USAID from the country, and by the 2014 Ukrainian crisis. NATO expansion also continues to be a major stumbling block to relations; NATO now includes several former communist states, and in 2008, future membership was promised to Georgia and Ukraine. In response to the large NATO expansion of 2004, Russia also withdrew from the Treaty on Conventional Forces in Europe. The rhetoric of many government officials on the topic is inflammatory; for example, in a 2007 interview with Yury Baluyevsky, head of the General Staff, he referred to the CFE treaty as a "yoke for Russia." 45

Russian relations with the United Kingdom also proved to be a major flashpoint during this period. In 2006, Alexander Litvenenko, a former Russian spy critical of the Kremlin, died mysteriously in a London hospital from radiation poisoning, leading the British government to accuse Andrei Lugovoy of assassinating him, most likely on direct orders from Moscow. Russia denies

\footnotetext{
${ }^{40}$ Nikitin (2008): 10.

${ }^{41}$ Nation (2007): 20.

${ }^{42}$ Baev (2012): 14.

${ }^{43}$ Military Strategy Document of the Russian Federation (2003), available from http://www.mid.ru/nsosndoc.nsf/osnddeng.

${ }^{44}$ Mankoff (2009).

${ }^{45}$ Interfax (November 13, 2007), archived in Johnson's Russia list; available from http://russialist.org/2007-235-44.php.
} 
these charges, but refuses to extradite the suspect. In 2008, Russia nationalized a large oil project owned by BP, and denied visas to company executives. ${ }^{46}$ The following year, Russia expelled four British diplomats, accusing them of spying, and shut down the British Council. In 2008, Russian long-range bombers violated British airspace, necessitating British fighter jets to chase them off. ${ }^{47}$ Tensions remain high.

The central difference between the Putin administration's foreign policy and that of the Yeltsin period is the Kremlin's new focus on restoring Russia's prestige and Great Power status. For example, the 2013 Foreign Policy Concept sees the removal of language concerning cooperation with NATO, and highlights Russia's great power status. ${ }^{48}$ Foreign policy concepts and other statements in recent years also highlight Gosudarstvennost (statism) and Derzhavnost (great power ideology) as the key principles for foreign policymaking. ${ }^{49}$ Speeches have also become more confrontational, such as Putin's 2007 speech to the Munich Security Conference. ${ }^{50}$ However, under both Putin and Yeltsin, Russian foreign policy has focused on a few key issues, in particular, maintaining control over other post-Soviet states, and preserving Russian territorial integrity. The Russian desire to retain influence in the 'near-abroad' is now the primary driving force in foreign policy. This has led to internal tensions, as Russian attempts to regain global influence (as a member of the G8, for example) often conflict with its desire to keep former Soviet states in line.

\subsubsection{Is Russian Foreign Policy Aggressive?}

Russian foreign policy certainly seems aggressive when one considers the many conflicts and territorial disputes in which it has been involved. Indeed, an analysis of this dissertation's dataset since 1991 shows that Russia engaged in more than 25 actions which could potentially be described as aggressive, ranging from military incursions like the War in Georgia, to covert aggression such as Russia's role in trying to prevent 'color revolutions,' to acts of verbal aggression such as Russia's

\footnotetext{
${ }^{46}$ Goldman (2008).

${ }^{47}$ RIA Novosti (March 25, 2010), available from http://en.rian.ru/russia/20100325/158312005.html.

${ }^{48}$ Foreign Policy Concept of the Russian Federation (2013), available from http://www.mid.ru/nsosndoc.nsf/osnddeng

${ }^{49}$ Mankoff (2009).

${ }^{50}$ Putin, Speech at the Munich Security Conference (February 12, 2007).
} 
consistent saber-rattling with the UK. About two thirds of these aggressive actions took place during the Putin (and Medvedev) administrations, but we also see several (such as military involvement in Abkhazia, Transnistria, and Chechnya) under Yeltsin. In addition, Russia has repeatedly used economic sanctions to deter nearby states from seeking broader ties with the West, including use of the 'energy weapon.' While this direct use of oil as a tool of foreign policy is not the focus of this dissertation, it is undoubtedly an aggressive foreign policy act.

It must be noted that Russia is both a de facto great power, and an autocracy, two factors which typically correlate with increased levels of aggression. During the same period, for example, the United States initiated two large-scale conflicts in Iraq and Afghanistan, and was involved in various military and diplomatic disputes. Despite this, Russian foreign policy since 1999 has seen numerous conflicts, far more than even other autocratic great powers (i.e., China). In addition, Russia's use of belligerent acts to constrain the states of the near abroad has showed a clear tendency towards escalation in aggression: verbal and economic sanctions are often used to bring states to heel (as in the case of Uzbekistan or Belarus). If these are unsuccessful, the Kremlin will often resort to covert actions (as in Ukraine and Georgia). Finally, if verbal, economic and covert actions fail to bring the wayward state back into the fold, conflict typically follows (as in the 2008 Georgia War, or the current crisis in Ukraine). In effect, Russia has shown a willingness and strong inclination to use aggressive means to advance its foreign policy interests.

\subsection{From Oil to Weak Foreign Policy}

\subsubsection{The Development of Russian Foreign Policy Institutions}

In the immediate aftermath of the Soviet collapse, there was a great deal of confusion in the realm of foreign policy, as states sought to find solutions to the collapse of the key Soviet military and foreign policy institutions. The 1991 formation of the Commonwealth of Independent States (as a 'replacement' for the USSR) left unresolved the question of whether former republics would continue to share military and diplomatic services, or whether each state would be responsible for 
its own foreign and defense policies. Prior to 1991, the republics had effectively depended on the Soviet infrastructure, with no real foreign service of their own. For example, at the fall of the USSR, the Soviet Foreign Ministry had over 3000 employees, while the Russian Foreign Ministry had only $244 .{ }^{51}$ Several major players in the foreign policy process, most notably the military and security services, pushed heavily for a new CIS-based military and foreign policy to simply replace Soviet-era coordination. The security service backed Council for Foreign and Defense Policy (which despite the name, was an NGO) even issued a report entitled "Will the Union be Revived?" which called for the recreation of the Soviet structure among the states of the CIS. ${ }^{52}$ The result was two years of effective 'non-decisions' in the foreign policy arena. ${ }^{53}$

By 1992, however, the former republics had arrived at an implicit understanding that states would act as separate entities, and in 1993, the new Constitution and Foreign Policy Concept of the Russian Federation laid out a purely domestic structure for foreign policymaking. This system would be based within the office of the President and the new Russian Ministry of Foreign Affairs, which drew the majority of its personnel (around 3,200 staff) from the old Soviet foreign service. ${ }^{54}$ Similarly, the new Russian intelligence agencies drew the majority of their personnel and equipment from the old Soviet KGB. Yeltsin sought to diminish the power of the chief intelligence agencies (the KGB and GRU), and to prevent them from challenging him. In particular, he broke up the KGB into numerous smaller agencies (chiefly the SVR and FSB), each tasked with a specific, small area of responsibility. ${ }^{55}$ However, in many cases, these agencies continued to operate in the same buildings, with the same personnel and hierarchy. Thus, the description of many Russian intelligence agencies as 'successors' of the KGB is entirely accurate.

The mid-1990s saw a power struggle within the Russian government as to who would have primacy in foreign affairs, with a number of former Soviet 'power ministries' fighting for influence, in what McFaul characterized as a very "new, ambitious institutional context." 56 The 1993 Con-

\footnotetext{
${ }^{51}$ Donaldson and Nogee (2005): 151.

${ }^{52}$ Tsygankov (2006): 124.

${ }^{53}$ McFaul (1997-8): 13.

${ }^{54}$ Donaldson and Nogee (2005): 151.

${ }^{55}$ Soldatov and Borogan (2010).

${ }^{56}$ McFaul (1997-8): 5 .
} 
stitution handed control of foreign policy to the President, cutting the Duma, Prime Minister and cabinet out of foreign affairs almost entirely. Although the Duma still serves as a forum for debate over foreign policy, the lack of true electoral variety within the lower chamber, and the appointed nature of the Federation Council serves to undermine even this minor role, leaving foreign policy in the hands of the President. The Constitution also did not create any clear institutional framework for foreign policy, leaving unclear which agencies would be responsible for advising the President, and for generating foreign policy stratagems. The importance of personal ties "became heightened in conditions of bureaucratic anarchy, fragile democratization and power vacuums." 57

The 1992 creation of the Security Council aimed to create an organization similar to the American NSC, which would deliberate on key issues. The council originally included senior ministers, cabinet members, the Prime Minister and the President. However, between 1992-95, the format of the council was slowly changed by Yeltsin, so that there was "no longer any clear-cut, legally codified membership criteria." ${ }^{58}$ Personal appointment by the President became a requirement of membership. This lack of legal structure persists to the present day, and the resultant lack of coordination between ministries often leads to contradictory foreign policy pronouncements. ${ }^{59}$ The Presidential administration is at all times surrounded by a competing group of ministries, councils and interest groups. The Security Council, Foreign and Defense Ministries and the Security Services (chief among them the SVR, FSB and GRU) are the main agencies seeking to advise the President. The Foreign Economic Ministry also advises on economic and trade matters. Yeltsin encouraged infighting between agencies, particularly between the various branches of the intelligence services. He believed this would help to prevent a unified coup against him by the security services. In addition, Yeltsin believed that encouraging competition between agencies would give him greater reliability in intelligence (i.e., multiple sources of information). However, during the 1990s none of these agencies was particularly strong or competent, and infighting instead weakened them. ${ }^{60}$

Outside of government, several lobbying groups and NGOs have played important roles in the

\footnotetext{
${ }^{57}$ Bobo Lo (2002): 31.

${ }^{58}$ Derleth (1996): 48 .

${ }^{59}$ Bobo Lo (2002).

${ }^{60}$ Soldatov and Borogan (2010).
} 
foreign policy process. During the Yeltsin era, industrialists played a major role in advising the government on foreign policy through groups such as the Civic Union. Equally important, however, were the group known as the 'Family,' members of Yeltsin's family and businessmen who bankrolled his 1996 Presidential campaign. The low capacity of the Russian state during this period made it difficult to avoid the demands of various constituencies. ${ }^{61}$ After Putin came to power, he effectively exiled many of these businessmen from politics, but they were quickly replaced by the group known as the 'Siloviki,' former (and current) members of the security services, many of whom serve as key advisors. There is also substantial crossover with energy companies. Gazprom, Transneft and Rosneft are often headed by Siloviki or former government officials, and exert considerable pressure on the President's office. This cross-fertilization of advisors between business and government increases the importance of profit and factors other than the national interest to policymakers. ${ }^{62}$ The continued importance of such informal advisors from civil society in the presidential advising process also served to undermine the power of legitimate government ministries in the formulation of foreign policy.

In addition to these groups, there have been a variety of short-lived organizations, such as the Foreign Policy Council, most of which were quickly disbanded, adding to the institutional confusion. As Donaldson and Nogee point out, "the concurrent existence... of the Security Council, the Defense Council... and a Foreign Policy Council... spoke to the persisting problem of a lack of coordination in Russian foreign and defense policy." 63 The influence of these groups has also risen and fallen over time. The Presidential Council, for example, was sidelined after its members voiced opposition to the Second Chechen War, to be replaced by the Security Council. This variance in institutional power matches varying foreign policy priorities, with some arguing that foreign policy was largely set by which approach was most 'persuasive' to the President, and by whom it was proposed. ${ }^{64}$

Although the Ministry of Foreign Affairs technically has primacy on foreign policy, and was the most coherent actor after the Soviet collapse, it failed to capitalize on this position, and has

\footnotetext{
${ }^{61}$ Marantz (1997).

${ }^{62}$ Dawisha (2011).

${ }^{63}$ Donaldson and Nogee (2005): 147.

${ }^{64}$ Spechler (2010): 39.
} 
become less an advisory body and more an agency for foreign policy implementation. ${ }^{65}$ The autonomy of the President from institutional actors has also increased dramatically since the 1990s; as Mankoff notes, "Yeltsin's Kremlin was often unable to coordinate the activities of the Security Council, Foreign Ministry, Defense Ministry, and a plethora of short-lived bureaucratic actors," but Putin's administration has had much greater success in keeping autonomy from these actors." 66 In particular, oil wealth has allowed the Putin regime to stabilize foreign policymaking around a small group of individuals, bypassing and contributing to the weakness of key institutions.

The security services have become increasingly prominent since the elevation of Vladimir Putin to the presidency. ${ }^{67}$ As a former director of the FSB, he has encouraged their increased role in policy formation. In 2003, a Presidential decree restructured several major parts of the security services, incorporating FAPSI (the signals intelligence corps) and the Federal Border Guards into the FSB. This reorganization dramatically increased the power of the FSB, which now has an estimated 269,000 personnel, making it the third largest military force in the country ${ }^{68}$ The importance of the security services in the foreign policy process cannot be understated: most decisions are taken by a group of key advisors, dominated by top former intelligence officers. By 2004, more than 6,000 former intelligence officers held high-level government positions, including the defense minister and several regional governors. ${ }^{69}$ For example, decisions on the recent crisis in Crimea were taken by a group comprising Sergei Ivanov, Vyacheslav Volodin, Vladislav Surkov, Sergei Lavrov and the heads of the security services, all key Putin advisors. ${ }^{70}$ It is notable that within this group, only Foreign Minister Sergei Lavrov has no connection to the security services.

A typical foreign policy decision will involve the President and only those advisors he deems necessary or helpful. These advisors may be representatives of institutions, but are also likely

\footnotetext{
${ }^{65}$ Arbatov (1993).
}

${ }^{66}$ Mankoff (2009): 58.

${ }^{67}$ It should also be noted that these organizations have suffered from serious recruiting problems since the fall of the USSR. Work for the KGB or GRU was one way in which educated Soviet citizens could travel abroad and access hard currency and western goods. Thus, these posts were sought after and elite. Since the collapse of the USSR, the private sector has become a more attractive and lucrative option to many young Russians, diminishing the quality of applicants to the security services.

${ }^{68}$ Staar and Tacosa (2004): 45.

${ }^{69}$ Staar and Tacosa (2004): 55.

${ }^{70}$ Reuters (March 11, 2014), "From loyal aides and 'inner voice', Putin hears no Crimea Dissent." 
to be personal appointments. Often for different decisions, different individuals will be present, with the role of the intelligence services being the only typical constant. The Foreign Ministry is generally present at discussions, but tends to be more involved in implementation than in advising. Information and input tends to come from a limited set of advisors. Thus, although Russian institutions themselves are reasonably well-developed (as a holdover from the Soviet period), there is no solid institutionalized system of foreign policy decision-making. Information comes from an extremely limited set of sources, and deliberation on foreign policy is limited.

\subsubsection{Are Russian Foreign Policy Institutions Weak?}

As outlined in Chapter Two, the institutional framework within which foreign policy is made, and the strength or weakness of that system is key to the theory of natural resources and aggression. In particular, we should expect institutions for foreign policy to be: (a) characterized by disagreements or by jockeying for influence by various individuals and groups, (b) personalized and primarily dominated by individuals or small groups, and (c) inefficient and suffering from communication problems. While dominance by the executive is common in most systems, it is extreme personalization of decision-making by individuals that we expect to see in an oil-rich state. The confusion that characterized Russian foreign policymaking after the fall of the USSR eventually yielded a system that does seem to correspond closely to these expectations, with an unclear institutional structure, and an extremely personalized system of decision-making.

Foreign policymaking in Russia tends to be an extremely personalized process. This can be illustrated by the rise and fall of the Security Council. The Security Council was designed to act as the central foreign policy advising body, but in practice, its scope and effectiveness has varied widely. As Staar notes, "depending on his relationship with the President, the SC secretary may become the second most important person in Russia, or just another functionary without access to the top of the pyramid." 71 Yeltsin appointed a series of loyalists to the council (e.g.,Skokov, Lobov, Lebed), while expanding the Council's power dramatically. In 1996, however, Lebed pushed for the

\footnotetext{
${ }^{71} \operatorname{Staar}(2002): 21$.
} 
Council to become similar to the old Soviet politburo; Yeltsin, fearful of the loss of Presidential privilege, forced him to resign, and reduced the importance of the Council. As a result, during the First Chechen War, the Security Council didn't even meet regularly, and decisions were taken personally by Yeltsin and top advisors. ${ }^{72}$ Yeltsin was also known to dismiss foreign ministers (i.e., Stepashin) whom he disliked. Similarly, Putin (and Medvedev) have tended to enlarge the Security Council's role when they trust its leadership, and remove powers at other times. ${ }^{73}$

Thus, throughout the 1990s, the Security and Defense councils had little input in policymaking. ${ }^{74}$ The Ministry of Foreign Affairs also struggled to maintain leadership on foreign policy issues. Many in the Ministry of Foreign Affairs and the Security Services were caught off guard by the emergence of new actors in the foreign policymaking process,${ }^{75}$ and the creation of the Ministry for Foreign Economic Affairs undermined their power on trade issues. Despite repeated decrees from Yeltsin that the Ministry should have primacy in foreign policy, there have been no structural changes to assure that this occurs. In practice, the Ministry is influential only when a Presidential loyalist is in charge. In recent years, the position of foreign minister has been filled by career bureaucrats (e.g., Lavrov), whose central function is less to advise, and more to implement Presidential decrees. ${ }^{76}$ There is no specific oversight institution for foreign policy, and no lawful foreign policy decision-making process. ${ }^{77}$

This renders personality extremely important in the foreign policy process, and personalization of the system has increased dramatically in the last decade. The President can alter foreign policy institutions to fit his needs, and tends to rely more on personal ties than on institutional hierarchy in decision-making. This "makes the personal attitudes and political skills of the top leader and his closest associates of particular importance." 78 As many authors have noted, the personal experiences and opinions of Presidents have strongly shaped Russian foreign policy, whose roots

\footnotetext{
${ }^{72}$ Derleth (1996): 52 .

${ }^{73}$ Donaldson and Nogee (2005): 153.

${ }^{74}$ Bobo Lo (2002): 33.

${ }^{75}$ Mankoff (2009).

${ }^{76}$ Ibid., 55.

${ }^{77}$ Blank (2012): 29.

${ }^{78}$ Donaldson and Nogee (2005): 177.
} 
are often more biographical than institutional. ${ }^{79}$ This is particularly common in analyses of foreign policy under Vladimir Putin, where biographical studies often attempt to draw parallels between Putin's life and his foreign policy choices. ${ }^{80}$

The personalization of the system is perhaps best illustrated by foreign policy formation during the period of the 'tandemocracy.' From 2008-2012, Putin stepped aside from the presidency, effectively swapping positions with his Prime Minister, Dmitri Medvedev. However, he carried much of the authority for foreign policy with him, and the Prime Minister's office became a major player in foreign policy for the first time. During this time, it was often difficult to assess who was really in control of foreign policy. ${ }^{81}$ The contradictory statements issued by both Medvedev and Putin during the Georgia war merely serve to highlight that position matters less than personality in this system, which rests on the "flexibility of institutional rules and constraints," allowing elites to achieve their own personal goals. ${ }^{82}$ This often means that foreign policy is not necessarily focused on the 'national interest,' but is instead "dictated by short-term personal interests." 83 Various authors note that the elite self-interest often trumps national interest, with profit motive being extremely important. ${ }^{84}$ The increasing prevalence of actors with ties to both business and government (such as the Siloviki) has heightened this tension. ${ }^{85}$

In addition to its extreme personalization, foreign policy institutions in Russia tend to be dysfunctional and inefficient. The Ministry of Foreign Affairs is known for its incompetence, and "Russia's press is filled with repeated instances of both Putin and Medvedev's repeated frustration and anger over the systematic inability to implement state policies." 86 There are consistent reports of infighting between institutions, with key figures often more interested in political power and standing than in policy outcomes. As early as 1993, "foreign policy formulation [had] become not just an object of contention between the usual differing positions, but also the victim of bitter

\footnotetext{
${ }^{79}$ Charap (2004): 55.

${ }^{80}$ See Hill and Gaddy (2013) for one excellent example of this type of study.

${ }^{81}$ International Institute for Strategic Studies Strategic Comments 18, no. 4 (2012).

${ }^{82}$ Dawisha (2011): 335.

${ }^{83}$ Shlapentokh (2000): 140.

${ }^{84}$ Blank (2012), Charap (2004), Dawisha (2011), among others.

${ }^{85}$ Soldatov and Borogan (2010).

${ }^{86}$ Blank (2012): 29.
} 
infighting among rival forces of society." 87 Yeltsin encouraged this infighting, which continues to this day. As Blank notes, "every reliable account of how the system actually operates points to a system of unending and often vicious bureaucratic struggle." 88 Though differing opinions and jockeying for influence is a central part of policy formation in any democracy, in Russia, influence over the foreign policy process relies primarily on personal ties and loyalty to the President, and the influence of various ministries rises and falls over time as individuals fall in or out of favor.

Russia's institutional framework for foreign policy-making thus seems to support the theory; while it is obvious that the President is responsible for foreign policy decisions, the institutional framework underlying these decisions is unclear and confused. Foreign policymaking is highly personalized, around Vladimir Putin himself, and those individuals whose input he values. The only strong institution is the security service, limiting opinions to a single point of view. Other institutions are weak, and struggle between government ministries, the military and external lobbying groups is constant. While this does not mean that Putin decides policy arbitrarily, he determines which views are heard. The process of foreign policymaking in Russia is therefore, as predicted by the theory, a confused and highly personalistic process.

\subsubsection{Is Institutional Weakness Oil-Related?}

Russian institutions have been weak since 1991, well before oil revenues became a major part of the government's budget (see Figure 4.1). initial institutional weakness was the result of uncertainty following the Soviet collapse, but state capture of Russian foreign policy institutions was also a consistent problem throughout the Yeltsin period. According to Light, Russia's "new bureaucratic

structures were inherently unstable... the foreign policy decision-making system was in flux." 89 The foreign policy system has in fact solidified since 1999, when oil revenues began to increase. This would seem to indicate that resource rents have had little to do with institutional weakness in the Russian case. However, the rise in resource rents also correlates closely with increasing levels

\footnotetext{
${ }^{87}$ Arbatov (1993): 5 .

${ }^{88}$ Blank (2012): 30.

${ }^{89}$ Light (1996): 41.
} 


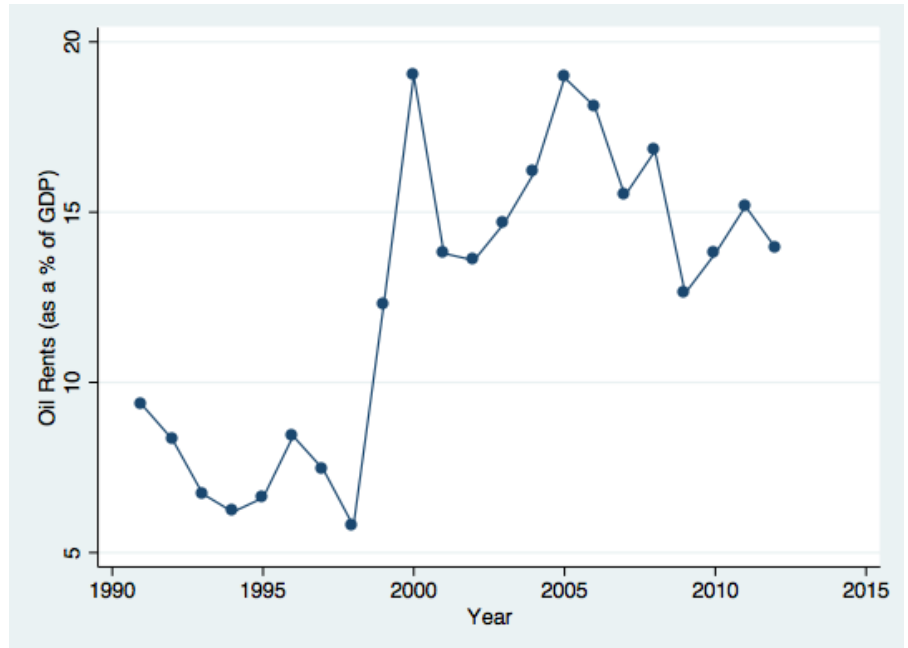

Figure 4.1: Russian Oil Rents (1991-2010)

of personalization within the foreign policy system. As many scholars have have noted, oil wealth has allowed Vladimir Putin to reduce the influence of the oligarchs, and to centralize and control the foreign policymaking process. ${ }^{90}$ In particular, as Mendras notes, oil wealth has been used by elites "to weaken further public institutions in order to develop their own system of rule." 91 This oil-enabled personalization and centralization of power has also affected foreign policy institutions.

In order to ascertain further the impact of oil revenues, it is helpful to consider the institutions of several similar non-oil states. Firstly, although China has suffered no political collapse, as an autocratic great power, it offers perhaps the best comparison in terms of pure size and power. In contrast to Russia, China's foreign policy institutions, although opaque, are characterized by broad membership and consensus-building strategies. Foreign policymaking is concentrated in the Politburo, but is deliberated in small committees (known as LSGs) which are made up of foreign policy specialists from various institutions. Politburo members are extremely responsive to their recommendations. ${ }^{92}$ Chinese institutions are not democratic, but neither information nor advice is lacking, and scholars highlight the "pivotal role of consensus building... both within and outside of

\footnotetext{
${ }^{90}$ Tsygankov (2006): 131.

${ }^{91}$ Mendras (2012).

${ }^{92}$ Jakobson and Knox (2010).
} 
the foreign policy establishment." 93

Secondly, Ukraine, although not a great power, provides a good comparison to Russia, as both are similar states which emerged from the Soviet collapse. Ukraine experienced similar levels of institutional weakness during the 1990s, and struggled to build a foreign policy system. In addition, policymaking in Ukraine continues to be opaque, with a corrupt political system. Despite this, one US nonprofit study concluded that, although it suffers from funding shortfalls, "the Ministry of Foreign Affairs is a moderately autonomous agency that is fairly capable of independent action."94 In addition, foreign policymaking in Ukraine tends to occur in a reasonably consensual manner, as constitutional reforms following the 2004 Orange Revolution reduced the power of the President and required increased consultation. ${ }^{95}$ In both states, although foreign policymaking is not as open or democratic as in the West, there is little of the extreme personalization found in the Russian case, indicating that oil revenues may indeed have shaped Russian foreign policy institutions.

\subsubsection{Russian Military Spending and Focus}

The theory of natural resources and aggression also leads us to expect that a resource-rich state is likely to spend a substantial amount of money on its' military, and will focus on military solutions to foreign policy problems. In the case of Russia, military spending has fluctuated over time, and major shifts in spending do track closely with state oil revenues. Figure 4.2 shows levels of military expenditure in Russia, compared to levels of revenue from oil received by the Russian state during the period 1991-2010. During the period 1991-2000, Russian military expenditure actually fell precipitously - from 5.5\% of GDP in 1992 to just 3.4\% in 1999 - a legacy of the Soviet collapse. ${ }^{96}$ Downsizing of the armed forces from the extremely militarized USSR necessitated a reduction in personnel from around 2.88 million personnel to only 1.6 million between 1991 and 1998. ${ }^{97}$ Although military reform was badly needed, both money and political will to do so were

\footnotetext{
${ }^{93}$ Ibid., 1.

${ }^{94}$ Biberman (2009): 3.

${ }^{95}$ Karatnaky (2005).

${ }^{96}$ Stockholm International Peace Research Institute Yearbook (2013), available from http://www.sipri.org/yearbook/2013.

${ }^{97}$ Arbatov (1998).
} 

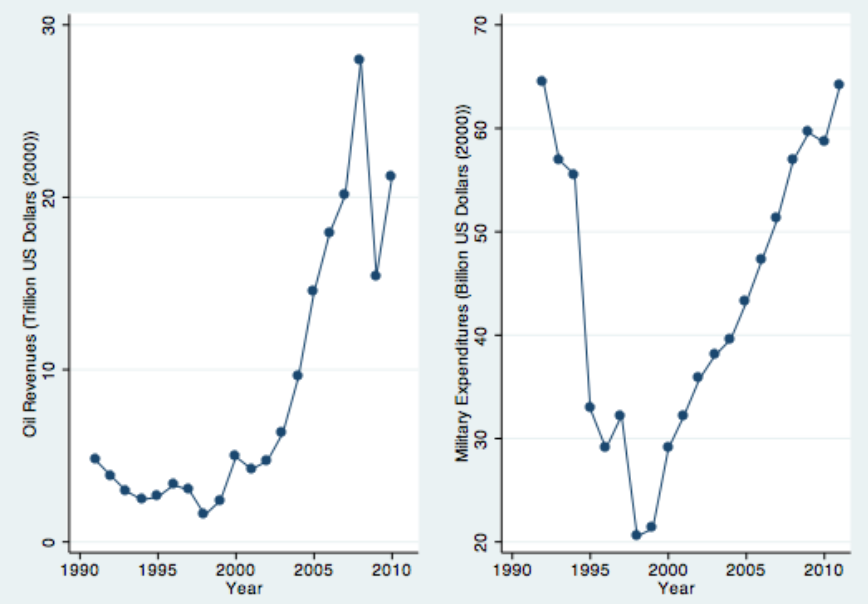

Figure 4.2: Russian Oil Revenues vs. Military Expenditure (1991-2010)

lacking, and no serious reform was undertaken by Yeltsin. Oil prices were low during this period, and the restructuring of the Russian economy left little funding for the military. In addition, Yeltsin was unwilling to anger the military's General Staff, on whose support he had relied during the 1993 crisis, and whom he might again need to combat domestic political enemies. ${ }^{98}$ After 1996, when Yeltsin felt relatively secure after re-election, he slashed military expenditure. Funding fell even further during the 1998 financial crisis, and budgetary pressures left the military unable to pay salaries or support key programs. As Arbatov noted in 1998, "Not since June 1941 has the Russian military stood as perilously close to ruin as it does now." 99

Since 2000, however, military funding has increased dramatically, by as much as 1\% of GDP in the last decade; the rapid growth of state oil revenues means that these increases are actually larger in real terms. During Putin's first term, for example, spending on the military doubled. ${ }^{100}$ Between 1999 and 2012, Russian military expenditure rose from 165 billion rubles per year to an astounding 2799 billion rubles. ${ }^{101}$ Political problems associated with reform remained, but by 
2003, the Ministry of Defense allocated additional funding for restructuring. ${ }^{102}$ Since 2011 alone, military funding has risen by $80 \%$, while funding for the police and special services has risen by over 50\%. ${ }^{103}$ Reform efforts have focused on transforming the Russian military from a Soviet era 'WWIII' focus, ending conscription, and improving training and salaries. The goal is a force which is " more mobile, more able to project power rapidly throughout Russia's expanse, and more capable of meeting the threat posed by terrorists or other insurgents in the Caucasus or Central Asia." 104 Although Russia ranked third in the world in 2013 in absolute military spending, behind the USA and China, military spending as a proportion of GDP (4.1\%) was among the highest in the world, ahead of the USA (3.8\%), China (2\%), and the UK $(2.3 \%)$. The only states in the world with higher military spending as a percentage of GDP are Saudi Arabia and the UAE, both of which are also oil states. ${ }^{105}$

It is also worth noting that increased military expenditure does not necessarily result in a better military. In the Russian case, many analysts agree that the "Russian military remains... largely ineffective, despite substantially boosted budgetary allocations since 2001."106 As Baev notes, "the lack of resources is not the main obstacle, as plentiful new funds have been pumped into the old structures in order to preserve their integrity." ${ }^{107}$ Much of this money was spent inefficiently, and much was lost to corruption. Finally, following Russia's unimpressive performance in the 2008 War in Georgia, the General Staff proposed a complete transformation of the Russian Army, from an undertrained conscripted army to a well-trained volunteer force. As Lannon notes, "increasing state revenue was essential for reform to succeed." 108 Since this time, military performance does appear to have improved.

Thus, the Russian case does seem to fit the prediction that oil rich states will channel much of that wealth into military development and funding. As revenues remained stable through the 1990s,

\footnotetext{
${ }^{102}$ Baev (2008).

${ }^{103}$ Goble (2014).

${ }^{104}$ Blank (2006): 67.

${ }^{105}$ Stockholm International Peace Research Institute, "Trends in World Military Expenditure, 2013," available from http://books.sipri.org/product_info?c_product_id $\overline{4} 76$.

${ }^{106}$ Barany (2006): 604 .

${ }^{107}$ Baev (2008): 17.

${ }^{108}$ Lannon(2011): 34.
} 
the government determinedly cut the military, but by 2000, funding began to rise dramatically, in line with oil prices. The theory also predicts that leaders in oil-rich states will tend to focus heavily on military options. This is certainly true in the Russian case, where a number of diplomatic incidents escalated quickly to the use of military force. The 2008 War in Georgia saw a quick Russian military response before any diplomatic solutions were considered. Similarly, the Russian government has a tendency to engage in escalation, positioning troops near the border during negotiations with nearby states, and violating borders, such as the current involvement of Russian troops in the Crimean crisis. In short, Russia has high levels of military spending, and a tendency to resort to military options in a crisis, as we would expect in a resource-exporting state.

\subsubsection{Government Constraints in Foreign Policy}

The third effect predicted by our theory is that petrostates will be less likely to care about public opinion on foreign policy issues, as oil wealth mitigates the need for taxation and active engagement with citizens. Thus, in a resource-rich state, we would expect to see that foreign policy often differs from public opinion. However, public opinion in autocracies is different than that of democracies, and most theories of public opinion and foreign policy draw primarily from democratic systems of government. ${ }^{109}$ In autocracies, public opinion tends to be of interest to leaders, but is not a key determining factor in policy outcomes. As Russia is (at least) a semi-autocratic state, we would therefore expect to see public opinion which often differs from foreign policy choices. Indeed, in Russia, mass and elite opinion on foreign policy do frequently differ dramatically. ${ }^{110}$ However, the Kremlin's foreign policy is also often popular among citizens, particularly as resource rents have allowed the government to influence media. This raises questions about the use of oil revenues to shape public opinion, and whether the relationship between oil and public opinion is

\footnotetext{
${ }^{109}$ See Tomz and Weeks (2013) for an excellent discussion of public opinion and conflict in democracies.

${ }^{110}$ It should be noted that Russian public opinion data is a relatively new phenomenon, as polls were forbidden during the Soviet period. Polls conducted shortly after the Soviet collapse often show an unwillingness among citizens to share their opinions. For example, in 1993, fully $24 \%$ of those respondents who self-identified as 'extremely attentive' to foreign affairs refused to give their opinion on NATO expansion (Zimmerman (2001): 241). Responsiveness has increased, but it is still common for surveys to have around $10 \%$ of respondents refuse to answer questions.
} 
multidirectional.

The opinions of Russian publics do tend to differ from those of elites, and as such, it has been argued that public opinion is a poor way to assess Russian foreign policy. Several surveys conducted at the end of the 1990s found differing opinions on key issues such as NATO expansion, Russian national interest and the CIS. For example, when asked in 1995, "Should Russian national interest extend beyond its current territory?" $80 \%$ of elites answered yes, in comparison to $60 \%$ of the public. ${ }^{111}$ Thus, Zimmerman notes that during the low resource-rent period of the 1990s, "the differences reported between elite and mass orientations to foreign policy... served as a constraint on foreign policy activism." 112

In the 2000s, foreign policy outcomes continued to differ from public opinion preferences. In general, scholars agree that public opinion in Russia is "more isolationist and less confrontational than elite opinion." 113 For example, even in 2012, as Russian policy was anti-Western, when asked if Russia should strengthen relations with the west, $76 \%$ of respondents agreed, while only $13 \%$ disagreed. ${ }^{114}$ Similarly, while the Russian government has been supportive of the Assad regime in Syria, a 2012 poll showed that only $11 \%$ of respondents agreed; 9\% supported the rebels, and $52 \%$ supported neither side. ${ }^{115}$ In 2003, another survey asked respondents how Russia should respond to threats against ethnic Russians in the 'near abroad.' $76 \%$ supported negotiation and $70 \%$ supported economic pressure, while only $23 \%$ supported military action. ${ }^{116}$ Despite this, the Kremlin has tended to focus on military solutions in Abkhazia, South Ossetia and Crimea.

In addition, public opinion in Russia has sometimes been critical of government foreign policy. For example, a 2012 poll asked respondents what they felt was the largest concern of Vladimir Putin's associates in policymaking. About the same number (40\%) believed that elites were driven by personal interests in foreign policy decisions, as those (41\%) who believed that national interest

\footnotetext{
111Zimmerman (2002): 91.

112Zimmerman (2002): 42.

${ }^{113}$ Mankoff (2009): 60.

${ }^{114}$ Levada (2013).

${ }^{115}$ Levada (2013).

${ }^{116}$ Rose and Munro (2008): 62.
} 
drives elites. ${ }^{117}$ Despite this, public opinion has been largely unimportant. As Mankoff argues, "That public opinion does not actually drive foreign policy in Russia can be seen in the divergence between public and elite sentiment and between public opinion and the government's actual policy choices."118 A 1999 poll asked elites asked which groups were most important to foreign policy formation, on a scale from 1 to 7 . On average, elites responded that public opinion was around 3.01 in influence, the lowest score of any possible response (for comparison, the President was 5.70, and business elites were 4.55). ${ }^{119}$

The relative unimportance of public opinion does tend to support our theory's hypothesis. However, this is also complicated by the role of media in shaping public opinion. As Petrova illustrates, governments which have substantial media control (often the case in petrostates) can use this to bolster support for conflict. ${ }^{120}$ Since 2000, the Putin regime has used resource wealth to buy up most of Russia's media outlets and to restrict freedom of the press. The Kremlin controls all three main television channels, and strongly influences journalists, leading Reporters Sans Frontiéres to place it $148^{\text {th }}$ in the world on its Press Freedom Index. ${ }^{121}$ Since public opinion is strongly shaped by the media, in recent years, public opinion has begun to align with the Kremlin's position on many foreign policy issues.

One poll exploring the issue of Russian intervention in South Ossetia and Abkhazia highlights this influence. 59\% of those polled in March 2008 agreed that the two territories should either join Russia or become independent states. However, by August 2008 and the breakout of the war, more than $80 \%$ agreed. Similarly, by August 2008, almost half of all Russians responded that the cause of the conflict was the United States trying to spread its influence in former Soviet states, while twothirds of respondents said that Western governments supported Georgia during the conflict because they wanted to damage Russia, a key Kremlin talking point. ${ }^{122}$ The ability of the government to

\footnotetext{
${ }^{117}$ Levada (2013).

${ }^{118}$ Mankoff (2009): 59.

${ }^{119}$ Zimmerman (2002): 40.

${ }^{120}$ Petrova (2008).

${ }^{121}$ Reporters Sans Frontiéres (2013), available from http://rsf.org/index2014/en-index2014.php.

${ }^{122}$ Russian Public Opinion Survey Booklet, Levada Centre (March 2008-9): p113-5; Available from [http://www.levada.ru/eng/]
} 
shape public opinion through control of the media further reduces constraints on policymaking.

In conclusion, the Russian government has pursued foreign policy objectives which are unpopular among the general population, supporting our theory, and implying that public opinion is at least somewhat unimportant to policymakers. However, it must also be noted that oil wealth has allowed the government to more fully control the media environment, and in doing so, to shape public opinion on foreign policy issues. Thus, foreign policy has tended to align more with public opinion in recent years, making this hypothesis more difficult to assess. Nonetheless, the Russian government is rarely constrained in foreign policymaking by public opinion.

\subsubsection{Conclusion}

In Section 4.2, we sought to assess whether the theorized links between oil and our theory's mediating variables (weak institutions, military spending and a lack of government constraints) are present in the Russian case. The Russian foreign policy process is indeed underinstitutionalized, a legacy of both the Soviet collapse and increasing resource revenues, which have allowed elites to bypass state institutions. The institutional framework for foreign policy advising is chaotic, and foreign policymaking, though centralized, is highly personalized. The Kremlin also spends substantial amounts of money on the armed forces, with these amounts increasing dramatically as oil revenues rose from 2000 onwards. Finally, public opinion is sometimes at odds with foreign policy choices, indicating that there may indeed be a lack of government constraints on foreign policymaking, although this finding is tempered by the involvement of the Kremlin in public opinion modification strategies. For all three variables, these outcomes appear stronger in the last decade than during the 1990s, correlating with the rise in oil revenues. The Russian case therefore shows strong evidence that oil production is linked to our mediating variables. This chapter will now examine several specific cases of foreign policy decision-making to assess whether these mediating

variables do indeed undermine the foreign policy process, and whether they contribute to aggressive behavior and conflict initiation. Thus, this section does not seek to show a direct causal link between oil and aggression, but rather how these oil-driven mediating variables can undermine 
foreign policy in specific cases. These cases will focus on Russian intervention in Kosovo (1999), the Second Chechen War (1999-2001) and the War in Georgia (2008).

\subsection{From Weak Foreign Policy Apparatus to Aggression}

\subsubsection{Russia and NATO in Kosovo (1999)}

Kosovo had been restive since the Yugoslav conflict in the mid-1990s, as the Dayton Peace Accords which ended that conflict failed to bring any resolution to the ethnically Albanian Kosovars who sought independence from Serbia. The early stages of the war were largely domestic, as the secessionist movement (the Kosovo Liberation Army) adopted guerrilla tactics. By mid1998, the increase in Serb violence against Kosovars, creating over 230,000 refugees, brought the issue back to international prominence. In response, the UN Security Council, including Russia, adopted Resolution 1199, “...condemning all acts of violence by any party, as well as terrorism in pursuit of political goals," and called for negotiations between all sides to end the conflict. ${ }^{123}$ Despite this, fighting continued, and NATO began to advocate intervention. While NATO members mostly favored military action to prevent further ethnic cleansing by Serbian troops, the Yeltsin administration was adamantly opposed to any intervention which violated Serb sovereignty. ${ }^{124}$

Though Yugoslavia and Russia had been at odds politically during the Cold War, they share strong historical and cultural ties. Both countries are ethnically Slavic, and both belong to branches of the Eastern Orthodox church. These ties, as well as Russia's traditional animus towards secessionist groups, made the Kosovo crisis a major concern for the Yeltsin administration, which feared similar international interest in the conflict in Chechnya. Russia did agree to the placement of UN monitors in Kosovo, but was adamantly opposed to NATO intervention. Many scholars argue that the expansion of NATO to include members of the former Warsaw Pact had Russia spooked about NATO aggression, ${ }^{125}$ leading Russia to support Milosevic out of fear, without considering

\footnotetext{
${ }^{123}$ United Nations Security Council Resolution 1199 (September 23, 1998).

${ }^{124}$ Caplan (1998).

${ }^{125}$ Averre (1999): 576.
} 
alternatives. ${ }^{126}$

\subsubsection{Negotiations and NATO Bombing}

As negotiations between NATO and the Serbian government failed, NATO allies agreed to begin bombing on March 23, 1999. A last minute phone call on the issue between Clinton and Yeltsin resulted in the Russian President yelling that any use of NATO force in the former Yugoslavia was 'forbidden,' before hanging up on Clinton. ${ }^{127}$ Nonetheless, bombing began as scheduled on March 24. In response, Yevgeny Primakov, the Russian Prime Minister, turned his plane around above Newfoundland, refusing to continue to Washington for talks. In a followup statement, Yeltsin stated that "Russia retains the right to take adequate measures, including military ones, to defend itself and the overall security of Europe," leaving unclear exactly how far Russia would go to protect Serbia. Russian forces were placed on high alert, beginning a two-month period during which Moscow pursued "a verbal confrontation with the West that teetered on the brink of a real confrontation." 128

Negotiations between Russia, Serbia and NATO members were carried out in an extremely haphazard fashion. Negotiations were initially managed by Primakov, but his personal disagreements with Boris Yeltsin meant that his opinions were often disregarded in policymaking. On April 14, Yeltsin instead appointed Viktor Chernomyrdin as Special Envoy for the Balkans, ostensibly to provide a unified front for negotiation. However, as Norris notes, this appointment also "highlighted the depth of the estrangement between Yeltsin and Primakov." ${ }^{129}$ Indeed, Chernomyrdin had been Yeltsin's first choice for Prime Minister, but was blocked by the Duma. Domestic political disputes thus played a major role in undermining negotiations, as the Russian government's official position was anything but clear. As Averre notes, "As the Kosovo crisis came to a head, the Yeltsin government... struggled to correct the weakness and inconsistency of its foreign policymaking." 130

\footnotetext{
${ }^{126}$ Levitin (2000): 137.

${ }^{127}$ Norris (2005): 3-4.

${ }^{128}$ Levitin (2000): 137.

${ }^{129}$ Norris (2005): 43.

${ }^{130}$ Averre (1999): 577.
} 
Throughout April, Russian policy vacillated between hard and soft line responses to the crisis. Late March negotiations between Russian and Serbian diplomats (including Primakov, Defense Minister Sergeyev, and Head of the SVR Vyacheslav Trubnikov) failed to secure results. On April 7, the Duma adopted a resolution asking Yeltsin to send weapons to Serbia, but the President refused to do so, fearing that weapons would be the first step towards Russia's entry into the war. Instead, Chernomydrin's appointment began a campaign of 'shuttle diplomacy,' as he traveled between Washington, Moscow, Belgrade and Brussels, trying to negotiate a ceasefire. His appointment did little to fix the problem, as military and security service representatives often sought to undermine his authority. The Ministry of Foreign Affairs was cut out by his appointment, so much so that another US negotiator reported that Minister for Foreign Affairs Ivanov would ask them for accounts of their meetings with Chernomyrdin. ${ }^{131}$ It was often unclear who had the authority to negotiate for Russia, a major concern for NATO negotiators, who relied on Russian diplomats as their only direct access to the Serbian government.

Mixed messages continued to emanate from Moscow throughout April, made worse by Yeltsin's inveterate drinking problem. For example, on April 11, as Foreign Minister Ivanov reassured US negotiators that Russia had no intention of fighting, Yeltsin made a series of drunken comments at a Kremlin ceremony hinting that Russian missiles had been retargeted at NATO countries. ${ }^{132}$ As negotiations continued into May, Chernomyrdin was joined by Leonid Ivashov, a hardline member of the military. According to US Deputy Secretary of State Strobe Talbott, Ivashov would negotiate alongside Chernomyrdin, yet following these meetings would immediately make public statements attempting to frustrate the diplomatic efforts. ${ }^{133}$ By late May, the deep fractures within the Russian government were obvious to all: Yeltsin dismissed Prime Minister Primakov, and only narrowly avoided his own impeachment by the Duma.

Russia's foreign policy was extremely inconsistent during this period, a fact exacerbated by the lack of effective coordination between relevant ministries. Norris, involved in the negotiations for

\footnotetext{
${ }^{131}$ Norris (2005): 308.

132 Sunday Times (April 11, 1999): "Enter the Bear."

${ }^{133}$ Talbott (2003): 348.
} 
the US, provides several telling anecdotes from his colleagues. As one US negotiator recalled,

"At the end of the second day [of negotiations], we got up and everybody shakes hands and we are about to walk out, and the Russian Foreign Ministry guys starting introducing themselves to their counterparts from the Russian Department of International Cooperation at the Defense Ministry. As screwed up as our own interagency process can be, at least we have one." 134

Another reported that:

"It was like playing chess with someone who doesn't know the rules... they didn't have a bureaucracy capable of effectively going through the motions." 135

Different Russian positions would often be advocated to NATO in different meetings, depending on the institutional affiliation of the Russian representative.

On June 4 a deal was reached, as Chernomyrdin effectively accepted NATO's terms, and convinced the Serbs to do the same. NATO began logistical preparations to send peacekeeping troops, with the major issue still under discussion being how Russian troops would participate. Public opinion at this time was largely in line with government policy. The public was strongly opposed to the NATO bombing, as were extra-governmental elites, who pushed strongly for a solution. ${ }^{136}$ However, citizens were also highly opposed to military intervention in Kosovo, and were extremely supportive of the Chernomyrdin deal (and diplomatic solutions in general). ${ }^{137}$ Elite opinion, however, was far more mixed. On June 5, Deputy Foreign Minister Avdeyev made a public statement disassociating the Foreign Ministry from the agreement. At the same time, the Russian Military Attache in Belgrade, Barmantseyev, began to openly encourage the Serbian government to reject the NATO treaty, agreed with Chernomyrdin only hours before! ${ }^{138}$

This pattern of institutional disobedience and disorganization undoubtedly worsened the crisis. While President Yeltsin was ultimately responsible for policy, two major flaws in the Russian foreign policy system helped to undermine the negotiation process. Firstly, foreign policy was

\footnotetext{
${ }^{134}$ Reported in Norris (2005): 101.

${ }^{135}$ Norris (2005): 308.

${ }^{136}$ Averre (1999): 579.

${ }^{137}$ Hedley (2008): 402.

${ }^{138}$ Norris (2005): 202-211.
} 
personality-driven: Yeltsin was prone to ignore officials he personally disliked (i.e., Primakov). This created confusion over which individuals were responsible for advising him on key decisions, which were "rarely based on complex analysis, and very often based on improvisation and irrational impulse." 139 Secondly, the Kremlin was unable to control state institutions, and vicious interagency conflict negatively impacted the ability of all involved to negotiate an end to ongoing airstrikes in Kosovo. US officials noted that:

“Russian military and diplomatic representatives... worked on largely separate tracks... exacerbating the confusion." 140

Levitin, First Secretary at the Russian Embassy, Belgrade, from 1996-1998, argues that Russian could have easily negotiated a peaceful end to the Serbian conflict if not for the disfunction of the government. ${ }^{141}$

\subsubsection{Operation Trojan Horse}

While the negotiation period corresponds to our theory, in particular, the presence of extreme institutional disfunction, it did not immediately result in aggression. Indeed, Yeltsin initially resisted hardliners in the Defense Ministry and sought a peaceful end to the conflict. However, the period following the successful negotiations saw a key case of Russian military aggression, and one of the most bizarre incidents in post-Soviet history: Operation Trojan Horse. In addition to further institutional disfunction, this incident highlights the bias towards military solutions which we would expect to see in a oil-rich state. The use of force in this case was the brainchild of members of the military's General Staff, who disagreed with the treaty negotiated by Chernomyrdin and Ivanov, and "sought to seize the initiative by creating a fait accompli" in Kosovo. ${ }^{142}$

Operation Trojan Horse originated as an alternate strategy planning operation. Chernomyrdin's negotiators, having agreed to NATO presence in Kosovo, were now negotiating the Russian role

\footnotetext{
${ }^{139}$ Levitin(2000): 130 .

${ }^{140}$ Norris (2005): 134 .

${ }^{141}$ Levitin (2000).

${ }^{142}$ Hedley (2008): 410.
} 
in peacekeeping, a key demand of the Kremlin. As negotiations continued, the Kremlin tasked military commanders and the intelligence community to come up with a covert strategy with the potential to improve their negotiating position. Key personnel involved included Chief of the General Staff Anatoly Kvashnin and Vyacheslav Trubnikov, Head of the SVR. Both men were hardliners, unhappy with NATO presence in Serbia. They proposed to Yeltsin an operation in which a brigade of Russian peacekeepers in Bosnia would cross Serbia by night and seize the airfield at Slatina, outside Pristina. This would allow Russia to bring in paratroopers in preparation for a broader deployment, and make it difficult for NATO to retake the airport. Although intended as nothing more than a backup plan, military leaders were able to persuade the pliable Yeltsin to initiate it.

On June 12, the plan was put into action, and a period of extreme confusion followed. Although Yeltsin had in fact approved the operation, this was unclear until some days later, with Western analysts and news sources attributing the midnight rush to Pristina airport to hardline military generals. ${ }^{143}$ Yeltsin's decision to send Russian troops to Kosovo was made at the behest of the General Staff - the order was formally given by Kvashin - without the involvement of civilian authorities in the Ministries of Defense or Foreign Policy. ${ }^{144}$ Neither Sergeyev nor Ivanov were aware of the troop deployment, and first learned of it from US negotiators. Ivanov, with no guidance from Moscow, asked the US State Department to help him to contact CNN, where he made a statement calling the occupation of the airport 'unfortunate,' and ordered the soldiers to withdraw immediately. This order was countermanded just two hours later by Yeltsin. ${ }^{145}$ While it is not uncommon for diplomats to become somewhat irrelevant after military action is initiated, it is extremely unusual for a government not to consult its own Ministry of Defense! The unclear institutional structure and extreme personalization of the foreign policy decision-making process allowed Yeltsin to make decisions in an arbitrary way, cutting entire agencies out of the process.

Operation Trojan Horse also highlights the rift between the civilian ministries and the military,

\footnotetext{
${ }^{143}$ Kommersant (July 6, 1999), "Secret Airport in Pristina."

${ }^{144}$ Headley (2008).

${ }^{145}$ Washington Post, (June 13, 1999), "NATO Occupies Tense Kosovo Capital."
} 
who were "testing the limits of civilian control and exploiting the shaky condition of their own President." 146 It also highlights the major problems with information flow in foreign policy. In making the decision to take the airfield, "remarkably little consideration was given to its broad foreign policy implications." ${ }^{147}$ In his insider's description of the crisis, Oleg Levitin highlighted the fact that:

"the highest level leadership... is protected as far as possible from the unpleasant reality, which is brought to its attention very carefully and in tiny helpings." 148

This is especially true in the case of Operation Trojan Horse, where Yeltsin was not told any details of the operation, and may even have been drunk or ill when he approved it. ${ }^{149}$ Although the President was the ultimate arbiter of foreign policy, information flow was controlled by the same bickering ministries, allowing different groups to advance their agendas with little thought for long term consequences.

Although Yeltsin claimed ownership of the Pristina airport operation, legitimizing it, the situation continued to slip out of his grasp. Various countries, including Hungary, Romania and Ukraine, denied the Russians overflight rights, meaning that the troops at the airport could not be reinforced by paratroopers as originally planned. ${ }^{150}$ This turn of events would have been obvious to Foreign Ministry officials, but not to former Soviet military commanders, who barely acknowledged these countries as independent entities. In addition, the Russian troops at Pristina lacked proper supply lines, and were soon reduced to begging the surrounding NATO troops for food and water. Eventually, on June 15, the Russians caved, and agreed to allow NATO troops to access the airport. They also agreed that there would be no Russian sector within Kosovo, although Russian troops would not technically be under NATO command. The largely peaceful deployment of NATO and Russian troops within Kosovo followed; the crisis was over.

The institutional confusion and weakness seen during negotiations was extremely noticeable

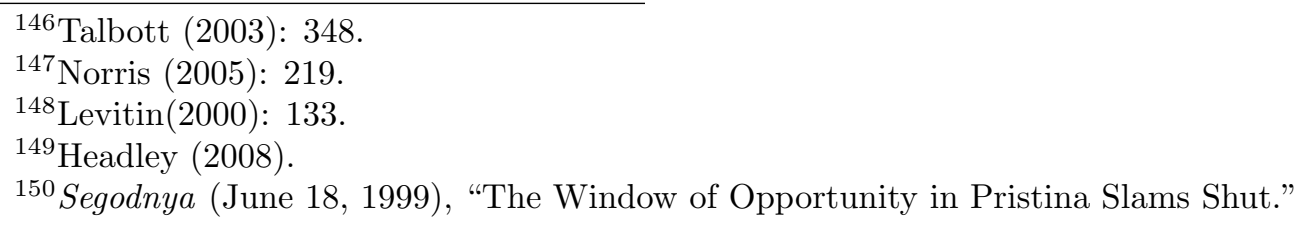


during the abortive military seizure of the Pristina airport. Since these plans were not viewed by the Defense or Foreign Ministries, no one was able to point out that deployment of paratroopers across half of Europe was wildly unrealistic. Competing statements by the Foreign Ministry, the President's office and the General Staff also left NATO unsure about who to negotiate with, creating a dangerous situation. In fact, it is likely that direct conflict between NATO and the Russian troops at the airport was prevented only by common sense on the part of NATO General Jackson, who refused orders to retake the airport by force. ${ }^{151}$ A senior White House official argued that "it's not a question, when Ivanov makes a statement, of doubting that individual, but seeing so many actors and the lack of coordination between those actors make people here wonder whether we can count on them." ${ }^{152}$ The operation was a profound failure for Russia, in large part due to the inefficiencies of Russian foreign policy institutions and the lack of information for decision makers.

\subsubsection{Russia in Kosovo: Theory of Oil and Aggression}

Russian involvement in Kosovo does conform to many of our theoretical expectations. The narrative above shows a personality-driven policymaking process riddled with inefficiency and infighting between state institutions, as predicted by the theory. While this weakness originally resulted from the Soviet collapse, it is clear that by 1999, the Russian foreign policy system was badly distorted. Information was unavailable to key decision makers, and entire ministries were often cut out of the process entirely. This infighting over foreign affairs, and the inability of any central authority to control the various agencies of the Russian state led to what one analyst describes as "the marked incoherence in foreign policy characteristic of the period." 153 We also see a strong reliance on military force among policymakers. After Chernomyrdin's early negotiations, the Kremlin sent in additional negotiators from the military and security services, such as Ivashov, many of whom were far more in favor of military action against NATO than their counterparts in the diplomatic service. Operation Trojan Horse highlights the tension between military and

\footnotetext{
${ }^{151}$ New York Times (September 10, 1999), "U.S. General Was Overruled in Kosovo."

152 Washington Post (June 13, 1999).

${ }^{153}$ MacFarlane (2006): 47.
} 
civilian authority, as negotiators attempted to order the Russian troops to leave, while members of the Military General Staff, backed by Yeltsin, ordered them to remain. Institutional weakness, combined with the Kremlin's military focus, undoubtedly contributed to the decision to enter conflict in this case. In line with our theory, public opinion does not appear to have played a major role in the crisis, although evidence suggests that the Russian public was in fact not particularly aware of the issues involved in the Kosovo intervention, and, other than an outpouring of rage generally directed at NATO, was largely uninvolved in the foreign policymaking process here. ${ }^{154}$ Thus, the Kosovo conflict does correspond to several of our theoretical expectations, particularly institutional weakness and poor information flow.

\subsubsection{The Second Chechen War (1999-2001)}

Sporadic conflict between Russia and rebel groups in Chechnya goes back more than two centuries, since the predominantly muslim Caucasus region was conquered by the Russian Empire in 1785, although much of this period was dominated by an uneasy peace. The region declared independence after the 1917 revolution, only to be reconquered in 1921 by the Soviet Union. During World War II, Stalin accused the Chechens of collaborating with Nazi forces, and had the population forcibly removed to camps in Central Asia, only permitted to return to the Caucasus in 1957. At the fall of the USSR, the Chechens again seceded, and de facto independence persisted for about two years. However, by 1994, ethnic cleansing of other groups by Chechens caused the Yeltsin government to intervene in an attempt to reassert control. The first Chechen War (1994-6) ended in a loss for Russian troops; badly prepared and poorly equipped, they were unable to fully exert control over the region. The high death toll among soldiers created widespread public discontent in Russia, and led to the signing of the Khasav-Yurt Accord in 1996, which left Chechnya a de facto autonomous state.

Aslan Mashkadov, the general credited with the Chechen victory in the first war, was elected President in 1997, and immediately signed a peace treaty with the Kremlin. However, large sections

\footnotetext{
${ }^{154}$ Zimmerman (2009) does note that public awareness of NATO and related foreign policy issues did rise sharply after this period, likely due to the Kosovo crisis.
} 
of Chechnya had been destroyed, leading to economic stagnation and high unemployment, while many of those displaced by the war were not able to return home. In addition, Mashkadov's government faced ongoing challenges from organized crime, and the growth of Wahhabist militia groups, such as that of Shamil Basayev. The Islamists were a major problem; even the 1999 imposition of Sharia law by the government did little to appease their demands for an Islamic Chechen Republic. ${ }^{155}$ Mashkadov's government was weak, and the region remained lawless. Although nominally a civil war, the large numbers of foreign fighters and Chechnya's status as a de facto independent state at the start of the war makes this case suitable for inclusion in this study of foreign and military policy.

\subsubsection{Ground War in Chechnya}

In August 1999, the Chechen conflict turned hot again. Rebel militias, particularly those led by Basayev and Ibn al-Hattab, launched a series of raids into the neighboring region of Dagestan, aiming to provide support to rebels in Dagestan and destabilize Russian control in that area. Foreign fighters and money poured into both Chechnya and Dagestan from foreign supporters of the islamists, including as much as $\$ 30$ million from Osama Bin Laden, who was himself reported to be considering a move to the region. ${ }^{156}$ The Russian government immediately ordered both the Ministry of Internal Affairs (MVD) and the Federal Security Service (FSB) to stop the invasion, a goal accomplished with great difficulty by mid-September. At the same time, a series of bombings in Russia took place, targeting apartment buildings and a shopping center. These attacks killed around 300 people, and injured over 2000, and were blamed on 'Chechen terrorists.' ${ }^{157}$ Although only limited evidence was ever found to link Chechen separatists to these incidents, ${ }^{158}$ this created a groundswell of support for Russian intervention in Chechnya, and airstrikes began in September.

On 1 October 1999, Prime Minister Putin announced that Mashkadov and his parliament constituted an illegitimate government, and that Russian troops would be sent into Chechnya to reassert

\footnotetext{
${ }^{155}$ Kramer (2004-5): 7.

${ }^{156}$ Comins-Richmond (2007), available from http://faculty.oxy.edu/richmond/csp8/second_chechen_war.htm. ${ }^{157}$ Kramer (2004-5).

${ }^{158}$ Mendelson (2002): 50.
} 
control using "all available means." 159 The war called for in the plan was less a counterterrorism campaign and more a large-scale projection of state power by the Russian military. ${ }^{160}$ The invasion was carried out using plans which had been drawn up earlier that year by committee headed by former Prime Minister Stepashin, ${ }^{161}$ although the invasion itself was much more aggressive in its prosecution than his original plan, which called only for the occupation of several smaller northern towns. Scholars have noted that the Russian government effectively 'slid into' the Chechen campaign, as the Dagestani offensive and 1999 terrorist acts encouraged the Putin government to make a stronger show of force. This was a strategically unwise decision, as Stepashin argued, noting that:

"I have had some experience in taking Grozny, so I knew the resistance would be fierce."

As he describes, his original plans were designed to prevent a long-running guerrilla war in Chechnya. ${ }^{162}$

A large-scale military offensive here was to some extent a strange decision, particularly since only three months had passed since Russia's disastrous and inept military foray into Kosovo. As several authors note, an independent Chechnya might actually have been in Russia's interests, but the impulse was ignored by policymakers in favor of military expediency. ${ }^{163}$ The Chechen situation could likely have been resolved by negotiations, or at least, the military action could potentially have been confined to Dagestan. Negotiation with Mashkadov's government might also have yielded positive results, and an increase in Russian funding and economic development in the region would have reduced the appeal of radicalism to the Chechen population. After the fall of Grozny, in early 2000, Russia again had the opportunity to seek a negotiated settlement to the conflict, but this idea was rejected, with Putin promising instead to "wipe out the terrorists and bandits." ${ }^{164}$ Negotiated, non-military settlement was rejected by Russian policymakers at every step of the war.

\footnotetext{
${ }^{159}$ Rossisskaya Gazeta (1 October 1999).

${ }^{160}$ Hill (2000): 13.

${ }^{161} \mathrm{Baev}(2004): 2$.

${ }^{162}$ New York Times (February 1, 2000), "A Look at How the Kremlin Slid Into the Chechen War."

${ }^{163}$ Hughes (2007): 206-7.

${ }^{164}$ Kramer (2004-5): 8.
} 
In the case of Chechnya, the decision-making process was far less transparent than even a few months earlier, a phenomenon that can be attributed to the Kremlin's sudden clampdown on media access to the corridors of power. The key personnel involved in the decision to enter conflict were Yeltsin, Putin, Stepashin, and key members of the security services. This period saw an increasing reliance on former security service personnel as key governmental advisors, and the decision to go to war appears to have been shaped more by a general concurrence on the part of the security services and military that Chechnya was a potential threat, ${ }^{165}$ than on any consensus between leaders. Other institutions, in particular, the Security Council and Foreign Ministry, were largely uninvolved in the process. As Baev notes, "this malfunctioning decisionmaking mechanism raises serious questions about its integrity, the chain of command, and the flow of information." 166 Putin and Yeltsin tried on several occasions to hand control of the conflict to the FSB, and when that failed, simply reorganized the cabinet to remove critics from key positions, replacing them with supporters. ${ }^{167}$

The decision to enter conflict was extremely personalized, and was largely based on Putin's strong opposition to Chechnya as an independent state, ${ }^{168}$ and to a desire by Yeltsin and others to bring an end to the insurgency. As noted by one expert in a US Senate hearing, "the frequent replacement of Prime Ministers [by Yeltsin] this past year... has possibly been the result of a conscious or subconscious search for someone capable of deciding for war." 169 The conflict can therefore to a large extent be attributed not to any change in institutional makeup or power distribution within the Russian government, but by the elevation of Vladimir Putin to Prime Minister, and his willingness to begin the conflict. ${ }^{170}$

${ }^{170}$ There are also a number of scholars who argue that the war was in fact geared primarily towards the election of Putin to the presidency, and to improving his popularity. While there is no hard evidence of this, it cannot be denied that the war permitted Putin to take control of the Russian government far more effectively, and with greater popularity, than if he had not been associated with the 'triumph' of Russian
} 
The Russian invasion of Chechnya began slowly: Russia had clearly learned some lessons from the First Chechen War, and both airstrikes and artillery were used to devastating effect before Russian ground troops attacked. ${ }^{171}$ As early as October 5, Russian ground troops crossed the Terek river, and approached Grozny, but remained in these positions during roughly three months of airstrikes. In mid-October, Mashkadov offered to negotiate a ceasefire with Russian forces and to crackdown on the warlords, but his overtures were rebuffed by the Kremlin. Airstrikes and artillery leveled the city, and the siege of Grozny began in December 1999. Russian forces finally seized the city on February 2, 2000, and by mid-2000, the Russian army controlled most major towns and villages in Chechnya. The delay in seizing the city was in part caused by caution and a desire to avoid casualties, and in part by the unclear chain of command. As Kramer notes, during the war, the "delineation of responsibilities and functions among several key Russian officials... [was] murky at best." He points out that although the MVD's regional operations staff was supposed to be in command, other key individuals such as the OGV commander, the army commander for the North Caucasus, and the FSB director for the region were all extremely influential. ${ }^{172}$ Since these officials did not share a common command chain or organizational infrastructure, much of the delay in taking Grozny was due to personal disagreement between these individuals.

As in Kosovo, the invasion was hampered by persistent conflict between institutions within the foreign policymaking process. There was no clear mandate for troops in Chechnya, as "what in August 1999 was presented as an operation to deter Chechen aggression against Dagestan; had in October become an effort to seal rebellious Chechnya off along the river Terek; in November a campaign to eliminate the terrorists, and finally in January 2000 a military operation in defense of Russian territorial integrity." 173 A long-running dispute between the Defense Ministry and its own senior generals was played out largely in the press, with each side making different comments on the Chechen situation, and seeking to control both the war and the process of military restructuring in general. In mid-2000, the head of the Security Council, Sergei Ivanov had to step in to act as an troops in Chechnya.

${ }^{171}$ Comins-Richmond (2007), available from http://faculty.oxy.edu/richmond/csp8/second_chechen_war.htm.

${ }^{172}$ Kramer (2004-5): 13 .

${ }^{173}$ Jonson (2001): 3 . 
arbiter between the military and civilian agency, ${ }^{174}$ but even this did not calm the situation, and in August 2000, President Putin sacked six generals on the staff of the Ministry of Defense, siding with the military and security services. ${ }^{175}$ Given these disputes, it is unsurprising that analysts view disfunction within the decision-making process as a major problem for Russia. As one author points out, "Russia would undoubtedly have fared better in Chechnya were it not for the corruption, cronyism, indifference and administrative incompetence that pervade the Russian army, security forces and political system." 176

In addition, decision-making was hampered by a lack of information, though nowhere near as badly as during the Kosovo crisis. Rival government agencies did not trade information, leaving troops vulnerable to attack. In addition, the central government often was not receiving better information than the general public from media sources. As Baev notes, throughout the conflict, we see "the near paralysis of the executive vertical in crisis situations, when Putin is unable to act due to an acute lack of reliable information." He argues that by 2004, Putin had "discovered that there was nobody around him whose opinion on Chechnya he could trust," seriously hampering efficient and informed decision-making. ${ }^{177}$

In May 2000, a provisional government was put in place, led by Akhmad Kadyrov, and the Putin administration restored Russian federal rule to the Chechen cities. Moscow implemented a policy known as Chechenization, where local leaders friendly to Moscow were elected (whether freely or not) to lead the region and continue the fight against extremists. ${ }^{178}$ Russian troops continued to fight Chechen rebels in the mountains. This was ineffectual; in many cases, Russian forces were "so busy just trying to ensure their own security [that they]...almost never can counter the resurgent guerrillas." 179 In March 2000, a series of ambushes claimed the lives of a number of Russian troops. While this case primarily focuses on the brief period of intense fighting, the

\footnotetext{
${ }^{174}$ Nezavismaya Gazeta (December 1, 2000), "Russian Security Council Secretary Interviewed."

${ }^{175}$ Moscow Times (August 1, 2000), "Putin Sacks 6 of Sergeyev's Generals," archived in Johnson's Russia list; available from http://www.russialist.org/4433.html.

${ }^{176}$ Kramer (2004-5): 63.

${ }^{177}$ Baev (2004): 2-4.

${ }^{178}$ Hughes (2005): 118 .

${ }^{179}$ Kramer (2004-5): 9
} 
conflict has not technically ended, and guerrilla attacks, bombings and assassinations have plagued Russian forces in the region throughout the last decade. The 2003 election of Ramzan Kadyrov (and the transfer of responsibility for security in the region from the MVD to the FSB) has brought an element of stability to the cities, but attacks by rebels in the countryside are still common.

Public opinion played more of a role in this crisis. The Moscow apartment bombings led to a dramatic shift in public opinion, with $62.5 \%$ of the Russian population favoring military intervention in Chechnya in late 1999, compared to only $3.2 \%$ in $1995 .{ }^{180}$ While strong public support does not allow us to test whether oil lessened government constraints in this case, it is illustrative that elites began planning a Chechen campaign long before public opinion supported such action. Public opinion later in the conflict began to turn against the war, but most of those who opposed the war were less concerned with human rights, and more concerned about loss of life among Russian soldiers. ${ }^{181}$ In fact, while groups such as the Committee of Soldiers Mothers expressed strong opposition to the war, as late as 2010, 59\% of Russians surveyed approved of Russian intervention in Chechnya. ${ }^{182}$

The Russian government also attempted to manipulate public opinion in favor of the war by controlling media access, and limiting reports about the war to victories. ${ }^{183}$ The government also sought to use media to demonize Chechens as "terrorists and bandits." ${ }^{84}$ In one analysis, the correlation of public opinion data with tv station availability shows that those respondents which had access to independent (non-government owned) media were significantly less likely to support the war in Chechnya than those with access only to government-owned tv stations. ${ }^{185}$ The Russian government, therefore, also took concrete steps towards ensuring favorable public opinion in the Chechen conflict.

Although beginning shortly after the Kosovo crisis, the Chechen conflict does not display the extraordinary level of disfunction exhibited by the Russian government in that case. Nonetheless,

\footnotetext{
${ }^{180}$ Pain (2005): 69.

${ }^{181}$ Mendelson and Gerber (2002): 290.

${ }^{182}$ Levada (2013)

${ }^{183}$ Baev (2004).

${ }^{184}$ Lapidus (2002).

${ }^{185}$ Petrova (2008): 25-6.
} 
while government officials were keen to point out that Russian troops acquitted themselves better in this conflict, this is a purely relative triumph. Military units involved consisted of MVD troops, OMON special police units, FSB Spetnaz, air force paratroopers, SVR reconnaissance units, GRU military intelligence units, and many others. While it is not uncommon for multiple military branches to be involved in an operation of this size in any country, there was no clear chain of command, leading to a "vast amount of duplication and waste," with one anonymous high-ranking officer reporting that:

"our forces in Chechnya have not been able to coordinate their actions during times of stress. The system is in utter disarray." 186

Another author notes that:

"these ministries and organizations had little experience working together, and their efforts to do so were often ineffectual." 187

The slow progress of the war and inability to end the insurgency can be attributed to these organizational shortcomings. By 2003, interagency disputes had become so difficult that the Ministry of Defense and the Ministry of the Interior had effectively partitioned Chechnya into zones rather than attempt to work together. ${ }^{188}$

The Second Chechen War was far bloodier than the first, leading US Secretary of State Madeleine Albright to call the Russian campaign

"An incredible act of misery." 189

There are no concrete figures, but unofficial estimates show roughly 15,000-20,000 Russian soldiers have been killed, and as many as 25,000-100,000 civilians. ${ }^{190}$ This does not include the several hundred Russian civilians killed in high-profile terrorist acts such as the Moscow Theatre crisis

\footnotetext{
${ }^{186}$ Kramer (2004-5): 14-15.

${ }^{187}$ Oliker (2001): 14 .

${ }^{188}$ Kramer (2004-5).

${ }^{189}$ Associated Press (January 31, 2000), archived in Johnson's Russia list; available from http://www.russialist.org/4082.html.

${ }^{190}$ Memorial Human Rights Center (2004), available from http://www.memo.ru/eng/memhrc/texts/5palest.shtml.
} 
(2002), Beslan School siege (2004), and the Moscow Metro bombing (2004). In short, the Second

Chechen War was extremely bloody for both Russia and Chechnya. While the region is finally back under Russian control, the ongoing guerrilla campaign undermines Russian authority, and continues to be costly for the Kremlin.

\subsubsection{Oil and Conflict in Chechnya}

The Second Chechen War, beginning only three months after the end of the Kosovo crisis, does demonstrate a somewhat less dysfunctional system than the one illustrated in Section 4.3.1. It is not clear, however, that institutions were in fact any stronger during this conflict, but merely that the Kremlin had better learned to control media access to the decision-making process. This case does support several of our theory's central expectations for policymaking in an oil-rich state, in particular personalization of the policymaking process and weak institutions. Policymakers were also confronted by a lack of information as they initiated and sought to manage the conflict. Thus, institutional weakness, as well as the Russian government's unwillingness to consider nonmilitary options contributed to both the initiation and poor implementation of the long and bloody campaign in Chechnya. As Baev notes, "it is exactly there [Chechnya] that deficiencies such as... the straightforward rejection of alternative options, the deficit of expert assessments and the propensity [of the system] to break down in crisis situations are particularly obvious." 191 It is unclear whether government constraints played a major role in this crisis, as public opinion was broadly supportive of the conflict, and the government engaged in opinion modification tactics. The Second Chechen War thus serves to highlight several of the ways in which the negative effects of oil production (weak institutions, poor information flow, and a focus on military solutions) can serve to undermine effective foreign policy and encourage aggression.

\footnotetext{
${ }^{191}$ Baev (2004): 2.
} 


\subsubsection{The War in Georgia (2008)}

The 2008 War in Georgia, also known as the Five Day War, was fought over the breakaway territories of Abkhazia and South Ossetia. As with most post-Soviet conflicts, border demarcation and ethnic tensions were the central concerns. The regions - peopled by ethnic Russians - had nominally been part of the Georgian SSR, but self-governing under Soviet rule, and didn't want to remain within Georgia, leading to the 1992-3 War in Abkhazia. During the war, there was mass ethnic cleansing of Georgians, as well as war crimes by both sides. Although nominally neutral in the conflict, Russian troops provided strategic and materiel support to the Abkhaz secessionists. The end of the conflict in 1993 left Abkhazia (and by extension, Adjara and S. Ossetia) as de facto self-governing states with Russian peacekeepers on the ground, an outcome fairly typical of post Soviet 'frozen conflicts.'

In 2003, the Rose Revolution in Georgia brought to power an anti-Moscow government, which succeeded in reinforcing military control over Adjara, and sent troops into the other two regions to retake control. These incursions failed, and undermined Russian-Georgian relations. In 2008, tensions again began to mount, and in April, President Putin instructed Russian government agencies to create closer ties with the de facto regional governments, as well as to provide citizens with consular assistance. This 'passportization' policy - giving ethnic Russians in S. Ossetia and Abkhazia Russian citizenship and passports - was a clear violation of international law. ${ }^{192}$ Shortly thereafter, a Russian MiG shot down a Georgian UAV over Abkhazia; in response, Georgia began to build up troops on Abkhazia's borders.

From May to July, a series of bomb blasts took place in Abkhazia and S. Ossetia, most near Georgian administered villages, along with brief exchanges of fire and light shelling around Tshkinvali. A series of military exercises also increased tensions: US-led "Immediate Response" exercises near Tblisi were followed quickly by large-scale Russian exercises known as "Kavkaz 2008," leading observers to note that both sides were preparing troop deployments for a full-scale conflict. ${ }^{193}$ One

\footnotetext{
${ }^{192}$ Independent International Fact-Finding Mission on the Conflict in Georgia (IIFFMCG - CEIIG) Report, Volume I (2009), available from http://www.ceiig.ch/Report.html.

${ }^{193}$ Popjanevski (2009).
} 
Kremlin insider, Gleb Pavlovsky, described the atmosphere as "a possible pre-war state of affairs in Russian-Georgian relations." 194 Interestingly, while many authors concur that conflict was expected by late summer, both sides expected it to occur in Abkhazia, not in South Ossetia where the conflict began. ${ }^{195}$

\subsubsection{From Roki to Tshkinvali}

Ultimately, it is not know which side actually initiated the 2008 War in Georgia conflict, and two competing narratives continue to be presented: either Russia retaliated against Georgian aggression to protect ethnic Russian citizens, or Russia was the aggressor, seeking to regain the breakaway territories. ${ }^{196}$ Given the buildup, war was effectively inevitable. Although there is no clear indication of which side fired the first shot on the evening of August 7th, Russia escalated the conflict quickly and decisively. On the morning of August 8th, Georgian ground troops launched a heavy artillery attack on Tshkinvali, occupying the city. Russian tanks and troops were seen at this time to be moving through the Roki tunnel (connecting South and North Ossetia). By mid-afternoon, Russian jets had attacked key targets in Georgia, and ground forces had launched a counterattack, retaking Tshkinvali by that evening. ${ }^{197}$ On August 8th, Russian forces also launched a cyberattack, relying largely on private citizens using off-the-shelf programs to initiate Denial of Service (DDoS) attacks against Georgian government and media websites. These attacks were wildly successful, effectively wiping out the Georgian government's ability to communicate with media sources, and allowing the Russian narrative of self-defense to dominate early news coverage. ${ }^{198}$

In line with this, the Georgia War is yet another example of the Russian government both pursuing a policy which was popular at home, and using the media and other tools to encourage this support. The intervention in Georgia was wildly popular with the Russian population, with over $80 \%$ of those surveyed in favor of the war. ${ }^{199}$ The Russian government was also successful

\footnotetext{
${ }^{194}$ IIFFMCG - CEIIG Report, Volume II (2009): 30, available from http://www.ceiig.ch/Report.html

${ }^{195}$ Felgenhauer (2009); Allison (2008).

${ }^{196}$ Allison (2008): 1145-6.

${ }^{197}$ Popjanevski (2009).

${ }^{198}$ Shakarian (2011).

${ }^{199} \operatorname{King}$ (2008): 9.
} 
at pushing its narrative of a righteous intervention to the domestic audience, and placed a lot of pressure on the media to carry this message, with the result that most Russians believed that the war was in no way an aggression, but rather a justifiable act of protection. ${ }^{200}$ Russian cyberattacks were geared at suppressing opposing points of view, and ensuring that the Kremlin's narrative was the only one reaching the population. ${ }^{201}$ This is again somewhat difficult to assess in terms of our theory: while popular support for the conflict was widespread, and government constraints cannot therefore be easily assessed, the Kremlin did actively seek to shape public opinion in support of its actions.

On August 9, Russia opened a second front in Abkhazia, shelling the Kodori Gorge (the location of the Georgian-sponsored Abkhaz government-in-exile), and initiating full-scale conflict on both fronts. It should be noted that this corresponded with the arrival of Prime Minister Putin in Vladikavkaz, North Ossetia, from Beijing where he had been attending the Olympics. In contrast to President Medvedev's measured, legalistic statement of the previous day (calling for 'limited conflict'), Russian media showed Putin meeting with military leaders and soldiers, directing military strategy and making strong statements about Georgian aggression. ${ }^{202}$ On August 10, the Georgian Ministry of Foreign Affairs requested a ceasefire, but the Kremlin refused. Georgia declared a unilateral ceasefire, and pulled its troops out of both South Ossetia and Abkhazia. However, airstrikes on Georgian troops and cities continued, and Russian troops began to push forward in their wake. By August 11, Russian forces had taken the Georgian towns of Gori and Poti, and had begun the push towards the Georgian capital, Tblisi. The seizure of Poti was particularly devastating, as it is Georgia's main port and route to the sea. ${ }^{203}$

Assessing the decision-making process in the Georgia War is difficult, in large part because the Putin/Medvedev administration has been very successful at limiting the access of even friendly media to the corridors of power. As Baev describes, "nearly everyday, state-run TV channels show footage of his meetings with key government officials, but apart from carefully scripted video,

${ }^{200}$ King (2008: 11.

${ }^{201}$ Shakarian (2011: 27.

202 Mankoff (2009): 82-3.

${ }^{203}$ Allison (2008). 
very little is known about the day-to-day work of the government. Even less is known about the preparation for strategic decisions." 204 Thus, the nine year gap between the Chechen conflict and the Georgia war saw a major hardening of the decision-making process, and its effective insulation from public scrutiny. The result is that we no longer see as much of the decision-making process as we did under Yeltsin, much of which now happens behind closed doors.

It is still unclear who made the decision to enter the conflict, with the most likely being Putin, senior military commanders, and a small group of advisors with ties to the security services, based in the Prime Minister's office. However, it is also possible the decision was taken by military commanders in the field. One Kremlin insider, Gleb Pavlovsky, even claimed that the decision to advance on Tblisi was part of an internal Kremlin power struggle, as Putin loyalists sought to undermine Medvedev's ties to the West. ${ }^{205}$ Given his public statements, it is extremely unlikely, despite his constitutional and institutional primacy, that the decision was made by President Medvedev. In addition, the decision to enter conflict does appear to have been made with limited information. The conflict, while generally anticipated, appears to have taken the Russian military by surprise. The Russian General Staff did not expect the conflict to begin in South Ossetia, and were surprised by its timing. On August 7, as the crisis began, Prime Minister Putin was in Beijing, the Head of the General Staff, Makarov had been in his post less than two weeks, and the General Staff was itself in the process of moving from one office building to another! ${ }^{206}$

The War in Georgia also clearly illustrates a reliance on military methods to solve problems. During the months leading up to the conflict, the Kremlin made no attempt to pursue a diplomatic solution to rising tensions. Instead of discouraging separatist groups from taking violent actions, or even seeking international mediation, Russia instead chose to bolster its own peacekeeping troops in the region, and prepare strategic plans for war. ${ }^{207}$ In addition, many scholars argue that "Moscow was not only anticipating, but also actively seeking and fomenting a confrontation with Tblisi." 208

\footnotetext{
${ }^{204}$ Baev (2004): 1.

${ }^{205}$ Felgenhauer (2009): 179.

${ }^{206}$ Cohen and Hamilton (2009): 23.

${ }^{207}$ IIFFMCG - CEIIG Report, Volume I (2009), available from http://www.ceiig.ch/Report.html.

${ }^{208}$ Popjanevski (2009): 155.
} 
Allison notes that many in the Russian Ministry of Defense viewed this 'defense' of Ossetian and Abkhaz civilians to be an excellent way to legitimize their military presence in the territory of other former Soviet states. ${ }^{209}$ The Russians also refused to accept a unilateral Georgian ceasefire on August 10, instead continuing their military advance into Georgian territory. While a brief conflict was perhaps unavoidable in this case, the Kremlin pushed strongly for a large-scale war. The UN Commission's Report on the Georgia Conflict concludes that while the Russian military response within South Ossetia to the Georgian attack on Tshkinvali may have been somewhat justified, neither the opening of a second front in Abkhazia, nor the military advance into Georgian territory proper were in any way justifiable. The report also argues that there were many nonmilitary options to resolve this conflict, none of which were pursued by the states involved. ${ }^{210}$

On August 12, President Medvedev, following a meeting with French President Sarkozy, the EU's key negotiator, announced that terms had been agreed for a ceasefire. Despite this, hostilities continued for several weeks, as Russian Defense Minister Lavrov gave orders for the Russian military to destroy "Georgian pockets of resistance," and to "determine just which areas of Georgia must be demilitarized and placed under control." ${ }^{211}$ Georgian National Security Chair Lomaia argued that Russian troops were not withdrawn, but merely redeployed, ${ }^{212}$ occupying buffer zones around South Ossetia and Abkhazia for as much as two months. In addition, during this period, Russia targeted key pieces of Georgian military infrastructure, and stole or destroyed various pieces of technology. On August 28, Medvedev made a speech in which he recognized both South Ossetia and Abkhazia as independent nations, condemning Georgian aggression, and called for other countries to recognize them. ${ }^{213}$ However, since then, fewer than ten states, none of which are major powers, have recognized the two regions as independent, and the UN still considers them to be part of Georgia. $^{214}$

More so than even Kosovo or Chechnya, the War in Georgia saw an extremely personalized

${ }^{209}$ Allison (2008): 1158.

${ }^{210}$ IIFFMCG - CEIIG Report, Volume I (2009), available from http://www.ceiig.ch/Report.html.

${ }^{211}$ Allison (2008): 1158.

${ }^{212}$ BBC News (17 August, 2008), "Russia pledge on Georgia pull-out."

${ }^{213}$ Medvedev Speech 2008.

${ }^{214}$ IIFFMCG - CEIIG Report, Volume II (2009), available from http://www.ceiig.ch/Report.html. 
foreign policy decision-making system, characterized by disagreements between individuals, and an unclear institutional hierarchy. Policy was in particular often characterized by the personal conflict between Putin and Medvedev. For example, when conflict first broke out, Medvedev gave a measured press conference where he described the conflict as limited, and suggested that Russia would be willing to abide by a ceasefire. In contrast, Putin flew from Beijing to Vladikavkaz to direct the military campaign; as the days progressed, Medvedev's position evolved to mirror Putin's, despite his constitutionally superior position. As Mankoff describes, "the war in Georgia offered a clear indication of the limits on Medvedev's authority; the Russian President announced the ceasefire and withdrawal of Russian troops from Georgia proper only to be overruled by the Prime Minister and military command." ${ }^{215}$ This incident occurred on August 10, when Medvedev announced that Russian troops would withdraw, only to change his position hours later after the Chief of the General Staff announced they would not be withdrawing, underlining Medvedev's powerlessness despite his high office. Throughout the crisis, Putin was at the forefront of events, taking decisions, and occupying the media's attention: he was the first to speak to Russia on television about the crisis, and the first to confer with world leaders. ${ }^{216}$

Even world leaders seemed confused about who was in charge, with President Sarkozy of France declaring that the tone varied wildly between Putin and Medvedev. US Defense Secretary Robert Gates told reporters that:

"[Putin] clearly, as far as I'm concerned, has the upper hand right now... [events] bespeak more of Putin having his hand on the steering wheel than anyone else," 217

a view corroborated by many other diplomats. In 2012, a retrospective film ('The Day That Was Lost') featuring comments by Chief of the General Staff Yuri Baluevsky alleged that Medvedev was unwilling to act during the Georgia crisis, and that Putin had to step in to prevent further serious delays in decision-making. Follow ups from journalists revealed a deep divide, with Medvedev claiming he acted swiftly, and didn't speak to Putin. In contrast, Putin and various senior military

${ }^{215}$ Mankoff (2009): 106.

${ }^{216}$ Associated Press (August 15, 2008), "War Shows Putin Still in Charge."

${ }^{217}$ New York Times (August 20, 2008), "West Baffled by 2 Heads for Russian Government." 
commanders claim that Putin had been intimately involved in decisions. ${ }^{218}$ The centralization of the decision-making process around Putin, despite his effective demotion to Prime Minister, implies a system which is deeply personalistic. President Medvedev was not able to enforce his will on Putin or the military, and policymaking was not guided by constitutional processes, but rather by informal power relationships. ${ }^{219}$ Thus, foreign policymaking in this case was almost entirely personality-driven.

The Georgia conflict was the Russia's first large scale conflict since the Second Chechen War, and involved as much as one-third of all Russian ground troops (70,000 men). Although Russia achieved swift victory, most observers agree that this had less to do with a well-orchestrated military campaign, and more to do with the use of strategic pre-planning and overwhelming force. ${ }^{220}$ While Georgia had been prepared for a localized conflict in one region, it was not prepared for full-scale war on both fronts, and could not triumph as a result. Around 170 Georgian soldiers and 71 Russians died in the conflict, with 1198 Georgians and 340 Russians wounded. ${ }^{221}$ These figures do not count the informal Abkhaz and South Ossetian militias, which suffered heavy casualties. It also does not count civilians: although civilian casualties were low, as many as 100,000 refugees were displaced by the conflict. ${ }^{222}$

The Georgia War does not show anything like the levels of institutional weakness and dysfunction exhibited in the Kosovo crisis. The restructuring in 2003 of the military and security services to create a more coherent hierarchy does appear to have reduced operational confusion. Despite this, cooperation between agencies was still limited. While central planning ensured that strikes were timed appropriately, other coordination was nonexistent. Russian commanders in the field, for example, had no control of air support, air strike targets or plans, which were controlled centrally from Moscow by Air Force General Zelin. ${ }^{223}$ The extremely successful cyber attacks were also

\footnotetext{
${ }^{218}$ Eurasia Daily Monitor (August 9, 2012), "Putin Confirms the Invasion of Georgia Was Preplanned," archived in Johnson's Russia list; available from http://www.russialist.org/russia-putin-confirms-invasionof-georgia-preplanned-742.php.

219 Ziegler (2009).

${ }^{220}$ Cohen and Hamilton (2011).

${ }^{221}$ Felgenhauer (2009): 178.

${ }^{222}$ King (2008); IIFFMCG - CEIIG Report, Volume I (2009).

${ }^{223}$ Cohen and Hamilton (2011): 25.
} 
timed to coincide with major offensives, but had no other coordination with the armed forces. ${ }^{224}$ As a result, they were only useful from a public relations stand point, and provided no military advantage.

The quality of the military was poor at best: success in engagements varied widely, Russian forces generally used Soviet tactics, and as much as $80 \%$ of the Russian weaponry used had not been refurbished since $1991 .^{225}$ As Lannon notes, "the conflict also revealed several severe shortcomings in the Russian military in regard to its force structure, command and control, weaponry, manning and air operations," leading several journalists to conclude that "Russian ground forces are uncontrollable and inadequate for conducting local wars like the one in Georgia." 226 These failures were so embarrassing as to result in a major 2009 initiative by the Kremlin to reform the armed forces. In addition, information shortages negatively impacted the war effort. For example, Russian air force targeters did not utilize current information, but rather relied on old Soviet maps to determine which targets were valid. This was despite the fact that Russian diplomats in Tblisi routinely passed military bases and military headquarters on their way to work. ${ }^{227}$ This accounts in large part for many of the negative stories about Russia targeting civilian buildings or areas, as information had not been updated in 15 years or more. In short, although the Russian military was more successful in Georgia than in Chechnya or Kosovo, this was more the result of overwhelming force than institutional capacity. Informational failures and institutional weakness did indeed negatively impact Russian performance in the conflict.

The Georgia war represents something of a victory for Russia in what Medvedev called "a zone of privileged interests." ${ }^{228}$ The Georgia war is also the spiritual ancestor of the current crisis in Ukraine, and many of the hallmarks of this conflict, i.e., passportization, and Russian concern for 'minority rights,' are extremely similar. However, the War in Georgia was also something of a stalemate for Russia. Abkhazia wishes to remain an independent state, but South Ossetians favor

\footnotetext{
${ }^{224}$ Shakarian (2011).

${ }^{225}$ Cohen and Hamilton (2011): 33.

${ }^{226}$ Lannon (2009): 35.

${ }^{227}$ Cohen and Hamilton (2009): 39.

${ }^{228}$ Trenin (2009).
} 
union with Russia, something the Kremlin cannot accommodate without drawing international ire. The countries have been recognized as independent by only three states: Nicaragua, Nauru and Venezuela. Russia's frequent allies in the states of the 'near abroad' are too fearful of losing their own ethnic Russian enclaves to recognize the states. The de facto situation in Abkhazia and S. Ossetia is thus largely unchanged since the conflict.

\subsubsection{Oil and Aggression: The War in Georgia}

Although analysis of the theory's validity within the Georgia crisis is more difficult than in the previous two cases - largely due to the Kremlin crackdown on information about decisionmaking - Russia's war in Georgia does generally meet our theoretical expectations. In particular, foreign policy remains a largely personalistic process, driven by individuals, not by constitutional prerogatives. This dichotomy is especially visible in the way that Medvedev deferred to Putin on all important issues, despite his constitutionally superior position. Institutions do appear to be somewhat stronger than in the first two cases, with a slight increase in coordination between agencies, and somewhat improved information flow, yet it is difficult to tell if this is actually the result of institutionalization, or simply that failures are now kept behind closed doors. The increasing centralization and personalization of the system implies the latter. The Georgian case also shows a strong reliance on military solutions to resolve diplomatic problems. In many ways, it can be argued that the Russian government's actions provoked this conflict, in particular by refusing to negotiate. The combination of weak institutions and military focus contributed to the ineffectiveness of the foreign policy process, as well as to the initiation of conflict in this case. Finally, as in the Chechen and Kosovar cases, there is limited evidence that government constraints were lessened by the presence of oil wealth. Again, this finding is complicated by the government's consistent use of the media to control and shape public opinion. Thus, although Russian decision-

making has become a more opaque process in recent years, it still bears many of the expected hallmarks of foreign policy making in an oil-rich state, in particular, poor information flow and personalization of the process. 


\subsection{Conclusion}

In conclusion, Russia appears to meet many of the expectations of the theory of natural resources and aggression, both broadly, and in the specific sub-cases discussed here. In particular, Russia's foreign policy has indeed been quite aggressive, even for a great power, involving military force, covert actions and economic sanctions. However, we must also assess whether these conflicts could more effectively be explained by alternative theories, such as the revolutionary theory of war, or indeed, whether standard realist explanations would suffice to explain these conflicts without the involvement of oil as a factor.

\subsubsection{Alternative Explanations}

\section{Revolutionary War Theory}

The revolutionary war theory cannot predict Russia's behavior during the period under study. Colgan's analysis argues that although the fall of the USSR technically qualifies as a revolution, neither the character of the government, nor its leaders, fit his behavioral definition of revolutionary governance. ${ }^{229}$ He argues additionally that Russia has not been aggressive since 1991 . The theory of revolutionary war would expect that Russia, as a non-revolutionary petrostate, would not be prone to conflict, and would be broadly peaceful. Thus, it cannot explain Russia's predilection to conflict in any of the cases discussed above, as governance was not revolutionary.

\section{Balance of Threat Theory}

In the absence of revolutionary governance, we must assess whether standard realist explanations for conflict can explain conflict in the Russian case. Balance of Threat theory does indeed do a passable job of predicting the Kosovo conflict, but cannot easily explain Russia's involvement in either Chechnya or Georgia. In the case of Kosovo, Russian leaders, especially those in the military, certainly perceived a threat from NATO involvement in the former Yugoslavia, although

\footnotetext{
${ }^{229}$ Colgan (2013): 65 .
} 
it is questionable whether this threat was so severe as to justify the extreme actions of Operation Trojan Horse. In contrast, however, neither the insurgency in Chechnya, nor Georgia offered a major threat to Russia. The situation in Chechnya in 1999 had not changed dramatically since the end of the first war, and the terrorist attacks of late 1999, while troubling, were not the actions of an organized Chechen government. These issues could likely have been better dealt with through economic aid and gradual political reform, neither of which were considered as options by Russian leaders. In the case of Georgia, the state possessed no offensive capabilities which would have rendered them a threat. Thus Balance of Threat theory cannot adequately explain Russia's initiation of at least two of our three conflicts without the involvement of outside factors such as oil.

\subsubsection{Russia: Personality-Driven Aggression}

This dissertation's theory therefore does a good job of explaining the Russian case when compared to alternative theories. Russia has been involved a number of conflicts since 1991, some of which could likely have been prevented if not for the pernicious influence of oil and gas production on government. The Russian case shows strong links between oil production and our mediating variables. Firstly, although institutional weakness was initially caused by the Soviet collapse, oil has inhibited the development of solid foreign policy institutions by enabling personalization and centralization of the system around a small group of individuals. As a result, foreign policymaking is highly personalized, institutions tend to be dysfunctional and inefficient, leading to internal fighting and a lack of good information. These institutions are notably weaker than those of similar non-oil states. Secondly, the Kremlin also displays a strong inclination towards the use of military force even in situations where diplomacy is a better option. As one author points out, "increasingly, the armed forces and a vision of security as emphasizing hard rather than soft security have come to the fore in Moscow's national security process." ${ }^{230}$ Even when negotiations occur, they are often undermined by covert military actions, as in the 2014 Ukrainian crisis. Finally, the Russian government does seem to have fewer constraints on its foreign policy behavior than other democracies.

${ }^{230}$ Trenin (2007): v. 
However, this finding is complicated by the fact that most foreign policy actions by the government are in fact extremely popular, and by the government's strategy of manipulating the media to build public support. Thus, this finding is mixed. The three sub cases in this chapter followed up on this general analysis, and seek to illustrate how these intervening variables, created by oil wealth, can undermine foreign policy's effectiveness and contribute to aggressive foreign policy. In the Kosovar, Chechen and Georgian conflicts, Russian policymaking was hampered by the personalization of the system, the inefficiency of state institutions, and the incompetence of the military. Russian leaders in each case ignored non-military alternatives. In each case, public opinion was already favorable towards military intervention, and so it is unclear how negative public opinion would have created constraints on leaders (or not). This chapter's analysis therefore supports the theory's main hypothesis, and finds that Russian foreign policy decision-making has indeed been indirectly undermined by oil, resulting in aggressive foreign policy. 


\section{CHAPTER V}

\section{Saudi Arabia}

Saudi Arabia, perhaps more so than any other state, is defined by its vast natural resources and role in global energy markets. Unlike Russia, Saudi Arabia has long been an ally of the United States, and is not often described as aggressive as a result. Yet, the Saudi state is regarded with suspicion by many western politicians and populations, in part because it has already used the "oil weapon," during the OPEC embargo of 1973-4. Saudi money and influence has also spread throughout the Middle East, with oil wealth used to finance various causes, many of which could be perceived as aggressive. This chapter is effectively split into three parts. In the first section, we will examine the historical relationship between oil and the Saudi state, before providing a broad overview of foreign policy since the end of the Cold War. In the second section, we will focus on the causal links between oil production and the theory's mediating variables: weak institutionalization, reliance on military force, and freedom from constraints in foreign policymaking, in order to examine whether oil production has undermined Saudi Arabia's foreign policy process in general. In the third section, we will focus on several sub cases, illustrating how these mediating variables can lead to state aggression in specific instances of foreign policy decision-making: the Saudi invasion of Yemen during the Houthi rebellion of 2009, and Saudi Arabia's response to the Arab Spring

in three key states (Bahrain, Yemen and Syria). This chapter's analysis indicates that the Saudi foreign policy system is indeed compromised in several of the ways suggested by theory, and that this contributed to aggressive foreign policy on at least two occasions. 


\subsection{Oil, Foreign Policy, and the Saudi State}

\subsubsection{A History of Oil in the Kingdom}

Although the Middle East is now the world's foremost source of oil, it was not well explored until the mid-20th century. In the 1920s, discoveries in Persia encouraged King Abd al-Aziz Ibn Saud to begin negotiations with American oil companies for the right to prospect in Saudi Arabia. This was a budgetary necessity for the king, whose major source of revenue - the taxes paid by hajj pilgrims visiting Mecca and - had largely dried up during the Great Depression. ${ }^{1}$ By the early 1930s, the King (and by extension, the treasury) was over $\$ 120,000$ in debt. ${ }^{2}$ In 1933 , Standard Oil purchased a concession to prospect in the Kingdom, and engineers finally struck oil at Damman (near the modern city of Dahahran) in 1938.

Large-scale production began in 1943, as British and American lend-lease funds poured into the country. ${ }^{3}$ This dramatically increased the government's revenue flows, with income rising from around $\$ 13.5$ million in 1946 to $\$ 212$ million in $1952 .{ }^{4}$ Although some of this early money was spent to build new palaces for the ruling family, the next two decades also saw substantial (if imperfect) redistribution of oil rents to the whole population through subsidies to education, healthcare, loans, basic commodities and social payments. ${ }^{5}$ This greatly enriched the Saudi people, but created major public sector expansion, a period of Dutch disease-style inflation, and a strong tendency towards clientelism. ${ }^{6}$

Indeed, the relationship between the Saudi state and the oil industry has been a strange one. Until the 1970s, lacking any cohesive bureaucracy, the Saudi government often relied on ARAMCO to perform many of its functions, and subcontracted infrastructure and development projects to the company. ${ }^{7}$ Initially, the al Saud received only limited income from oil, but in 1950, Ibn Saud

\footnotetext{
${ }^{1}$ McHale (1980): 628.

${ }^{2}$ Rasheed (2002): 93.

${ }^{3}$ During this period, Standard Oil rebranded itself the Arabian-American Oil Company (ARAMCO).

${ }^{4}$ Rasheed (2002): 94.

${ }^{5}$ McHale (1980): 631.

${ }^{6}$ Auty (2001): 81; Hertog (2008).

${ }^{7}$ Rasheed (2002): 96.
} 
threatened to nationalize the oil industry if profit-sharing was not increased. The result was a deal between the Saudi government, US oil companies and the US government. Oil companies would henceforth split all profits 50/50 with the Saudi government, and in turn, the US government would provide them a tax cut (known as the 'golden gimmick') equal in value to the lost profits. Following the ascension of Faisal to the throne in 1962, the government created Petromin, a national oil company. Although Petromin was intended to assume control of all production it never succeeded in doing so, largely because of incompetence. ${ }^{8}$ Instead, the Saudi government sought to effect the 'Saudization' of ARAMCO itself, which became fully owned by the government in 1980, although partner companies continued to operate ARAMCO's oil fields and American businessmen continued to sit on ARAMCO's board. Finally, in 1988, the government renamed the company Saudi Aramco, and assumed all these functions directly. Foreign oil companies operating in Saudi Arabia are now restricted to the small Saudi-Kuwaiti neutral zone.

Saudi Arabia is a key founding member of OPEC. Created in 1960, members believed the organization would allow countries to exercise sovereignty over their natural resources. In 1973, following the Yom Kippur War, King Faisal notified the US that OPEC would use the 'oil weapon' if the US did not pressure Israel to return land occupied during the war. Scholars generally agree that President Nixon didn't believe this threat, ${ }^{9}$ and on October 7 th of that year, OPEC hiked oil prices by $70 \%$, and mandated a cut of $5 \%$ in production for each month that the US continued to support Israel. In March 1974, after Kissinger negotiated the withdrawal of Israel from the Sinai, Saudi leaders, worried about undermining the US in the Cold War, pushed strongly for an end to the embargo. ${ }^{10}$ Although there have been other significant oil shocks in the period since 1974 (i.e., following the Iranian Revolution and the Gulf War), Saudi Arabia has focused on ensuring that the embargo would not be repeated. ${ }^{11}$ Saudi Arabia, as OPEC's swing producer, has the ability to alter prices unilaterally through changes in production, and has shown itself willing to do so,

\footnotetext{
${ }^{8} \operatorname{Hertog}(2008): 16$.

${ }^{9}$ Elass and Jaffe (2010): 31.

${ }^{10}$ Elass and Jaffe (2010): 35.

${ }^{11}$ Gately (1984): 1104.
} 
deterring cheating by cartel members, and keeping production levels steady. ${ }^{12}$

Today, Saudi Arabia is the world's largest oil producer, with proven reserves of 267 billion barrels (or around one-fifth of the world's conventional reserves). ${ }^{13}$ Over half of these reserves are in just eight mega fields, primarily in the east. Saudi oil is particularly valuable, as it has the lowest exploration and production $(\mathrm{E}+\mathrm{P})$ cost in OPEC, at around $\$ 3$ per barrel. All important decisions on production and exploration are made by the King and his advisors. ${ }^{14}$ Although the kingdom benefits from high oil prices, rulers have sought for the last thirty years to keep oil prices moderate, fearing that extreme oil prices could encourage conservation efforts; Modern Saudi oil policy is focused on maintaining stability of the current order, ${ }^{15}$ and on meeting growing domestic and foreign demand. ${ }^{16}$

\subsubsection{Saudi Foreign Policy: 1990-2012}

Saudi foreign policy has been extremely consistent over time: the al Saud family tends to pursue a largely non-aggressive, diplomatic foreign policy, focusing on regional mediation, relations with the US, and on containing Iran and Iraq, their two greatest rivals. However, the Saudi government (and indeed, many private citizens) also works behind the scenes, contributing large sums of money to various foreign causes, including humanitarian organizations and militias in the Palestinian territories, Iraq and Syria. The US-Saudi relationship remains the lynchpin of Saudi foreign policy, but the gap between the two states has widened considerably since the $9 / 11$ terrorist attacks. In addition to the US, Saudi foreign policy is particularly impacted by its problematic relations with three states: Iraq, Yemen and Iran.

Saudi Arabia's major conflict during this period was the 1990 invasion of Kuwait and parts of the Kingdom by Iraq, resulting in the coalition-led Gulf War. Until this time, Saudi-Iraqi relations had been generally good, as both countries were Sunni-led, and both opposed to Iran. Indeed,

\footnotetext{
${ }^{12}$ The downside to this power, as noted by Auty (2001), is that Saudi leaders cannot not alter production to meet domestic needs, inhibiting their ability to develop the economy.

${ }^{13}$ Figures from the US Energy Information Administration, available from http://www.eia.gov/.

${ }^{14}$ Sarbu (2011): 21-23.

${ }^{15}$ Elass and Jaffe (2010).

${ }^{16}$ Lahn and Stevens (2011): 1.
} 
Saudi Arabia had strongly supported Hussein's government during the Iran-Iraq war, providing as much as $\$ 21$ billion of direct support to Iraq, as well as free access to Saudi ports and cheap access to Saudi oil. ${ }^{17}$ The attack on Kuwait thus came as a surprise to the Saudis, who had sought repeatedly to address Iraqi concerns over Kuwait diplomatically: first, through the 1989 signing of a non-aggression pact with Iraq, and secondly in early 1990, by offering a large financial settlement to the Iraqi government in exchange for giving up its claims to Kuwait. The invitation of US and coalition troops to defend the Kingdom and remove Iraqi troops from Kuwait (at up to $\$ 60$ billion expense to the Saudis $)^{18}$ would set in motion many of the foreign policy challenges of the next two decades.

Saudi Arabia's more recent engagement with Iraq has been one of cautious engagement, pursuing "a policy of limited political accommodation... while planning for the risk of war." ${ }^{19}$ From 1991 to 2004, up to 5,000 US troops remained stationed inside Saudi Arabia (mostly at al-Kharj) to defend against Iraq. Following the US invasion of Iraq in 2003, most of these troops have been withdrawn, and Saudi foreign policy towards Iraq now focuses on engagement, and on minimizing Iranian influence. The Kingdom has also funded Sunni religious leaders and groups, many of whom are engaged in ongoing insurgent behavior. ${ }^{20}$ Although Saddam Hussein's government has been removed as a threat, Iranian influence in Iraq is now a major concern for Saudi leaders.

The Kingdom also experienced a number of border clashes with Yemen during this period. Saudi Arabia has long interfered in Yemeni affairs, funding insurgents, and helping to create divisions between North and South Yemen to keep the state weak. However, the 1990 unification of Yemen, as well as the Saleh regime's support for Iraq during the Gulf War destroyed the friendly relationship. In that year, Saudi Arabia expelled tens of thousands of Yemeni workers from the Kingdom, cutting remittances (one of Yemen's main income sources). ${ }^{21}$ In 1994, the Kingdom supplied the breakaway movement of Ali Salim Al-Baidh with money and arms, instigating civil war. ${ }^{22}$ A number of border

\footnotetext{
${ }^{17}$ Eilts (2004): 225.

${ }^{18}$ Niblock (2006): 152.

${ }^{19}$ Cordesman (2003): 52.

${ }^{20}$ RAND Corporation (2009): 67.

${ }^{21}$ Cordesman (2003): 65-66.

${ }^{22}$ Anthony (2000): 83.
} 
clashes occurred in 1997 at Rub al-Khali, and wider clashes occurred in 1998. Finally, in 2000, the two countries successfully agreed to border demarcation in most disputed areas, but Saudi Arabia continues to be heavily involved in Yemeni affairs, even providing funding to the Yemeni government and militias in their fight against Iranian-sponsored militias in the 2004-2009 Sa'dah conflict. This fighting spilled over the Saudi border several times in 2009, including the occupation of a Saudi village by several hundred Yemeni rebels, and a large air and ground campaign by Saudi troops in retaliation. ${ }^{23}$ In general, Yemen poses a major threat to Saudi interests: it is extremely poor, susceptible to influence from both Sunni extremists (i.e., Al Qaeda) and from Iran, and has the potential to be a military threat.

The third major country of concern for Saudi foreign policy is its antagonistic relations with Iran, although the post-Cold War period has seen some improvement in this relationship. Relations between the Kingdom and Iran are poor for a variety of reasons, in particular the historical enmity between Sunni and Shi'a muslims, the Iranian regime's opposition to monarchical governance, the likely involvement of Iranian terrorists in the Khobar Towers bombings, and competition for regional dominance. ${ }^{24}$ During the 1990 s, formal relations between the states improved, with visits by senior Iranian officials to Saudi Arabia. However, indirect rivalry has continued: even as formal relations improved, Iranian and Saudi money flowed into proxy conflicts in various countries (i.e., Lebanon, Iraq, Syria, the Palestinian territories, Yemen and Bahrain). ${ }^{25}$ The fall of Iraq in 2003 created a pro-Iranian government in that state, adding to Saudi feelings of 'encirclement' and the perception that competition with Iran is a zero-sum game. ${ }^{26}$ The Arab Spring has also worsened relations, as Iran's focus on mobilizing Arab street movements comes at the expense of Saudi influence and allies. ${ }^{27}$ Saudi intervention (with over 1500 troops) in the Bahraini crisis of 2011 is a direct response to this. ${ }^{28}$ Both nations are heavily involved in the Syrian civil war.

Saudi foreign policy is perhaps most closely identified with the United States, which has supplied

\footnotetext{
${ }^{23}$ New York Times (January 12, 2010), "Saudi and Yemeni Forces Fight Rebels on 2 Fronts."

${ }^{24}$ Cordesman (2003): 47-53.

${ }^{25}$ RAND Corporation(2009): 26, 67.

${ }^{26}$ Aarts (2009): 67.

${ }^{27}$ RAND Corporation (2009): 22.

${ }^{28}$ Jones (2012): 43.
} 
military equipment and training to the Kingdom since the 1950s. This relationship is based on pragmatism, and in practice, the fact that Saudi Arabia is dependent on the US for military matters often leads them to demonstrate their independence on other matters. ${ }^{29}$ After the Gulf War, the US maintained high levels of troops in the Kingdom as a bulwark against Iraq. These troops were withdrawn after the 2003 Iraq War. The US and Saudi Arabia continue to cooperate on many matters, but observers note that "neither government was prepared for the shock of Saudi involvement in the 9/11 attacks." ${ }^{30}$ The September 11th attacks, carried out by 19 hijackers (of whom 15 were Saudi citizens) were committed with the stated goal of removing American troops from Saudi Arabia. In many ways, the Saudi royal family neglected to consider fully the domestic effects of the US-Saudi alliance.

The Kingdom reacted to the attacks in two ways. Firstly, they began to slowly remove American troops from Saudi territory. Secondly, they sought to win back American goodwill through a major anti-terrorism campaign, focused on domestic militants. ${ }^{31}$ Two joint task forces between the US and the Kingdom were set up to combat terrorism, and to identify and prevent terror financing networks. Over 4000 militants were arrested, and Saudi banks were required to identify terrorist assets and freeze them. ${ }^{32}$ The royal family also co-opted a number of radical clerics with money, encouraging them not to preach extremism (though this is unlikely to be stable in the long-term). ${ }^{33}$ These efforts have been modestly successful, but the needs of the al Saud to balance the demands of the US against domestic stability have made the process extremely difficult. ${ }^{34}$

The problem of nullifying terrorist networks is compounded by the propensity of the regime to support radical Wabbahist clerics and groups across the Middle East in order to prop up the regime's domestic legitimacy. For decades, the Kingdom has funded the spread of Salafist ideology, often through funding radical clerics or providing fundamentalist textbooks in the Middle East,

\footnotetext{
${ }^{29}$ Eilts (2004): 239.

${ }^{30}$ Cordesman (2003): 118.

${ }^{31}$ Niblock (2006): 167.

${ }^{32}$ Cordesman (2006): 33-34.

${ }^{33}$ Bremmer (2004): 25.

${ }^{34}$ Alghanim and Salhi (2010): 99.
} 
and other areas such as Chechnya. ${ }^{35}$ This is largely geared towards bolstering the legitimacy of the al Saud, who depend heavily on support from Wahabbist clerics to retain their hold on power. ${ }^{36}$ In addition, Saudi private citizens, including members of the royal family did (and still do) give money to islamic 'humanitarian causes,' but this money is often used by groups such as Hamas to fund militant operations. ${ }^{37}$ These ties to radical Islam make it extremely difficult for Saudi Arabia to effectively fight terrorism.

Throughout the last two decades, the Saudi government has consistently sought to apply a two-pronged approach to foreign policy, using mediation and diplomatic means to resolve conflicts while privately funding opposition groups or movements deemed necessary; the 2011 intervention of Saudi troops in Bahrain represents a major departure from the regime's normal means of conducting foreign policy. Saudi leaders have consistently sought to resolve regional disputes, in particular, the Arab-Israeli peace process. Although a major 2002 push for peace was unsuccessful, the "Saudi Peace Initiative is increasingly seen as the basis for Arab-Israeli negotiations." 38 Likewise, the Kingdom has been involved in negotiations on Lebanon, Syria, and the Arab Spring, although Saudi success is typically limited only to bringing the parties together. ${ }^{39}$ At the same time, however, the regime tends to privately fund opposition groups which support their broad aims. ${ }^{40}$ Thus, in Lebanon and Syria, Saudi Arabia is providing money, oil and weapons to regime opponents, as well as funding Saudi-friendly regimes to suppress protests during the Arab Spring. ${ }^{41}$ This dual approach is typical of Saudi foreign policy, particularly since 2001.

In conclusion, Saudi foreign policy in this period has been focused not only on mediation, the fight against terrorism and relations with the US, but also on containing Iranian influence both at home and abroad, and on preserving a high level of influence within the region. Although the USSaudi relationship remains important, it is far more 'transactional' than before 2001, as the Saudi

\footnotetext{
${ }^{35}$ Gause (2011): 20-21.

${ }^{36}$ Bremmer (2004): 23.

${ }^{37}$ Alghanim and Salhi (2010): 102-3; Cordesman (2003): 102

${ }^{38}$ Bahgat (2006): 49.

${ }^{39}$ Kamrava (2013): 8.

${ }^{40}$ Gause (2011): 20.

${ }^{41}$ See Jones (2011), among others.
} 
government focuses on local disagreements with Iraq, Iran and Yemen. As former US Secretary of State Dean Acheson noted, like any nation, "the purpose of the Kingdom of Saudi Arabia is to survive, perchance to prosper, but only under the al Saud dynasty." 42 The central tension this imposes - achieving foreign policy objectives while maintaining domestic stability - continues to pose major challenges. For this reason, the Kingdom tends to pursue an overt foreign policy, combined with many covert actions.

\subsubsection{Does Saudi Foreign Policy Exhibit Aggressive Tendencies?}

Many observers have described Saudi Arabia as a non-aggressive oil state, since it has been involved in few recent overt conflicts. ${ }^{43}$ Indeed, the dataset shows that the Kingdom only initiated six conflicts and fifteen threats between 1960-2001. Conflicts in the dataset are minor, and include two border clashes with Egypt, the two Arab-Israeli wars, major border disputes with Yemen in 1980, and border clashes with Qatar in 1992. The threats/sanctions are primarily economic in nature, and are directed against a variety of countries. Since 1990, other than the coalition retaliation against Iraq in 1992, the Saudi military and National Guard have only been involved in two large-scale conflicts: the 2009 Sa'dah war in Yemen, and involvement in the 2011 Bahraini crisis. The Kingdom has also had great success during the last two decades in resolving outstanding border disputes with its neighbors.

However, a closer look at the history of Saudi foreign policy reveals that although the Saudi government rarely enters conflict directly, it frequently interferes in the affairs of nearby countries in a variety of ways. These include financial incentives for governments to continue proxy wars (such as that offered to Iraq during the Iran-Iraq war), and financial or logistical support to non-state actors. The latter has been particularly prevalent; even while publicly supporting peace talks, the Saudi government has supported insurgents in countries such as Yemen (1994, 2004, 2009), Syria (2013), Eritrea (2008-2011), Iraq (2003-2013), and Palestine (1990-2013). In many of these

\footnotetext{
${ }^{42}$ Eilts (2004): 219.

${ }^{43}$ It should also be noted that many observers fail to discriminate between 'non-aggressive' and 'US ally.' Since Saudi Arabia is a long-term US ally, it is naturally viewed as less threatening than a state like Iran.
} 
countries, the Kingdom funded groups who could be expected to reliably resist Iranian influence, as well as anti-Iranian governments. In addition, throughout the 1980s and 1990s, the Kingdom funded a number of extreme Salafist groups, many of which also had militant or terrorist ties. In short, insofar as Saudi Arabia has exhibited aggression in foreign policy, it takes a form more akin to that of the superpowers during the Cold War, involving the use of proxy actors in third party states. Thus, Saudi Arabia can be regarded as a mixed case; although not overtly aggressive, it nonetheless has covertly initiated and taken part in many conflicts.

\subsection{From Oil to Weak Foreign Policy}

\subsubsection{The Development of Foreign Policy Institutions}

Despite the formation in 1930 of a Foreign Ministry, early Saudi relations with other states were typically carried out on an informal basis, through envoys chosen personally by King Abd al-Aziz. The paucity of educated Saudis often led the King to use foreigners for this purpose, who did not always advocate the Saudi position. For example, the exiled Palestinian Ahmad Shuqairi was the Kingdom's first ambassador to the UN, but largely used his position to argue for Palestinian statehood. ${ }^{44}$ As Eilts notes, "[this] system of using such foreign advisors was notoriously inefficient." 45 In a similar way, diplomacy with the US, the Kingdom's most important partner, was typically carried out directly through oil companies. It was only after the expansion of the Saudi state in the 1950s and 1960s that the foreign ministry became more involved in the process of diplomacy, and the Kingdom founded its first intelligence service, the Al Mukhabarat Al A'amah (GIP). From 1930 to 1975, the position of foreign minister was occupied by Prince (later King) Faisal bin Abdulaziz.

As Hertog describes, "the Saudi state was created rapidly between the 1950s and the early 1980s through the decisions of a few Saudi royals." 46 The process of development depended almost

\footnotetext{
${ }^{44}$ Eilts (2006): 240.

${ }^{45}$ Ibid., 242.

${ }^{46}$ Hertog (2008): 10.
} 
entirely on the individual who headed each ministry. If a minister was keen to expand his agency, it was; if his interest was elsewhere, institutions frequently languished. ${ }^{47}$ Thus, after Faisal's ascension to the throne in 1964, he began to involve the foreign ministry more directly in decisions, and chose to keep the position of foreign minister in addition to his other duties. However, at this time, the ministry only included a deputy minister, and small Arab, European, African and Political bureaus. ${ }^{48}$ Instead of formal briefs, Faisal would have various advisors 'sit' with him while he pondered foreign affairs issues, and offer advice if asked. Although the institutions involved are now formalized, this personal consultative process still largely describes foreign policy decisionmaking to this day. ${ }^{49}$

Following the 1980 appointment of Faisal's son, Prince Saud to the post of foreign minister, he took steps to modernize and expand the foreign ministry, which now analyses information on a variety of issues. There is anecdotal evidence that the foreign service is slowly become more professionalized, as career bureaucrats now perform many functions formerly performed on an ad hoc basis. ${ }^{50}$ However, the process of hiring bureaucrats from abroad continues to some extent (i.e., many military and foreign policy functions are outsourced), meaning that Saudis are not necessarily in full control of their own destiny. ${ }^{51}$ The Kingdom is particularly reliant upon US-based defense and infrastructure firms, with whom it contracts to build new infrastructure projects, buy armaments, and even staff defense and intelligence installations. This arrangement is institutionalized in the US-Saudi Technical Cooperation Agreement, signed in 2008 (renewed in 2013), which obligates the US government to "make available for sale... its capacity in the areas of critical infrastructure protection and public security... including technical assistance." 52 Technical assistance will be provided "directly or through US government contractors." 53 That the Kingdom is so strongly reliant on contracted assistance highlights the weaknesses of the domestic bureaucracy, as oil money

\footnotetext{
${ }^{47}$ Ibid., 3-4

${ }^{48}$ Eilts (2006): 243.

${ }^{49}$ Balka (2008): 26.

${ }^{50}$ Nonneman (2006): 336.

${ }^{51} \mathrm{Al}-$ Hegelan and Palmer (1985): 49.

${ }^{52}$ US-Saudi Technical Cooperation Agreement (2008), US Department of State, available from http://www.state.gov/documents/organization/109344.pdf.

${ }^{53}$ Ibid.
} 
allows the al Saud to bypass it by substituting the hiring of outside experience.

Other ministries involved in the foreign policymaking process developed in a similar way to the foreign ministry. The security service (GIP) was created in 1952, but did not develop until during Faisal's reign. Similarly, the creation of the GSS domestic intelligence agency during the 1970s was largely driven by Faisal's son, Prince Turki. In addition to the Ministry of Foreign Affairs and the intelligence services, several other agencies are involved in the foreign policy process, notably the Defense and Commerce Ministries, and the overarching National Security Council. Despite this, the main players in the foreign policy making process are still the King and his closest advisors. They deliberate and take advice from tribal leaders, merchant families, technocrats and the religious hierarchy (the Ulama). ${ }^{54}$ In addition, as Abdullah Alasker, member of the Majlis points out, the King:

"always consults with senior members of the royal family before making any crucial decision." 55

Most decisions are in fact taken within the royal family, which consults with other groups, but is not ruled by them, particularly on foreign policy matters. Much as the development of agencies was driven by the influence of those in charge, the agencies influence over foreign policy decisions is effectively dependent on their minister's clout. As Naif notes, there is really "no political structure outside of the monarchy and Council of Ministers," 56 most of whom derive more power from their royal status than they do from their ministerial positions. ${ }^{57}$

In the 1990s, the Saudis undertook a major constitutional overhaul. The Kingdom actually has no written constitution, as its Islamic origins prohibits the creation of any constitutional document other than the Q'uran. Nonetheless, the 1992 reform package did serve to codify governmental relations and succession in the Basic System of Rules, ${ }^{58}$ and created a consultative council, the

\footnotetext{
${ }^{54}$ Balka (2008): 3.

${ }^{55}$ Alsultan (2013): 459.

${ }^{56}$ Naif (1993): 8.

${ }^{57}$ Nonneman (2006): 337.

${ }^{58}$ The succession is a major issue for Saudi foreign policy, as the sons of Abdulaziz are rapidly aging. The 2006 creation of the Ascension Council from among the senior princes and their sons was designed to ensure a stable transition to the next generation of rulers, but it has yet to be put to the test.
} 
Majlis as-Shura, with ninety members drawn from the business, academic, and religious elite. ${ }^{59}$ The Majlis is parliamentary in nature, but it is essentially a deliberative body, not a legislative one. In effect, the Majlis acts as a sounding board for senior royals on important issues, and as a way for the al Saud to coopt potential opponents. ${ }^{60}$ The body cannot overrule the King or his Council of Ministers. As a result, the influence of the Majlis on foreign policy is minor, and purely deliberative in nature.

A typical foreign policy decision will involve the King and a number of his closest advisors. These will likely include the heads of relevant ministries and other important figures, who will provide advice on the decision. Impartial information provided by the foreign ministry or intelligence services is only one piece of advice among many that the king will recieve. In the case of an extremely important decision, the King will consult with senior members of the royal family, as well as with the Majlis and religious leaders. Finally, once a broad consensus is reached, the King will make a decision and delegate its implementation to the appropriate agency or ambassador.

Thus the development of foreign policy institutions in Saudi Arabia was late, uneven and is today somewhat incomplete. It was not until the 1970s that the Kingdom sought to develop a coherent foreign policy bureaucracy, and much diplomacy was and is still handled personally by members of the royal family. In lieu of an institutionalized system of foreign policy making, decisions on foreign policy are left entirely to the King and his senior advisors, who utilize a largely informal system of consultation and deliberation when making decisions. Although the Saudi bureaucracy has an increasing impact on the implementation of policy, this is necessarily less in matters of foreign policy than in other issue areas. ${ }^{61}$ This renders the foreign policy bureaucracy particularly weak.

\footnotetext{
${ }^{59}$ Aba-Namay (1998): 239-41.

${ }^{60}$ Dekmejian (1998): 217.

${ }^{61}$ Nonneman (2006): 337.
} 


\subsubsection{Are Saudi Foreign Policy Institutions Underdeveloped?}

This section seeks to shed light on one of the dissertation's key hypotheses in the context of Saudi Arabia. Are foreign policy institutions, as suggested by the theory, weak? Since Saudi Arabia is a petrostate, we would expect its foreign policy institutions to be (a) characterized by disagreements or by jockeying for influence by various individuals and groups, (b) primarily dominated by individuals or small groups, and (c) inefficient and suffering from communication problems. Many scholars have written about the Kingdom's underdeveloped institutions, but there has been little study of specific foreign policy institutions. It seems clear, however, that many of our theoretical predictions are in fact borne out in the Saudi case. The Kingdom's foreign policy process exhibits far fewer disagreements and less internal conflict than the Russian case, but the process is dominated by the royal family, and is extremely weakly institutionalized.

As discussed in Section 3.1, the al Saud royal family dominates all decisions within the Kingdom. This is especially true on foreign policy issues, where they have less need to placate the Ulama. As Nonneman notes, the "Saudi state, in essence, is a family oligarchy," a form of government more akin to medieval monarchical regimes than any modern state. ${ }^{62}$ Indeed, he argues that "most of the real decision-making power lies with the senior royal princes," not with the bureaucrats who staff the foreign or defense ministries. ${ }^{63}$ Interestingly, although the decision-making process is - as predicted - controlled by a small group, this produces an interesting style of consensual governance, where the leaders tend to focus on finding an acceptable middle ground for all parties. As Hill and Nonneman describe, "although the King has the final say on matters where he insists, there tends to be informal consultation." ${ }^{64}$ Unfortunately, this deliberative form of decision-making also has downsides: the royal family's need to present a united front means that key "decisions may be postponed or compromises forged to preserve the facade of consensus." 65 Decisions thus may be focused less on successful foreign policy outcomes, than on preserving the monarchical status

\footnotetext{
${ }^{62}$ Nonneman (2006): 324.

${ }^{63}$ Ibid., 337.

${ }^{64}$ Hill and Nonneman (2011): 9.

${ }^{65}$ Quandt (1981): 83-6.
} 
quo. This is particularly notable in the Kingdom's approach to Wahabbist radicals throughout the Middle East, which can at best be described as "systematically mismanaged." 66

Insofar as there are conflicts within the foreign policy process, they tend to coalesce around personalities, not policies, and to take place privately within the royal family, rather than publicly. Ministries tend to be 'owned' by individual princes (and a few non-royals), creating mini-fiefdoms, within which the minister can pursue any goals as he wishes. ${ }^{67}$ This is made worse by the fact that appointments are effectively for life, and are often hereditary. Many of the most senior royals have been in their positions for decades: there have been only two foreign ministers since 1930, Faisal bin Abdulaziz, and his son, Saud. Similarly, Sultan bin Adbulaziz, the recently deceased Minister for Defense was in his position for almost five decades (1963-2011). There is also a strong tendency for leaders to retain their ministerial portfolios as they advance in seniority: King Faisal remained Foreign Minister throughout his reign, and his half-brother Sultan was both Crown Prince and Defense Minister for over six years. Factions within the royal family often determine who is permitted to control specific ministries, with blood ties to current leaders, maternal lineage and in particular the degree of relationship to Ibn Saud all playing a role in determining seniority.

In one such example, in the years following the September 11th attacks, the Saudi government created the National Security Council (NSC), designed to coordinate between various security and intelligence agencies on the vital topic of anti-terrorism. Prince Bandar bin Sultan, a successful former ambassador was appointed as Director General. Yet, as one observer noted, "[Bandar] has a very small staff and the NSC so far has been little more than a base for Bandar that has no practical impact or influence in coordinating the activities of other elements." 68 Prince Bandar is unpopular among fellow royals, and is often suspected of being too close to US leaders after his many years spent in the West. As a result, he had no real power base within the Kingdom. This has served to undermine not only his personal success, but the success of the NSC, which should have been a vital component of the Saudi anti-terrorism effort. ${ }^{69}$ Personal opinion and stature thus plays a vital role

\footnotetext{
${ }^{66}$ McMillan, Cordesman, Fandy and Mohamedi (2002): 6.

${ }^{67} \operatorname{Hertog}(2008): 12$.

${ }^{68}$ Cordesman (2009): 119.

${ }^{69}$ Ibid.
} 
in determining which policies are chosen and successfully implemented, making overpersonalisation a major problem for the Kingdom's bureaucracy. In another example, many observers attribute much of the Saudi lethargy and leniency in pursuing domestic groups with links to Al Qaeda to the tacit support for Al Qaeda of Prince Nayef, Interior Minister from 1975-2012. ${ }^{70}$ While conflict over issues is expected between leaders in any system of government, the bureaucratic autonomy enjoyed by the Kingdom's princely 'fiefdoms' makes this personality-driven conflict much more damaging to long-term foreign policy interests.

Both Bandar and Nayef also illustrate another flaw of the Saudi system - both princes spent substantial time during their tenure in office abroad, ill or otherwise indisposed. The extreme age of many Saudi leaders, who often die in office, means that they frequently spend months at a time indisposed or abroad seeking medical treatment. The gerontocratic nature of the Kingdom's government creates two problems for foreign policy making. Firstly, decision-making is either effectively suspended during the period of incapacitation, or is delegated to junior ministers, weakening the ministry's internal bureaucratic process. Secondly, the highly personal nature of decision-making means that an agency whose minister is incapacitated may simply not be represented at the negotiating table. As Naif describes, participation in the Saudi system is entirely personal: "the system favors one-on-one access and personal attention, rather than rules and bureaucracy." 71 In such a personality driven system, the absence of the principal from negotiations likely ensures that important information and opinions fail to be considered in the policymaking process.

As predicted by the theory, the Saudi bureaucratic process is indeed inefficient and poorly organized. In large part, this stems from the fact that each ministry is its own fief, effectively walled off from its counterparts. Communication between agencies and ability to coordinate, even when engaged on the same tasks, is poor. ${ }^{72}$ In addition, bureaucratic flexibility and professionalism are in short supply. In a survey of 231 senior Saudi bureaucrats, Al-Hegelan and Palmer found that the majority reported major difficulties in obtaining information and coordinating between agencies. ${ }^{73}$

\footnotetext{
${ }^{70}$ Doran (2004): 39.

${ }^{71}$ Naif (1993): 5 .

${ }^{72}$ Hertog (2008): 4.

${ }^{73}$ Al-Hegelan and Palmer (1985): 61.
} 
There are also a number of cultural issues, as the pervasive effects of rent-seeking encourage citizens to bypass the bureaucracy in favor of taking their case to the most senior official available. ${ }^{74}$ Rent-seeking also means that many bureaucrats receive their jobs as benefices, and are therefore unqualified for the work. As a result, the inefficiency of the bureaucracy in implementing policy frequently undermines the decisions reached at the highest levels. ${ }^{75}$ In particular, the Saudi external intelligence organization (GIP) is known to be moribund, relying heavily on human intelligence networks set up over 50 years ago, and is entirely dependent on US sources of information. ${ }^{76}$

In short, in terms of our theoretical expectations, the Kingdom does exhibit many of the outcomes we would expect to see in the foreign policy institutions of an extremely oil-rich state. Although the Saudi system of decision-making is fundamentally consultative, that consultation happens within a small group of senior princes, advised by religious and business elites. The system is entirely dominated by the al Saud, who are often more concerned with the stability of the domestic system than the national interest in foreign policy. In addition, although the system is broadly consensual, this is because the conflict is hidden behind locked doors: all debate occurs within the family. Saudi foreign policy institutions in general are inefficient and highly personalized. Thus although the Saudi system of governance is effectively unique in the modern world, the foreign policy institutions largely conform to our theoretical expectations.

\subsubsection{Is Institutional Weakness Oil-Related?}

The creation and development of the Saudi state dovetails almost exactly with the Kingdom's increasing reliance on oil exports and revenues. As Figure 5.1 shows, although oil revenues fluctuate - unsurprising, considering oil's volatile nature - they have been consistently higher than $20 \%$ of GDP since the 1970s. Institutions have been consistently weak throughout this period, and have never developed beyond basic organizational structure, limited in both scope and efficiency. This is of particular interest to our study, as institutions have shown no true development, even as

\footnotetext{
${ }^{74}$ Ibid., 53.

${ }^{75} \operatorname{Hertog}$ (2008): 11.

${ }^{76}$ Cordesman (2009): 233.
} 


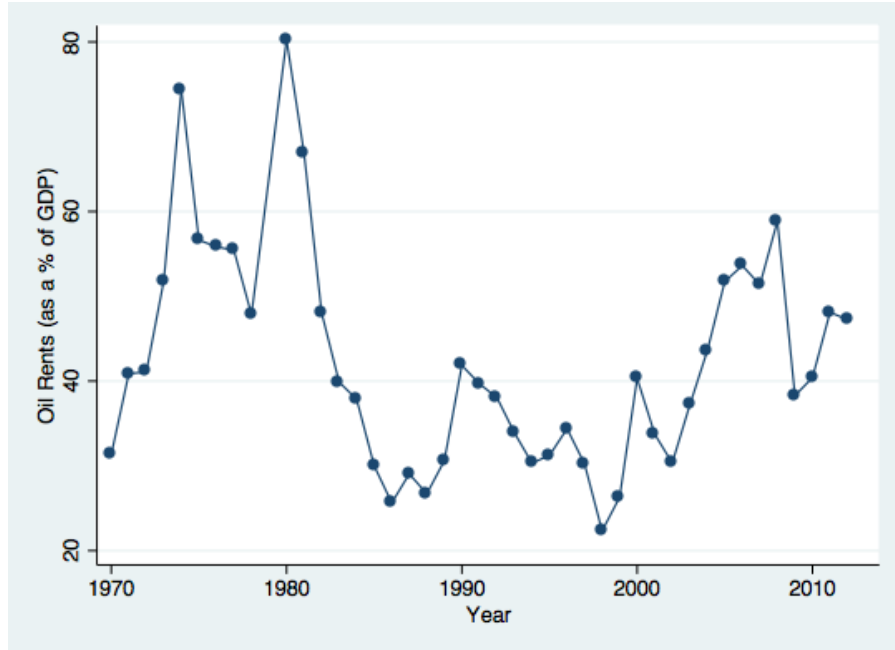

Figure 5.1: Saudi Oil Revenues (1970-2010)

Saudi Arabia has transitioned from an extremely poor tribal society to an urbanizing, increasingly educated and wealthy country. Such limited institutional scope combined with economic and social development is only possible because of the vast quantities of wealth which flow into Saudi Arabia from oil exports. The Saudi government has also shown itself willing to use money to circumvent the need for institutional development, by hiring outside help in foreign and military affairs. ${ }^{77}$ Again, this is a direct result of oil wealth - without such revenue to outsource the bureaucracy, the Saudis would have to develop institutions in order to control their population, manage the military, and coordinate foreign affairs.

We can further examine the impact of oil revenues by considering the foreign policy institutions of similar, non-oil states. This is certainly difficult in the case of Saudi Arabia, as the prevalence of oil in the Middle East means that many comparable states - those located nearby, with similar tribal cultures or colonial backgrounds - are themselves oil-producing. However, there are a few states which meet our criteria. Firstly, Jordan is extremely similar to the Kingdom, emerging from the colonial period as an absolute monarchy, but has never received oil revenues higher than $0.05 \%$ of GDP. ${ }^{78}$ Like Saudi Arabia, Jordan shows some institutional weakness in foreign policy, in

\footnotetext{
${ }^{77}$ See Al-Hegelan and Palmer (1985).

${ }^{78}$ Data from World Bank. Available from www.worldbank.org/data.
} 
particular, the fact that its foreign ministry largely implements, rather than influences foreign policy. In contrast, however, the key players in Jordanian foreign policy include not only the constitutional monarch and his advisors, but also the Prime Minister, cabinet, foreign policy specialists and the lower house of parliament. ${ }^{79}$ Jordan also has an extremely strong set of intelligence agencies, who cooperate broadly with their western counterparts, and often occupy key decision-making roles in government after retirement. In addition, from the 1920s until 1990, the Jordanian government adopted a focus on "regime-led state-building" to strengthen political institutions, and improve the stability of the government,${ }^{80}$ resulting in a reasonably strong institutional framework for foreign policymaking.

Secondly, Egypt (prior to the Arab Spring) was culturally and historically similar to Saudi Arabia, and, until the last few years, was also consistently authoritarian (if not monarchical). Although Egypt has a small amount of oil production, it only qualified as a 'petrostate' for three brief years during the 1980s, and revenues otherwise stayed well below $10 \%$ of GDP. ${ }^{81}$ Unlike Saudi Arabia, Egyptian governance and foreign policy are reasonably well-developed, and "critical state institutions were allowed a very considerable degree of internal autonomy." ${ }^{2}$ The Egyptian state has often been described as somewhat 'balkanized,' but individual institutions tend to have a strong sense of professionalism and integrity, resulting in high state capacity. Foreign policy under military rule, while centered around the President, was influenced by professional diplomats in the foreign ministry, and by officers of the security services. ${ }^{83}$ Thus, both Egypt and Jordan, although culturally similar to Saudi Arabia, do not exhibit the acute institutional weakness found in that case, indicating strongly that oil revenues helped to undermine Saudi institutional development.

\footnotetext{
${ }^{79}$ Ryan (2002): 68 .

${ }^{80}$ Lucas (2006): 7 .

${ }^{81}$ Data from World Bank. Available from www.worldbank.org/data.

${ }^{82}$ Foreign Policy (July 17, 2013), "Egypt's Wide State Reassembles Itself."

${ }^{83}$ Ibid.
} 

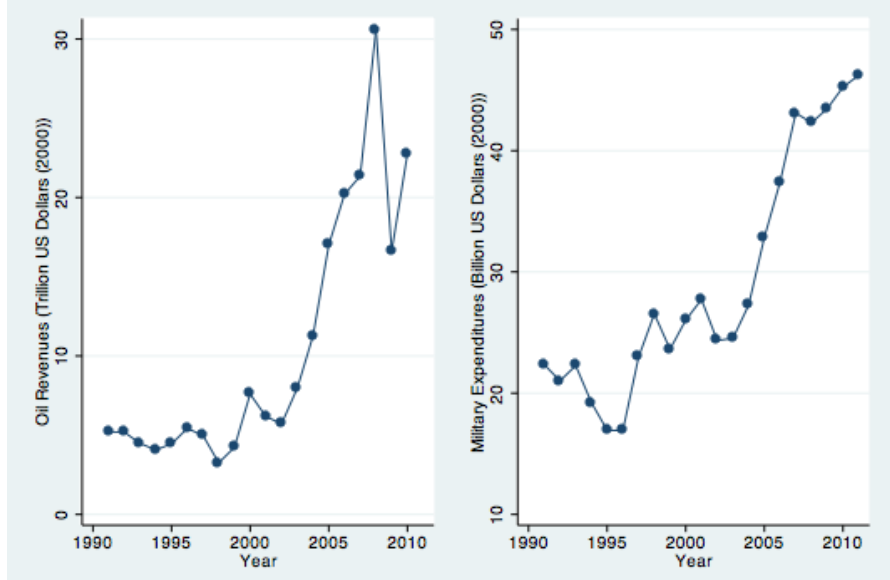

Figure 5.2: Saudi Oil Revenues vs. Military Expenditure (1991-2010)

\subsubsection{Military Expenditure in the Kingdom}

Saudi Arabia is often cited as an example of an oil-rich state with large military expenditures, as its very public purchases of huge weapons packages from the US and other western states are commonly reported in the media. Indeed, Saudi Arabia is one of the world's most profligate countries in terms of arms purchases. While the median country spends around 3\% of GDP, Saudi Arabia has consistently spent between $8 \%$ and $14 \%$ of GDP on military equipment since the 1980 s. $^{84}$ As GDP grows (largely driven by oil prices), Saudi military spending remains a relatively consistent share of GDP. There is little doubt that this spending was financed by oil revenues; Figure 5.2 shows the level of military expenditure during the period 1991-2010, compared to levels of oil revenue. The graphs track extremely closely, with increased levels of oil revenue almost always correlating with an increase in military spending, and years with particular spikes in oil price (i.e., 1997, 1999, 2007) also experience an increase in military spending. As predicted by many theorists of military spending, expenditures do not always fall in line with small dips in oil price, but tend to experience smaller drops (since military spending is hard to cut, or 'sticky.') 85

At its peak in 2007 , the Kingdom was spending $\$ 43.1$ billion dollars a year on its military.

\footnotetext{
${ }^{84}$ All figures from the Stockholm International Peace Research Institute Military Expenditure Database, available from http://www.sipri.org/research/armaments/milex/milex_database.

${ }^{85} \operatorname{Chun}(2010)$.
} 
Much of this money is used to buy advanced weapons systems. The US receives the lion's share of Saudi defense spending (i.e., between 2001-2004, $\$ 3.8$ billion of a total $\$ 5.6$ billion in spending went to US companies). ${ }^{86}$ In recent years, the Kingdom has purchased (among many items) 312 M1A2 tanks, 4 Badr-class missile frigates, 154 F-15 strike fighters, and a variety of advanced anti-tank and missile weaponry. ${ }^{87}$ Other purchases of note include Cruise missiles from the US (2010), ICBMs from China (1988), Typhoon fighter jets from the UK (2005) and various weapons from Russia. ${ }^{88}$ Although the Saudi military is extremely well equipped, it is not well qualified to deal with much of this extremely advanced weaponry. As a result, these figures also included large amounts spent on hiring contracting companies to staff key installations and provide training to Saudi troops.

Unfortunately, although the Kingdom has the highest rate of military spending in the Gulf, ${ }^{89}$ the military is in fact extremely inadequate. ${ }^{90}$ The Saudi government has major manpower issues, with too small (and unwilling) a population to fully staff the military. ${ }^{91}$ In one study immediately following the Gulf War, RAND noted that Saudi Arabia and Kuwait together could only realistically provide $1 / 2$ to $2 / 3$ of the required troops to defend themselves against Iraqi attack; ${ }^{92}$ these figures have not dramatically improved since then. Indeed, most Saudi military expenditure isn't devoted to building up troops or improving training, but rather to maintaining the highest possible level of technology. ${ }^{93}$ The military also has significant problems with quality and management of forces. In particular, the heavy involvement of royal princes in the officer corps, and overcompartmentalization of different branches of the armed forces means that the military is far less competent than it should be. ${ }^{94}$ This bears a strong resemblance to Russia, where oil money flows freely to the military, but has not substantively improved readiness.

Saudi military spending is also complicated by the heavy involvement of the US in defending the

\footnotetext{
${ }^{86}$ Cordesman (2006): 32 .

${ }^{87}$ Cordesman(2010): 5 .

${ }^{88}$ Bahgat (2006): 425.

${ }^{89}$ Wilner and Cordesman (2012): 54.

${ }^{90}$ Pascal, Kennedy and Rosen (1979): viii.

${ }^{91}$ Kechichian (1999): 249.

${ }^{92}$ RAND Corporation (1991): 26.

${ }^{93}$ Cordesman (2010): 2.

${ }^{94}$ Cordesman (2003): 45.
} 
Kingdom and providing security guarantees. From 1991-2003, the US kept around 5000 troops in Saudi Arabia, ${ }^{95}$ along with US Air Operations Headquarters for the region. ${ }^{96}$ In addition, though the Kingdom has "cut back steadily on foreign manpower and contractor support since the early 1990s," 97 it also relies heavily on US-based contractors such as Boeing and Raytheon to fill out technical gaps in the military. The Kingdom has also on infrequent occasions paid other states to help its defense; for example, US costs for Operation Desert Storm (around $\$ 60$ billion) were borne in full by the Saudi treasury. ${ }^{98}$

Saudi military spending is clearly extremely high, funded largely from the proceeds of oil sales as predicted. However, the theory also predicts that leaders in oil-rich states will also tend to focus heavily on military options. It is less clear that this is case in Saudi Arabia, whose diplomats typically operate not through arms, but through negotiations and direct cash transfers. ${ }^{99}$ For example, in 1991, rather than taking military action against Saddam Hussein, the Saudis instead sought to buy him off, offering cash in exchange for Iraq giving up its claims to Kuwaiti territory. The Kingdom also seems to prefer secretly financed covert operations to overt military threats, such as its involvement in the Iraqi or Syrian conflicts. In short, although the Kingdom does have the extremely high levels of military spending predicted by the theory, its leaders do not tend to use overt force. While this finding does not undermine the dissertation's theory (in particular as the ability to fund such covert operations comes directly from oil revenues), it does imply that the relationship between oil revenues and aggression may not always involve direct military expenditure.

\subsubsection{Government Constraints in Foreign Policy}

The third effect predicted by our theory is that governments with large quantities of oil revenue will be less likely to care about public opinion, and less likely to attempt to form coalitions in support of specific foreign policies. The Saudi regime conforms to some extent to this prediction,

\footnotetext{
${ }^{95}$ Eilts (2004): 239.

${ }^{96}$ Niblock (2006): 151.

${ }^{97}$ Cordesman (2003): 67 .

${ }^{98}$ Niblock (2006): 152.

${ }^{99}$ Gause (2011): 20.
} 
ignoring public opinion on some important foreign policy issues. However, the regime also takes care to avoid publicizing unpopular policies, and takes particular care that the opinions of certain groups (notably religious conservatives) are looked after.

Public opinion in the Kingdom is notoriously hard to measure. Few opinion polls are permitted, and cultural issues such as access to women respondents, and unwillingness to discuss political matters with strangers seriously restricts the ability to poll Saudi citizens. ${ }^{100}$ Despite this, Champion notes that "the regime skillfully tracks and responds to the nuances of public opinion." 101 This is accomplished through the use of an ad hoc network of informants, situated in major groups of society, who report on opinion around them. In addition, the intelligence service also has a network specifically devoted to gathering public opinion (in addition to reporting seditious talk against the royal family). ${ }^{102}$ These methods likely produce more reliable results for the al Saud than formalized polling, as pollsters often have trouble accessing rural areas, in addition to the cultural issues above.

The Saudi government has tended to listen to public opinion on many matters of foreign policy while ignoring it on a few major issues. This tends to match our theoretical predictions, as the theory does not predict that an oil-rich government will always oppose public opinion, merely that it can go against it as needed. In this case, the al Saud tend to be extremely responsive to public opinion on certain issues: in particular, pragmatism among Saudi citizens over the Israel-Palestinian conflict (i.e., a clear majority is willing to accept Israeli control over Jerusalem in exchange for a Palestinian state or other concessions) has led the Saudi government to take a moderate line in peace talks. ${ }^{103}$ Similarly, the Saudi government has tended to hide actions which are unpopular. In 2010, only $1 / 3$ of Saudis said that they would support a US military strike against Iranian nuclear facilities; the regime said little publicly, but privately strongly urged the US to take action against Iran. ${ }^{104}$

\footnotetext{
${ }^{100}$ Pollock (2010).

${ }^{101}$ Champion (1999): 50.

${ }^{102}$ Ibid.

${ }^{103}$ Pollock (2010): 47.

${ }^{104}$ Ibid.
} 
However, the al Saud have also been willing to buck public opinion on important issues, in particular the Kingdom's strong relationship with the US. In the mid-1990s, only Saudi Arabia and Kuwait (among Arab states) stood publicly with the US against Iraq, and refused to criticize US sanctions, despite public opinion to the contrary. ${ }^{105}$ During the Six-Day War, Saudi public opinion was strongly in favor of entering the conflict, but leaders decided that this was not pragmatic, and refused to enter the conflict. ${ }^{106}$ Operation Desert Fox in 1998 was also strongly opposed by the majority of Saudis, ${ }^{107}$ as was the 2003 Iraq War, where $95 \%$ of Saudis polled had an unfavorable opinion of the US. ${ }^{108}$ Despite this, although the Saudi government refused in both cases to allow the US to launch their attack from Saudi bases, they still permitted refueling of US ships and overflight rights within their territory. Saudi Arabia also cooperates with the US on anti-terrorism, despite the assertion of more than $1 / 3$ of the Saudi population $(36 \%)$ that it is an 'islamic duty' to fund mujahadeen fighters around the world. ${ }^{109}$ Though these examples are limited, they do serve to illustrate that the Saudi government is willing to ignore public opinion when they deem it necessary.

However, there are groups which the al Saud is unwilling to ignore, in particular religious conservatives. The Ulama are strongly conservative, and support the export of a rigid, hardline form of Wahhabist islam. Because the Ulama provide domestic legitimacy to the regime, they are consulted on most important matters of foreign policy, and allowed a great deal of influence. For example, the support of Wahhabist movements abroad is strongly favored by conservatives, and has been pushed strongly by the government, despite yielding terrible results. Many of the clerics sponsored by these programs have since turned against Saudi Arabia (with Bin Laden the most extreme example), and have turned either to democratic activism or even terrorism. ${ }^{110}$ Most observers agree that the Saudi policy of exporting extremism is fundamentally flawed, as it

\footnotetext{
${ }^{105}$ Lynch (2003): 57.

${ }^{106}$ Eilts (2004): 227.

${ }^{107}$ Champion(1999): 55.

${ }^{108}$ Telhami (2003): 1.

${ }^{109}$ Pollock (2010).

${ }^{110}$ Gause (2011): 20-21.
} 
radicalizes muslims across the region, and turns them towards Iran. ${ }^{111}$ The government is also largely unwilling to confront pro-al Qaeda clerics for fear of angering the Ulama, resulting in a major foreign policy and security risk. ${ }^{112}$

In short, although the Saudi government is willing to ignore public opinion when necessary, there are certain groups it is unwilling to antagonize. The al Saud also often seek to portray their actions as in line with public opinion even when they are privately opposing these views. However, the willingness of the government to ignore public opinion on major issues like its relationship with the US does imply that the Saudi state is somewhat free of the need for public support, and therefore is in line with our theoretical expectations.

\subsubsection{Conclusion}

This section sought to shed light on whether the theorized links between oil and our mediating variables (weak institutionalization, high military expenditure, and lack of constraints) are present in the Saudi foreign policymaking process in general. There is indeed strong evidence of overpersonalisation and weak bureaucracy as predicted by the theory. The peculiar development of the Saudi state's institutions, in large part the result of oil wealth, appears responsible for many of these shortcomings. The Kingdom also spends massively on military equipment and technology, with spending rising in lockstep with oil revenues. However, although the al Saud have shown themselves able to ignore public opinion on a number of occasions, the fact that they feel the need to both appease the religious lobby and to keep many of their decisions secret imply that the regime's ability to make foreign policy is not wholly without constraints. Thus, we find strong evidence that oil production has undermined foreign policy institutions and increased military expenditure in the Saudi case, but weaker evidence that it removes constraints on policymakers. This chapter will now examine several specific cases of foreign policy decision-making, using process tracing to assess whether our three mediating variables do indeed increase the likelihood of aggression, and undermine good quality foreign policy. These sub cases will focus on one case of overt aggression

\footnotetext{
${ }^{111}$ Ibid., 27.

${ }^{112}$ Niblock (2006): 162.
} 
(the Saudi ground war in Yemen in 2009), and three different Saudi responses to the Arab Spring, including military intervention in Bahrain in 2011, diplomatic efforts to resolve the Yemeni crisis in 2011, and covert funding of military action in Syria (2011-present).

\subsection{From Weak Foreign Policy Apparatus to Aggression}

\subsubsection{Saudi Arabia and Yemen}

Yemen has long been one of Saudi Arabia's biggest security problems. This section will examine Saudi involvement in the Sa'dah War in Yemen (2004-present), in particular the decision to invade Northern Yemen in 2009, the biggest military operation in the Arabian Peninsula since the 1991 Gulf War. ${ }^{113}$ The background to this conflict is complex; since the founding of the Kingdom, relations with Yemen have been at times cordial, and at times extremely confrontational. The long shared (and disputed) border between the two states, and Yemen's chronic instability have worried the Saudi leadership for decades. Indeed, King Abdulaziz is reputed to have called his senior sons to his deathbed, and admonished them to "keep Yemen weak" in order to protect Saudi Arabia. ${ }^{114}$ The Kingdom has at various times funded coups against the Yemeni government, funneled billions of dollars to tribal leaders, and provided both monetary and military support to the regime itself.

There is a long history of antagonism between the two states, beginning with Abdelaziz's failed 1934 attempt to conquer Yemen. During the 1964 Civil War in North Yemen, the Saudis threw their support behind the royalist cause, and granted the Yemeni royal family asylum in the Kingdom. This soured relations with the new republican (and pro-Egyptian) government, and led to many minor border clashes, but by the 1970s, the common threat faced by both countries from communist South Yemen caused Saudi Arabia to throw its support behind the government in Sanaa. Throughout this period, Saudi Arabia has worked through two primary sources of influence: monetary contributions, and tribal ties between the al Saud and the Yemeni Hashed

\footnotetext{
${ }^{113}$ Guzansky (2011): 61.

${ }^{114}$ Hill and Nonneman (2005): 11.
} 
tribe of Abdullah al-Ahmar. ${ }^{115}$ Thus in addition to funding the Saleh regime, the al Saud have also to some extent undermined the Yemeni government by funding conflict among the tribes. ${ }^{116}$ The Saudis opposed Yemeni reunification in 1990 (fearing that it could create a strong opponent on their southern border), and even funded separatists in the 1994 Civil War. ${ }^{117}$

Relations throughout the early 1990s were extremely antagonistic. In 1990, Yemen supported Saddam Hussein in the Gulf War, resulting in the expulsion of tens of thousands of Yemeni migrant workers from the Kingdom. A series of border clashes followed, resulting in tens of deaths, and in 1995, Yemen fired on a Saudi plane. However, following these tensions, the two nations agreed to set up a commission to more clearly define the border, and an agreement was successfully finalized in June 2000. ${ }^{118}$ Following the border agreement, the Kingdom withdrew from Yemen to a large extent, and subsidies to Sanaa fell. ${ }^{119}$ By the late 2000s, however, security concerns led the Kingdom to become more involved again, ${ }^{120}$ this time focusing on pro-government, antiseparatist campaigns, both against the northern Houthi rebellion, and against Al Qaeda in the Arabian Peninsula (AQAP) in the south. ${ }^{121}$ The growing Saudi perception of threat from Yemen led them to abandon their post-2000 passivity and become more active, ${ }^{122}$ taking efforts to prevent militants crossing the border.

Saudi Arabia's relationship with Yemen has therefore been long and fraught, with policies which often blur the line between tribal/domestic politics, and foreign policy. As Terrill notes, "some observers suggest that Saudi Arabia views this role as so important that challenging Saudi interests in Yemen is sometimes viewed as equally offensive as interfering in Saudi domestic politics." ${ }^{123}$ Saudi interference in Yemen contributes to instability by funding both the government and alternate sources of power within the state. The 2009 military intervention in Yemen's Sa'dah War should

\footnotetext{
${ }^{115}$ Halliday (1984): 358.

${ }^{116}$ Cordesman (2003): 64-5.

${ }^{117}$ Ibid.

${ }^{118}$ Anthony (2000): 80.

${ }^{119}$ Hill and Nonneman (2011): 9.

${ }^{120}$ Hill, Nonneman and Wolff (2011): 10.

${ }^{121}$ Alley (2010): 72.

${ }^{122}$ Guznansky (2011): 57.

${ }^{123}$ Terrill (2011): x.
} 
therefore be viewed within the context of this long and ambivalent Saudi-Yemeni relationship.

\subsubsection{2004-2009: Entering the Conflict}

The Houthi rebellion began in 2004 in the north of Yemen among the Zaidi Shi'a followers of Hussein al-Houthi, and is primarily carried out by the group Shabab al-Marmineen (SAM; the 'Believing Youth') through insurgency tactics. The Houthis have religious differences with the government (both Sanaa and Riyadh consider them to be heretics), and separatist goals. The Yemeni government has at various times attempted to negotiate a ceasefire, but the Houthis have violated such agreements repeatedly, most notably in 2007, when violence reached its zenith soon after Sanaa agreed to free a number of Houthi militants in exchange for a ceasefire. ${ }^{124}$ Since the start of the conflict, over 5,000 have died, and more than 150,000 Yemenis (and some Saudis) have been displaced by fighting. ${ }^{125}$ The Yemeni government has accused both Iran and Syria of providing arms and funding to SAM, but there is no 'official' evidence that this is accurate. ${ }^{126}$ In contrast, there is strong evidence that Saudi Arabia has provided funding and arms to SunniWahhabi militias and to the regime in Sanaa to aid in their fight against the Houthi. ${ }^{127}$ In 2005 , the Kingdom began work on the construction of a security fence, to prevent the fighting in northern Yemen from spilling across the border. ${ }^{128}$ This was largely unsuccessful, as the Yemeni border remains porous, and arms and terrorist groups continue to cross the border with impunity. ${ }^{129}$

From 2007, the Saudis became increasingly concerned with the violence in north Yemen, but lacked the means to address it. Yemen policy had typically been dealt with more as a matter of internal and tribal security, rather than through the Foreign Ministry. In addition, although ostensibly responsible for Yemeni policy, neither the Saudi-Yemeni High Coordinating Council, nor the Saudi-Yemeni border committee has had any significant input on policy in the last twenty

\footnotetext{
${ }^{124}$ Freeman (2009): 1008-1014.

${ }^{125}$ Schmidinger (2010): 40.

${ }^{126}$ Ibid., 1014.

${ }^{127}$ Glosemeyer (2009): 10-11.

${ }^{128}$ Associated Press (June 2, 2006), "Saudi, Yemeni Ministers Sign Border Demarcation Agreement in Southeast Yemen."

${ }^{129}$ Terrill (2011): 19.
} 
years. ${ }^{130}$ Instead, as is typical in Saudi foreign policy, one ministry (the Special Office for Yemen Affairs), under the control of a single prince (Prince Sultan bin Abdulaziz) was responsible for the creation and implementation of policy on Yemen. ${ }^{131}$ Most diplomacy was carried out personally by Prince Sultan (or his sons), who negotiated with tribal leaders and disbursed up to $\$ 3.5$ billion a year to various groups inside Yemen. ${ }^{132}$ The Special Office generally controlled Yemen policy, and had kept it relatively stable from 1980 to 2000. In 2000, then-Crown Prince Abdullah pushed strongly for a border agreement, in an apparent attempt to weaken Sultan, and to stop him and his sons from enriching themselves further through the Special Office. ${ }^{133}$ Thus from 2000, the newly signed border agreements, and Sultan's declining health led the Kingdom to withdraw from Yemen, letting many vital networks decay. In 2005, Sultan was diagnosed with colon cancer, and began to spend months abroad for treatment; his ill health accelerated, and by 2009, it was generally understood that he suffered from Alzheimer's disease and dementia. Even more disturbingly, leaked government documents from 2009 suggested that Sultan was:

"for all intents and purposes incapacitated," 134

even as Saudi media described him as chairing the Council of Ministers in the King's absence.

Sultan's absence from policymaking in the late-2000s led to general confusion surrounding Saudi policy on Yemen: policy became diffuse across many agencies, with little coordination, and the financing arm of his Special Office for Yemen Affairs was effectively shut down. ${ }^{135}$ Since this time, Boucek and Ottaway argue that the Kingdom has not had "a single, well-articulated policy towards Yemen. Rather, many actors in the Kingdom have financial and patronage ties to a range of Yemeni organizations, individuals and groups." ${ }^{136}$ Thus, at the same time as Houthi violence in northern Yemen increased, it became increasingly unclear who in the Kingdom was responsible

\footnotetext{
${ }^{130}$ Hill and Nonneman (2011): 9.

${ }^{131}$ Boucek and Ottaway (2010): 98.

${ }^{132}$ Hill and Nonneman(2011): 9.

${ }^{133}$ Stenslie (2013): 1.

${ }^{134}$ Henderson (January 7, 2011), available from Washington Institute at http://www.washingtoninstitute.org/policy-analysis/view/saudi-arabias-oil-policy-vacancies.

${ }^{135}$ Hill and Nonneman (2011): 9.

${ }^{136}$ Boucek and Ottaway (2010): 98.
} 
for Yemen policy. The key players in the 2009 crisis appear to have been King Abdullah, Prince Nayef (Minister of the Interior), his son Prince Muhammed (Deputy Minister of the Interior), Prince Muqrin bin Adbulaziz (Head of the Intelligence Services), and Prince Khaled bin Sultan. In particular, Prince Khaled's involvement highlights the importance of family ties in Saudi decisionmaking; his relatively junior status as an Assistant Minister for Defense was offset by his ties to his father Sultan's Yemeni networks. Yemen policy is now effectively coordinated by this ad hoc committee at a high level, with little (if any) coordination between agencies themselves. This poses a particular problem in a gerontocracy such as Saudi Arabia, as policy formulation and implementation at such a high level has frequently paused for months at a time as various officials were abroad for surgery, or otherwise indisposed. ${ }^{137}$

Compounding the lack of experienced leadership in the Kingdom was the fact that Sheikh Abdullah al-Ahmar, the central Saudi broker in Yemen throughout the Cold War, died in 2007. al Ahmar had been the lynchpin of Saudi policy in Yemen, passing information to the Saudis and funds to tribal leaders (often up to $\$ 7000$ per year to each tribal leader). ${ }^{138}$ With his death, many of his networks became inaccessible to the Kingdom. ${ }^{139}$ When combined with Prince Sultan's incapacitation and the loss of his personal ties in Yemen, the Saudis lost most of their informational networks and ties to tribal leaders within a short time-span, highlighting the perils of personalitydriven diplomacy. While Saudi leaders often fall back on American intelligence when their own sources fail, this has not been possible in Yemen, where the Kingdom instead often provides the CIA with its most detailed intelligence. ${ }^{140}$ The Saudi intelligence service has also had major problems infiltrating Yemeni groups, both AQAP, and the Houthis in the north: although they rely heavily on Yemeni intelligence, the Political Security Organisation is so badly compromised by rebel groups that they have received practically no information from it. ${ }^{141}$ Saudi intelligence gathering networks therefore struggled in the late 2000s to obtain useful intelligence on the Houthi

${ }^{137}$ Hill and Nonneman (2011): 11.

${ }^{138}$ Mideast Mirror (June 8, 2011), "Buying Loyalty in Yemen."

${ }^{139}$ Hill, Nonneman and Wolff (2011): 10.

${ }^{140}$ Intelligence Online (June 30, 2011), "CIA relies on Riyadh in Yemen."

${ }^{141}$ Hill and Nonneman (2011): 16. 
situation. ${ }^{142}$

The central decision to enter the Houthi conflict in 2009 was therefore taken by an extremely small group, many of whom had little experience with Yemeni affairs prior to the mid-2000s, working with limited information. The decision conformed to the standard Saudi policy of 'keeping it in the family,' and we therefore have little evidence of who was involved in the decision to enter the conflict in Yemen, other than the likelihood that those individuals named above were probably involved. However, several observers have noted that the interior ministry was in no way involved in the conflict itself, ${ }^{143}$ implying that neither Nayef, nor his son Muhammed were major players in the decision to enter the conflict in 2009. Thus, the decision to enter the conflict in Yemen was taken by an extremely small group, many of whom had little experience with Yemen, and probably had limited information on the conflict. This corresponds to our theoretical expectations.

The Saudis did not initially rely on military means to resolve the Houthi conflict, or more precisely, did not rely on their own military means. Instead, they funded military action by Sunni militias and the government of Yemen, only using their own military force after direct attacks on the Kingdom in 2009. The initial funding of others to do the fighting for them mirrors much of Saudi policy for the last thirty years. As Guzansky notes, "Saudi Arabia has traditionally tended to avoid direct confrontation with strong enemies. Instead, it uses its deep pockets to increase its influence." 144 This is similar to Saudi policy in the south of Yemen since 2004, where the Saudis have focused on financial means in their largely unsuccessful effort to coopt tribal networks and conduct a 'hearts and minds' campaign against AQAP militants. ${ }^{145}$ In contrast, Saudi funding in the north of Yemen went directly to military action, in particular the funding in August 2009 of a massive Yemeni offensive against the Houthi, Operation Scorched Earth. The offensive involved more than 40,000 Yemeni troops, and 'indiscriminate' artillery bombings, as Yemeni President

\footnotetext{
${ }^{142}$ It is also worth noting that Yemen itself is an oil-rich state. While a study of its' institutions is outside the scope of this case study, it is interesting to note that many authors also cite Yemen's poor foreign policy, and domestic security institutions as a key cause of the country's turmoil, in line with this study's theory.

${ }^{143}$ Hill and Nonneman (2011): 18.

${ }^{144}$ Guznansky (2011): 57.

${ }^{145}$ Ibid., 14.
} 
Saleh vowed to crush the rebels with an "iron fist." ${ }^{146}$ While this funding of other militant actors does not necessarily constitute direct conflict, it is certainly a form of aggression, and in this way, Saudi actions in Yemen had been aggressively militaristic for some years.

However, in November 2009, in response to Operation Scorched Earth, Houthi forces crossed the Saudi border in a number of places, attacking a number of small Saudi villages and killing several Saudi border guards and civilians. ${ }^{147}$ The Saudi government retaliated with a massive air and ground assault against rebel positions in Saudi Arabia and in Yemen. In the days preceding the attack, Yemeni troops were also allowed to enter Saudi territory in order to flank Houthi positions. ${ }^{148}$ One Saudi source described the attack as a "sustained action" which would "clean out" Houthi strongholds in coordination with Yemeni troops. ${ }^{149}$ The attack constituted the largest ground campaign in the Arabian peninsula since the Gulf War. ${ }^{150}$

As is usual in Saudi foreign policy, it is extremely difficult to assess who was involved in the decision to enter the conflict and whether there were major constraints on decision makers. The key players named above were likely involved, as well as other members of the royal family. In particular, the public face of the attack was Prince Khaled bin Sultan (some commentators at the time even suggested that the attack might have been geared to raise Khaled's profile as a worthy successor to the throne, although his subsequent fall from grace makes this less likely). ${ }^{151}$ The Ulama were publicly supportive of the conflict, as the Houthis are considered heretics; only six months previously, 22 well-known Saudi religious clerics had denounced the Houthi rebellion, claiming it was funded by Iran and attempting to impose Shi'a beliefs on Sunnis. ${ }^{152}$ Public opinion was also generally amenable to an attack, although it is certainly difficult to assess true public opinion when regime propaganda in favor of the conflict had been playing on television for months. ${ }^{153}$

\footnotetext{
${ }^{146}$ Boucek (2010): 9.

${ }^{147}$ Terrill (2011): 19.

${ }^{148}$ Boucek (2010): 11.

${ }^{149}$ American Enterprise Institute (January 4, 2010), "Tracker: Saudi Arabias Military Operations Along Yemeni Border," available from http://www.criticalthreats.org/yemen/tracker-saudi-arabia\%E2\%80\%99smilitary-operations-along-yemeni-border.

${ }^{150}$ Guzansky (2011): 61.

${ }^{151}$ Hill and Nonneman (2011): 18.

${ }^{152}$ Freeman (2009): 1014.

${ }^{153}$ Hill and Nonneman (2011): 18.
} 
There was no significant opposition from business groups, likely because Saudi-Yemeni trade is only a tiny fraction of the country's economy. Saudi Arabia imports mostly agricultural products from Yemen, while exports are extremely limited and tend to be re-exports of goods from Asia or the US. This results from the lack of any significant Saudi manufacturing sector in the oil-heavy economy. Instead, the biggest flow of money between the two states is in fact remittances, as Yemeni domestic workers in Saudi Arabia send money home. ${ }^{154}$ As a result, there was no real lobbying from business groups, as trade was not likely to be affected by any attack. Thus there was no true public opposition to the attack in the Kingdom, meaning that we cannot easily assess the role of constraints on government in this case.

Despite this, the lead up to the Houthi conflict does correspond broadly to the expectations of our theory. Firstly, even without knowing exactly who was involved in this decision, we know that it was made by a few individuals. Secondly, the decision was based on little information, as there were few in the Saudi government with any experience of Yemeni affairs, and the most experienced offices on this subject (the Special Office for Yemen Affairs and the Interior Ministry) appear to have been largely ignored in the process. Finally, the regime faced no significant domestic opposition in its decision to enter conflict.

\subsubsection{2009-2010: The Houthi Campaign}

We can also assess the Houthi conflict itself in order to see whether the theoretical implications of foreign policymaking in a resource-rich state are also notable in the conduct of the war. In particular, by studying the conflict itself, we can better analyze institutional frameworks and relationships, allowing us to assess further the deficiencies caused by oil production. Formal Saudi involvement in the Houthi campaign began in November 2009, after SAM rebels crossed the border in several places and killed Saudi border guards. In response, the Saudi government evacuated more than 240 border villages, ${ }^{155}$ and initiated a major campaign in North Yemen, beginning with

\footnotetext{
${ }^{154}$ Library of Congress (August 2008), "Country Profile: Yemen," Available from http://lcweb2.loc.gov/frd/cs/profiles/Yemen.pdf.

${ }^{155}$ BBC Monitoring Mideast (November 12, 2009), "Qatari Paper says Saudi Attack on Huthists 'Sharp Change' in Foreign Policy."
} 
aerial bombardments, both shelling and bombing Houthi villages using F-15 and Tornado fighter jets. ${ }^{156}$ As the Houthi rebels had typically employed guerrilla tactics, these bombardments were extremely indiscriminate, and targeted Houthi villages and towns. The Saudis also initiated a naval blockade of Yemen's Red Sea coast to prevent the militants from receiving resupply of arms and ammunition. ${ }^{157}$

The air campaign appears to have been extremely successful, with Saudi forces conducting up to 70 air raids per day. ${ }^{158}$ Following the air campaign, the Saudi army moved into northern Yemen to secure the area, but met heavy resistance from Houthi fighters, including suicide bombings. ${ }^{159}$ Although the Saudis deployed overwhelming force, casualties among Saudi troops were extremely high, with estimates of around 113 troops killed, and thousands injured. ${ }^{160}$ Saudi military and institutional performance were seriously lacking during the war; despite ample time to prepare for such a contingency, the campaign was "poorly planned and executed," with the high fatality rate at least partly due to friendly fire incidents. This performance was embarrassing, especially considering that the Kingdom "deployed massively disproportionate force." ${ }^{161}$ The key Saudi tactics of heavy artillery and air bombardment, followed by infantry mop-up, were only partially successful, keeping the Houthis on the run, but doing little to end the conflict and little to stem Saudi casualties. ${ }^{162}$ Indeed, it was reported that King Abdullah was furious that the military was not "more capable, give the billions invested in its modernization." 163 These problems led the Kingdom to seek outside help, appealing to various countries for assistance from their special forces. The Kingdom received

\footnotetext{
${ }^{156}$ Associated Press International (November 5, 2009), "Diplomats: Saudi Bombs Yemen rebels Across Border."

${ }^{157}$ Al Jazeera (November 11, 2009), "Saudis "to Keep up Houthi Campaign."”

${ }^{158}$ American Enterprise Institute (January 4, 2010), "Tracker: Saudi Arabias Military Operations Along Yemeni Border," available from http://www.criticalthreats.org/yemen/tracker-saudi-arabia\%E2\%80\%99smilitary-operations-along-yemeni-border.

${ }^{159}$ It should be noted that throughout the campaign, Saudi officials denied that there were any troops in Yemen. News reports and other sources confirm this to be entirely untrue - Saudi forces did conduct extensive air and ground campaign inside Yemen.

${ }^{160}$ Associated Press International (January 23, 2010), "Saudi: Bodies of 20 Soldiers Found on Yemen Border."

${ }^{161}$ Hill and Nonneman (2011): 17.

${ }^{162}$ Terrill (2011): 20.

${ }^{163}$ Hill and Nonneman (2011): 17.
} 
some troops from Jordan, but was publicly refused aid by Egypt. ${ }^{164}$ In short, the ineptitude of the Saudi military machine proved a major problem during the conflict.

The management of the conflict also showed a strong tendency towards personalization (and as a result, ineptitude). Prince Khaled bin Sultan was in charge of the assault, despite his relatively insignificant post as an Assistant Minister for Defense. While it is not surprising that he would fill in for his indisposed father, the more senior Deputy Minister for Defense (Prince Abdul-Rahman) was effectively bypassed. This seems to be an extension of the previously discussed habit of setting up royal fiefdoms within various ministries; ${ }^{165}$ as Prince Sultan was the Kingdom's primary expert and arbiter of Yemeni affairs, the duty appears to have fallen naturally to his son. It was Prince Khaled who reportedly ordered the Saudi military to cross the Yemeni border (in possible violation of the King's orders). ${ }^{166}$ Khaled was also the face of the operation, attending meetings with the King and foreign dignitaries (such as CIA Director Leon Panetta), and acting as the Kingdom's main spokesman on the conflict. In one notable speech to journalists, Khaled promised that the Kingdom would:

"hit [the] Houthis hard," and would not stop bombing until they "retreat tens of kilometers inside their border." 167

According to a number of sources, Khaled was also responsible for many of the conflict's major tactical blunders, resulting in loss of life among Saudi troops. ${ }^{168}$

The lack of Saudi intelligence from Yemen also proved to be a problem in the prosecution of the war. The US provided the Kingdom with some basic targeting information, but the Saudis were effectively reliant on the government in Sanaa to provide targets for them to hit. As a result, Prince Khaled is reported to have ordered a variety of air strikes which were later determined to be

\footnotetext{
${ }^{164}$ American Enterprise Institute (January 4, 2010), "Tracker: Saudi Arabias Military Operations Along Yemeni Border," available from http://www.criticalthreats.org/yemen/tracker-saudi-arabia\%E2\%80\%99smilitary-operations-along-yemeni-border.

${ }^{165}$ Hertog (2008): 4.

${ }^{166}$ Hill, Nonneman and Wolff (2011): 12.

${ }^{167}$ Al Jazeera (November 11, 2009), "Saudis to Keep Up Houthi Campaign;" Agence-France Presse (November 10, 2009), "Saudi to Bomb Until Yemen Rebels Back Off: Minister."

${ }^{168}$ NPR (October 22, 2010), "Foreign Policy: A Prince's Mysterious Disappearance."
} 
inappropriate, with one US embassy cable from Riyadh detailing the fact that, instead of Houthi militants:

"Yemeni military planners had presented [the] pilots with coordinates to strike the headquarters of General Ali Mohsin," 169

a Yemeni general and rival of President Saleh. The US also confronted Saudi Arabia about a number of its errors, including the targeting of a hospital and other civilian targets. According to one leaked cable, Khaled admitted to the US ambassador that this was because Yemeni targeters had informed the Saudis it was a militant base. He complained that Yemeni intelligence was politically motivated and inadequate for Saudi purposes. ${ }^{170}$ In short, the lack of good information and intelligence seriously hampered the Saudi war effort.

Air assaults continued throughout November and into early December, as Saudi forces sought to control major towns and villages in Sa'dah, as well as to prevent border crossings by Houthi forces. In general, Saudi forces struggled to take and defend territory. ${ }^{171}$ On December 25th, 2009, King Abdullah announced that the army had successfully driven the Houthi threat from its territory, ${ }^{172}$ but combat in fact continued until January of 2010. At that time, the Houthi rebels withdrew from all remaining positions inside Saudi Arabia, claiming that they had been offered a ceasefire; the Saudi government in contrast claimed a military victory. ${ }^{173}$ State media successfully spun the conflict as a 'heroic struggle' against terrorists and heretics, portraying the ceasefire as a major victory. ${ }^{174}$ Despite this, Houthi groups were already back in control of Sa'dah province by 2011, and although they no longer attack Saudi border posts, continue their internal insurgency within Yemen. ${ }^{175}$

\footnotetext{
${ }^{169}$ Hill and Nonneman (2011): 5.

${ }^{170}$ The Guardian (8 April 2011), "WikiLeaks: Yemen Tricked Saudis into Nearly Bombing President's Rival."

${ }^{171}$ American Enterprise Institute (January 4, 2010), "Tracker: Saudi Arabias Military Operations Along Yemeni Border," available from http://www.criticalthreats.org/yemen/tracker-saudi-arabia\%E2\%80\%99smilitary-operations-along-yemeni-border.

${ }^{172}$ Ibid.

${ }^{173}$ Boucek (2010): 11.

${ }^{174}$ Hill and Nonneman (2011): 18.

${ }^{175}$ Ibid.
} 


\subsubsection{Saudi Arabia, Yemen and the Theory of Oil and Aggression}

As the narrative above attempts to illustrate, Saudi intervention in Yemen does indeed correspond to many of the expectations of our theory, although the paucity of information about the Saudi decision-making process does make drawing concrete conclusions difficult. Saudi policymaking towards Yemen generally has displayed flaws which are consistent with foreign policy in an oil rich state: weak institutions and an overpersonalisation of diplomacy, which leads to fragmented and disorganized foreign policy creation and implementation. The already complex Saudi-Yemeni relationship is complicated further by "the absence of a well-delineated Saudi policy, with clear lines of control and leadership." 176 The decision to enter the 2009 Houthi conflict was taken by a small group of individuals, none of whom had much prior experience in Yemeni affairs, without much information. The Saudis also chose to focus on military solutions, first by paying Yemen to fight the Houthis, and then by attacking themselves. There also appear to have been few constraints on policymakers, although it is obviously difficult to ascertain opposition to the government in a system as closed as the Kingdom. During the conflict, both the general disorganization of institutions and the personal nature of decision-making serve to underscore the poor bureaucratic structure and weaknesses of the Saudi foreign policy process. In short, the 2009 Sa'dah conflict in Yemen is an excellent illustration of our theory, showing the ways in which the negative effects of oil production (weak institutions, lower constraints, and a focus on militarization) can both encourage aggression and undermine the production of good foreign policy.

\subsubsection{Saudi Arabia and the Arab Spring}

The Arab Spring which erupted in 2011 took many observers, including the al Saud family, by surprise. In the two years that followed, the Kingdom was heavily involved in an attempt to contain the movements of the Arab Spring and roll them back where necessary, leading some to describe Saudi Arabia's role as 'counterrevolutionary.' Indeed, as one scholar noted, "Saudi Arabia

\footnotetext{
${ }^{176}$ Boucek and Ottaway (2010): 98.
} 
is determined to crush the Arab Spring." 177 The movements of the Arab Spring threaten Saudi domestic stability, the stability of pro-Saudi governments in the region, and the balance of power between Saudi Arabia and Iran. This section will thus attempt to evaluate Saudi foreign policy choices during this difficult period, focusing on three distinct choices: the largely peaceful Saudibrokered diplomatic resolution of the crisis in Yemen (2011), the brutal Saudi military intervention in Bahrain (2011), and the ongoing covert Saudi involvement in the Syrian civil war (2011-2013).

The Arab Spring began suddenly in Tunisia during the first days of 2011, and quickly spread, leading to mass street protests in more than a dozen countries. Although protestors in different countries had many different aims, the common causes of democracy and anti-corruption pervaded most of these protests. Saudi Arabia itself did not experience the levels of protest seen in nearby countries, yet it still experienced unrest, particularly in the Shi'a dominated Eastern Province, where more than 10,000 protestors marched in the streets. ${ }^{178}$ In large part, the Saudi government was able to minimize the effects of these protests by demonizing them as sectarian in nature. Clerics denounced the marchers as Shi'a partisans, ${ }^{179}$ while the regime "frightened its own Sunni majority by exaggerating the Iranian expansionist project in the region." 180 Saudi Arabia also quelled dissent by announcing massive new social spending on education and housing through aid packages totaling over $\$ 100$ billion in direct transfers to citizens. ${ }^{181}$ As a result, Saudi street protests subsided quickly, and a proposed 'Day of Rage' failed to attract participants, despite social media campaigns by activists. ${ }^{182}$

Nonetheless, these protests, in addition to the fact that "the same factors which caused uprisings elsewhere [i.e., high unemployment, pervasive corruption, and widespread repression] exist in the Kingdom" led the al Saud to take an active role in attempting to resolve the crises of other nations. ${ }^{183}$ Indeed, Saudi Arabia played at least a minor role in almost every country in the region,

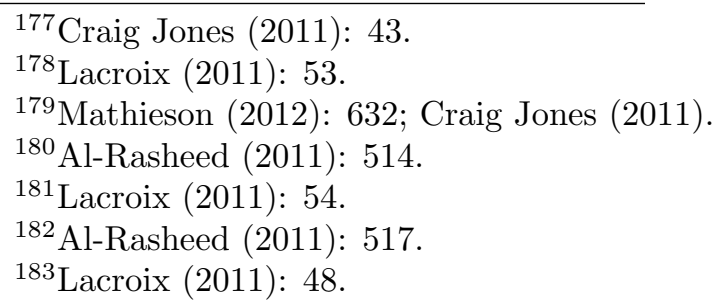


including a $\$ 4$ million aid package to prop up Egypt's post-Mubarak government, financial support to Jordan and Morocco, and providing a safe haven for deposed dictators (i.e., Tunisia's Ben Ali). The Kingdom played a more important role in three key states: Yemen, Bahrain and Syria. In Yemen, the government, already weakened by a decade of civil strife, was further threatened by mass protests in the streets of the capital. The fear of turmoil on their southern border led the Kingdom to take a dominant role in the power transfer that followed. ${ }^{184}$ Bahrain presented a more challenging situation, with mass protests in the Shi'a-majority, Sunni-ruled state. These protests quickly turned violent as the al Khalifa regime sought to repress them. Finally, the conflict in Syria began in April 2011, starting with mass protests calling for the regime to step down after the torture of several young boys, and culminating in civil war. The Saudi government would like to see the Assad regime fall, but the Syrian conflict continues to grind on, with no clear end in sight, a point of frustration and concern for the Kingdom's leaders.

\subsubsection{Saudi Arabia Enters Bahrain: A Military Response}

The first crisis to draw Saudi attention was Bahrain, where in early 2011, protestors began to agitate for greater political freedoms and rights for the country's majority Shi'a population. Although a number of non-sectarian groups (such as the al-Haqq Movement for Liberty and Democracy) were involved, the mass protests were focused on the fact that while Bahrain's ruling al Khalifa family is Sunni, two-thirds of the population are Shi'a muslims. ${ }^{185}$ Shi'ites in Bahrain have been systematically discriminated against, and are frequently denied the rights to build mosques, take certain jobs, or enter the armed forces. Although they constitute the majority of the Bahraini population, the Shi'a are treated as a minority. ${ }^{186}$ By February 14, protests in the centre of Manama had grown to thousands of people. The Bahrainis initially tried to quell the protests by buying off the population, providing cash transfers of $\$ 2650$ to each family. ${ }^{187}$ The family also tried sending Crown Prince Salman, a noted reformer to negotiate with the protestors. These measures were

\footnotetext{
${ }^{184}$ Hill, Nonneman and Wolff (2011): 4.

${ }^{185}$ Dalacoura (2012): 65-8.

${ }^{186}$ Craig Jones (2011): 55.

${ }^{187}$ Burns (2013): 431.
} 
unsuccessful, however, and protests continued to swell, focusing on the Pearl Roundabout in the capital, Manama. By mid-February 2011, the regime began to use the Sunni-only military to suppress the still-largely peaceful protests. ${ }^{188}$ The death toll was low, but police fired on protestors repeatedly, and protestors began to blockade important areas like the financial center. ${ }^{189}$ It was at this point that the Bahraini government turned to Saudi Arabia (through the GCC) for help.

Although the two kingdoms are nominally and legally separate, Bahrain relies heavily on the Kingdom in matters military, financial and political. The two families are distantly related, as the al Khalifa originate in the Nejd region of Saudi Arabia, and have strong ties to the Saudi branch of Wahhabist Islam. ${ }^{190}$ Bahrain's economy is heavily dependent on financial services and oil refining, and handles both Saudi money and transit of Saudi oil. The Kingdom is Bahrain's largest trading partner, with over $26.7 \%$ of imports and $3.4 \%$ of exports to Saudi Arabia. Saudi investments in Bahrain tend to top $\$ 1$ billion each year, and Saudi citizens make up over $70 \%$ of Bahrain's large tourist industry. ${ }^{191}$ In addition to these strong economic links, there are strong links between Saudi Shi'a in the Eastern province and Bahraini Shi'a. Saudi citizens protesting in the Eastern Province in 2011 carried Bahraini flags, and were heard to chant "Free Bahrain," and "one people, not two people." 192

As a result, the protests in Bahrain terrified the al Saud: Firstly, they feared the potential spillover of revolution from Bahrain into the Shi'a population of the Eastern Province, the location of the Kingdom's largest oil field and most refineries, and around 10\% of the population, predominantly Shi'a. ${ }^{193}$ Secondly, they feared the loss of a friendly Sunni monarchy on their border. Loss of Bahrain's economic contribution to the kingdom would not only be extremely damaging, but the creation of a democratic Shi'a majority state, likely to be friendly to Iran, on the Saudi border carried major security implications. For this reason, the crisis in Bahrain was one of the gravest

\footnotetext{
${ }^{188}$ Ibid., 430-441.

${ }^{189}$ Ibid., 441.

${ }^{190}$ Nurazzaman (2013): 371.

${ }^{191}$ Ibid., 368.

${ }^{192}$ Mathieson (2012): 633-637.

${ }^{193}$ Nurazzaman (2013): 371.
} 
threats to Saudi Arabia in many years. ${ }^{194}$

The key decision makers in the Kingdom on this issue were similar to those involved in the 2009 Yemen crisis, and the foreign ministry itself again played a relatively minor role, with personal networks and diplomacy trumping any form of organized diplomacy. Prince Nayef and his interior ministry (including his son Muhammed) played a major role, and each visit of a Bahraini royal to Riyadh involved a private meeting with Nayef. In contrast, it is unclear whether Foreign Minister Saud was present at key meetings, and he primarily acted as a spokesperson. Saud appears to have acted more as a messenger than a decision maker during the crisis. King Abdullah himself was heavily involved in decisions on the Bahraini issue, as was Prince Muqrin, head of the GIP. Finally, Bandar bin Sultan, former ambassador to the US, was recalled to the Kingdom after several years in effective exile. It is strongly suspected that he was recalled to head the Saudi response to the Arab Spring, and to act as an intermediary with the US and other Arab states on the issue. ${ }^{195}$ Defense Minister Sultan, although formally involved in the process, was likely incapacitated throughout the crisis, and died in October of that year.

The health issues associated with such a personalistic form of governance again undermined the Saudi decision-making process. Although protests in Bahrain began in January 2011, no major decisions were made until late February, when King Abdullah finally returned to the kingdom after three months abroad for surgery and physical therapy to treat a herniated disk. ${ }^{196}$ Immediately following his return, the Kingdom announced two major social spending packages to quell unrest. Underlining the importance of Abdullah's presence is the fact that he was met at the airport in Riyadh not only by various senior princes, but also by the Prime Minister of Bahrain. ${ }^{197}$ During his absence, much of the day-to-day diplomacy had been carried out by Prince Nayef, but as one expert noted:

"King Abdullah's the central figure and ultimately calls the shots, but he's not in

\footnotetext{
${ }^{194}$ Freeman (2011): 31.

${ }^{195}$ Intelligence Online (March 31, 2011), "Princes Try to Extinguish Arab Revolts; Saudi Arabia."

${ }^{196}$ CNN (February 23, 2011), "Saudi King Returns Home to Shaken Mideast."

${ }^{197}$ International Herald Tribune (March 15, 2011), "Strain Tugs at Ties with a Key U.S. Ally; Saudis Taking a Dim View of American Stances from Mubarak to Bahrain."
} 
perfect health and neither are the people around him. It's not contributing to the Saudis ability to create a coherent policy and establish facts on the ground." 198

During the first six months of 2011, King Abdullah was too frail to conduct a full day's work, Defense Minister Sultan was abroad for medical treatment, and both Interior Minister Nayef and Foreign Minister Saud were unwell. ${ }^{199}$ Thus the personality-driven nature of the Saudi system, combined with the extreme age of its leaders, continues to pose problems for coherent foreign policy.

The individuals involved in the decision appear to have differed on the correct course of action, and disagreement appears to again have been purely personal (not institutional) in nature. From the limited information available, it appears that Nayef (possibly supported by Muqrin) may have supported a crackdown, both in Saudi Arabia and in Bahrain. Certainly, both princes had been involved in the 2009 Saudi crackdown on Shi'a in the Eastern Province, and a number of officials from the interior ministry and armed forces who were known to be involved in the crackdown were sent to Bahrain as political and military advisors in late $2010 .^{200}$ In contrast, King Abdullah, always considered more of a reformer, appears to have been reluctant to intervene in Bahrain, and was only persuaded to do by the idea that Bahrain was in fact a source of possible 'contagion' (i.e., of unrest) for the Kingdom. ${ }^{201}$ Domestically, the issue was also tied up with the thorny issue of reform, which splits members of the royal family into two rough blocks: reformers (i.e., Abdullah) and conservatives (i.e., Nayef). ${ }^{202}$ There is even speculation that the reform/conservative divide, which is mirrored in Bahraini politics, led Bahraini Prime Minister Hamad (a noted conservative) and Nayef to agree that an intervention had to happen before Bahraini Crown Prince Salman negotiated a liberalizing compromise with protestors, initiating the attack. ${ }^{203}$ Although little hard evidence exists to back this assertion up, it cannot be discounted as a possibility.

\footnotetext{
${ }^{198}$ Reuters (September 29, 2011), "Frail Saudi Royals Face Hard Diplomatic Choices."

${ }^{199}$ Ibid.

${ }^{200}$ McLatchy Washington Bureau (June 22, 2011), "Wikileaks: Saudi Crackdown on Shi'ites has Echoes in Bahrain."

${ }^{201}$ Freeman (2011): 31.

${ }^{202}$ Al-Rasheed (2011): 518-9.

${ }^{203}$ Hilterman (2011); Seznec (2011).
} 
On March 14, around 1500 Saudi National Guardsmen marched across the causeway into Bahrain, supplemented by small numbers of troops from Kuwait and the UAE. They were invited to do so by Bahrain's monarch, as part of the Peninsula Shield Force (the GCC's common defense body), but were predominantly Saudi, and key decisions were taken in Riyadh. ${ }^{204}$ Although the force was ostensibly tasked with protecting vital infrastructure ${ }^{205}$ observers describe a brutal crackdown on protestors, as "armed security forces, including throngs of sword-wielding vigilantes... [who] violently routed tens of thousands of peaceful protesters." 206 The crackdown also included "mass arrests, the destruction of Shi'a places of worship, arbitrary detention and torture, and the dismissal of hundreds of protesters from their jobs." ${ }^{207}$ Bahraini and Saudi forces also blockaded hospitals, so that the injured could not receive medical attention without facing arrest. ${ }^{208}$ The suppression campaign lasted until early June 2011, and has been largely successful: Bahrain is the only monarchy under serious threat to survive the Arab Spring. ${ }^{209}$

Why did the Saudi government decide to militarily intervene in such a spectacular fashion? It is true that the government in Riyadh had exhausted several options already, in particular the ability to buy off the population in Bahrain, which had failed early in the year. The Saudis were also seriously worried about unrest spilling over to the Eastern Province. However, the Bahrainis did not really need military help; the Bahraini army is 30,000 men, many of whom come from Pakistan and other Sunni muslim countries and are extremely loyal to the royal family. ${ }^{210}$ The Saudis could easily have provided funding or arms to Bahrain to assist in putting down the rebellion, much as they did in other countries. It is therefore notable that the Saudis, known for using money instead of troops wherever possible, resorted to violence. Instead, it seems that the Saudis, by sending in their military, were attempting to send a strong message to both their own population, and to Iran, discouraging further unrest. $^{211}$

\footnotetext{
${ }^{204}$ Hiltermann (2011).

${ }^{205}$ Ayoob (2011).

${ }^{206}$ Craig Jones (2011): 43.

${ }^{207}$ Dalacoura (2012): 72 .

${ }^{208}$ Burns (2013): 441.

${ }^{209}$ Allansson et al (2011): 55 .

${ }^{210}$ Seznec (2011).

${ }^{211}$ Al-Rasheed (2011): 523.
} 
Intelligence collection appears to have been less of an issue in this crisis than others, partly because most information came directly from Bahrain. The major role played by the intelligence services during this crisis was to disseminate propaganda, aligning Shi'a protestors with Iran, and delegitimizing them as a result. ${ }^{212}$ The Kingdom's leaders also sought to win over public opinion in favor of intervention this way. In effect, the Saudis sought to use sectarian fears as a counterrevolutionary strategy: by exaggerating religious differences they raised fears of a Bahrain run by the Shi'a majority, and encouraged public opinion which favored the intervention. ${ }^{213}$ Public opinion was thus generally in favor of intervention, but it is impossible to say what role government propaganda played in creating this.

The case of Bahrain provides some support for our theory, but the lack of available information makes assessment difficult. Once again, the opacity of Saudi decision-making results in a policy process that is extremely difficult to observe or assess. Nonetheless, foreign policy making in this case does conform to several of our key expectations. Policymaking was - as always - highly personalized, with ministry fiefdoms and family ties proving more important to policymaking than other factors. The reliance on individuals weakened policymaking, and diplomacy was conducted in a highly personalized manner. For example, it appears that a decision on Bahrain could not be taken until King Abdullah returned to the Kingdom, which delayed action and likely reduced available options. Conflict between personalities (in particular, the reform/conservative divide) also appears to have been a problem. The Kingdom does appear to have relied heavily on military options in this case, even when other options were available. In short, a lack of information makes it difficult to assess the case of Bahrain, but it does seem to fit well with the picture of Saudi foreign policy as that of an oil-rich state: weak institutions, personality-driven diplomacy, and a reliance on the military.

\footnotetext{
${ }^{212}$ Lacroix (2011): 54.

${ }^{213}$ Al-Rasheed (2011): 513.
} 


\subsubsection{Yemen and Syria: Diplomacy and Covert Action}

As the Saudi intervention in Bahrain occurred, other protests were expanding throughout the Arab world. Major protests against the oppressive and corrupt government of Ali Abdullah Saleh began to spread in Yemen, reaching their height in late Spring 2011. As Section 5.3.1 discusses, although they cooperate on issues of common concern (such as the Houthi conflict or the fight against AQAP), there has been little love lost between the al Saud and the government of Yemen over the years. Indeed, one leaked cable from 2010 quoted Mohammed bin Nayef describing Yemen to US Envoy Richard Holbrooke as a failed state, due to the weaknesses of President Saleh's government. ${ }^{214}$ However, unlike the Bahraini uprisings, the protests in Sanaa were not sectarian, and were broader in nature (protestors sought higher wages, lower unemployment, and an end to government corruption), making intervention more difficult to justify for the Saudis.

The Saleh regime attempted to quell the protests with patronage, bribery, a lowering of the income tax, increased wages for civil servants, and the creation of a 'loyal' countermovement (primarily a propaganda tool). When these attempts failed, the regime began to respond violently, beginning with the massacre of around 50 peaceful demonstrators by government rooftop snipers in March 2011. ${ }^{215}$ The GCC (again, led almost exclusively by Saudi Arabia) instead attempted to negotiate a peaceful transfer of the presidency to one of Saleh's lieutenants, but was unsuccessful, as the president continually refused to give up his power. The proposed deal (amnesty for Saleh in exchange for his stepping down within 30 days) was agreed to by all parties three times, yet President Saleh refused to sign, even at a formally arranged signing ceremony in May. ${ }^{216}$

In response, the al Ahmar tribe launched attacks on the Saleh regime, killing over 140 government soldiers between May and June. ${ }^{217}$ It can be inferred that the Saudi government either authorized or did not object to this use of force: they have long controlled the Ahmar tribe, and routinely give each Ahmar tribal chief up to $\$ 7000$ per year in exchange for their loyalty. ${ }^{218}$

\footnotetext{
${ }^{214}$ Reuters (December 2, 2010), "Saudis Think Yemen is a Failed State - Leaked US Cable."

${ }^{215}$ Thiel (2012): 43-44.

${ }^{216}$ Al Jazeera (May 22, 2011), "Yemen Transition Deal Collapses."

${ }^{217}$ Agence France Presse (June 8, 2011), "Saudis May be Key to a Yemen Solution."

${ }^{218}$ Mideast Mirror (June 8, 2011), "Buying Loyalty in Yemen."
} 
Throughout this time, protests and violence grew, with the Saleh regime effectively under siege. ${ }^{219}$ Finally, in June 2011, after being seriously wounded in an RPG attack on his palace, Saleh fled to Saudi Arabia for medical treatment, where he remained until September. A ceasefire was negotiated, but fighting continued throughout the summer and into autumn (although it is difficult to assess how much of Yemen's conflict was related to the protests, and how much to its internecine domestic problems). ${ }^{220}$

Saleh returned to Yemen in late September, but continued to refuse to give up power. It was not until November 23rd, following increasing levels of violence and a UN Security Council resolution calling for his removal from power that he signed the GCC accord and turned over power to his Vice President. ${ }^{221}$ This peaceful solution was brokered by the Kingdom, and conforms well to the common understanding of Saudi foreign policy, with the Kingdom primarily using money and soft power to mediate conflicts. ${ }^{222}$ However, Saudi policy was in many ways extremely schizophrenic in this case: the Kingdom continued to give massive amounts of money to Yemeni tribes fighting the government, even as they called publicly for an end to the violence. In addition, Saudi Arabia is reported to have sent military advisors to help the Saleh regime repress the violence. In effect, the Saudis, while negotiating for peace, continued to fund both sides of the conflict.

This schizophrenia is mirrored in the policy-making process, with major divisions within the royal family on how to deal with the Yemeni issue; various reports indicate that Prince Nayef continued to back the Saleh government, while Prince Sultan (or more likely his son) favored finding an alternative among the al Ahmar tribes to run Yemen. ${ }^{223}$ All parties within the Kingdom were reluctant for anything other than a managed elite transition, one reason why they kept up the pressure on Saleh throughout the process. ${ }^{224}$ There was also a strong generational schism within the royal family, with younger members keen to cut the Saleh regime loose, and older princes preferring an intra-regime transition. As with many foreign policy debates, the fact is that "there 
is no one single Saudi policy. Each issue is handled from a different point of view." ${ }^{225}$

Thanks to this debate, internal discussions of the Yemen problem dragged on through the summer, as did negotiations with America and other outsiders. In addition, the absence of several key decision makers from the Kingdom, either for health reasons, or on vacation, further reduced the pace of negotiations to a crawl. ${ }^{226}$ American officials expressed frustration that they could not get the Saudis to discuss Arab Spring related issues in a timely fashion, ${ }^{227}$ despite the fact that the Kingdom relies heavily on the provision of US intelligence. ${ }^{228}$ The process was also complicated, as one report put it, by the fact that "Saudi Arabia's foreign policy system still lacks advanced strategic capacity, operational skills and experience." ${ }^{229}$ As in previous instances, it was extremely unclear which princes and ministries were responsible for Yemen policy, and it is entirely possible that the funding discrepancies noted above were the result of different agencies pursuing different policies. As Nonneman notes, "the problem.. is that internally, there's no cohesion." Instead, there is a "diffuseness of policymaking, [a] lack of coordinated strategizing and lack of coordinated implementation policy," with "no clarity exactly who has the main voice." ${ }^{230}$ Saudi policy in Yemen in 2011 was therefore the result of an extremely underinstitutionalised foreign policy system.

At the same time, the uprising in Syria was beginning to gather steam. Demonstrators took to the streets to protest the torture of a number of children arrested for writing anti-government slogans. The regime, rather than offering concessions, sought to violently repress the protests, and clashes between police and protestors spread throughout the country, worsening throughout 2011. By late 2011, the protests had become violent, and developed into a full-fledged civil war between rebels and pro-Assad government forces by early 2012. In total, as many as 7500 people were estimated to have died in the first year of the conflict alone. ${ }^{231}$ Since that time, violence has continued unabated; the Syrian opposition has fragmented badly, and little progress is being made

\footnotetext{
${ }^{225}$ Reuters (July 14, 2011), "Saudi Policy on Yemen and Syria seen Floundering."

${ }^{226}$ Ibid.

${ }^{227}$ International Herald Tribune (March 15, 2011), "Strain Tugs at Ties with a Key U.S. Ally; Saudis Taking a Dim View of American Stances from Mubarak to Bahrain."

${ }^{228}$ Gause (2011): 30 .

${ }^{229}$ Hill and Nonneman (2011): 9.

${ }^{230}$ Hill, Nonneman \& Wolff (2011): 10.

${ }^{231}$ International Institution for Strategic Studies Strategic Comments 18, no. 2 (2012): 1.
} 
by either side in the conflict.

Unlike Bahrain and Yemen, the Kingdom's leaders did not view the Syrian government as a friendly power; the regime in Damascus has always been a strong supporter of Iran. As one scholar describes, "it is not coincidental that Saudi Arabia has been especially adamant about calling for Assad's ouster and for a transitional government...The fight inside Syria is a microcosm of the regional struggle between Sunni Saudi Arabia and Shi'ite Iran." ${ }^{232}$ In addition, King Abdullah personally blames the Syrian government for the assassination of his close friend, former Lebanese Prime Minister Rafik Hariri. ${ }^{233}$ Thus, from the start, the Saudis were keen to see the Assad regime fall, and undertook some diplomatic overtures to that end. As early as March 2011, Bandar bin Sultan, Saudi Arabia's new head of intelligence, began to coordinate international support for the removal of the Assad regime, using his many contacts in Washington and elsewhere to build support. $^{234}$

However, the Saudis largely ignored the crisis in Syria as they focused on other countries during the Arab Spring. As one commentator noted in September 2011, "diplomats have long described Saudi foreign policy as working like a searchlight: able to focus sharply on a single dominant issue, but lacking the capacity to follow up its interest when attention has moved elsewhere." 235 With their attention focused on Egypt, Bahrain, and Yemen, the Saudis therefore remained largely uninvolved in Syria until early 2012. Following the resolution of the Yemeni crisis in late November 2011, the Saudis turned their attention to diplomatic solutions to the Syrian crisis, pushing strongly for a UN Security Council resolution calling for the removal of Bashar al-Assad. The failure of this resolution to pass in February 2012 led King Abdullah to strongly criticize the UN:

"we all used to take pride in the United Nations... but what took place does not augur well, as world confidence... has undoubtedly been shaken." 236

The King was also reported to have told Russian Prime Minister Medvedev that further dialogue

${ }^{232}$ Carpenter (2013): 4 .

${ }^{233}$ Foreign Policy (July 24, 2010), "The Prince and the Revolution."

${ }^{234}$ Intelligence Online (March 31, 2011), "Princes Try to Extinguish Arab Revolts; Saudi Arabia."

${ }^{235}$ Reuters (September 29, 2011), "Frail Saudi Royals Face Hard Diplomatic Choices."

${ }^{236}$ New York Times (February 10, 2012), "In Rare, Blunt Speech, Saudi King Criticizes Syria Vetoes." 
on Syria was "pointless," and that action must be taken. ${ }^{237}$

Beginning in spring 2012, therefore, the Saudis began to supplement their diplomatic support for Syria's rebels with financial and military aid. The Kingdom shut down its embassy in Damascus, and more importantly, began to negotiate with Jordan to permit the passage of weapons from Saudi sources to Syrian rebels. ${ }^{238}$ Thus by mid-2012, the Kingdom was heavily involved not only in diplomatic efforts to remove Bashar al-Assad from power, but in funding and arming the Syrian opposition. By mid-2012, the Washington Post reported that:

"Saudi officials have been circumspect about their direct support to Syrian rebels, although government officials privately said Riyadh is buying arms and ammunition, as well as paying salaries for soldiers who defected from the Syrian military to join the rebels." 239

Similar reports claim that although the Saudis are not acknowledging it, Kalashnikovs and millions of rounds of ammunition have been sent to Syria. Until mid-2013, the Saudis refrained from sending heavy weapons to Syria, but following months of frustration with US unwillingness to enter the Syrian conflict, there are numerous reports of anti-tank missiles, ${ }^{240}$ anti-armor rockets, and other heavy weaponry being funneled through Jordan into Syria. ${ }^{241}$ In addition, the Kingdom is paying Qatar to provide logistical and military support to various Syrian rebel groups, and is spending tens of millions of dollars to fund training for more moderate Syrian opposition groups (such as Jaysh al-Islam). ${ }^{242}$ They are also hiring Pakistani instructors, with the goal of unifying more than 50 distinct rebel brigades into a force capable of challenging Damascus. ${ }^{243}$ In addition, the Kingdom continues to push diplomatically for multilateral action to remove Assad; Russian press reported in August 2013 that Prince Bandar met with President Putin and offered to buy $\$ 15$ billion of weapons from Russia and to invest in the country in exchange for Russian condemning,

\footnotetext{
${ }^{237}$ RIA Novosti (February 22, 2012), "Saudi Arabia King: Current Dialogue on Syria 'Useless'."

${ }^{238}$ Agence-France Presse (March 17, 2012), "Saudi Sends Military Gear to Syria Rebels: Diplomat."

239 Washington Post (October 8, 2012), "Saudis Line Up Against Syrian Regime."

${ }^{240}$ New York Times (September 9, 2013), "Tracking the Syrian Crisis and the International Response."

${ }^{241}$ Foreign Policy (July 24, 2010), "The Prince and the Revolution."

${ }^{242}$ The Guardian (November 7, 2013), "Syria Crisis: Saudi Arabia to Spend Millions to Train New Rebel Force."

${ }^{243}$ Foreign Policy (November 8, 2013), "Saudi Arabia's Shadow War."
} 
rather than supporting, Syria. ${ }^{244}$ However, it is almost certain that the Saudi military will not become directly involved in this crisis, as a larger regional conflict with Iran would likely result.

It is extremely difficult to determine who the key decision makers have been in Saudi involvement in Syria, not least because the last two years have seen rapid changes in top positions within the Kingdom. In this time period, the gerontocratic tendencies of the Saudi state have only intensified, with no clear line of succession to a younger generation. ${ }^{245}$ The death of Crown Prince Sultan, after several years of incapacitation, in October 2011, led to the elevation of Prince Nayef to Crown Prince, and the appointment of Prince Salman as Minister of Defense. Although Salman had been Governor of Riyadh province for forty-eight years, he had previously played no role in foreign policy. Crown Prince Nayef himself succumbed to a stroke in March 2012, and died in June of that year, elevating Prince Salman to Crown Prince. Prince Salman was deputized to run the Kingdom in August 2012 (while Abdullah was abroad for medical care), but he is also in poor health. With his lack of knowledge in foreign affairs and health issues, it is unlikely that Salman plays any major role in the Arab Spring crises; his health is declining, and he suffers from dementia, with various sources reporting that he no longer makes any important decisions. ${ }^{246}$

In general, in addition to the King and Prince Muqrin, the Interior Ministry, and the GIP remain heavily involved in issues of the Arab Spring, while the Foreign Ministry has been largely sidelined, and tends to act only as a mouthpiece for policy. Turki al-Faisal, son of the Foreign Minister, has been increasingly acting as the Kingdom's spokesperson abroad, despite his lack of formal position. ${ }^{247}$ Yet even as Saudi Arabia has become increasingly tied involved in the Syrian crisis, foreign policy in the Kingdom has become increasingly sclerotic. US National Security Advisor Thomas Donilon blames the Kingdom's inability to adequately address the issues raised by the Arab Spring to this slow withering of elderly royals, arguing that:

"[our conversations] have been strained in part by the slow-motion transition of power."

\footnotetext{
${ }^{244}$ Agence-France Presse (August 8, 2013), "Moscow Rejects Saudi Offer to Drop Assad for Arms Deal." ${ }^{245}$ Gause (2011): 10-11.

${ }^{246}$ World Tribune (August 12, 2013), "Ailing Saudi Crown Prince Suddenly Takes 'Special Leave'."

${ }^{247}$ Reuters (September 29, 2011), "Frail Saudi Royals Face Hard Diplomatic Choices."
} 
Another US official noted that:

"we're focused on... the next generation, who seem to understand a lot better what's got to happen." 248

Indeed, the next generation of Saudi leaders are beginning to enter key positions, although the method of succession conforms clearly to the fief-like nature of Saudi bureaucracy. Thus, Muhammed bin Nayef has taken over for his father at the Interior Ministry, Prince Miteb, son of the King, has replaced his father as head of the National Guard, and Crown Prince Salman was appointed Defense Minister to replace his full brother Sultan. Two key exceptions are the elevation of Prince Muqrin to Second Deputy Prime Minister (i.e., second in line to the throne), and his replacement at the GIP by Prince Bandar bin Sultan. Both Princes are younger, favor cooperation with the US, and are known to be competent. The appointment of younger princes may reflect an acknowledgement among the family that the frailty of its leaders is beginning to seriously compromise the personal form of diplomacy favored by the Saudis. ${ }^{249}$ In particular, the recall of Prince Bandar from his effective exile in the US (after a falling out with the King) to manage the Syria crisis likely reflects the fact that no other senior prince can be found who is qualified for the job. ${ }^{250}$ The slow transfer of authority to the next generation results in a government which is almost immobile, even on key issues.

In addition to personality-driven problems, the Saudi response to the Syrian crisis has demonstrated deeper institutional issues. Firstly, the sidelining of the foreign ministry is largely due to internal prestige, rather than any specific shortcoming in its efforts on the issue. The importance of the interior ministry (in an issue which is manifestly non-domestic) reflects more the preeminence of the Minister in decision-making than the relevance of his ministry to the issue at hand. It is therefore extremely unlikely that leaders are making well-informed decisions when backed by a bureaucracy with no mandate to monitor or study the issue under discussion! Secondly, in supporting

\footnotetext{
${ }^{248}$ International Herald Tribune (March 15, 2011), "Strain Tugs at Ties with a Key U.S. Ally; Saudis Taking a Dim View of American Stances from Mubarak to Bahrain."

${ }^{249}$ Reuters (September 29, 2011), "Frail Saudi Royals Face Hard Diplomatic Choices."

${ }^{250}$ Foreign Policy (July 24, 2010), "The Prince and the Revolution."
} 
the Syrian rebels, the Kingdom has relied heavily on logistical support from other regional partners. For example, the Saudis have paid the Qataris to provide intelligence and logistic support to the Syrians. As one leaked report notes:

"[they] have a lot of money but very poor intelligence and human resources and organizational skills... they are very dependent on the western military.... they are too used to having relationships with clients and using personal networks." 251

The Saudi decision to hire logistical and intelligence support in Syria is in fact a reflection of their weakness in intelligence gathering anywhere other than the Kingdom itself (and Yemen), and their usual reliance on the US in this regard.

Public opinion in the Syrian crisis has been less relevant than in other Arab Spring-related debates. The Saudi public has been almost uniformly supportive of Saudi actions in Syria. In response to a call by King Abdullah for donations for the 'brave Syrian people,' for example, one telethon in July 2012 saw eager Saudis pledge over $\$ 150$ million in humanitarian aid. ${ }^{252}$ Wealthy Saudis have opened their wallets to many Syrian groups, a trend fueled not only by humanitarian demands, but by the fear that Iran may become dominant in the region. ${ }^{253}$ Thus, public opinion has not played a major role in this crisis. Whether this will change as Saudi intervention in Syria increases remains to be seen.

\subsubsection{Saudi Arabia and the Arab Spring: The Theory of Oil and Aggression}

The narrative above attempts to illustrate the Saudi foreign policy decision-making process during the recent series of crises known as the Arab Spring. As in the case of the Houthi rebellion, Saudi choices during the Arab Spring correspond closely to many of the expectations of our theory, particularly those relating to the institutional structure of foreign policymaking. Also similar is the complete lack of public information about Saudi decision processes, which does make it difficult to assess who is making decisions, and how the bureaucracy operates. Nonetheless, Saudi responses

\footnotetext{
${ }^{251}$ The Guardian (November 7, 2013), "Syria Crisis: Saudi Arabia to Spend Millions to Train New Rebel Force."

${ }^{252}$ Washington Post (October 8, 2012), "Saudis Line Up Against Syrian Regime."

${ }^{253}$ Ibid.
} 
to the Arab Spring tend to illustrate similar problems. Firstly, the overpersonalised nature of decision-making means that decisions are often being made by non-experts, or by ministers with no background in an issue. The personalistic nature of Saudi diplomacy means that many decisions are undermined by the health issues of the elderly royals involved, and means that foreign policy is slow, sclerotic and non-responsive. Secondly, the diffuse nature of Saudi foreign policy means that different ministries may in fact be working against each other without realizing it, as in the case of the Yemeni uprising. Again, in such a personalistic system, the absence of key figures at the top of the hierarchy thus has the ability to undermine the entire system.

Third, public opinion appears not to have played a major role in decisions during the Arab Spring, although it is worth noting that the regime took great care to portray each of these three crises as a sectarian struggle in an attempt to win over domestic support. Given these efforts, it is almost impossible to determine the impact of public opinion on leaders vs. the impact of propaganda in shaping public opinion. Finally, Saudi Arabia did not always resort to military means to resolve these crises. They did use primarily military means in Bahrain, even when it was not strictly necessary, but refused to get militarily involved in either Syria or Yemen. It is worth questioning the extent to which Saudi actions (i.e., supplying arms, funding fighters) are aggressive, even if they do not involve direct military conflict. There is certainly no doubt that in each of these three conflicts, the Kingdom attempted to impose its will directly on a third party state, and was willing to use non-diplomatic means to do so. In general, the Saudi response to these crises was disorganized, personalistic, and unplanned, as predicted by our theory. Thus, the case of the Arab Spring is broadly supportive of the theory, showing the ways in which the damage caused by oil wealth to the Kingdom's foreign policy apparatus can ultimately lead to aggressive and poorly formulated foreign policy.

\subsection{Conclusion}

In conclusion, although Saudi Arabia has a reputation for being non-aggressive, it in fact appears to correspond closely with our theoretical expectations, though the Kingdom is less likely to be 
overtly conflictual in its actions, and far more likely to either attempt to impose its will on other states by the use of incentives, or to act violently through proxies. In effect, although Saudi Arabia rarely invades other countries, its influence can be found behind the violent actions of many thirdparty actors across the Middle East. This chapter has sought to illustrate that this dissertation's theory, rather than alternate explanations, provides the best explanation of this aggression.

\subsubsection{Alternative Explanations}

\section{Revolutionary War Theory}

Similar to the Russian case, the theory of revolutionary war does not adequately explain the several cases of Saudi aggression shown in this chapter. Due to the theory's focus on militarized interstate disputes as the sole aspect of state aggression, it does not seek to explain non-MID conflict or aggression. As the analysis above has shown, however, Saudi aggression has tended to primarily involve covert actions and the funding of proxy actors. While Colgan argues that such behavior "does not constitute significant aggression," Saudi involvement in Yemen, Bahrain and Syria has frequently been large-scale, and has altered the outcomes of entire conflicts. ${ }^{254}$ It is extremely hard to argue that such behavior was in no way aggressive. Even without this oversight of analysis, the theory of revolutionary war predicts that Saudi Arabia should be non-aggressive. The Al-Saud monarchy are the polar opposite of a revolutionary government, seeking in all things to maintain the status quo. As such, the theory of revolutionary war cannot explain why Saudi Arabia has been so aggressive in recent years.

\section{Balance of Threat Theory}

As revolutionary government is not present in the Saudi case, it is important to evaluate whether the conflicts laid out in this chapter could simply be explained by standard neorealist balance of threat arguments. These theories do not do a good job of predicting or explaining Saudi involvement in Yemen, where a minor threat from a small group of rebels was greeted with an overwhelming

\footnotetext{
${ }^{254}$ Colgan (2013): 249.
} 
military response. The Houthi rebels were politically troubling, but posed no real threat to the Saudi state, and could have been dealt with using back-channel funding to Yemen as had previously been the case, if not for the institutional incompetence which rendered this option unusable. Balance of threat theory also does not do a good job of explaining Saudi overreaction to the events of the Arab Spring, although Saudi involvement in Syria as a counter to Iranian expansion can perhaps be explained as such. Again, these revolutions, although politically troubling to the Saudi monarchy, did not pose any major military threat. As such, Saudi aggression in the cases discussed above was usually disproportionate to the level of threat faced by the country, and is not well explained by classic Balance of Threat theory.

\subsubsection{Saudi Arabia: Institutional Fragmentation and Aggression}

Thus, when compared to other theories, this dissertation's theory of oil and aggression explains the Saudi case well. This case shows clear links between oil and our mediating variables (in particular, weak institutionalization). The development of Saudi institutions, with the use of oil rents to circumvent the development of a coherent bureaucracy, and the creation by princes of individual fiefdom-ministries has undoubtedly led to the underdeveloped foreign policy apparatus. The endemic personalization of foreign policy, and incompetence of the bureaucracy underscore this point. In addition, as expected, the Saudis do spend excessively on armaments. While they seldom use their own military, the Kingdom's leaders rarely shy away from arming or paying other groups to act on their behalf. Thus, despite the Saudi reputation for negotiation, they do in fact often rely on military action. Finally, the Saudi system does exhibit some, but not complete, freedom from constraints in policymaking. The royal family's use of oil rents to manipulate public opinion means they do not question foreign policy; however, the al Saud do listen carefully to the opinions of religious leaders. The two sub cases also followed up on this general analysis, and provided an illustration of how these factors, created by oil wealth, can ultimately lead to aggressive foreign policy. In the 2009 Yemeni crisis, as well as Saudi responses to the Arab Spring, we find that foreign policy making - as far as can be determined from public sources - was extremely personalistic, focused 
on military means, and marred by conflict between individuals and institutions. This chapter's analysis, therefore, does indicate that Saudi foreign policy system has indeed been undermined by oil, resulting in aggressive foreign policy on multiple occasions. 


\section{CHAPTER VI}

\section{Venezuela}

As one of the world's oldest oil-rich states, Venezuela has long been a popular choice among social scientists studying oil's effects on economic, political and social development. Indeed, Venezuela is a major locus in some of the most pernicious debates on the existence and magnitude of the socalled 'resource curse.' Until 1998, Venezuela was a strong supporter of US foreign policy, and relatively peaceful. From 1999, under the presidency of Hugo Chávez, however, it became known for its belligerent, anti-US foreign policy. This dichotomy is of particular interest to this dissertation, as Venezuela was, despite being an oil state throughout the 20th century, not considered aggressive prior to the Chávez regime. Thus this chapter will seek to explore why we see this shift towards aggression. Again, this chapter is comprised of three sections: 1) a broad examination of Venezuela, oil and foreign policy since the end of the Cold War; 2) a study of whether oil is linked to the study's mediating variables (weak institutionalization, reliance on military force and government freedom from constraints); and 3) several sub cases (focusing on the Venezuelan-Colombian relationship and on Venezuela's covert and verbal aggression), focusing on the implications of mediating variables for aggression. The Venezuelan case finds some support for the theory in the pre-1999 period, where the pacted party-centric system of democracy served as a substitute for weak foreign policy institutions. However, there is substantial evidence to support the theory in the post-1999 period, as weak institutions and a focus on military solutions led to consistent low-level conflict with Colombia, as well as strong covert support for terrorism. 


\subsection{Oil and Foreign Policy in Venezuela}

\subsubsection{A History of Oil in Venezuela}

Oil production began in Venezuela as early as 1914, with the first multinational oil company - Shell - involved as early as 1917. Since that time, the relationship between oil and the state has characterized and shaped Venezuelan politics more strongly than any other factor. ${ }^{1}$ During the early period of oil extraction, multinational oil companies kept much of the profit. However, the 1943 Hydrocarbon Act, negotiated between the government and the Seven Sisters oil cartel established higher taxes, and the principle of 50-50 profit sharing. Thus, throughout most of the 20th Century, the Venezuelan state has consistently drawn 50-65\% of its revenues from oil. ${ }^{2}$

Indeed, the primary political debate in Venezuela has consistently been how the state should handle oil production and revenues. One side argues that the oil industry should be left alone, while the other believes that it should be more closely controlled as a tool for development. As Hellinger notes, oil is for one side "a lifeline to the west," while to their opponents, it is a principle tool for asserting anti-western sovereignty. ${ }^{3}$ This contentious debate can be illustrated by the memoirs of President Betancourt, whose tenure saw the nationalization of the oil industry. The chapter on his predecessor Juan Vicente Gomez, who supported a liberal oil industry with foreign investment, is entitled Una Republica en Venta ("The Sellout of the Republic"), while Betancourt's own policies are introduced with the title La Siembra del Petroleo ("The Sowing of the Oil.") ${ }^{4}$ In this way, supporters of nationalization in Venezuela often demonize liberal opponents as pawns of foreign corporations.

From 1960, the state used the Hydrocarbons Act to gradually erode foreign control of the oil industry, requiring a government share of $60 \%$ in all projects. ${ }^{5}$ In 1974 , the government formally nationalized the oil industry, creating Petroleas de Venezuela S.A. (PdVSA). The goal was to

\footnotetext{
${ }^{1}$ Alverez and Hanson (2009).

${ }^{2}$ Bridgewater (2010): 39-40.

${ }^{3}$ Hellinger (2006): 14.

${ }^{4}$ Mommer (1998): 12.

${ }^{5}$ Bridgewater (2010): 41.
} 
better enable the state to regulate the boom/bust cycle, ${ }^{6}$ but instead revenues were ploughed into ambitious social and infrastructure projects. The oil price increases of the 1970 s allowed the government to fund Import-Substitution Industrialisation style programs, but required the state to borrow massively during bust periods. ${ }^{7}$ By 1982, as oil prices fell, the government ordered PdVSA to withdraw its capital from American banks, and transfer it to the state for use. This reduced PdVSA's ability to invest in exploration, and much of the money was wiped out by depreciation. ${ }^{8}$ PdVSA was also encouraged by the government to violate OPEC quotas, a plan which backfired when production was increased to a level where it impacted global prices, reducing revenues further. ${ }^{9}$ By 1983, the government's wild spending precipitated a currency crisis, as foreign banks refused to lend. The government was forced to seek an IMF/World Bank bailout, and to liberalise the oil industry. PdVSA itself emerged from this liberalization (known as the 'apertura') much stronger, and promoted a process known as 'internationalization, ${ }^{, 10}$ effectively a means to hide profits by investing them offshore. ${ }^{11}$ During the apertura period, PdVSA was a technocratic, meritocratic company, and executives often played a role in national economic policy. ${ }^{12}$ However, this approach was not popular, and it was largely on a platform of opposition to privatization that Hugo Chávez was elected in 1999, promising to "subordinate PdVSA to the Venezuelan state." 13 His vision of the oil industry was as a fund for social development, implying "a politicized PdVSA with a social mandate that supersedes the profit mandate." 14

In April 2002, leaders at PdVSA called for a general strike - of over 18,000 workers - in protest of this plan. Shortly after, a coup put members of the armed forces in charge in Caracas; among the first actions of its leaders were the reinstatement of the head of PdVSA, and the restoration of PdVSA's autonomy. ${ }^{15}$ Within three days, however, Chávez had been restored to power; he fired

\footnotetext{
${ }^{6}$ See Karl (1997).

${ }^{7} \operatorname{Karl}(1997)$.

${ }^{8}$ Mommer (1998): 20-21.

${ }^{9}$ Phillip (1999): 368 .

${ }^{10}$ Ibid., 28.

${ }^{11}$ Hammond (2011): 362.

${ }^{12}$ Phillip(1999): 374.

${ }^{13}$ Wiseman and Beland (2010): 144.

${ }^{14}$ Deshazo (2008): 3.

${ }^{15}$ Bridgewater (2010): 96.
} 
all 18,000 workers, replacing them with loyalists. In 2006, the regime nationalized all oil and gas projects in the country. Taxes have been raised to more than $50 \%$ on oil production, and PdVSA is in addition required to spend at least $10 \%$ of its budget on social programs (i.e., more than $\$ 14.4 \mathrm{bn}$ in 2007). ${ }^{16}$

Under Chávez, even as social spending rose by as much as $314 \%,{ }^{17}$ oil exports have declined substantially. Venezuela's oil fields are very mature, requiring substantial investment to maintain production levels. With PdVSA's profits funneled into social 'misiones,' and foreign firms skittish, investment is limited. PdVSA has begun to explore new fields in the Orinoco Belt, but this region's super-heavy crude is extremely expensive to extract and refine. ${ }^{18}$ The result of these policies, experts estimate, is that Venezuelan production has dropped by as much as one-third. ${ }^{19}$ In addition, PdVSA now lacks the managerial competence, technical knowledge or investment funds to prevent the decline. ${ }^{20}$ The oil industry's problems are now the major policy concern facing a post-Chávez Venezuela.

\subsubsection{Venezuelan Foreign Policy: 1990-2013}

Venezuela has always punched above its weight in foreign affairs, leading some scholars to refer to Venezuelan Exceptionalism. This importance can be attributed to oil, which has made Venezuela one of Latin America's wealthiest states. Prior to 1999, Venezuelan foreign policy under the presidencies of Caldera and Perez (the Punto Fijo period) was pro-US, pro-democratic and largely unremarkable. However, beginning with the 1999 election of Hugo Chávez, we see major changes, as he instigated a populist, anti-US, and pro-authoritarian foreign policy. ${ }^{21}$ Chávez's actions have dramatically increased Venezuela's visibility on the world stage, but it is still unclear

\footnotetext{
${ }^{16}$ Alvarez and Hanson (2009).

${ }^{17}$ Hammond (2011): 368.

${ }^{18}$ US Energy Information Administration Venezuela Country Report (2012); available from http://www.eia.gov/countries/analysisbriefs/Venezuela/venezuela.pdf.

${ }^{19}$ Deshazo (2008): 3 .

${ }^{20}$ Ladislaw and Verrastro (2012).

${ }^{21}$ Throughout this chapter, I refer to the period after 1999 as the 'Chávez regime.' Despite Chávez's death in mid-2013, his influence is still strong, and the Venezuelan government still bases its decisions on Chavista ideology. It is unclear what difference, if any, his successor Nicolás Maduro (previously Chávez's foreign minister) will make in foreign policy.
} 
what effects - if any - his policies have produced.

Between 1958 and 1999, Venezuela pursued an active pro-democracy foreign policy, unusual in the context of Latin America, as was Venezuela's democratic stability. This can be attributed to the stability of the Punto Fijo pact, as well as high oil rents, which helped to reduce the potential for class conflict. ${ }^{22}$ The two parties also had strong ties with other international Christian Democratic and Social Democratic parties, contributing to a Western-leaning foreign policy, ${ }^{23}$ and leading one US representative at the Organisation of American States to refer to the country as "the bannerbearer of democracy in Latin America." ${ }^{24}$ Throughout this period, although Venezuela was a key trade partner for the US, supplying at least $10 \%$ of US oil imports, the US tended to accord it only "a secondary status in a region that was, normally, of only tertiary concern." 25

Indeed, this attitude is borne out in the complete lack of interest by US lawmakers and scholars towards Venezuela during the 1990s. A search of the US congressional record finds Venezuela mentioned only briefly in reports related to US counter-narcotic campaigns. ${ }^{26}$ Several scholars have argued that Venezuela was a 'safe' partner for the US, an exception to the 'backwardness' of the rest of Latin America, and a trusted ally, meriting little further scrutiny. ${ }^{27}$ Naím offers a more cynical explanation, arguing simply that "for decades, Venezuela was too boring to offer foreign academics and journalists the sort of intellectual challenges that make reputations and boost careers." 28 It is true that this period saw no memorable incidents in foreign policy. There were no major conflicts during the period, and Venezuelan border disputes with Colombia and Guyana remained largely insignificant. ${ }^{29}$ The country tended to simply be broadly supportive of US policy initiatives.

In 1999, the collapse of the Punto Fijo system was brought about by the election of Hugo Chávez, who rose to power on a tide of discontent with the government's neoliberal economic

\footnotetext{
${ }^{22}$ Ellner and Tinker-Salas (2007): 6 .

${ }^{23}$ Corrales and Romero (2013): 126.

${ }^{24}$ Aviles (2005): 48.

${ }^{25}$ Dodson and Dorrage (2008): 73.

${ }^{26}$ Data available from http://www.congress.gov.

${ }^{27}$ Ellner and Tinker-Salas (2007): xiii-xiv.

${ }^{28}$ Naím (2001): 18.

${ }^{29}$ Davies (2002).
} 
policies. In contrast to the earlier period, an extraordinary amount of ink has been spilled by western politicians and academics on the topic of Hugo Chávez's activist foreign policy. His actions have included vast amounts of foreign aid, virulent anti-US rhetoric, the funding of terrorist groups and extremist politicians, and a variety of trade and security deals with authoritarian regimes. Most importantly, Chávez has flipped Venezuelan policy $180^{\circ}$, rejecting the strong relationship with the US. In addition, Chávez has dramatically increased the country's international involvement: by 2008, the president had "spent more than 450 days abroad, in a total of 150 countries, at a cost [to Venezuela] of $\$ 55$ million." 30

Chávez is perhaps best known for his belligerent oratory. From calling George W. Bush a 'donkey,' a 'drunkard,' and 'satan,' to publicly insulting the King of Spain, Chávez's speeches focus on anti-western, anti-imperialist sentiments, and on the promotion of the 'Bolivarian Revolution. 31 The Chávez regime also funds Telesur, an CNN-style news network focused on bringing his political ideas and slanted news to voters throughout Latin America. ${ }^{32}$ The Chávez regime is also active in other areas, such as promoting the 'rise of the left' through subsidies to countries such as Bolivia, providing free (or cheap) oil supplies and direct support for social projects. For example, as much as $54 \%$ of Cuba's oil comes from Venezuela, at below market rates. ${ }^{33}$ Venezuela has even supplied cheap energy to poor Americans through the Citizens Energy Oil Heat Program. Venezuela has also used FONDEN (PdVSA's social fund) to buy up the national debt of friendly countries, as in the 2006 purchase of $\$ 1.3$ billion in Argentinian bonds and $\$ 100$ million of Paraguayan bonds. ${ }^{34}$

A key means for transferring wealth has been through the creation of two new international organizations. ALBA (Bolivarian Alliance for the Peoples of Our America), founded in 2004 by Cuba and Venezuela, focuses on regional trade. The organization facilitates Venezuela's foreign aid, such as its deal with Cuba exchanging oil for medical assistance. ALBA was founded in direct opposition to US neoliberal trade and investment policies: for example, members of ALBA

\footnotetext{
${ }^{30}$ Ortiz (2011): 81, in Clem and Maingot, eds. (2011).

${ }^{31}$ Corrales and Romero (2013): 20.

${ }^{32}$ Dodson and Dorrage (2008): 73.

${ }^{33}$ Corrales and Romero (2013): 27.

${ }^{34}$ Burges (2007): 1348.
} 
are encouraged to consider barter rather than traditional trade. ${ }^{35}$ However, ALBA has only nine members, leading some to speculate that it has stagnated, and holds little appeal for those countries which are not already Chavista-leaning. ${ }^{36}$ In contrast, Petrocaribe, founded in 2005, has been successful in attracting new members with oil subsidies. Since OPEC rules forbid members from offering price concessions, Petrocaribe instead offers states interest-free loans with extremely favorable payment terms, effectively reducing the cost of the oil. ${ }^{37}$ The organization is the biggest single source of concessional finance to the Caribbean region, providing up to $\$ 1.1$ billion a year, mostly from Venezuela. ${ }^{38}$ Petrocaribe also funds projects, such as the upgrading of refineries in Jamaica, Nicaragua and Dominica. Though these organizations have disbursed billions, they have not achieved Venezuela's stated goal of 'political harmonization.' While the Caribbean countries are happy to accept concessional finance, most do not intend to implement Bolivarian-style economic or social measures, calling into question how effective this funding has been as a tool of Venezuelan foreign policy. ${ }^{39}$

Foreign aid has been somewhat more effective as a tool of political change in Latin America, where it has been used to bolster the chances of left-leaning candidates in elections. Cash donations and medical equipment worth up to $\$ 1.6$ billion were provided in Nicaragua in the run-up to 2007 presidential elections, won by Chávez supporter Daniel Ortega, who also received direct campaign finance support. Venezuelan oil money also contributed to the election of the Correra regime in Ecuador, and Bolivian President Eva Morales' reelection. In Bolivia, Venezuela provides direct funding to some military units, and the Venezuelan ambassador himself personally wrote and handed out large checks to local Mayors. ${ }^{40}$ One program, dubbed the 'Miracle Mission,' gave food and humanitarian aid to revolutionary parties throughout Latin America, to be used to attract new followers among the poor of those nations. ${ }^{41}$ This foreign aid (up to $\$ 17$ billion) is being used

\footnotetext{
${ }^{35}$ Girvan (2011): 117, in Clem and Maingot, eds. (2011).

${ }^{36}$ Jacombe (2011).

${ }^{37}$ Girvan (2011): 122, in Clem and Maingot, eds. (2011).

${ }^{38}$ Girvan (2011): 122, in Clem and Maingot, eds. (2011).

${ }^{39}$ Girvan (2011): 125-6, in Clem and Maingot, eds. (2011).

${ }^{40}$ Corrales and Romero (2013): 26.

${ }^{41}$ Ortiz (2011): 82, in Clem and Maingot, eds. (2011).
} 
to buy influence and alter the politics of other states. As one scholar notes, possibly the greatest danger Venezuela's foreign policy poses to the US "has less to do with aggressive actions... than with something else... generous handouts peppered with a pro-poor distributionist discourse." 42

The Chávez regime has also focused creating anti-western alliances. Under Chávez, Venezuela has signed treaties with a veritable who's who of pariah states: Iraq (under Hussein), Iran, Zimbabwe, Syria, Libya, Sudan, Belarus and North Korea. For example, Iran's President Ahmadinejad visited Venezuela five times between 2000 and 2010, and Chávez visited Tehran four times, despite the fact that "Chávez's economic ties with Tehran in no way compare to the significance of his trade with the US, China or other Latin American nations." 43 These policies have continued since 2013 under the new administration of Nicólas Maduro, who has committed to support the embattled Assad government in Syria. ${ }^{44}$ Chávez also sought to align with Russia and China, and had a good relationship with President Putin, which led to the 2004 signing of several substantive agreements on energy and military purchases. ${ }^{45}$ The Venezuelan government has also repeatedly sought to shift its oil exports towards China and away from the US. Several Chinese companies are involved in oil development projects in Venezuela, and China even supported Venezuela's 2006 bid to obtain a seat on the UN Security Council. ${ }^{46}$ However, neither Russia nor China supports Chávez's more extravagant foreign policy goals, and economic ties remain limited.

Venezuela's major conflict since 1999 is with Colombia, an adversarial relationship worsened by Chávez's decision to end drug-related overflights by the US military, and by the Chávez regime's ideological ties to and financial support for revolutionary Marxist-Leninist groups such as the FARC and ELN. ${ }^{47}$ Thus, tensions have remained high throughout the last decade. This relationship is explored further in Section 6.3.1. Venezuela's other main dispute, its claim to the Esequiba region of Guyana, also saw only a few minor incidents between 2000 and 2013, involving minor border violations and shots fired by both sides.

\footnotetext{
${ }^{42}$ Corrales (2011): 32, in Clem and Maingot, eds. (2011).

${ }^{43}$ Lapper (2006): 32.

${ }^{44}$ Corrales and Romero(2013): 180.

${ }^{45}$ Katz (2006): 5.

${ }^{46}$ Rios (2013): 64-65.

${ }^{47}$ Corrales and Romero (2013): 100.
} 
Venezuelan foreign policy has thus been substantially more active under the presidency of Hugo Chávez than under his predecessors. Although oil has always allowed the country to punch above its weight in foreign affairs, Chávez has changed the landscape of Venezuelan foreign affairs, pursuing a verbally confrontational foreign policy supplemented by foreign aid, political interference in the affairs of other states, and attempts to create anti-US, authoritarian alliances.

\subsubsection{Is Venezuelan Foreign Policy Aggressive?}

Venezuelan foreign policy under the Puntofijismo was certainly not aggressive; indeed, to many observers, it was so unremarkable as to be barely worth studying. In contrast, scholars and policymakers initially rushed to decry the Chávez regime's bellicose and aggressive actions. In March 2008, President George W. Bush described Venezuelan foreign policy as "little more than empty promises and a thirst for power," criticizing Chávez's support for the FARC and describing Venezuela's response to the 2008 Colombian crisis as "the latest step in a disturbing pattern of provocative behavior by the regime in Caracas." 48 Scholars have written papers questioning "how... a trusted ally became a pariah," 49 and analyzing Chávez's attempts to foment Bolivarian revolution in other countries. ${ }^{50}$ However, the Venezuelan state has not initiated any major overt conflict since 1990. Those who argue that Chávez's government is not truly aggressive focus on the importance of his verbal abuse for domestic support, allowing him to safeguard the revolution at home and seek out like-minded governments abroad. ${ }^{51}$ Some scholars argue that Chávez is merely trying to "leverage his country's oil wealth as a device for placing Venezuela in an international leadership position." 52

Although much of Venezuela's foreign aid has been peaceful, a substantial fraction has been directed at parties and groups with revolutionary intent and violent means. Venezuelan elites have signalled their desire for revolution in Colombia, and the regime has also provided direct funding

\footnotetext{
${ }^{48}$ Agence France Presse (March 13, 2008), "Bush Lashes Out At Chavez."

${ }^{49}$ Ellner and Tinker-Salas (2007): xiii.

${ }^{50}$ Deshazo (2008): 5 .

${ }^{51}$ Trinkunas (2011): 19, in Clem and Maingot, eds. (2011).

${ }^{52}$ Burges (2007): 1344 .
} 
to regional terrorist groups such as the FMLN in El Salvador, and the Sandinistas in Nicaragua, ${ }^{53}$ as well as support for groups such as Hezbollah through its ties to Iran. ${ }^{54}$ Even the language used by Venezuelan officials to describe foreign policy is violent in nature, talking of the need to end "cocktail diplomacy," and move towards a foreign service "prepared for a scenario of war, terrorism and political hegemony." 55

Venezuela thus has a mixed record of aggression. From 1990-1999, the country was not aggressive, but since that time, the country has been verbally and economically aggressive, and has funded pariah states and violent revolutionary groups. In 2008 Congressional Testimony, one expert argued that Venezuela is a 'mid-level security threat,' to the US: not truly dangerous, but enough so to be worrying to US policymakers. ${ }^{56}$ This chapter therefore focuses on understanding why we see such a pronounced change in levels of aggression after 1999, and on exploring the extent to which aggressive Venezuelan foreign policy since that time has resulted from our study's mediating variables (weak institutions, a lack of government constraints and a focus on military solutions).

\subsection{From Oil to Weak Foreign Policy}

\subsubsection{Institutional Development and Foreign Policy}

Venezuela began the process of building institutions, including those for foreign policy, following its independence in 1830. For most of the 19th and early 20th century, the country was governed by a series of Caudillos (or strongmen), who largely formulated policy personally and developed little in the way of a coherent bureaucracy. As Karl famously described, "Venezuela [during this period]... could boast of no civil service... Instead, it suffered from a legacy of extreme administrative weakness that is remarkable even in the context of Latin America." 57 The modern Venezuelan state only emerged in the transition to democracy in 1958 under the pacted democracy of the

\footnotetext{
${ }^{53}$ Trinkunas (2011): 22, in Clem and Maingot, eds. (2011).

${ }^{54}$ Corrales and Romero (2013): 31.

${ }^{55}$ Ortiz (2011): 82, in Clem and Maingot, eds. (2011).

${ }^{56}$ Corrales (2008).

${ }^{57}$ Karl (1997): 74.
} 
Punto Fijo arrangement.

Named for the location of its signing, the Punto Fijo was an arrangement between the two major political parties of the day, the Acción Democrática (AD) and the Social Christian party (COPEI). Both sides had seen the problems of conflictual politics, and so they chose to hobble their own power, forming a congressional committee to manage affairs. Regardless of elections, the makeup of the committee would remain the same: eight representatives of the $\mathrm{AD}$, four from $\mathrm{COPEI}$, three from the Communists, and three independent members. ${ }^{58}$ This institutional framework highlighted cooperation and consultation, and ensured that political stakes remained low in controlling oil rents. In effect, party leaders "explicitly crafted the pact as an institutional arrangement to modify the payoff structure of the game to induce cooperation." 59 The cartel-like structure of the Punto Fijo was extremely stable.

However, the newly democratic rulers of Venezuela in 1958 inherited a weak foreign ministry and a intelligence service better known for its oppressive domestic activities than its foreign intelligence gathering. The administration of Romuló Betancourt sought help from the UN, who helped to create the Public Administration Commission (CAP), which aimed to improve the professionalization of the bureaucracy and foreign service, and to increase bureaucratic access and advice to leaders. However, the reforms were blocked by party leaders, who saw an opportunity for patronage, and instead sought to control appointments. ${ }^{60}$ The bureaucracy, including the foreign ministry, therefore was weak, and largely made up of political appointees rather than meritocratic appointments. Though the foreign ministry was weak, party elites agreed that the sustainability of the Punto Fijo system was reliant on US support, and so agreed to follow a solid pro-US, pro-democracy foreign policy.

The military, frequently another key source of input on foreign relations, was largely subordinated to civil authority during this period. Although it did retain some autonomy, Venezuela's history of military coups led leaders to distrust its advice. During this period, the military did

\footnotetext{
${ }^{58}$ Monaldi, Gonzalez, Obuchi and Penfold (2004): 6.

${ }^{59}$ Ibid.

${ }^{60}$ Ibid., 36-7.
} 
develop strong international ties, with a US Military Assistance group in residence in Caracas to advise on strategy, and senior military officers attending training at US institutions. ${ }^{61}$ Thus, the military acted as a link to western foreign policy ideas (although a small group of the military, including a young Hugo Chávez, rejected them forcefully and even attempted a coup in 1992). Throughout the 1970s and 1980s, many Venezuelan scholars of foreign policy also had the opportunity to travel to the US and Europe on government-funded scholarships, to encourage the development of new foreign policy ideas. As a result, many Venezuelan experts in foreign policy had surprisingly western-focused and liberal views on foreign policy, when compared to their counterparts in other Latin American states. ${ }^{62}$

The government during this period also frequently set up ad hoc committees, each of which would be tasked with studying and making policy recommendations on a specific topic. The input of these committees was substantial, often eclipsing that of the formal bureaucracy. Although this broadened the scope of opinion on a topic, participation in these committees tended to be limited to a few well-connected groups of elites. On average, $60 \%$ of these committees were made up of civil servants or politicians, with the rest of the positions going to wealthy businessmen and key supporters of the regime. ${ }^{63}$ The key ad hoc committee on foreign policy throughout the Punto Fijo period was the Comisión de Relaciones Exteriores (CARE), was primarily comprised of key officials from the Presidential administration, the legislature, and a selection of former presidents and foreign ministers. ${ }^{64}$ Thus, foreign policy was typically decided by the President in consultation with party leaders, with only limited input from the bureaucracy, which operated primarily as a diplomatic service, handling implementation of policy, but rarely being involved in its formulation.

Since 1999, there have been major changes in the bureaucracy, as well as substantial constitutional changes. These reforms, initiated after Chávez's election, reduced the legislature from bicameral to unicameral, removed the political independence of the courts, and lowered the elec-

\footnotetext{
${ }^{61}$ Avila (2009): 1557.

${ }^{62}$ Giacalone (2012): 343.

${ }^{63}$ Crisp (2000): 107-19.

${ }^{64}$ McCarthy-Jones (2010): 52.
} 
toral threshold needed to pass new legislation. ${ }^{65}$ One scholar notes that all areas of the state were targeted: "The period between 1999 and 2003... followed a consistent pattern: the government would target institutions almost one at a time, attempting to strip each of power in turn." 66 In 2004, the Chávez administration prioritized the 'reform' of the foreign service, appointing Nicolás Maduro as Foreign Minister, and giving him a mandate to develop an 'anti-imperialist' Ministry. Funding for the Ministry expanded by 12,000\% (from 59.1 million bolivars in 1999 to 7.3 billion bolivars by 2008) during Chávez's decade in power, and the funds "have been accompanied by a sustained effort to infuse the Foreign Service with the official state ideology." ${ }^{67}$ As Maduro described in one public interview:

"We will have a more efficient ministry, better organized, disciplined and that has a cohesive discourse in all scenarios. And besides has the capacity to gain consensus on the basis of just positions, not on the basis that we allow things to continue the same." 68

The reform included substantial reassignment of diplomats who had begun their careers under the Punto Fijo, and the appointment to positions at all levels of those who were strong and active supporters of the Bolivarian revolution.

Similar reforms took place in the intelligence services, as well as in the military. Following the military's attempted coup in 2002, the Venezuelan government has made a concerted effort to reform the military away from a US model, altering strategy towards the guerrilla-style tactics favored by the Bolivarian leader. ${ }^{69}$ The 1999 constitution removed congressional oversight of military promotions, allowing Chávez to position friendly officers in key command positions. In addition, military salaries have been raised, by as much as $187 \%$, and the government buys officers new weapons, homes and luxury goods in an attempt to coopt additional support. ${ }^{70}$ Despite this funding, the military has not integrated these systems into its command structure. As Trinkunas

\footnotetext{
${ }^{65}$ Corrales (2006).

${ }^{66}$ Corrales and Penfold-Becerra (2007): 100.

${ }^{67}$ Ortiz (2011): 81-2, in Clem and Maingot, eds. (2011).

${ }^{68} \mathrm{McCarthy-Jones}$ and Turner (2012): 557.

${ }^{69}$ Avila (2009): 1561.

${ }^{70}$ Corrales and Romero (2013): 132.
} 
notes, "The mobilization of the Venezuelan army to the Colombian border during the March 2008 crisis highlighted numerous weaknesses in the readiness and logistics of the armed forces." 71 The government has also funded 'Bolivarian' militias as an alternative military; these are answerable only to the President.

Under the Punto Fijo, the Dirección Nacional de los Servicios de Inteligencia y Prevención (DISIP) was the country's primary intelligence agency. Although it primarily concerned itself with domestic matters, it had strong ties to the CIA. After the 1999 election, Hugo Chávez appointed Jésus Urdaneta to run the organization, and tasked him with rooting out these ties. In response, the CIA cut ties with DISIP in 2001. ${ }^{72}$ In 2005, Chávez appointed Henry Rangel Silva (an ally with known ties to the FARC) to run the agency. Silva fired half the agency's staff, renamed it (SOBIN) and redirected its mission towards the success of the revolution. New personnel are vetted for loyalty, the same intellectual purge which occurred in the military and foreign service. There are also now strong links between SOBIN and Cuban intelligence, with reports that "the two... agencies appear to be competing with each other for the [Venezuelan government's] attention."73 Reports strongly indicate that the Cubans effectively run SOBIN, and that Chávez trusted them more than his own countrymen, making impartial advice from the SOBIN to Venezuelan leaders entirely unlikely.

In effect, the key actors in foreign policy have shifted substantially since 1999. In the 1990s, a key decision in foreign policy would involve the input of a broad array of individuals within the political class: business groups, party leaders, PdVSA managers, technocrats and labour groups. ${ }^{74}$ Advice tended to come from ad hoc committees, academics trained abroad, and through informal channels, and the foreign service and military tended to perform an implementation role rather than an advisory role. Although decisions were ultimately made by the President, he would consult with a broad range of groups and get approval from leaders in both parties (and even input from their international Christian and Social Democratic brethren). Thus, although the bureaucracy was

\footnotetext{
${ }^{71}$ Trinkunas (2011): 27, in Clem and Maingot, eds. (2011).

${ }^{72}$ Ginter (2013): 229.

${ }^{73}$ Ginter (2013): 230.

${ }^{74}$ Corrales and Romero (2013): 126.
} 
extremely weak, the necessary consensus and advisory functions were handled instead through the Punto Fijo system.

In contrast, a foreign policy decision in the period since 1999 is entirely different. The key actor is still the President, but institutional changes mean that veto players are effectively non-existent. Chávez (and now Maduro) do not need to obtain the cooperation of the legislature, and they have successfully co-opted the foreign ministry and military. It is unclear if leaders receive impartial or professional advice, or if they are merely relying upon their own worldview. Academics are no longer encouraged to study abroad, instead they are pushed towards studies which favor Marxism, and the Bolivarian ideal of "confrontational autonomy. ${ }^{75}$ A typical foreign policy decision is thus taken without input or advice from bureaucracy or experts. As one scholar notes: "Chávez has succeeded in monopolizing policy-making and chooses, seemingly without opposition, the priorities in foreign policy." 76

\subsubsection{Are Venezuelan Foreign Policy Institutions Underdeveloped?}

Are Venezuela's foreign policy institutions weak, as the theory suggests? We would expect Venezuela, as a long-time petrostate to have foreign policy institutions that are (a) characterized by disagreements or by jockeying for influence by various individuals and groups, (b) primarily dominated by individuals or small groups, and (c) inefficient and suffering from communication problems. From 1958-1999, Venezuela's foreign policy making was indeed primarily dominated by small groups, but was generally efficient and cooperative. However, it should be noted that the cooperation was not the result of any formal foreign policy institutions, but instead the peculiar nature of Venezuelan pacted democracy. In contrast, the period after 1999 saw a foreign policy that was almost random in its reactive nature, inefficient, and dominated by a single individual (and few advisors).

Under the Punto Fijo, decisions were made by a small group of senior politicians, but they were typically made in broad consultation with other elites, and disagreements were rare. The

\footnotetext{
${ }^{75}$ Giacalone (2012): 344.

${ }^{76} \mathrm{McCarthy-Jones}$ and Turner (2011): 564.
} 
dominant characteristics of policy-making were that of a "centralized state... [with] strongly organized national parties that monopolized political action... a professional political class, and a subordinated military," resulting in a state-centric elite model of decision-making. ${ }^{77}$ In part, the lack of disagreement in foreign policy is a reflection of a conscious choice on the part of elites that a non-confrontational, pro-US foreign policy was the best means of ensuring the stability of their rule, meaning that the foreign policy choices were necessarily limited. This does not necessarily mean that Venezuelan foreign policy institutions were strong during this period; instead, the strength of the party system, in particular the Punto Fijo arrangement appears to have compensated for the weakness of the oil state's bureaucracy.

While this produced stable foreign policy, it was an insular form of governance, in effect, a policy-making cartel among elites. ${ }^{78}$ This eventually led to the system's collapse, as the population rejected the economic inequality created by stagnating oil rents. Despite the regime's stability, various metrics showed institutions to be ineffectual. The World Bank's Global Competitiveness report showed Venezuela to be one of the worst performers in the world in public policy outcomes. While government effectiveness was never high, it had declined from $24 \%$ to around $10 \%$ by the end of the Punto Fijo (while the regional average is closer to 40\%). As Karl describes, "the dominance of political criteria [under the Punto Fijo arrangement]... often prevented the attainment of high technical standards within the bureaucracy." 79 Naim similarly argued in 2001 that "this governmental incompetence has many causes, not all of them attributable to President Chávez, who inherited a deeply damaged institutional setting in which most public agencies could barely function." 80

If foreign policy was somewhat weak prior to 1999, it became far more so thereafter. Disagreements were still limited in the formation of foreign policy, but this was not the result of consultation and cooperation, but instead the result of centralization of foreign policy into the hands of one man. Chávez received little to no external advice, and used his ministers purely to

\footnotetext{
${ }^{77}$ McCarthy-Jones (2010): 51.

${ }^{78}$ Monaldi, Gonzalez, Obuchi and Penfold (2004): 42.

${ }^{79} \operatorname{Karl}(1997): 108$.

${ }^{80}$ Naim (2001): 28.
} 
implement policy, resulting "in a policymaking process that is largely determined by the president's own personal perception." 81 Numerous destructive decisions highlight this lack of advice, ranging from the major purchases of weapons completely at odds with the army's stated strategy, ${ }^{82}$ to the anti-Chávez backlash seen in countries like Peru following aggressive financial aid campaigns. ${ }^{83}$ In 2008, Chávez publicly took a snap decision to move troops to the Colombian border, just one example of a rash and undebated policy which "held the potential to escalate rather than temper the situation." 84

In addition, bureaucracy continues to be inefficient under Chávez, although revolutionary zeal has now replaced patronage as the key to bureaucratic appointments. The Chávez regime fosters bureaucratic chaos through continuous cabinet turnover: most cabinet ministers stay less than six months in any given post, reducing even further their use in decision-making. ${ }^{85}$ As Naim notes, “Chávez's own inexperience and his exaggerated reliance on loyalty as the principal, and often only, criterion for selecting his main collaborators [has] led to a disastrously incompetent team." ${ }^{86}$ Perhaps the best example is the current President, Nicólas Maduro, who was a bus driver before Chávez appointed him to several key posts. Maduro spent several years as Foreign Minister despite his lack of languages, higher education, or any knowledge of the topic, and was later appointed Vice President and Chávez's successor.

Thus foreign policy in both periods meets many of our criteria for weak foreign policy institutionalization in an oil-rich state. Formal foreign policy institutions prior to 1999 were weak, and characterized by inefficiency. Perhaps most telling is the effective non-participation in the policy sphere of those organizations (i.e., Foreign Ministry, DISIP) which are intended to manage foreign policy. However, the Punto Fijo system provided a parallel system of foreign policymaking expertise and consultation, minimizing disagreements, and keeping foreign policy relatively stable during this period. In contrast, after 1999, the administration of Hugo Chávez destroyed this sys-

\footnotetext{
${ }^{81}$ McCarthy-Jones and Turner (2011): 564.

${ }^{82}$ Trinkunas (2011): 27, in Clem and Maingot, eds. (2011).

${ }^{83}$ Deshazo (2008): 6.

${ }^{84}$ McCarthy-Jones and Turner (2011): 560.

${ }^{85}$ Corrales (2006).

${ }^{86}$ Naim (2001): 28.
} 
tem. Foreign policy since then has been almost entirely personified by Chávez, who frequently made decisions with limited advice or input from others. It is too soon to tell whether this pattern continues under his successor, Maduro, but it seems likely. In short, in both periods, institutions appear to be somewhat weakened by oil wealth, although the pacted democratic system of the 1950s-1990s helped to mitigate the problems associated with weak foreign policy institutions, while the constitutional reforms carried out by the Chávez regime since 1999 instead appear to have exacerbated them.

\subsubsection{Is Institutional Weakness Oil-Related?}

Venezuelan institutions have been weak for more than a century, although the peculiarities of the Punto Fijo system helped to mitigate this problem, at least in foreign affairs. Oil has, in general, provided the Venezuelan government with substantial revenue during this period, though as Figure 6.1 shows, these revenues have been extremely erratic. As Karl notes, early Venezuelan governance was characterized by the presence of Caudillos, whose dominant trait was their desire to pillage as much of the oil revenue as possible, while providing little-to-no institutional development. ${ }^{87}$ The emergence of the modern Venezuelan state in 1958, and its institutional development (or lack thereof) coincided with the massive rise in global oil prices of the 1970s, providing little incentive to develop strong institutions.

We can further assess whether Venezuela's institutional weakness is the result of oil by looking at the institutions of several comparable non-oil producing states. Perhaps the best comparison is that of Colombia, which shares strong cultural ties with Venezuela, and was in fact part of the same state until 1831. The two countries' foreign policy apparatus are structurally quite similar, as is that of many Latin American states. As one author notes, "the presidentialist character of Colombia's political regime... and the marginal role played by the legislature has historically granted the execute a significant degree of autonomy in the formulation of foreign policy." 88 In addition, similar to Venezuela, Colombia's Ministry of Foreign Relations is generally weak, and

\footnotetext{
${ }^{87} \operatorname{Karl}(1997): 74$.

${ }^{88}$ Tickner(2001): 2.
} 


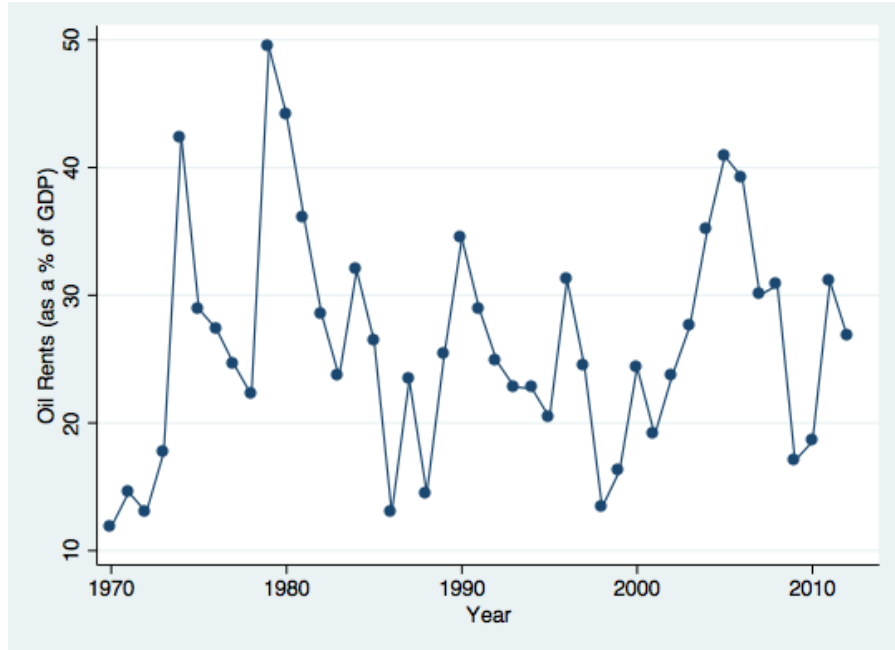

Figure 6.1: Venezuelan Oil Revenues (1970-2010)

focuses more on implementation. In contrast to Venezuela, however, Colombia has a strong system of foreign policy advising, known as the CARE committee, an organization comprised of all former presidents and other congressionally appointed members. Through this institution, the legislature exerts a strong bipartisan influence on foreign policy. ${ }^{89}$ In general, Colombian foreign policy has similarities to that of the Punto Fijo system; however, it is far more strongly institutionalized than Venezuela's current foreign policy system.

Given the similarities with Colombia, it is perhaps difficult to assert that Venezuela's institutional weakness is oil-related. However, there are several states in Latin America which do not exhibit this weakness. Chile, for example, despite a history of both military rule and democratic governance, has a strong constitution and well-defined foreign policy process. Chile has never been an oil producer, and receives little revenues from any natural resource. ${ }^{90}$ Chile's constitution, approved under military rule by plebiscite in 1980, creates a large number of veto players, and allows for a foreign policy which is concentrated in, but not dominated by the executive branch. A large and active Ministry of Foreign Relations is in charge of coordinating, planning and executing foreign policy, along with a National Security Council formed of key elected officials. As

\footnotetext{
${ }^{89}$ Ibid., 2.

${ }^{90}$ Data from World Bank. Available from www.worldbank.org/data.
} 
one author describes, "Chile's foreign policy is part of a long tradition anchored by the country's democratic institutions..." meaning that personality has never been paramount in the process. ${ }^{91}$ Another author notes that despite ideological differences, "a body of technocrats played an important role at the highest level of policymaking" in all Chilean governments. ${ }^{92}$ Thus, although Latin American countries do tend to have weaker institutions, not all are weak in the area of foreign policy. In addition, even a relatively weak institutional case like Colombia is still comparatively much stronger than Venezuela, implying strongly that a unique factor such as oil has played a key role in producing the institutional weakness we see in the Venezuelan case.

\subsubsection{Military Expenditure in Venezuela}

For the last decade, Venezuela's military expenditures, especially large purchases of arms from countries such as Russia, China and Israel, have alarmed western governments. Yet these large military expenditures are nothing new, as Venezuelan politicians have always spent an outsized portion of their budget - especially considering the lack of major threats - on the military. Indeed, one author points out that the only change in major military expenditure since 1999 is that the purchases are no longer being made from the US. ${ }^{93}$ Figure 6.2 shows Venezuelan spending on military expenditures (in billions of US dollars) compared to oil revenues. As the chart illustrates, Venezuelan military spending has been reasonably high since 1990, and tends to be somewhat volatile, with spikes which tend to correspond to spikes in the price of oil (and therefore government revenues). However, despite spikes in the chart, Venezuelan spending on arms has remained consistently high since the $1950 \mathrm{~s}$, typically remaining between $1.2 \%$ and $1.6 \%$ of GDP. This overall consistency in spending is masked by the fact that Venezuela's GDP growth is driven by oil, and so military expenditure and oil revenues tend to rise and fall in tandem. ${ }^{94}$ Military spending did rise substantially during the 2000s in conjunction with record prices for oil, reaching spending of

\footnotetext{
${ }^{91}$ Morandé(2003): 245.

${ }^{92}$ Silva (1991): 385 .

${ }^{93}$ Trinkunas (2011): 18, in Clem and Maingot, eds. (2011).

${ }^{94}$ All figures from the Stockholm International Peace Research Institute Military Expenditure Database, available from http://www.sipri.org/research/armaments/milex/milex database.
} 


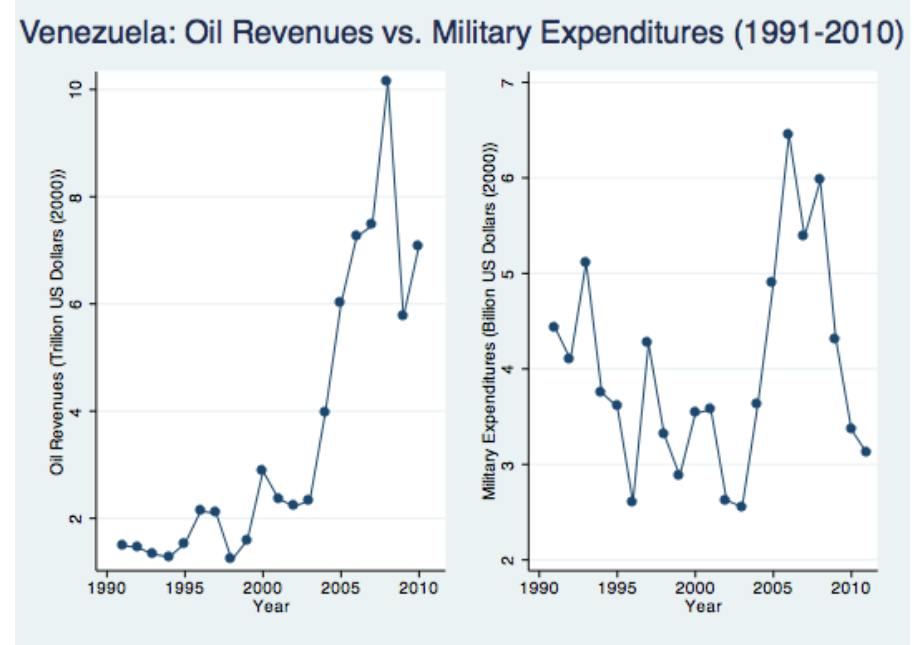

Figure 6.2: Venezuelan Oil Revenues vs. Military Expenditure (1991-2010)

almost $\$ 6.5$ billion in 2008 (inflation adjusted to 2010). ${ }^{95}$

Since the election of Hugo Chávez in 1999, much of this money has been spent in major arms purchases, often to replace those weapons which US embargoes have rendered useless or irreplaceable. For example, in 2006, Caracas entered into a deal with Russia to buy fifty MiG-29 fighter jets; these planes were needed to replace Venezuela's inoperative fleet of American F-22 fighters, which have been grounded by an inability to purchase replacement parts from the US. ${ }^{96}$ In addition to planes, Venezuela has purchased 100,000 Kalashnikov rifles, 5,000 sniper rifles, and $\$ 384$ million of helicopters and anti-aircraft defenses from Russia, while the country's purchases from China include JYL-1 long-range surveillance radar systems and eight JL-8 Nanchang fighter jets. ${ }^{97}$ By 2007, Venezuela had become Latin America's largest arms purchaser, and was a more prolific military consumer than Iran or Pakistan. ${ }^{98}$

In addition, there is evidence that Venezuelan military spending may have been even higher under the Chávez administration than official statistics suggest. Colgan points out that SIPRI and other sources draw their information from Venezuela's official statistics, which do not include

\footnotetext{
${ }^{95}$ Ibid.

${ }^{96}$ Katz (2006): 6 .

${ }^{97}$ Colgan (2010a): 553.

${ }^{98}$ New York Times (February 25, 2007), "Venezuela Spending on Arms Soars to World's Top Ranks."
} 
extrabudgetary expenditures or those made via FONDEN (PdVSA's slush fund). ${ }^{99}$ These expenses, including some arms purchases, as well as the entire funding of the newly created Territorial Guard are typically accounted for off-budget. These are significant estimates, with Jane's Defense Report estimating that by 2010, the Territorial Guard consisted of more than 110,000 troops. By estimating numbers of troops as well as tallying publicly available accounts of weapons purchases, he estimates that the military budget may be as much as $0.4 \%$ of GDP higher than listed in official statistics, and that Venezuela's overall military spending may be $20-70 \%$ higher than the figures cited above. ${ }^{100}$ In addition, neither set of data includes extra budgetary spending sent to foreign groups which serves a military purpose, such as Venezuela's financial support of the FARC.

As in both the Saudi and Russian cases, greater military spending has not necessarily yielded greater efficiency or preparedness. Trinkunas notes that "despite billions of dollars in new acquisitions, the Venezuelan military has yet to integrate these systems into an effective national defense structure." 101 One central problem is the contrast between official strategy and purchases. Under Chávez, the Venezuelan military has created a new military doctrine, the Defensa Integral de la Nación, which plans for prolonged insurgency-style warfare against an invading force. However, the weapons being purchased are (with few exceptions) fighter jets, radar, naval supplies and other heavy weaponry, unsuited to the type of campaign strategists expect. Thus, the military's focus on training for asymmetric warfare and its arms purchases are at odds. ${ }^{102}$ Venezuela does have extremely high levels of military spending, as expected of an oil-rich state. Leaders also focus on the use of the military, whether for martial tasks, or simply to implement social programs. The use of arms purchases and the movement of troops to signal intent is common, as in the 2008 Colombian crisis. In addition, the creation of a large auxiliary army in the Territorial Guard (which may have as many as 110,000 soldiers) is another sign of government focus on militarization. ${ }^{103}$ It appears that Chávez, perhaps drawing from the example of Cuba, is attempting to appear strong through

\footnotetext{
${ }^{99}$ Colgan (2010a): 549 .

${ }^{100}$ Ibid., 547-51.

${ }^{101}$ Trinkunas (2011): 27, in Clem and Maingot, eds. (2011).

${ }^{102}$ Ibid., 20-27.

${ }^{103}$ Colgan (2010a): 553 .
} 
military procurement and training; oil wealth provides the means.

\subsubsection{Government Constraints in Foreign Policy}

The third effect of oil on foreign policy predicted by our theory is the idea that governments which draw most of their income from oil will be less likely to attempt to create coalitions to back foreign policy, as oil insulates these politicians from the need to create broad public coalitions of support. As a result, we would expect to see that oil-rich countries have foreign policy outcomes which are often contrary to public opinion. Venezuela seems to conform well to this prediction, as the Chávez regime's foreign policy has frequently been at odds with public opinion. However, as in Saudi Arabia and Russia, the Venezuelan case also illustrates the perils of studying foreign policy in an oil-rich state, as oil wealth also enables leaders to mold public opinion to be more supportive.

Under the Punto Fijo, public opinion and foreign policy were broadly in line with each other. Foreign policy tended to focus on good relations with the US, and with partner states in Latin America. Venezuelans tended to be supportive of good relations with the US: in one 1996 survey, a whopping $71.8 \%$ of respondents had a very good, good, or average opinion of the US, with only $9.8 \%$ claiming a bad or very bad opinion of the US. ${ }^{104}$ Similarly, relations with other Latin American states indicated public approval of relations with close allies. For example, in the same survey, when asked which Latin American country they admired most, respondents opted first for Venezuela (27.5\%), but then for a selection of US allies: Mexico (11.9\%), Brazil (10.9\%), Argentina (9\%), and Colombia (4.1\%). Notably, countries which would later become key allies under Hugo Chávez, were not popular, e.g. Bolivia (0.5\%), Ecuador (0.4\%) and Cuba (2.4\%). ${ }^{105}$

In 2000, cracks began to form between public opinion and the broad thrust of Venezuelan foreign policy. As discussed in Section 1.2, the newly elected administration made an effective about-turn in foreign policy, cutting ties with the US, and focusing on relations with Cuba and other Bolivarian or socialist governments. Public opinion, however, continued to be supportive of a broader pro-democracy foreign policy. For example, one 2002 poll illustrates that while a majority

\footnotetext{
${ }^{104}$ Data from Latinobarometer (1996); available from http://www.latinobarometro.org. ${ }^{105}$ Ibid.
} 
of Venezuelans (53\%) still believed that Venezuela should seek closer ties with all countries in the region, a much larger proportion $(63 \%)$ believed that in reality, the Chávez government was only focused on creating ties with autocratic states. Even more telling, only $3.2 \%$ of respondents believed that this focus on ties with autocratic states was a good foreign policy choice. ${ }^{106}$ This lack of trust is illustrated in another key poll result, this time from 2007. When asked whether they have confidence in various leaders to do the right thing in global affairs, fewer respondents had no confidence at all in George W Bush (48\%) than in Majmoud Ahmadinejad (54\%), ${ }^{107}$ one of Chávez's new key partners. ${ }^{108}$

The mid-2000s also saw major discrepancies between public opinion and key foreign policy priorities of the Chávez regime. Public opinion did not tend to support profligate foreign aid spending, with $60.8 \%$ disapproving of infrastructure projects in other countries. Another 2007 poll showed only $38.7 \%$ of Venezuelans approved of foreign aid spending. ${ }^{109}$ In $2008,63 \%$ of Venezuelans also believed that the FARC was a terrorist group (while the Chávez administration denied it publicly), while in 2008, a massive $79.7 \%$ believed that Hugo Chávez was entirely mistaken about the prospects for war with the US. ${ }^{110}$ In short, it is clear that a majority of Venezuelans did not support key government initiatives in foreign policy. As Corrales and Romero note, "Venezuela's foreign policy is not driven by the majority's demand, and is in fact carried out contrary to the majority's wishes." 111 They argue that Chávez is not dependent on society for support, and only requires the support of ideologues among his own party, as oil wealth has enabled increasing control of the government apparatus, and lessened the costs of such foreign policy choices.

However, as in both prior cases, we must be cautious about drawing conclusions from available public opinion data. As several authors note, public opinion has changed since 2000. For example, by 2005 , only $34 \%$ of respondents believed that Venezuelan foreign policy focused on autocratic

\footnotetext{
${ }^{106}$ Magdaleno (2011): 49, in Clem and Maingot, eds. (2011).

${ }^{107}$ Data from Pew Global Attitudes Project (2007); available from http://www.pewglobal.org.

${ }^{108}$ Respondents were evenly split over their own leader, with $25 \%$ professing lots of confidence in Hugo Chávez's role in world affairs, $29 \%$ with some confidence, $22 \%$ with not much confidence, and $23 \%$ with no confidence at all.

${ }^{109}$ Magdaleno (2011): 62-3, in Clem and Maingot, eds. (2011).

${ }^{110}$ Ibid., 60-4.

${ }^{111}$ Corrales and Romero (2013): 138.
} 
regimes, down almost $30 \%$ since $2002 .{ }^{112}$ Similarily, while $71.8 \%$ had at least a somewhat favorable opinion of the US in 1996, this figure had fallen to $55.7 \%$ by $2011 .{ }^{113}$ Likewise, in 2002, $52 \%$ of Venezuelans felt that their way of life needed to be protected from foreign influence, but by 2007, this proportion had risen to $67 \% .^{114}$ These discrepancies are likely the result of media manipulation, as media within Venezuela has become increasingly biased towards regime support, and international media has been censored. ${ }^{115}$ Venezuelans are also increasingly poorly informed about foreign policy, illustrated by the fact that in $2006,69.5 \%$ of respondents in one survey did not believe that the Chávez government gave large amounts of foreign aid. ${ }^{116}$ Several authors also note that some of Chávez's foreign policy actions were specifically geared towards increasing domestic support for his regime and foreign policy, adding yet another wrinkle to the relationship between foreign policy and public opinion. ${ }^{117}$ Thus, the Venezuelan case again illustrates the difficulty of assessing public opinion in a resource rich state. Oil wealth has permitted the Chávez regime to ignore public opinion, but has also helped the regime to mold it.

\subsubsection{Conclusion}

This section sought to assess whether the Venezuelan case exhibits characteristics consistent with the theorized links between oil and our mediating variables. Venezuela has certainly always had a weak bureaucracy, a factor attributed by many scholars to its early dependence on oil. The foreign policy bureaucracy has been further weakened and personalized since 1999, and to some extent, the foreign policy bureaucracy has also been supplanted by imported Cuban civil servants, further weakening its impartiality and professionalism. Venezuela is also one of the world's biggest military spenders, particularly during the period of high oil prices during the 2000s. Finally, there is also evidence that public opinion has generally not been supportive of foreign policy, at least since 2000. However, the increasing manipulation of public opinion by the regime also makes this

\footnotetext{
${ }^{112}$ Magdaleno (2011): 53, in Clem and Maingot, eds. (2011).

${ }^{113}$ Data from Latinobarometer (1996; 2011); available from http://www.latinobarometro.org.

${ }^{114}$ Data from Pew Global Attitudes Project (2002; 2007); available from http://www.pewglobal.org.

${ }^{115}$ Magdaleno (2011): 53, in Clem and Maingot, eds. (2011).

${ }^{116}$ Ibid., 61.

${ }^{117}$ Dodson and Dorraj (2008): 72 .
} 
claim difficult to test. Thus, there is reasonable evidence of weak institutions, strong evidence of military spending and a lack of foreign policy constraints in the Venezuelan case. The chapter will now examine several specific cases of foreign policy decision-making to assess the potential links between our mediating variables and state aggression. These sub cases will focus on VenezuelanColombian border tensions (particularly the war scare of 2008), and on Venezuela's verbal aggression and covert support for terrorism since 1999.

\subsection{From Weak Foreign Policy Apparatus to Aggression}

\subsubsection{Venezuela and Colombia}

Border conflict has been a consistent problem between Venezuela and Colombia, two countries once part of the same state. In this section, we will examine the Venezuelan-Colombian relationship since 1990, with particular attention to clashes in 1995, 2005, 2008 and 2009-10. While relations between the two states have not seen major conflict since their split in 1830, the long, poorly-defined border has seen consistent low-level conflict related to Colombia's ongoing guerrilla war, making it a security concern for both states. Prior to the election of Hugo Chávez in 1999, the countries tended to cooperate to a limited extent on border issues, but recent years have seen an increase in hostilities and an arms-race in military spending. However, as one scholar notes, "despite the billions of dollars in arms spending over the past decade, as well as the inflammatory and loud sabre-rattling, the notion of a war between Colombia and Venezuela remains highly unlikely in the short to medium term." 118

Until 1830, Colombia and Venezuela were nominally part of the same country, first a part of the Spanish Empire in Latin America, and then part of the Gran Venezuela under the leadership of Simon Bolivar. ${ }^{119}$ The central foreign policy concern for both states was the legacy of imprecise Spanish frontiers, leading to major territorial disputes on land and in the Gulf of Venezuela. In particular, Venezuelan control of Los Monjes islands, close to the Colombian mainland, are an

\footnotetext{
${ }^{118}$ Rochlin (2011): 257.

${ }^{119}$ Ibid., 237-8.
} 
obstacle to easy demarcation of borders. ${ }^{120}$ As a result, war scares with Colombia have been common, especially during the dictatorship of Gen. Pérez Jiménez (1952-58). ${ }^{121}$ In addition, Colombia's ongoing civil conflict has been a source of concern to Venezuelan leaders. The most notable armed group in Colombia, the Fuerzas Armadas Revolucionarias de Colombia (FARC), was founded in 1964 as a typical communist insurgent group, but soon became involved in the drugs trade, allowing it to continue its guerrilla war to the present day. Another such group, the Ejército de Liberación Nacional (ELN) has also been successful in holding territory and conducting guerrilla operations against the government. In addition to these groups, there are a range of rightwing paramilitary groups. Throughout the Punto Fijo period, the FARC and ELN were hostile to Venezuela, and frequently crossed the border to kill soldiers and civilians, leading the government of Venezuela to complain that Colombia did nothing to prevent this. ${ }^{122}$

In spite of these tensions, Colombia has always been Venezuela's main regional trade partner, and "the close economic dependence between the two countries means that ideological and political spats cannot last very long without the necessities of urgent diplomatic niceties to avert economic crisis." 123 Throughout the 20th century, "the foreign policies of both Venezuela and Colombia towards each other oscillate[d] between cooperation, most notably in trade, to antagonism and aggressive stances that have in some circumstances placed both nations close to the brink of war." 124

\subsubsection{Venezuela and Colombia during the Punto Fijo Period}

On August 9, 1987, the Colombian naval corvette Caldas entered Venezuelan territorial waters in the Gulf of Venezuela, claimed the territory for Colombia, and began to remove Venezuelan naval and fishing vessels from the area. In response, Venezuela dispatched naval frigates and F-16 fighters to the area. Although no shots were fired, tensions were extremely high, with many worried that war was imminent. ${ }^{125}$ Ultimately, however, Colombia withdrew its ships and negotiations on

\footnotetext{
${ }^{120}$ Aguilera (1994): 10-11.

${ }^{121}$ Trinkunas (2011): 16-7, in Clem and Maingot, eds. (2011).

${ }^{122}$ Aguilera (1994): 25.

${ }^{123}$ Rochlin (2011): 257.

${ }^{124}$ McCarthy-Jones (2010): 56.

${ }^{125}$ George (1988): 140 .
} 
border areas were begun under the auspices of the Organisation of American States (OAS). ${ }^{126}$ In particular, personal negotiations by the two presidents at the border helped to calm tensions. ${ }^{127}$ This incident was the most serious of the late Punto Fijo period, and led the two countries to set up a commission with a mandate to review and resolve border crises, particularly in the disputed Gulf of Venezuela. ${ }^{128}$

All major incidents between Colombia and Venezuela during the 1990s were related to the border, with clashes in 1988, 1993, 1994 and 1995. These incidents frequently involved Venezuelan troops fighting guerrilla fighters, who were themselves opposed to the Colombian government, and sought sanctuary in the ill-defined border region. In 1993, four members of the Venezuelan national guard were killed in Tachira state, with five more killed a week later in the Alto Apure region. ${ }^{129}$ This resulted in a protest note from the Venezuelan Foreign Minister Fernando Ochoa Antich to his Colombian counterpart, reproaching him for not preventing these incidents. ${ }^{130}$ In 1994 , a helicopter carrying Venezuelan troops violated the Colombian border while following guerrillas. The chopper received ground fire, and crashed, requiring a second helicopter to evacuate the troops from Colombian territory. Although the Colombian government protested the incursion privately, President Trujillo sought to minimize the incident, fearing that it could harm his chances in a close election year. ${ }^{131}$

The 1995 incident was also linked to illegal immigration, as Colombian refugees took the opportunity of porous borders to flee conflict. Indeed, immigration into Venezuela has been a consistent problem, as more than 1.5 million Colombians have crossed the border, around 1/10th of Venezuela's population. ${ }^{132}$ In March 1995, the government of Rafael Caldera, angry over the killings of eight Venezuelan soldiers by Colombian guerrillas, airlifted 5000 troops to what he described as a 'major

\footnotetext{
${ }^{126}$ New York Times (August 24, 1987), "Two Claims of Territory Roil Waters in Gulf of Venezuela."

${ }^{127}$ Library of Congress (December 1990): "Country Profile: Veneuzela," available from http://lcweb2.loc.gov/frd/cs/vetoc.html.

${ }^{128}$ Aguilera (1994): 10-11.

${ }^{129}$ Ibid., 25.

${ }^{130}$ Ibid.

${ }^{131}$ Ibid., 54-5.

${ }^{132}$ George (1988): 142.
} 
theatre of operations. ${ }^{, 133}$ Once there, Venezuelan soldiers combed the border, rounded up 1000 Colombian immigrants, burned their houses and crops and deported them. Though the Colombian government protested the violence, the Venezuelan government accused the Colombians of failing to secure the border, and of weakening Venezuela's security. ${ }^{134}$ President Caldera again requested of Colombia the right to 'hot pursuit' of guerrillas across the border, but was denied. Although these incidents were clearly challenging to both countries, the Colombian government sought to resolve the conflict alone, and refused help from neighboring states. ${ }^{135}$

There were no incidents in this period which involved Venezuelan troops fighting Colombian ones; instead, both sides struggled with guerrilla groups. Tensions were largely defined by Colombia's unwillingness to allow Venezuelan troops to pursue guerrillas across the border. On the Venezuelan side, officials in fact often showed a strong streak of common sense, as in 1998, when Rafael Caldera authorized Colombian troops to pursue a guerrilla group responsible for bombing the Colombian town of Ragonvalia into Venezuelan territory. ${ }^{136}$ Thus, there was no conflict between the states, with the Caldas frigate incident in 1987 coming closest. The key question is therefore why we do not see conflict during this period.

First, both countries were governed under similar systems of pacted democracy. Foreign policy was primarily made by the cabinet in both countries, and the similar systems had strong personal links. Though Colombia's National Front pact nominally ended in 1974, politicians from the two main parties continue to control the government till the present day, with both parties having strong links with their counterparts in Venezuela throughout the Punto Fijo period. Both countries shared common foreign policy goals in many areas, in particular, "stability adequate to preserve formal internal democracy and forestall pressure from radical leftist and militaristic currents." ${ }^{137}$ On the Venezuelan side, policy was crafted through the party-pact structure, and with the help of the Comisión de Relaciones Exteriores (CARE), allowing for careful consultation between many

\footnotetext{
${ }^{133}$ New York Times (March 17, 1995), "Nationalist Fever Helps Heat Up Another Latin Border." ${ }^{134}$ Ibid.

${ }^{135}$ Tokatlian (2000).

${ }^{136}$ Guo (2012): 44.

${ }^{137}$ George (1988): 140.
} 
parties on these issues. These factors ensured that policy was more collaborative than conflictual.

Secondly, both countries were allied with the US, which often intervened diplomatically, as it did during the Caldas incident, to minimize tensions. Indeed, the Caldas dispute may itself have been initiated by Colombia precisely to engage the international community, and "force the internationalization of the dispute" 138 rather than being a true potential conflict. Finally, the Colombian and Venezuelan governments shared a common enemy in the FARC, ELN and other communist guerrilla and terrorist groups. While the disputed border complicated this relationship, it did not minimize the fact that cooperation was the best solution for both states. Indeed, senior Colombian military officers expressed fear during the Caldas incident that "even a brief external war would produce dangerous internal military weakness which could be exploited by leftist guerrilla forces," and sought to avoid conflict as a result. ${ }^{139}$ For these reasons, the Punto Fijo period was largely peaceful in Colombian-Venezuelan relations despite ongoing border disputes and other points of friction.

\subsubsection{Hugo Chávez's Reversal}

The ascension of Hugo Chávez to the presidency in February 1999 brought massive changes to this relationship, leading to a period of high tensions between both states. The primary reason for this hostility was the fact that Hugo Chávez's Bolivarian movement was more closely aligned ideologically with the FARC and ELN than with the Colombian government, a viewpoint he made clear within the early months of his presidency, when he declared Venezuela's neutrality in the Colombian conflict, implicitly recognizing the FARC as a legitimate combatant party, rather than a terrorist group. ${ }^{140}$ There were at least five low-level conflicts (with the potential to escalate to war) between Colombia and Venezuela between 1999 and 2010, although the period since that time has seen some reconciliation between the two states. In addition, the Chávez government's covert support for the FARC (covered in Section 6.3.2) can certainly be described as a form of aggression,

\footnotetext{
${ }^{138}$ George (1988): 151 .

${ }^{139}$ George (1988):159.

${ }^{140}$ Shifter (1999): 17.
} 
and was a key element in strained relations. The period between 1990-2010 saw four breaks in diplomatic relations, two calls for all-out war by leaders, and one trade embargo.

The earliest incident during Chávez's tenure took place in March 2000, when the Venezuelan government authorized four helicopters and two airplanes to bombard an area in the Catatumbo area of Colombia near the border. It is unclear what their motives were, as little information is publicly available on the incident, but it did serve to heighten tensions. ${ }^{141}$ Hugo Chávez also supported Venezuelan truckers in their blockade of the Colombian border. The truckers were agitating for increased security for their convoys on Colombia's guerilla-infested roads. These two incidents, combined with Hugo Chávez's potential ties to the FARC led the Colombians to briefly recall their ambassador for talks. ${ }^{142}$

During this early period, US ties also served to worsen relations. The US-proposed Plan Colombia, a comprehensive plan to send over $\$ 7$ bn to Colombia from the US in troops and money, was designed to help fight the drug-related insurgency. ${ }^{143}$ However, the Venezuelan government described this as a US move to gain a military foothold in Latin America, increasing tensions. There are many strong connections between Colombia and the US: the US supplies high-tech weapons and intelligence assistance to Colombia in its fight against the FARC, such as satellite phone wiretaps and satellite surveillance information. Colombia also allows the US to station anti-drug troops on its territory, and has reoriented its foreign policy stance since Chávez came to power. The creation of a new air force and intelligence post at Palanquero, Colombia, ideally situated for watching Venezuela highlights this. Venezuela is now a key adversary for both Colombia and the US, and is perceived as: "evil, anti-Colombian and violent" by many in both states. ${ }^{144}$ In addition to the base agreements, both US and Colombian elements may have been involved in the 2002 coup against Chávez: one investigation by the State Department's Inspector General found that the National Endowment for Democracy and the Pentagon had "provided training, institution-building and support to individuals and organizations understood to be actively involved in the brief ouster of the

\footnotetext{
${ }^{141} \mathrm{Gao}(2012): 44$.

${ }^{142}$ Financial Times (November 27, 2000), "The Americas: Colombia recalls its ambassador."

${ }^{143}$ Rochlin (2011: 253.

${ }^{144}$ Lindsay-Poland (2010): 24.
} 
Chávez government," while the CIA knew about the coup six days before it happened. ${ }^{145}$ Following failure of the coup, its leader, Cormona, also sought refuge at the Colombian embassy, where he was granted asylum and safe passage out of Venezuela. These actions, in addition to the ideological distance between Colombia and the new Venezuelan government ensured that relations remained highly conflictual.

In 2005, a high-level FARC official, Rodrigo Granda, was arrested in Caracas at the Bolivarian People's Congress, and was quickly taken to the border and turned over to Colombia. The arrest, made by local police, did not have the official sanction of the Chávez government, who accused the Colombians and the CIA of bribing their security forces to assure Granda's illegal extradition. ${ }^{146}$ In response to the incident, Venezuela suspended trade and diplomatic relations with Colombia. ${ }^{147}$ Relations were restored following a summit brokered by Fidel Castro later that year, but the incident highlighted the ideological distance between the Chávez government and many of Venezuela's civil servants and policemen, holdovers from the Punto Fijo era who were still opposed to the FARC and other revolutionary groups. While foreign policy was typically handled by the cabinet in previous eras, the Rodrigo Granda incident saw the investiture of foreign policy in the person of Hugo Chávez, with other officials involved only as messengers.

In November 2007, a minor diplomatic disagreement related to ongoing negotiations between Colombia, Venezuela and the FARC again led to the severing of diplomatic ties. President Uribe of Colombia asked that negotiations between Venezuela and the FARC end, leading Chávez to sever all ties with Colombia, and threaten to cut off trade. Like many foreign policy decisions, this one was made hastily and by Chávez himself, stating that:

"While President Uribe is president of Colombia, I will have no type of relationship with him, or with the government of Colombia." 148

The decision was extremely short-sighted, leading to food shortages in Venezuela as Colombian

\footnotetext{
${ }^{145}$ Aviles (2005): 48.

${ }^{146}$ International Institute for Strategic Studies (May 2011), "The Farc Files: Venezuela, Ecuador and the Secret Archive of 'Raúl Reyes."

${ }^{147}$ Financial Times (January 20, 2005), "Lula Acts to Broker End to Standoff over Farc 'arrest'."

${ }^{148}$ New York Times (November 29, 2007), "Chavez Says He'll Cut Ties With Colombia And Its Leader."
} 
trade, one of Venezuela's key sources of food, ended briefly. By December, diplomatic relations had been restored, and the Chávez government accepted Colombia's offer of 'supportive trade' to help alleviate the food shortages. ${ }^{149}$

Although this period marked the beginning of increased tensions with Colombia, it is worth noting that the Venezuelan population was never particularly supportive of such an antagonistic policy. Between 2006 and 2008, fully $47 \%$ of Venezuelans surveyed approved of the policies of the Colombian leadership, while during the same period, the proportion who approved of their own leadership dropped from $61 \%$ to $47 \% .{ }^{150}$ Similarly, despite Chávez's repeated insistence that Venezuela must prepare for war with the US and Colombia, a 2006 survey showed that $79.7 \%$ of Venezuelans did not agree, and did not feel prepared. ${ }^{151}$ Chávez's ongoing belligerence towards Colombia was therefore at odds with popular opinion, as predicted by our theory. It is again worth noting that public opinion polls are often misleading: as one author illustrates, polls in countries like Venezuela are often suspect, and can be subject to massive variance depending on which organization conducts the poll. ${ }^{152}$

March 2008 saw the biggest crisis of the last decade, with armies mobilizing to the border, and war a serious possibility. The crisis began on March 1, when Colombian troops, aided by US intelligence, attacked a FARC camp approximately 1.1 miles inside Ecuador, killing over 20 operatives, including the head of the FARC's international committee Raul Reyes. ${ }^{153}$ In addition, Colombian troops seized three laptops, containing more than 8,000 word documents relating to FARC activities and leaders; these were turned over to INTERPOL, and then to the International Institute for Strategic Studies in London for analysis; the laptop files purported to show strong links between the Venezuelan and Ecuadorian governments and the FARC (See Section 6.3.4). ${ }^{154}$ The incident became a major regional crisis, as anti-Colombian states such as Venezuela, Ecuador

\footnotetext{
${ }^{149}$ El Universal (December 27, 2007), "Envoy to Venezuela says Colombia ready "to turn the page" on recent impasse."

${ }^{150}$ Gallup World Report (November 24, 2009), "Colombians and Venezuelans at Odds on Leadership," available from http://www.gallup.com/poll/124478/colombians-venezuelans-odds-leadership.aspx.

${ }^{151}$ Magdaleno (2011): 60, in Clem and Maingot, eds. (2011).

${ }^{152}$ Rosnick (2012).

${ }^{153}$ Waisberg (2009): 476.

${ }^{154}$ Crandall (2011): 236.
} 
and Bolivia condemned the attack.

The following day, Chávez spoke about the incident on his tv show, Aló Presidente, publicly describing the attack as a violation of sovereignty, and holding a minute's silence for Reyes, whom he described as a 'true revolutionary.' ${ }^{155}$ While on air, Chávez also publicly discussed policy responses with his Foreign and Defense Ministers, and ordered ten tank battalions, naval and air forces to the Colombian border. All Colombian diplomats were expelled from Venezuela, ${ }^{156}$ and he again threatened to end Colombian trade, raising the prospect of food shortages within Venezuela. ${ }^{157}$ The tone of discussion on the show was extremely belligerent, with Chávez threatening Colombia:

"If you decide to do this in Venezuela, pal, we'll send you a few Sukhoi [planes]."158

Despite Venezuela's moves towards conflict, Colombian Defense Minister Santos said that he did not believe it was necessary to send troops to the border in response. In a newspaper interview that day, retired Venezuelan General Miguel Aparicio concurred, arguing that:

"This is just another of Chávez's orders made without thinking, and without any military advice. We are getting use to his impulsiveness and instability - it is an empty threat." 159

On March 4, President Uribe apologized for the raid at an emergency meeting of the OAS. Although the OAS condemned the attack as a violation of territorial integrity, it noted that Ecuador and Venezuela have commitments under international law not to support terrorism. ${ }^{160}$ Another emergency summit, this time coordinated by the Rio Group, in Dominica, saw a more conciliatory line from both parties. Indeed, Chávez appeared to have backed away from his prior belligerent stance, and gave a speech in which he stated:

"We still have time to stop a whirlpool which we could regret. Let's stop this, let's reflect, let's be cool-headed." 161

\footnotetext{
${ }^{155}$ New York Times (March 3, 2008), "Troops Mass at Colombian Borders in Crisis Over Killing of Rebel."

${ }^{156}$ New York Times (March 6, 2008), "Regional Bloc Says Ecuador's Sovereignty Was Violated."

${ }^{157}$ Financial Times (March 5, 2008), "Uribe accuses Venezuela of backing Farc 'Genocide'."

${ }^{158}$ New York Times (March 3, 2008), "Troops Mass at Colombian Borders in Crisis Over Killing of Rebel."

${ }^{159}$ Financial Times (March 4, 2008), "Venezuelan Action Falls Short of Chavez's Bellicose Bluster."

${ }^{160}$ Waisberg (2009): 478.

${ }^{161}$ McCarthy-Jones (2010): 119.
} 
Negotiations were successful, and by March 9, Venezuela had withdrawn its troops, and resumed low-level diplomatic relations with Colombia. ${ }^{162}$

The 2008 crisis highlights several factors of interest to our theory. In particular, the decisionmaking process was particularly centralized and attenuated in this case, with key decisions made personally by Hugo Chávez, sometimes publicly, and often on a whim. In a discussion of Chávez's televised responses, McCarthy-Jones notes that: "President Chávez's speech [on March 2] contained critical elements that reveal the way in which foreign policy-making is undertaken and formulated. Chávez's immediate response manifested in the rapid implementation of policies that were reactive in nature, and which held the potential to escalate rather than temper the situation... President Chávez at times dictates Venezuelan foreign policy without consultation with ministers of the relevant portfolios." 163 Few analyses of the crisis reference any actor other than Hugo Chávez, who has "shown a propensity to transcend his role as president and act as the state itself in policy matters." 164

The Venezuelan-Colombian relationship highlights some of the flaws of an extremely personalized foreign policy system, in particular the fact that decisions are frequently swayed by ideology or emotion, and are often not the most rational choice. For example, in the 2008 incident, Chávez's decisions are clearly reactive, and often illogical. The decision to cut trade with Colombia would have resulted in major food shortages and would have been extremely destructive to the Venezuelan economy, which had over $\$ 6$ bn in trade with Colombia in 2008 alone. ${ }^{165}$ In addition, the decision to send troops to the Colombian border was extremely ill-considered. Venezuela has only 115,000 fighters in comparison to Colombia's 254,000 troops. Colombian troops are also substantially more experienced in combat and better trained than Venezuela's army, which is generally regarded as weak. ${ }^{166}$ While it is possible that these oversights were due to intelligence failures, it seems more likely that the ad hoc, reactive nature of foreign policy making means that decisions are made on the

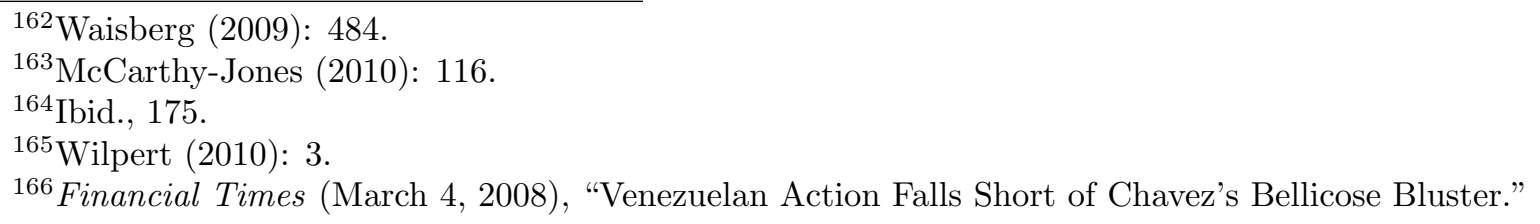


spur of the moment, relying on personal perceptions, before ramifications are fully considered. ${ }^{167}$ Indeed, if Hugo Chávez was indeed truly conducting his meetings with ministers on these issues on his television show, it is clear that he is not receiving good information and advice.

These criticisms are indicative of a broader problem in Venezuelan foreign policy during the 2000s; President Chávez often made foreign policy pronouncements publicly before they were discussed in cabinet, and many of his decisions, as McCarthy-Jones notes, were rash, requiring reversal of these policies later. On March 2, Chávez effectively declared war on Colombia, yet by March 7, he was publicly calling for negotiations to end conflict. Similarly, at various times, Chávez has had to retreat from key threats, such as ending trade or diplomatic relations, when the effects of those policy choices are too onerous for his government to bear. Indeed, the 2008 crisis would likely have come to war between Colombia and Venezuela if not for the Colombian insistence that it would not move troops to the border, and US pressure on Colombia to avoid escalation. In a news interview shortly after the crisis, retired Venezuelan General Francisco Udon argued that the only reason for a lack of conflict in this case was the 'statesmanlike behavior' of the Colombian leadership. ${ }^{168}$

Tensions between Colombia and Venezuela remained high through 2008-2009, with a number of minor border and political incidents. The key point of contention for Venezuela was the ongoing US plan to move several bases from Ecuador into Colombia, which led Chávez, on Aló Presidente, to appeal to the population to:

"Prepare for war, and to help the people prepare for war..." with the US. ${ }^{169}$

In October 2009, Venezuela announced that it had captured two Colombian spies near the border. Although denied by Colombia, various leaked cables confirm that the Colombian military did indeed secretly keep a base in Venezuela, home to a 100-man counterguerilla squad. In addition, Colombian intelligence was also revealed to be running a number of operations inside Venezuela, including the

\footnotetext{
${ }^{167}$ McCarthy-Jones and Turner (2011): 560.

${ }^{168}$ BBC Worldwide Monitoring (February 7, 2008), "Venezuelan Retired General says Chavez Wants to Create FARC Border State."

${ }^{169}$ McCarthy-Jones (2010): 123.
} 
capture and extradition of 30 members of the FARC and ELN by bribed Venezuelan troops. ${ }^{170}$

In response to the US base deal, as well as to Colombian accusations of Venezuelan support for the FARC, Chávez on November 8 ordered his Minister of Defense (again via television program) to deploy 15,000 additional troops, plus 500 armored vehicles to the border region in Tachira state, location of the main border crossings to Colombia. ${ }^{171}$ Shortly after, Venezuelan troops bombed two cross-border footbridges, destroying them to prevent further use by 'spies.'172 Chávez also threatened to cut off oil supplies to the US if Colombia attacked. ${ }^{173}$ Though no shots were fired, these moves were extremely provocative, and disproportionate. As one senior US official described to the New York Times:

"These are calculated provocations by President Chávez. Colombia hasn’t been taking that bait, [but] isolated incidents could result in situations where both sides would exchange fire." 174

Tensions died down until July 2010, when Venezuela again cut diplomatic relations as a response to Colombian accusations of Venezuelan support for the FARC. ${ }^{175}$

In many of these cases, the Chávez government has taken a strongly military stance, even where the situation did not perhaps warrant it. This is perhaps unsurprising from a man who spent his life as an army officer, and in most crises during the period, Hugo Chávez tended towards a militaristic response. In 2008 and 2009, troops were sent to the border before any attempt at negotiation. Even his rhetoric tends to be militaristic: for example, in response to a Colombian accusation that Venezuela gave weapons to the FARC, Chávez devoted a whole episode of his tv show Aló Presidente to personally demonstrating the use of rocket launchers and grenades, both boosting his military credentials among the population, and encouraging the population to focus on military tactics. ${ }^{176}$ In particular, the fact is that Chávez has a tendency to respond to all incidents

\footnotetext{
${ }^{170}$ Huertas (2012).

${ }^{171}$ McCarthy-Jones (2010): 123.

172 The Guardian (November 20, 2009), "Venezuela Blows Up Border Bridges With Colombia."

${ }^{173} \mathrm{Gao}$ (2012): 44.

174 The Washington Times (December 10, 2009), "Colombia Faces Border Tensions with Venezuela."

${ }^{175}$ BBC Worldwide Monitoring (July 23, 2010), "Venezuela Severs Ties with Colombia."

${ }^{176}$ McCarthy-Jones (2010): 121.
} 
with military force. The US base deal should be a political issue, not a military one, yet troops were mobilized several times in response. Likewise, troops were sent to the border in response to Colombian accusations of support for the FARC (a political issue), Colombian complaints about weapons shipments (also a political issue), and the 2008 Ecuadorian crisis (which was not an attack on Venezuela). Military buildup, as well as trade embargoes and the cessation of diplomatic ties have been the government's default response to any and all crises.

Interestingly, since 2010, there has been an effective normalization of relations between Venezuela and Colombia. Full diplomatic relations were restored in August 2010, and a summit meeting between Chávez and new Colombian President Juan Manuel Santos Calderon at Santa Maria, Colombia in the same year saw both states present a more friendly and unified front. ${ }^{177}$ In November of that year, Venezuela extradited three members of the FARC to Colombia, breaking a decade-long pattern. ${ }^{178}$ Although there is no love lost between the two leaders - Chávez even publicly asserted that Santos had tried to have him assassinated! - relations have improved dramatically. ${ }^{179}$ Most scholars agree that the reconciliation is a result of Venezuela's failing economy, and its desperate need for trade. ${ }^{180}$ It remains to be seen whether this trend will continue under Chávez's successors, or whether any improvement in the Venezuelan economy will bring with it a return to hostilities.

\subsubsection{Venezuela and Colombia: Theory of Oil and Aggression}

The narrative above attempts to explore the troubled Venezuelan-Colombian relationship, in particular its variation over time. While there have been consistent tensions between the two states, largely related to border issues and to Colombia's ongoing civil conflict, these issues were handled substantially better by leaders during the Punto Fijo than by the new Bolivarian regime. The period before 1999 had few major incidents, and conflicts tended to be settled through negotiation, while the period since then has been extremely strained, with a number of high profile incidents, and several near-conflict situations, largely prevented by Colombian, not Venezuelan leadership. While

\footnotetext{
177Wilpert (2010): 3 .

${ }^{178}$ Wilpert(2011): 3 .

${ }^{179}$ New York Times (August 11, 2010), "Leaders Repair Ties Between Colombia and Venezuela."

${ }^{180}$ Corrales and Romero (2013): 195-6.
} 
the theory of oil and aggression predicts the latter period well, it does not predict the relatively peaceful period of the Punto Fijo.

However, some explanation for this may be found in key differences in policymaking during these two periods. During the Punto Fijo, although the bureaucracy was weak, foreign policy decisions were still taken by a broad group within the pacted democracy. Crises tended to be handled well, with the President seeking advice from his cabinet, and from the CARE special committee, made up of individuals with extensive experience in foreign affairs. Policy tended not to be reactive, or focused on military options, and public opinion was largely in line with government policy. Thus, I argue that the Punto Fijo pact system offered an alternative 'semi-bureaucratic' system for coherent foreign policymaking, halting incipient conflicts early, and smoothing the path to peaceful cooperation.

In contrast, our theory's predictions track closely with the regime of Hugo Chávez and his successors, who have no such replacement policymaking system. Under Chávez, foreign policy has been narrowly made, with advice and input limited to a few key advisors, and often, to Chávez himself. Policy was frequently made on the spur of the moment, and tended to focus excessively on military solutions, even when the perceived problem was social, economic, or political. In addition, public opinion did not differ much from the Punto Fijo period, meaning that the government typically ignored or dismissed public opinion concerns in regard to Colombia. In short, the relationship with Colombia, since 1999, is an excellent illustration of the ways in which oil wealth can undermine foreign policymaking, ultimately producing aggressive and conflictual outcomes.

\subsubsection{Hugo Chávez: Covert and Verbal Aggression}

In recent years, Venezuela has perhaps been best known for the verbal belligerence of its leaders, as well as for covert political, military and economic support for terrorist groups, rogue and pariah states. While these acts were not overtly aggressive, and rarely involved Venezuelan military action, there is no denying that they are forms of aggressive foreign policy, with major implications for the security of other states. In this case, we will focus on two different aspects of non-conflict, 
belligerent foreign policy: Venezuelan financial and material support for terrorism, and Chávez's well-known verbal aggression. As in Section 6.3.1, it must be noted that there was a qualitative difference in foreign policy between the more stable pre-Chávez period, and the post-1999 period. Prior to 1999, Venezuelan leaders rarely issued verbal threats, and were opposed to international terrorism and guerrilla groups. It is likely that the same factors which mitigated the effects of weak institutions on conflict with Colombia also mitigated their effects regarding other foreign policy issues. For this reason, this section will focus on the period since 1999. While Venezuela has been involved in no full overt conflict in the last decade, it has funded terrorist groups and been heavily involved in smuggling of arms and drugs, leading some to describe Venezuela as 'Latin America's new Cuba,' in effect, a state which does not initiate large-scale conflicts, but which consistently funds covert and illegal aggressive actions against other states.

\subsubsection{Venezuelan Support for Terrorism}

Hugo Chávez's election to the presidency in 1999 brought with it a major change in official Venezuelan ideology, with the government now choosing to align more closely with Marxist revolutionary socialism than with the previous government's parliamentary social democratic principles. This served to bring the Venezuelan government closer to various socialist revolutionary groups throughout Latin America, many of which have been classed as terrorist groups by Western governments. Venezuela has supplied money and arms to many of these groups to achieve their aims. These relationships, as well as Chávez's choice to align with various rogue or pariah states led to close relationships with terrorist groups from outside Latin America, such as Hezbollah. Venezuela also acts as a facilitator for state sponsors of terrorism (such as Iran and Libya) which are under international sanctions, providing arms and money to these groups. In short, Venezuela has become a major sponsor of international terrorism, as well as financial support mechanism for several highly unsavory pariah states.

Venezuela's ties to the FARC (and to its sister group the ELN) from 1999 are based on a common ideological framework. Indeed, Hugo Chávez's involvement with key leaders in the FARC 
dates not from 1999, but from the period immediately following his failed 1992 coup. FARC leaders, impressed with the young military commander's actions, contacted him during his brief period in prison, and he retained contact with the FARC throughout the 1990s as he attempted to build a socialist movement in Venezuela. ${ }^{181}$ Following his democratic election, Chávez not only continued to build close (if secret) ties with FARC leaders, but also attempted to remodel Venezuela's military strategy to more closely emulate the FARC's '4th Generation Warfare' strategies, which he argued would be necessary to fight inevitable the "Guerro del Todo el Pueblo" (War of all Peoples) against the West. ${ }^{182}$ Chávez admires the FARC deeply; as one author notes: "Chávez has retained a fascination with the FARC as a rare example of a Latin American guerilla organization whose ideology and military capability have survived the end of the Cold War... His growing interest in asymmetric warfare has only added to FARC's appeal." 183

Indeed, the Chávez government views the FARC as co-belligerents in their struggle against the US, and against non-socialist governments throughout Latin America. During the period from 19992008, however, the Venezuelan government did not publicly support the FARC, but did effectively ignore the FARC's use of Venezuelan territory as a safe haven from US and Colombian forces and provide materiel support. They also refused to classify the group as a terrorist organization, arguing that it was a legitimate combatant, a stance which angered several neighboring states. ${ }^{184}$ Venezuela's strategic alliance with the FARC is seen as a way for them to further revolution in Colombia, and "implies agreement... as to the illegitimate nature of the Colombian political regime and the need to resort to violence to solve it." 185 Chávez frequently offered to act as an "impartial mediator' of the Colombian situation, and the government's close financial and military ties with the FARC largely remained secret until the 2008 Colombian raid in Ecuador which resulted in the death of a senior FARC commander and the capture of his diary and files.

\footnotetext{
${ }^{181}$ International Institute for Strategic Studies (May 2011), "The Farc Files: Venezuela, Ecuador and the Secret Archive of 'Raúl Reyes."

${ }^{182}$ Mainwaring (2007): 33 .

${ }^{183}$ International Institute for Strategic Studies (May 2011), "The Farc Files: Venezuela, Ecuador and the Secret Archive of 'Raúl Reyes."

${ }^{184}$ Corrales and Romero (2013): 100-1.

${ }^{185}$ Ortiz (2011): 85, in Clem and Maingot, eds. (2011).
} 
During the raid, Colombian troops captured three laptops, two external hard drives and three usb thumb drives, stocked with up to 38,000 files. ${ }^{186}$ The files, particularly those found in Raul Reyes personal briefcase, contained correspondence, descriptions and photographs of key meetings. Reyes had been previously disciplined by other FARC leaders for his poor operation security in storing such files on easily accessible and unencrypted hard drives, but this does not appear to have worked. ${ }^{187}$ As such, the files represented a virtual goldmine of evidence for Colombian and international officials seeking to isolate the FARC's sources of funding and weapons. Shortly after their capture, the laptops were turned over the INTERPOL to be verified, and thereafter were given to a team of researchers at a London think-tank for full analysis. ${ }^{188}$ These files served to verify the earlier suspicion of links between Venezuela and the FARC; during the 2005 arrest of Rodrigo Granda, he had been found to have phone numbers of key Venezuelan officials in his phone, but until 2008, no proof of more substantive links had been found. ${ }^{189}$

The documents showed clear personal and financial links between key members of the Venezuelan government, and FARC leaders. Although no document concretely links Hugo Chávez financially to the FARC, he certainly was involved in meeting key leaders, and his closest deputies often disbursed funds or arms personally to the group. Chávez himself met with FARC leaders on multiple occasions, often under the guise of 'peace negotiations.' At one covert meeting in 2000, Chávez met with Raul Reyes and agreed to lend the FARC hard currency for weapons purchases. ${ }^{190}$ In 2007, Chávez was involved in another series of meetings with the FARC, ostensibly to act as a mediator arranging the release of hostages. The files, however, reveal that during this process, Chávez met with Ivan Marquez, another key member of the FARC's Secretariat. The two discussed the FARC's overall military strategy, and Chávez offered a $\$ 300$ million loan, as well as the use of Venezuelan territory and medical facilities for group members to rest and recuperate. ${ }^{191}$

\footnotetext{
${ }^{186}$ Denvir (2008): 5.

${ }^{187}$ International Institute for Strategic Studies (May 2011), "The Farc Files: Venezuela, Ecuador and the Secret Archive of 'Raúl Reyes."

${ }^{188}$ Crandall (2011): 236.

${ }^{189}$ Financial Times (January 20, 2005), "Lula Acts to Broker End to Standoff over Farc 'arrest'."

${ }^{190}$ New York Times (May 10, 2011), "Venezuela Asked Colombian Rebels to Kill Opposition Figures, Analysis Shows."

${ }^{191}$ Padilla (2010): 80.
} 
Cooperation with the FARC appears to have been a open secret at the top levels of government, with trusted lieutenants doing much of the work in maintaining the relationship. Both Ali Rodriguez Araque (Venezuela's Foreign Minister from 2004-6) and his head of security, Julio Chirino, frequently met with FARC leaders. In 2006, Chirino was sent to bolster ties with the group after the Rodrigo Granda affair soured relations. During this meeting, he set up direct communication links between Chávez and the FARC Secretariat, and offered to facilitate arms deals, and to disseminate FARC propaganda through Venezuelan media channels. ${ }^{192}$ Araque also arranged for the FARC to assassinate Henry Lopez Sisco, a key opponent of Hugo Chávez, though this attempt failed. ${ }^{193}$ Henry Rangel Silva, head of Venezuelan intelligence agency DISIP, also met on a regular basis with FARC leaders, at one meeting stressing that a Colombian-Venezuelan deal on intelligence-sharing was fake, and reinforcing the government's support for the FARC. ${ }^{194}$ In 2007, Minister of the Interior Ramon Rodriguez Chacin was designated as the unofficial go-between for relations. During his tenure he oversaw the transfer of AT-4 $85 \mathrm{~mm}$ antitank rockets and launchers (purchased by Venezuela from Russia), and helped to set up contact between the FARC and an Australian arms dealer who supplied Chinese-made weapons. ${ }^{195}$ Among those not named, but effectively identified in the files include five top Venezuelan generals.

Thus, contacts were largely between the elite layers of the Venezuelan state and the FARC; it is unlikely the bureaucracy was involved in these operations, which were more of a covert, guerrillastyle operation than a state-funded one. Indeed, the fact these ties existed before the Bolivarian movement came to power highlight the lack of involvement of institutions in the decision-making process. Ties between Venezuelan and FARC leaders were not only financial, but personal, as top aides to Chávez identified strongly with their FARC counterparts. A quote in one letter from Venezuela's Minister of the Interior illustrates this:

"Dear Raul, a brotherly and revolutionary greeting to you and your comrades in the

\footnotetext{
${ }^{192}$ International Institute for Strategic Studies (May 2011), "The Farc Files: Venezuela, Ecuador and the Secret Archive of 'Raúl Reyes."

${ }^{193}$ New York Times (May 10, 2011), "Venezuela Asked Colombian Rebels to Kill Opposition Figures, Analysis Shows."

${ }^{194}$ International Institute for Strategic Studies (May 2011), "The Farc Files: Venezuela, Ecuador and the Secret Archive of 'Raúl Reyes."

${ }^{195}$ Padilla (2010): 81-2.
} 
struggle... I must emphasize my willingness to cooperation, which constitutes a revolutionary obligation, and matter of personal affection for you." 196

An incriminating film, found among the Reyes files also shows Chacin telling the FARC commander:

"We're closely following your struggle. Keep up this spirit, maintain this strength and count on us." 197

Current Venezuelan President Nicolas Maduro and Rodrigo Granda are also reputed to be good friends. ${ }^{198}$ In perhaps the most damning report, the US Office of Foreign Asset Control named three key government officials as terrorist collaborators, Hugo Carvajal (head of Venezuelan Military Intelligence), Henry de Jesus Rangel (head of DISIP) and Ramon Rodriguez (Minister of Interior and of Justice under Chávez). 199

In addition to elite level contacts, there has been some broader cooperation between the FARC and Venezuela's military and intelligence services, although the involvement of low-ranking troops in anti-FARC raids and arrests, often in direct contravention of orders from Caracas, suggests that support for the FARC is not widespread at lower levels of government. Nonetheless, DISIP, Venezuela's intelligence agency, has involved FARC guerrillas in training their operatives. Evidence suggests that they may have also sought FARC expertise in domestic terror tactics in an attempt to vilify and undermine Chávez's opponents. ${ }^{200}$ The military has also sought FARC experts to train their troops, though they are not publicly identified as such. As of 2010, there were four key FARC camps in Venezuela, the largest of which was known as 'Asamblea' and was used to train Venezuelan militias in asymmetric warfare tactics. ${ }^{201}$ In 2010, Colombian Ambassador Luis Alfonso Hoyos presented evidence of these camps to a meeting of the OAS, including satellite photos and

\footnotetext{
${ }^{196}$ International Herald Tribune (May 13, 2011), "Dear Comrade... The Farc files lift the lid on Hugo Chvez's Venezuela."

${ }^{197}$ Financial Times (March 5, 2008), "Uribe accuses Venezuela of backing Farc 'Genocide'."

198 Univision (April 11, 2013), "Los secretos de las FARC sobre Nicolás Maduro."

${ }^{199}$ Denvir (2008): 4.

${ }^{200}$ New York Times (May 10, 2011), "Venezuela Asked Colombian Rebels to Kill Opposition Figures, Analysis Shows."

${ }^{201}$ Padilla (2010): 84.
} 
maps, which showed over 1500 FARC and ELN rebels on Venezuelan territory. ${ }^{202}$

In short, there are deep ties between the Venezuelan government and the FARC, but these relations are shaped more by perceptions and by ideological affinity than by any concrete foreign policy decision-making process. Venezuela's continued support for the FARC is deeply unpopular among the population: as late as 2008, $63 \%$ of Venezuelans believed that the FARC were a terrorist organization, and only $14 \%$ of those surveyed were in favor of redesigning the FARC as a nonterrorist group. ${ }^{203}$ This is likely why the Chávez and Maduro governments have gone to such lengths to hide the relationship. As relations between Venezuela and Colombia have improved over the last three years, support for the FARC has, at least ostensibly, been dropped. Indeed, the Venezuelan government has several times turned over minor information on the FARC or low-level prisoners to Colombia to bolster that relationship. ${ }^{204}$ However, there are many signs of continued deep (and secret) ties between the Venezuelan state and the rebel group. Venezuela's ongoing involvement with the FARC is a deeply antagonistic action, as they are effectively fomenting civil war in their nearest neighbor, and funding the overthrow of its democratically elected government. The decision to ally with the FARC closely matches our theoretical expectations: the decision was taken and implemented by a small group of individuals, with no formal bureaucratic input, and in direct opposition to popular public sentiment. The decision has deeply hurt Venezuela, which has received sanctions and international opprobrium for these actions. In addition, while this support is not necessarily military, per se, it certainly indicates an affinity for violent means in foreign policy.

More recently, the Venezuelan government has begun to develop ties with other terrorist groups, as well as a penchant for drugs and arms smuggling, which has seriously concerned western governments. As several reports describe, Venezuela is now a gathering point for international terrorists, as well as a hub for transnational organized crime. ${ }^{205}$ Venezuela has ties to Iranian group Hezbollah, and to ETA, the Basque separatist group, with evidence suggesting that both groups have

\footnotetext{
${ }^{202}$ BBC Worldwide Monitoring (July 23, 2010), "Venezuela Severs Ties with Colombia."

${ }^{203}$ Magdaleno (2011): 64, in Clem and Maingot, eds. (2011).

${ }^{204}$ Wilpert (2011): 3 .

${ }^{205}$ US News (April 24, 2013), "Iranian-Sponsored Narco-Terrorism in Venezuela: How Will Maduro Respond?"
} 
personnel present in training camps in Venezuela, where FARC members provide training in irregular warfare and terror tactics, alongside Venezuelan informal militias. ${ }^{206}$ Similarly, the Reyes files indicate that the Coordinadora Continental Bolivariana (CCB), an overarching revolutionary Latin America terror network, was in fact founded inside Fuerta Tiena, Venezuela's military intelligence headquarters. ${ }^{207}$ Senior members of the government have also been implicated; in 2008, Ghazi Nasr al Din, a senior Venezuelan diplomat in London and Chargé d'Affaires at the Embassy in Lebanon, was cited in a report by the US OFAC, and accused of facilitating funding to Hezbollah. ${ }^{208}$ Their report also accused Din of arranging the transport of Hezbollah members to Caracas, and even coordinating with them on operations.

Venezuela has also provided support to several pariah states and sponsors of state terrorism, such as Syria, Sudan, Cuba and Iran. ${ }^{209}$ The regime has particularly close ties with Iran, as "Chávez and his allies have allowed Iran... to open financial facilities, front companies and dedicated shipping lines to evade sanctions on its nuclear program." ${ }^{210}$ Venezuela is now one of Iran's primary mechanisms to access international finance, currently forbidden under US sanctions. There is a strong criminal element to these ties, with cocaine smuggling the glue that ties disparate groups together. The Chávez government has refused to cooperate with the international community in bringing international terror suspects to justice. The 2010 failure of Caracas to extradite ETA terrorist Arturo Cabillas to Spain led the EU to consider major sanctions on Venezuela. ${ }^{211}$ By 2006, the US had sent more than 130 formal requests for information relating to terrorist suspects and groups (i.e., financial information or biographical data) to Venezuela, but none had received a response, leading the US to embargo all weapons sales to Venezuela. ${ }^{212}$ Venezuela's close relaVenezuela to the List," available from http://www.heritage.org/research/reports/2010/01/state-sponsorsof-terrorism-time-to-add-venezuela-to-the-list.

${ }^{210}$ Farah (2012): 17.

${ }^{211}$ McClatchy Washington (October 18, 2010), "Spain-Venezuela Ties Strained as Hugo Chávez Stonewalls ETA Investigation."

${ }^{212}$ McClatchy Washington (July 14, 2006), "Venezuela Rebuffs U.S. Requests for Information on Terror Suspects."
} 
tionship with Iran also violates a number of sanctions, including those related to IAEA nuclear development. ${ }^{213}$ These policies have continued under the presidency of Nicolas Maduro, who has promised "integral support" for the Syrian pariah regime at "every international organization." 214

The links between Caracas and a number of notable terrorist groups are strong, implying that Venezuela's support for terrorism is not solely linked to its conflict with Colombia. These actions again appear to be linked to the perceptions and ideologies of a small group of individuals, particularly Chávez himself. In 2008, for example, Chávez ordered the printing of special copies of a book by Spanish radical Jorge Verstrynge, which advocated the use of islamist-style terror tactics in Latin America, to be distributed to his officers corps, in the hopes it would inspire them to solidarity with these groups. ${ }^{215}$ The appointment of Henry Rangel Silva, a public supporter of international radical terrorism, as Chávez's Minister of Defense, also serves to underline the personality-driven nature of these decisions, and their importance to key officials, who are often personally involved in drugs trafficking. As with Venezuela's relationship with the FARC, these actions are deeply harmful to the long-term interests of the Venezuelan state, and have resulted in sanctions and damage to the economy. There is no economic rationale to ties with states like Iran, North Korea and Libya, ${ }^{216}$ again highlighting the fact that these decisions are, as suggested by our theory, aggressive, and truly not in Venezuela's national interest.

\subsubsection{Hugo Chávez's Verbal Aggression}

No discussion of aggression in Venezuelan foreign policy during the last decade would be complete without a brief examination of Hugo Chávez's well-known verbal threats and belligerence. While Chávez's rhetoric can hardly be described as conflict, it has certainly had a major impact on foreign affairs, with his statements increasing his notoriety on the world stage, and encouraging western politicians to see him as a major threat. At the same time, many of his statements were irrational and strange, and many seemed to serve no clear function in foreign policy, highlighting the

${ }^{213}$ Neilson (2009): 96.

${ }^{214}$ Corrales and Romero (2013): 180.

${ }^{215}$ Farah (2012): 57.

${ }^{216}$ Corrales and Romero (2013): 163-5. 
ongoing personalization of foreign policy in Venezuela. In addition to his public speeches, Chávez had both a tv and radio show, and used these to speak to the Venezuelan population at length.

Chávez's commentary provides us some of the best insight into his thinking, particularly as there is so much material to analyze: between 1999-2002 alone, Chávez spent some 311 hours on the air in Venezuela, during which he himself talked for the equivalent of 25 days! ${ }^{217}$ Several studies indicate that the president did not fully trust the Venezuelan (and international) media, or even his own government communication bureaucracy. As such, he used the office of the President "as the principle source for political communication, with his radio and tv program Aló Presidente" being the main source of government information for the population. ${ }^{218}$ The show would air each Sunday, for 3-5 hours, and in addition to presenting his own thoughts on domestic and foreign policy issues, Chávez would conduct important state meetings, in particular of the Council of Ministers. Aló Presidente has been extensively studied by scholars of rhetoric and communication, as its format, where a head of state directly governs and discusses issues with the population, is entirely unique. This led the New York Times to brand it the "realest reality show in the world," and note that:

"Chávez makes so much policy, ad hoc, on the show that cabinet members and army officials are required to attend tapings just to keep up." 219

As well as providing us with an interesting window into Venezuelan policy-making, the unscripted show is the source of much of Chávez's oft-quoted aggressive rhetoric. Until 2008, he would frequently address sections of the show directly at US President Bush, whom he nicknamed "Mr. Danger." In the show's most famous segment, in 2006, Chávez described President Bush as:

"A coward, a killer, a [perpetrator of] genocide, an alcoholic, a drunk, a liar, an immoral person, Mr Danger. You are the worst, Mr. Danger. The worst of this planet A psychologically sick man, I know it." 220

On another episode, he referred to US Secretary of State Condoleeza Rice, telling her:

\footnotetext{
${ }^{217}$ Méndez-Rivera (2006): 129.

${ }^{218}$ Ibid., 128.

${ }^{219}$ New York Times (May 4, 2012), "The Realest Reality Show in the World."

${ }^{220}$ Aló Presidente Broadcast (March 2006).
} 
"Go to hell, gringos! Go home!...You've forgotten me, missy." 221

Chávez has also devoted shows to describing Barack Obama as a "fraud," and encouraging Secretary of State Hilary Clinton to:

"Resign, along with those other spies and delinquents working in the State Department." 222

In addition to personal attacks, Chávez often used the show to decry the evils of American 'imperialism,' and to push his socialist agenda. The show is carried live throughout Latin America on Telesur, the CNN-style, Venezuelan-backed news network. ${ }^{223}$

Although his television appearances are the source of many of Chávez's more bizarre quotations, he also tended to include belligerent and aggressive rhetoric in his public speeches, "using international organizations such as the non-aligned movement, the OAS and the UN as platforms for expressing his criticisms of American policies." 224 In his oft-quoted speech before the UN General Assembly in 2006, Chávez described President Bush as the "devil," who had left behind a "smell of sulphur" at the podium. At another public speech in Tehran later that year, Chávez accused Israel of "perpetuating a holocaust" in Lebanon. Later the same week, he told a public audience in Tehran:

"Let's save the human race, let's finish off the U.S. empire!" 225

Chávez has also used his speeches to laud dictators, calling Robert Mugabe a "liberator," Muammar Gaddafi a "a revolutionary and martyr," and Alexander Lukashenko of Belarus a close friend. Following Chávez's death, his successor Nicolas Maduro seems determined to keep up Chávez's strange legacy of aggressive rhetoric; in May 2013, Maduro described Obama as the "chief of the devils," and a "puppet of the imperial power." 226

${ }^{221}$ Aló Presidente Broadcast (January 1, 2007).

${ }^{222}$ Aló Presidente Broadcast, (December 9, 2010).

${ }^{223}$ Dodson and Dorraj (2008): 77.

${ }^{224}$ Lapper (2006): 19.

${ }^{225}$ Washington Post (July 30, 2006), "Hugo Chavez Receives Iran's Highest Honor."

${ }^{226}$ Agence France Presse (May 5, 2013), "Venezuelan President Nicolás Maduro Blasts 'Devil' Obama." 
Despite this, Venezuelan foreign policy decisions often seem entirely distinct from these flamboyant statements. McCarthy-Jones notes that "While much of President Chávez's foreign policy announcements in relation to the US can be provocative and even defamatory in nature, they rarely result in policy outcomes." 227 Although these statements appear on his television show alongside policy decisions, there is often no follow-through; in effect, policies are announced, but never implemented. There are several arguments which can explain this discrepancy: First, that these statements are "merely the product of his eccentric personality," second, that they are "cover for more pragmatic goals," or third, that they "lack political coherency and are intended merely as propaganda." 228 There is certainly some evidence that these aggressive remarks are not for an international audience at all, but are instead intended to distract from domestic problems. As one author shows, Chávez's worst rhetoric lines up perfectly in time with periods of domestic unrest in Venezuela. ${ }^{229}$ If his rhetoric is domestically focused, however, it has not been successful in attracting viewers; one survey showed that $74 \%$ of Venezuelans reported strong dislike for Aló Presidente! $!^{230}$

Although we can't discount the idea that Chávez's verbal aggression is aimed at a domestic audience, it nonetheless has a major impact on Venezuela's role in world affairs. Chávez's remarks have been referenced by Western policymakers as a key reason to fear Venezuela's foreign policy. As one scholar notes, Chávez's rhetoric in the mid-2000s caused "a prolonged period of tense political relations between the US and Venezuela." ${ }^{231}$ A number of articles by US scholars during that time sought to assess whether he was truly as aggressive as his rhetoric indicated; most concluded that Venezuela's ties with the FARC and saber-rattling were of concern to the US, and that rhetoric was indicative of aggression. ${ }^{232}$ In addition, as described more fully in Section 6.3.1, Chávez's aggressive oratory with regard to Colombia and other Latin American states has often worsened conflicts or derailed key negotiations. For example, his repeated insistence that sanctions were forthcoming

\footnotetext{
${ }^{227}$ McCarthy-Jones (2010): 139.

${ }^{228}$ Ortiz (2011): 79, in Clem and Maingot, eds. (2011).

${ }^{229}$ Corrales and Romero (2013): 11.

${ }^{230}$ Méndez-Rivera (2006): 130.

${ }^{231}$ McCarthy-Jones (2010): 139.

${ }^{232}$ See Neilson (2009), or Lapper (2006).
} 
with Colombia has served to undermine what should have been Venezuela's strongest trading relationship. Chávez's rhetoric has thus had an appreciable effect on Venezuela's international relations.

It is not possible to assess verbal belligerence in terms of our theory, as aggressive rhetoric does not necessarily equate to actual aggression. However, I argue that it can be a key indicator of one of the theory's predictions: that foreign policy in a weak institutional environment will tend to be overly personalized and conducted within an aggressive/militaristic mindset. Hugo Chávez's oratory reveals a great deal about foreign policymaking in Venezuela, in particular, that policymaking often happens without consultation of relevant ministries or advisors. Indeed, foreign policy in Venezuela often takes place inside the mind of one man, rather than in a collaborative process. Aggressive rhetoric may therefore be an excellent gauge for understanding a country's level of foreign policy institutionalization.

\subsection{Conclusion}

Despite the lack of major conflict between 1990 and 2013, Venezuela's recent reputation as an extremely aggressive state appears to be deserved. In addition to long-running border disputes with Colombia, the Venezuelan state under Hugo Chávez has sponsored revolutions and terrorist groups in other states, and has engaged in global arms and drug trafficking. This aggression is entirely at odds with Venezuelan foreign policy prior to 1999, which was generally peaceful and cooperative. Since the country has been an oil-rich state since the 19th century, explaining this discrepancy is a challenge for our theory.

\subsubsection{Alternative Explanations}

\section{Revolutionary War Theory}

In contrast to previous chapters, revolutionary war theory does a good job of explaining Venezuela's recent aggression under Chávez. As Venezuela was largely peaceful under the non- 
revolutionary Punto Fijo, and quite aggressive under Chávez's revolutionary government, it does appear that "the differences in preferences between the revolutionary government of Hugo Chávez and the non-revolutionary governments that preceded him are more important in determining the behavior of Venezuela than mere changes in the country's oil income." ${ }^{233}$ However, while this provides one case in which the revolutionary war theory can explain outcomes, it is important to remember that this dissertation's theory is not negated by such a finding, as oil-induced weak institutions were indeed present in both periods, and played a major role in Venezuela's choice to adopt aggressive foreign policy.

\section{Balance of Threat Theory}

Balance of Threat theory does a good job of predicting conflict under the Punto Fijo, but a poor job of predicting conflict under Hugo Chávez. None of the conflictual situations discussed in this chapter presented a clear or immediate threat to Venezuela, and as a result balance of threat theory would predict a lack of aggressive behavior, as we saw prior to 1999. In contrast, the sudden spike in aggressive behavior following 1999 was not accompanied by any corroborating spike in threat towards Venezuela. Indeed, in the Colombian case, the Chávez regime actively moved away from a solid, security-supporting beneficial alliance in favor of unwarranted aggression. This irrationality is impossible to reconcile with standard defensive realist explanations of conflict.

\subsubsection{Venezuela: Conflict as a Probabilistic Outcome}

Despite the fact that alternative explanations can also serve to explain Venezuelan foreign policy, the evidence presented in the case also does a reasonable job of explaining outcomes in this case. Nothing in the Venezuelan case undermines this dissertation's theory, and we do find clear links between oil and several of our intervening variables. Firstly, institutions were weak throughout the post-Cold War period. During the Punto Fijo period, foreign policy institutions were ineffectual, with patronage appointments serving to undermine the efficacy of the bureau-

${ }^{233}$ Colgan (2013): 222. 
cracy. This weakness continued under the Chavista government, with appointments made on the basis of ideological purity. The undermining of state institutions (i.e., legislature, military, foreign service) through constitutional reform, and the tendency to appoint highly unqualified individuals to ministerial posts helped to concentrate decision-making power in the hands of a single individual, Hugo Chávez. Secondly, we find strong evidence that oil wealth led to military spending by successive Venezuelan governments, with the only difference between the pre-1999 and post-1999 periods being who supplied the arms. Finally, foreign policy and public opinion were largely in alignment during the Punto Fijo period, but we see contradictions between public opinion and the foreign policy of the Chávez regime, implying some government freedom from constraints. As in prior cases, assessing this is difficult, as oil wealth can also shape public opinion.

Given that we find weak institutionalization and high military spending in both periods, the chapter then sought to explore the links between our mediating variables and aggression, focusing on differing levels of aggression over time. The Colombian case shows how the Punto Fijo's informal party system acted as an alternate forum for foreign policy formulation, counteracting institutional weakness and allowing for cooperative foreign policy. In contrast, during the Chávez era, this system did not exist, so weak institutions left foreign policymaking vested in a single individual, with the result that it was reactive and conflictual. Major conflict was only prevented by the restraint of the Colombian government. Venezuela's covert support for terrorism shows a similar policy-making process, often relying solely on Hugo Chávez's personal perceptions rather than professional information or advice. Chávez's verbal aggression since 1999 provides another indicator of the extreme personalization of policymaking. In short, the Venezuelan case does meet most of the expectations of our theory, despite the lack of conflict during the Punto Fijo period. This case thus serves to illustrate the probabilistic nature of our theory (i.e., oil does not necessarily always produce conflict), as well as the ways in which other factors, such as informal institutions, can help to overcome oil-induced weakness in the policymaking process. 


\section{CHAPTER VII}

\section{Conclusion}

Oil-rich states are commonly assumed to be aggressive, yet we have little scholarly understanding of why, relying instead on an assumption that wealth results in military buildup and aggression. This dissertation's primary contribution has been to flesh out this relationship, by exploring whether natural resource-rich states are indeed more aggressive than others, and then by focusing on the ways in which the domestic production of natural resources (particularly oil) impacts the formation of foreign policy. Thus in contrast to other theories which rely on oil as merely a means for aggressive foreign policy, this dissertation has theorized three distinct mechanisms by which oil impacts foreign policy behavior.

\subsection{A Theory of Natural Resources and Aggression}

Scholars in international relations have rarely examined the links between resource wealth and foreign policy, and those few works which do treat oil simply as a facilitating factor for aggressiveness. In effect, it is argued that oil makes you rich, increasing military expenditure. Since this provides no actual impetus for conflict, these accounts rely on non-oil factors to explain aggressive outcomes, such as Colgan's focus on 'revolutionary governance,' which interacts with oil wealth to produce aggression. Instead, this dissertation draws from the well-developed comparative politics literature on natural resources to argue that oil production distorts the state in ways that undermine rational foreign policy formation, and encourage aggression. Oil production impacts foreign 
policy indirectly, helping to create mediating factors (such as weak institutions), which in turn foster aggressive foreign policy.

This dissertation's central argument focuses on the link between large-scale oil production and weak state capacity. High resource rents provide leaders with few incentives to build strong institutions, and as a result, inhibit the development of state capacity and the growth of a meritocratic bureaucracy. This relationship does not affect all countries equally, as those which have already developed strong institutions at the time of oil discovery will be comparatively less affected. However, for the many developing countries with large quantities of oil, this creates two main problems for the formation of pragmatic foreign policy: 1) over-personalization of the foreign policy process, and 2) a lack of reliable information for decision makers when making foreign policy decisions. As a result, their foreign policy is less cooperative and deliberative, and leaders have a greatly increased chance of rationally miscalculating their opponent's capacity or resolve, increasing the probability of conflictual foreign policy actions. Thus, oil-weakened institutions have the potential to undermine foreign policy formation by making it less cooperative, less informed and more confrontational.

Oil also has several other impacts on foreign policy. First, oil does indeed enable conflictual behavior by allowing countries to build up their military. This in turn, increases the perception of decision makers in these states that they are more likely to win a conflict. ${ }^{1}$ Thus, the greatly increased military expenditure which is common in resource-rich states is likely also to alter leaders' assessments of potential conflicts. Secondly, this dissertation argued that oil production tends to increase state control of the economy, freeing government from the constraints of private industry, and permitting greater freedom in foreign affairs. In addition, governments may use resource rents to shape or control the domestic media market, alleviating the constraints of public opinion in foreign affairs. Both of these factors can act as enabling factors for state aggressiveness.

\footnotetext{
${ }^{1}$ One caveat to this argument: even with oil-driven military buildup, rational leaders are still unlikely to challenge states which are far more powerful than themselves. Instead, conflictual behavior is more likely to be oriented towards states of similar size or capabilities.
} 


\subsection{Differing Outcomes in Oil-Rich States}

The three cases presented in Chapters Four, Five and Six each discuss policymaking in a resource-rich state, and in general find that oil production does inhibit foreign policy formation in the ways discussed above. However, there are many petrostates in the world, from different regions, and with different institutional structures. This section seeks to further illustrate this by focusing on two extremes: an exceptionally aggressive petrostate (Iraq), and a petrostate which has shown no interest in conflict (Kazakhstan).

\subsubsection{A Pugnacious Petrostate: Iraq}

Iraq has been known globally over the past two decades as both an oil-rich state, and one which has been extremely aggressive in foreign policy. Under the leadership of Saddam Hussein, Iraq initiated major wars against Iran in 1980, and Kuwait in 1990. In addition, Iraq was frequently involved in various border clashes and minor conflicts. ${ }^{2}$ Iraq's foreign policy during this period was indelibly shaped by oil wealth, as high resource rents helped undermine already weak institutions, resulting in a highly personalized and militarized foreign policy which often tended towards aggressive behavior.

Iraq is a major global oil producer, possessing the world's fifth largest proven reserves, ${ }^{3}$ although infrastructure problems and recent conflicts keep overall production levels lower than they could be. Oil was first produced in Iraq in the early 20th Century by the Anglo-Persian Oil Company, and was a major contributor to the British (and American) war effort in both World War I and World War II. The 1958 revolution in Iraq ushered in a less western-friendly regime, but it was not until ten years and several coup d'états later, that the regime began the process of nationalization. Oil revenues had always formed a large part of state revenues (typically around $20 \%$ of GDP), but increased

\footnotetext{
${ }^{2}$ Iraqi foreign policy since Hussein's overthrow in 2003 has been convoluted, and often impossible to untangle from various aspects of US foreign policy during the occupation of Iraq. There have also been major entanglements between various branches of the Iraqi military, intelligence services and foreign service and US agencies since this time. For this reason, we will focus here only on the period before the 2003 invasion when Iraq's foreign policy was definitively domestic.

${ }^{3}$ US Energy Information Administration Iraq Country Report (2013); available from http://www.eia.gov/countries/analysisbriefs/Iraq/iraq.pdf.
} 
after nationalization was completed in 1972. For example, in 1975, Iraq earned revenues of 51.6\% of GDP from oil production, and by 1980, this had risen to $71 \%$ of GDP. ${ }^{4}$ Revenues fell during the Iran-Iraq war, as production was disrupted, but remained high on a comparative basis (i.e., $26 \%$ of GDP). Similarly, production was disrupted by the First Gulf War, and sanctions following the conflict were intended to prevent the Hussein government from profiting from oil. However, the UN's oil-for-food program was widely corrupt, allowing the regime to steal over $\$ 1$ billion from the humanitarian operation. ${ }^{5}$ With additional income from black market sales, sanctions made little impact, and Iraq earned revenues of $72-74 \%$ of GDP per year through $2000 .{ }^{6}$ In short, Iraq is one of the world's richest petrostates, where astronomical levels of oil revenue have a major impact on state finances. ${ }^{7}$

Foreign policy in Iraq has been notably conflictual since the rise of the Ba'athist Party in the 1970s, and at various times drew arms and monetary support from both US and the Soviet Union. During the 1970s, Iraq sought to be a leader among Arab states, and participated in the 1973 Arab-Israeli War. However, despite its support for pan-Arabism, Iraq's relations with Egypt were extremely antagonistic throughout the 1970s and 1980s, as both nations sought to be the 'leader' of the Arab world. Iraq broke diplomatic relations with Egypt in 1977 over Egypt's acceptance of the Camp David Accords, and at the 1978 Arab League, Saddam Hussein pushed for the expulsion of Egypt from the League. In 1980, shortly after the Iranian revolution, Iraq launched a preemptive war over disputed border areas surrounding the Shatt al-Arab river at the confluence of the Tigris and Euphrates rivers. Although Iraq claimed the invasion to be self-defense against Iranian predation, it is likely that the attack was motivated by Iranian weakness following the revolution. ${ }^{8}$ The war lasted a decade, and involved use of chemical and biological weapons on both sides. Despite this, Iraq received funding and technical assistance from the US, who saw the

\footnotetext{
${ }^{4}$ Data from World Bank; available from http://data.worldbank.org.

${ }^{5}$ Council on Foreign Relations Backgrounder (2005); available from http://www.cfr.org/iraq/iraq-oilfood-scandal/p7631.

${ }^{6}$ Data from World Bank; available from http://data.worldbank.org.

${ }^{7}$ The coalition invasion of Iraq in 2003 also disrupted production, but it is now resuming, and by 2012 revenues are again close to $50 \%$ of GDP, although this is less relevant to a discussion of the Ba'athist era.

${ }^{8}$ Sick (1999): 231.
} 
opportunity to undermine Iran. ${ }^{9}$ Shortly after, Iraq began a dispute with Kuwait; in addition to territorial issues, Kuwait was not willing to forgive Iraq's massive war debts. In August 1990, Iraqi troops crossed the border, and within two days had occupied Kuwait, forcing its royal family to flee, and threatening Saudi Arabia. In response, in early 1991, an international coalition of states initiated the bombing and ground invasion of Kuwait, forcing the Iraqis back to their own borders and reinstalling the Kuwaiti government; Saddam Hussein only narrowly avoided being forcibly removed from power, and was forced to submit to international inspections and sanctions. This, however, did not stop the regime from attempting to assassinate President Bush in Kuwait in 1993, from moving troops to the Kuwaiti border and threatening invasion in $1994,{ }^{10}$ or from challenging the inspections apparatus in 1998, resulting in four days of bombing by US and UK. ${ }^{11}$ The period 1998-2001 also saw increasing military clashes between Iraqi and allied fighter jets in the no-fly zone. These actions, in addition to suspicions that the Hussein regime was developing chemical, biological and nuclear weapons eventually led to the 2003 coalition invasion of Iraq.

Iraq's foreign policy during these two decades was undoubtedly quite aggressive. In order to ascertain whether this behavior was linked to oil, we must examine whether oil was linked with our theory's mediating variables (weak institutions, military expenditure and freedom from constraints). Under the Ba'ath party, Iraqi foreign policy was primarily made at the cabinet level, with input from the Foreign Ministry and from the Iraqi Intelligence Service. The latter reported directly to the President, and was responsible for both external intelligence gathering and internal security. Despite this, one author notes that the jurisdiction of the intelligence agencies "is designed to overlap in order to encourage competition and to ensure that no one service will be strong enough to threaten Saddam." ${ }^{12}$ The military similarly was under the direct command of the President, who acted as Commander-in-Chief, and made tactical and strategic decisions. This centralization of power posed major problems for Iraqi military performance. In addition, the foreign ministry, intelligence service and military command tended to be chosen for loyalty rather

\footnotetext{
${ }^{9}$ Foreign Policy (2013); available from http://www.foreignpolicy.com/articles/2013/08/25/

${ }^{10}$ Congressional Research Service (1999): 9-12.

${ }^{11}$ Congressional Research Service (2002).

${ }^{12}$ Al-Marashi (2002).
} 
than for qualifications; Saddam in particular filled the ranks of the civil service with members of key Sunni tribes who could be depended on to be loyal. ${ }^{13}$ Members of his own tribe and his relatives were deemed particularly trustworthy, and often filled the highest ranks of government. ${ }^{14}$ This resulted in high levels of incompetence, especially among military commanders. ${ }^{15}$ In captured documents, a senior Iraqi leader describes how Saddam selected only the "uneducated, untalented, and those who posed no threat to his leadership for key roles." 16

The opacity of decision-making in such a system makes it difficult to ascertain the level of professionalization of the bureaucracy, but the extreme personalization of the foreign policymaking system cannot be denied. As US General Schwarzkopf described:

"Saddam is no strategist, nor a soldier. His poor understanding of military affairs, and his complete subordination of military strategy to the ultimate goal of political survival..." 17

undermined policy implementation. The position of Foreign Minister, most notably held by Tariq Aziz from 1983-1991, did exist independently, but they acted less as advisors and more as implementers of policy. As one author describes, "Saddam has created a totalitarian state in which all power flows from him;" 18 Saddam's power in foreign policy matters was effectively absolute. Even among cabinet level officials, information was often lacking. For example, in 2002, many cabinet members genuinely believed that Iraq still possessed Weapons of Mass Destruction, even as their leader knew that they did not. ${ }^{19}$ Iraq's leadership was under the direct personal control of Saddam Hussein; as a result, "policymaking is highly idiosyncratic and is characterized by a clandestine, almost furtive quality." 20

\footnotetext{
${ }^{13}$ Byman, Pollack and Waxman (1998): 129.

${ }^{14}$ Al-Marashi (2002).

${ }^{15}$ Karsh (1997-8): 91.

${ }^{16}$ Foreign Affairs (May/June 2006); Available from http://www.foreignaffairs.com/articles/61701/kevinwoods-james-lacey-and-williamson-murray/saddams-delusions.

${ }^{17}$ Freedman and Karsh (1991): 36.

${ }^{18}$ Byman, Pollack and Waxman (1998): 128.

${ }^{19}$ Foreign Affairs (May/June 2006); Available from http://www.foreignaffairs.com/articles/61701/kevinwoods-james-lacey-and-williamson-murray/saddams-delusions.

${ }^{20}$ Sick (1999): 244.
} 
This exceptional level of personalization in foreign policymaking also had negative consequences for information flow, as far as can be determined from such an opaque system. However, as many sources indicate, the personalization of the system certainly prevented this information from getting to the top levels of governance. In his US Congressional Testimony during the Gulf War, Post describes foreign policymaking in Iraq as a process of self reinforcement:

"He is surrounded by sycophants, who are cowed by Saddam's well-founded reputation for brutality, and who are afraid to contradict him. He... equates criticism with disloyalty.... This combination of limited international perspective and a sycophantic leadership circle has in the past led him to miscalculate." 21

The consequences of disagreement were dire. In 1982, as the war was going badly for Iraq, Iran agreed to a ceasefire on the condition that Hussein was removed from power. At a cabinet meeting, the Minister of Health suggested that Saddam temporarily step down and retake the Presidency once peace was restored. Saddam thanked him for his candor, and ordered his arrest. The next day, the minister's wife was given his mangled corpse in a black canvas bag. ${ }^{22}$ This system was even described by one of Saddam's senior ministers thus:

"Directly disagreeing with Saddam Hussein's ideas was unforgivable. It would be suicide." 23

Thus, the extreme personalization of the system, combined with Saddam Hussein's own paranoia, dramatically undermined information flow, and the influence of any other voice in foreign policy decisions.

From the 1970s, Iraq had high levels of military spending, which have risen in line with oil prices. From 1970-1980, Iraq spent approximately $\$ 375$ million on weapons, a figure that had increased to around $\$ 1.1$ billion by the time Iraq invaded Kuwait in 1990. Despite European and American

\footnotetext{
${ }^{21}$ Post (1991): 284.

${ }^{22}$ Post (1991): 384.

${ }^{23}$ Foreign Affairs (May/June 2006); Available from http://www.foreignaffairs.com/articles/61701/kevinwoods-james-lacey-and-williamson-murray/saddams-delusions.
} 
sanctions on weapons following the Gulf War, Iraq continued to spend between $\$ 1$ and $\$ 2$ billion per year on arms until 2003, mostly from China and Russia. ${ }^{24}$ The majority of Iraq's arms were purchased from the USSR, including items such as 245 PT-76 tanks, 2150 T-62 tanks, 60 MiG-21 fighter jets, as well as hundreds of transports, bombers, ARMs, radar emplacements and scores of small weapons. ${ }^{25}$ Despite this, training and command failures meant that Iraqi troops often foundered under combat conditions. As Karsh notes, Iraqi soldiers "were poorly trained, and... had low technical skills to maintain and employ the modern weapons systems at their disposal." 26 Nonetheless, Saddam Hussein's government showed a marked inclination towards military solutions to all problems. In the run up to the Gulf war, for example, the Kuwaiti government offered to pay $90 \%$ of the amount demanded in order to prevent conflict. However, Iraq refused this generous offer, and initiated an invasion. This pattern repeats at many other times, as Saddam's conviction in his own military genius, his faith in new armaments, and his conviction that his troops performed well (despite all evidence), led him to seek no-win conflicts. ${ }^{27}$

The third factor examined by our theory - lower government constraints - is certainly true in the case of Iraq, where a single individual was able to parlay oil wealth into an almost limitless exercise of power. In such a regime, it is almost impossible to assess whether public opinion is opposed to policy as polls do not exist, and the penalties for criticism can be severe. However, as several authors have noted, "popular opinion is not entirely irrelevant to Iraqi policymaking... Saddam has repeatedly demonstrated that he can be responsive to public opinion under certain conditions." 28 These conditions are rare, and there have been only a few occasions where the regime, in response to fears about domestic unrest, changed course on foreign policy. The Ba'ath party also made significant efforts to shape popular opinion, such as an attempt to hide evidence of missile attacks during the Iran-Iraq war by quickly repairing and repainting damaged areas! ${ }^{29}$ In short, while it

\footnotetext{
${ }^{24}$ Stockholm International Peace Research Institute Yearbook (2013), available from http://www.sipri.org/yearbook/2013.

${ }^{25}$ Data from SIPRI Arms Transfer Database; available from http://www.sipri.org/databases/copy_of_armstransfers.

${ }^{26}$ Karsh (1997-8): 91.

${ }^{27}$ Foreign Affairs (May/June 2006); Available from http://www.foreignaffairs.com/articles/61701/kevinwoods-james-lacey-and-williamson-murray/saddams-delusions.

${ }^{28}$ Byman, Pollack and Waxman (1998).

${ }^{29}$ Ibid., 143.
} 
is true that there are no major constraints on the regime, it is impossible to assess whether this is the result of oil or simply of Iraq's malignant authoritarianism.

Thus, Iraq does demonstrate the institutional weakness and military focus we expect in an oil-rich state. These factors were instrumental in Iraq's aggressiveness during the Saddam Hussein era. For example, in the Iran-Iraq war, the decision to initiate conflict was based on a series of misperceptions and lack of information for key policymakers. As one author describes, "Iraq... has committed the common mistake of trying to bite off more than it can chew, having overestimated its own power and underestimated that of its opponent." 30 In the lead up to the conflict, Iraq saw Iran's motivations as similar to itself, and expected that a limited war would be successful. Iraqi troops quickly took territory, but stopped within five days, seeking a ceasefire. Unfortunately, Iran was not interested in this kind of limited war, and fought back, leading to a decade long war. ${ }^{31}$ Thus, Saddam entirely misinterpreted Iran's resolve due to an over reliance on personal impressions. He was also confident in both his own ability as a general, and his troops, and as a result, refused to listen to his advisors when the war was going poorly. In 1986, for example, a number of top generals challenged Saddam on his conduct of the Iran-Iraq war, and persuaded him to change his strategy. Although the changes resulted in victory, all were purged shortly afterwards. ${ }^{32}$ This made information flow an echo chamber, resulting in a long and bloody conflict.

Weak institutions also played a major role in the Gulf War crisis. The invasion of Kuwait, designed to shore up the regime and improve Iraq's economy, actually had the opposite effect. As one article notes, prior to the war, "Saddam Hussein should have had serious misgivings regarding Iraq's capacity to sustain a prolonged and ferocious conflict." ${ }^{33}$ In fact, he made crucial errors of misjudgment at almost every major juncture. Initially believing that the West would not intervene, he chose to invade, yet when it became clear that he was facing an international coalition, refused to back down and withdraw. He also underestimated how many troops he had available to fight in Kuwait, forgetting that Iraqi soldiers were needed in other areas (such as guarding the Syrian and

\footnotetext{
${ }^{30}$ Karsh (1997-8).

${ }^{31}$ Ibid., 92.

${ }^{32}$ Freedman and Karsh (1991): 36.

${ }^{33}$ Freedman and Karsh (1991): 9.
} 
Turkish borders). ${ }^{34}$ In addition, Iraqi military strategy was deeply flawed, and the Iraqis did not realize until too late that their Maginot Line-style fortifications could be easily bypassed. These failures are not unexpected, yet Saddam retained a firm belief in his own superiority as a general and refused to consult others for advice. In one discussion with his closest advisors in late 1990, he described how he

"forbade the intelligence outfits from deducing from press and political analysis anything about America. I told them that [this] was not their specialty... I said I don't want either intelligence organization to give me analysis - that is my specialty." 35

As with the Iran-Iraq conflict, no dissent was permitted. When several senior officials, feeling that the situation was grave, expressed their opinion that Iraqi forces should withdraw, Saddam fired them all and replaced them with family members and loyalists. ${ }^{36}$

These two specific conflicts highlight the extent to which weak institutions, through the extreme personalization of Iraqi foreign policy, made it more aggressive. In both cases, a lack of information, and a misplaced trust in Iraqi military prowess led Saddam Hussein to entirely miscalculate his opponent's capacity and resolve, and his own chances in a conflict. While most accounts of Iraqi behavior during the 1970s-1990s blame aggressiveness on Saddam Hussein's personality flaws, the fact is that he would not have been able to control so much of the decision-making process in a more institutionalized, less corrupt system. Iraq's oil wealth helped to produce weak institutions and a high personalized system of policy making, in addition to increasing military spending and focus. As a result, Iraq's leaders pursued an aggressive foreign policy.

\subsubsection{A Peaceful Petrostate: Kazakhstan}

Kazakhstan is the largest country in Central Asia, and a major producer of oil and natural gas. Yet since the fall of the Soviet Union, Kazakhstan has had a remarkably peaceful foreign policy,

\footnotetext{
${ }^{34}$ Ibid., 13.

${ }^{35}$ Foreign Affairs (May/June 2006); Available from http://www.foreignaffairs.com/articles/61701/kevinwoods-james-lacey-and-williamson-murray/saddams-delusions.

${ }^{36}$ Post (1991): 286.
} 
pursing what many scholars term a 'multi-vector' foreign policy: seeking trade and cooperation with all major players, including Russia, Europe, the US and China. Although stronger institutionally than some of the states discussed previously, Kazakhstan nonetheless has relatively weak institutions, a strongly personalized and corrupt system of policymaking and moderate levels of military spending. This section therefore seeks to explore why despite possessing several of these factors Kazakhstan does not typically act aggressively.

Kazakhstan has the world's ninth-largest petroleum reserves, and is also a major state producer of natural gas. During the Soviet period, Kazakhstan acted as the USSR's oil and gas supplier, exporting its resources to other Soviet states for refining and use. As a result, when the Soviet Union fell in 1991, Kazakhstan was left with few choices: the country is landlocked and was entirely dependent on existing infrastructure (i.e., pipelines and rail) to transport its natural resources. Russia used this leverage to pressure Kazakhstan to accept Russian companies as shareholders, allowing them a controlling stake in the ownership of the large gas field at Karachahanak. ${ }^{37}$ During this period, Kazakh revenues from oil and gas were significant, but comparatively small, as Russia (a monopsony buyer) refused to pay market prices. From 1991-1999, Kazakhstan averaged between 7\% and $12 \%$ of GDP from oil production. The state also received substantial revenues from natural gas exports, increasing this to revenues of between $10 \%$ and $19 \%$ of GDP each year from oil and gas. ${ }^{38}$ This situation improved in 2001, when Kazakhstan signed deals allowing for transportation of oil and gas by rail to Europe and China. Several new pipelines were constructed allowing Kazakhstan to sell oil to China (2003) and Europe (2005), as well as natural gas to China (2009). These have provided alternate buyers, and greatly "boosted Kazakhstan's bargaining power in natural gas price negotiations with Russia." 39 Since that time, the government has received much higher revenues from natural resources, with the combined revenues from oil and gas reaching $48.5 \%$ in 2008. Revenues are somewhat lower following the financial crisis, but were still recorded as $32.1 \%$ in 2012. ${ }^{40}$ Kazakhstan intends to increase production threefold over the next decade, which will

\footnotetext{
${ }^{37}$ Kubicek (2004): 209.

${ }^{38}$ Data from World Bank; available from http://data.worldbank.org.

${ }^{39}$ Danchecnko et al (2010): 5.

${ }^{40}$ Data from World Bank; available from http://data.worldbank.org.
} 
only increase these already bloated revenue streams. ${ }^{41}$

Kazakhstan's foreign policy has been heavily focused on trade and new markets. Indeed, many scholars have argued that the reason for Kazakhstan's balanced, multipolar foreign policy is its desire to open as many markets as possible for its oil and gas exports. As Hanks notes, "the Central Asian states were the least prepared for independence" from the USSR, and Kazakhstan was no exception, with no obvious resources for foreign policy. ${ }^{42}$ Kazakhstan was also heavily dependent on Russia, with a population that was as much as $50 \%$ ethnic Russian, no independent refining capability, and no standing army to protect its border with China. ${ }^{43}$ During this period, the state eagerly joined the Russian-led Collective Security Treaty Organization, but its status as one of only four post-Soviet nuclear states also allowed it to build strong diplomatic ties with the US and China. In exchange for giving up nuclear weapons, these states provided Kazakhstan with security guarantees. However, Russia was heavy-handed with Kazakhstan during this period (i.e., demanding low prices, distributing passports to Russians living in Kazakhstan, etc.), driving Kazakhstan to seek other partners. Kazakhstan also successfully implemented a number of marketfriendly reforms. ${ }^{44}$ Since 2003 , the country has enjoyed more autonomy in foreign affairs.

Kazakhstan has not initiated any major conflicts since independence, and has rarely even been involved in diplomatic disputes. The country has three minor border concerns. The first concerns the division of the oil-rich Caspian Sea. Russia pushed this issue during the early 1990s, but Kazakhstan refused in 1998 to discuss the issue further. ${ }^{45}$ There has been no violence between the major claimants (Russia, Kazakhstan, Azerbaijan, Turkmenistan and Iran). The second is the long border with Uzbekistan, which saw several military clashes in 1999-2000. These were followed by negotiations which more clearly delineated the border, although drug smuggling and illegal immigration remain a problem. ${ }^{46}$ Finally, Kazakhstan's border with China has been disputed, and the Chinese have challenged the border several times. However, Chinese military superiority is

\footnotetext{
${ }^{41}$ Hanks (2009): 258.

${ }^{42}$ Hanks (2009): 261.

${ }^{43}$ Ipek (2007): 1181.

${ }^{44}$ Gleason (2001): 171.

${ }^{45}$ Kubicek (2004).

${ }^{46}$ Zardykhan (2002): 173.
} 
such that Kazakhstan has been unwilling to force the issue, and a border pact was signed in 1998, ceding 157 square miles to China. ${ }^{47}$ These issues are minor, and have not presented any threat to the country.

Thus, Kazakhstan's foreign policy since 1991 has not been overly aggressive or conflictual. This is puzzling, as Kazakhstan certainly meets our definition of a natural resource-rich state. In order to assess this further, we will focus on whether Kazakhstan, in addition to resource wealth, also shows the theory's mediating variables, in particular, weak institutions. Foreign policy in Kazakhstan is primarily made at the top levels of government, and the system bears a strong resemblance to its Russian counterpart. In the aftermath of the Soviet collapse, Kazakhstan had no real institutions, to the extent that President Nazarbayev ruled by decree from 1993-1995. ${ }^{48}$ Since that time, the President has been the primary decision maker in foreign policy, advised by the Security Council. The key agencies for foreign policy are the Ministry of Foreign Affairs and the Kazakh National Security (KNB) agency, which are usually (but not always) represented on the Security Council. Instead, appointments to the Security Council, made personally by the President, have come from backgrounds as diverse as former KGB operatives, politicians, family members, journalists, and even the former manager of a supermarket; ${ }^{49}$ the main criteria for selection appears to be personal trust of the President. Parliament plays no role in foreign policy, and is a one-party rubber-stamp organization. ${ }^{50}$ Thus, as Gleason describes, in "the highly personalistic context of Central Asian politics, individual leaders' preferences played a significant role in the selection and implementation of policies." 51 The system is extremely personalized, and President Nazarbayev's closest relatives hold a variety of critical posts. Indeed, in a move reminiscent of monarchical rule, closer relations with Kyrgyzstan were sealed in 1998 by the marriage of Nazarbayev's daughter Aliya to the son of Kyrgyz President Akayev! ${ }^{52}$

In addition to high levels of personalization, the Kazakh bureaucracy (though often described

\footnotetext{
${ }^{47}$ Ibid., 180.

${ }^{48}$ Ipek (2007): 1192.

${ }^{49}$ Kassenova (2005): 162.

${ }^{50}$ Matveeva (2002): 27.

${ }^{51}$ Gleason (2001): 169.

${ }^{52}$ Hoffman (2000): 240-1.
} 
as better than that of neighboring countries) is generally inefficient and corrupt. Shortly after independence, the government pursued a policy of Kazakhification, which removed ethnic Russians from posts at the Ministry of Foreign Affairs and most embassies, and replaced them with ethnic Kazakhs. ${ }^{53}$ This removed the only existing knowledge base, leaving the foreign service to effectively start over. In addition, "active recruitment of public service managers in Kazakhstan resembles a patronage system... positions are often filled by friends, relatives and other quid pro quo relationship figures." 54 Clan structure is key to this patronage, as members of Nazarbayev's own Ulu Zhan clan are favored for appointments within the bureaucracy, "creating privileged nodes of access... for his clan-based network." 55 There is a high turnover rate among civil servants in all agencies due to low compensation, and the inefficiency of the system. For example, one survey by the UN Division for Public Administration (UN DPDAM) revealed that nearly $40 \%$ of civil servants admitted they had never received any on-the-job training. ${ }^{56}$ Corruption permeates the Kazakh civil service, even public universities, where professors often insist on adequate bribes in order to pass a student. ${ }^{57}$ The development of the Kazakh civil service closely mirrors our theory, as "Kazakhstans fiscal regime... has continued to rely on boosting its tax and collection rates... only in the energy sector." 58 As Pomfret describes, resource revenues strongly reduced Kazakhstan's incentive to develop strong institutions. ${ }^{59}$ The result is a civil service characterized by high levels of incompetence and personalization.

Since independence, Kazakhstan has had moderate levels of military spending, with expenditure around $0.6 \%$ of GDP prior to 2001, and around $1 \%$ of GDP thereafter. ${ }^{60}$ While these amounts are low by comparison to other resource-rich states, they are much higher than Kazakhstan's neighbors. With no independent military force following the fall of the USSR, much of this money has been 
spent on building a military, and on buying equipment for it. Security guarantees offered by Russia, the US and China in Kazakhstan's first decade as an independent country mitigated the need for immediate high military spending, and the state remains in favor of strategic military partnerships with those states. ${ }^{61}$ Despite this, resource-wealth has allowed Kazakhstan to become the best equipped and most combat-capable country in Central Asia, with a standing army of $68,000 .{ }^{62}$ In recent years, the Defense Ministry reduced its outlay by ordering much of its weaponry from Russia, from whom it receives concessionary pricing. Indeed, Allison argues that Kazakhstan's main reason for remaining a member of the CSTO is the discounted weapons available to members. ${ }^{63}$ In 2010 alone, Kazakh purchases from Russia included 120 anti-tank missiles, 44 IFVs, 31 APVs and 21 APCs, among other equipment. ${ }^{64}$ Though it cannot compete with Chinese or Russian military spending, Kazakhstan outspends its non-great power neighbors in real terms by a substantial margin. In 2000, for example, while Kazakhstan spent $\$ 343$ million (US) in military expenditure, Tajikistan spent only $\$ 18.5$ million, and Uzbekistan spent only $\$ 94.4$ million. Similarly, in 2004, Kazakhstan spent $\$ 747$ million, while neighboring Kyrgyzstan spent only $\$ 118$ million. ${ }^{65}$ In short, despite a more modest level of spending than we have seen in some other resource-rich states, Kazakhstan is by a large margin the biggest military spender within its region. However, the Kazakh government has shown little reliance on military means, and does not appear to focus on military solutions, a finding in opposition to our theory's expectations.

Our theory's third mediating variable - lower government constraints - is certainly present in the Kazakh case. Public opinion is effectively irrelevant in the formation of foreign policy, and strict government control of the media makes it difficult to assess public opinion. Media freedom in Kazakhstan is strictly controlled, and journalists who criticize regime policy face threats to their lives. Freedom of speech is generally not permitted, and NGOs (both on domestic and foreign

\footnotetext{
${ }^{61}$ Ipek (2007): 1192.

62 Zardykhan (2002): 173.

${ }^{63}$ Allison (2004).

${ }^{64}$ Data from SIPRI Arms Transfer Database; available from http://www.sipri.org/databases/copy_of_armstransfers.

${ }^{65}$ Stockholm International Peace Research Institute Yearbook (2013), available from http://www.sipri.org/yearbook/2013.
} 
policy issues) tend to be dismantled by the government. ${ }^{66}$ The Nazarbayev government takes a strong hand in shaping media reportage on key issues; his eldest daughter runs the country's largest television station. ${ }^{67}$ In short, the Kazakh government is a fairly typical strict authoritarian state in regards to public opinion and media, making hypotheses about government constraints difficult to assess.

Kazakhstan does therefore meet some of our theory's expectations, in particular, a weak foreign policy bureaucracy, and moderate levels of military spending, outstripping its neighbors. Yet it does not exhibit the aggressiveness this would lead us to expect. One potential explanation for this discrepancy is that Kazakhstan was rarely in a position where military force was required. Although the country has had several border disputes, they have rarely involved the use of force. In the only such incident, border tensions with Uzbekistan spawned several minor military clashes in 2000, when a unit of Uzbek military were found unilaterally demarcating the border. Kazakhstan quickly deployed troops to the area, but also initiated negotiations on defining the border. By 2001, the two countries had signed an agreement which successfully delimited $96 \%$ of the border. ${ }^{68}$ It is unclear why this crisis did not escalate, although one senior Kazakh military official - MajorGeneral Husain Berkaliyev - told press that due to a lack of funds, Kazakhstan had difficulty even patrolling the border ${ }^{69}$ the Kazakh government may therefore have been content to avoid conflict in this case. Aside from this single incident, there have been almost no other border incidents which presented even the potential for a military response. As discussed in Chapters Two and Three, oil-driven weakness in foreign policy does not automatically lead to conflict, it simply makes conflict more likely in cases where it was already possible. Thus, in part, Kazakhstan's lack of aggressiveness may have been driven by a lack of potential conflict.

Kazakhstan's neighbors may also provide an explanation. Although the state has experienced border issues with China, and various diplomatic disputes with Russia, none has turned to conflict.

\footnotetext{
${ }^{66}$ Ibrayeva and Nezhina (2012): 53.

${ }^{67}$ Hoffman (2000): 240.

${ }^{68}$ International Crisis Group (2002): 8-9; available from http://www.crisisgroup.org/en/regions/asia/centralasia/033-central-asia-border-disputes-and-conflict-potential.aspx.

${ }^{69}$ Ibid.
} 
Firstly, although Kazakhstan is a reasonably large resource-producing state, both China and Russia are great powers, with which a smaller and relatively new Kazakh military could not hope to contend. Thus there has been little incentive for Kazakhstan to push border issues with China. ${ }^{70}$ Secondly, despite various disagreements with Russia, Kazakhstan was dependent on Russia until the early 2000s (and partially thereafter) for Russian refining and transport of Kazakh oil and gas for sale in Europe. Thus, oil revenues were contingent on keeping Russia happy, explaining in large part why "Nazarbayev clearly maneuvered to avoid antagonizing his larger neighbor." 71 The need to keep both larger neighbors happy is frequently cited as a reason for Kazakhstan's 'multi-vector' foreign policy. Kazakhstan's lack of aggression towards China and Russia is therefore also in line with our theoretical assumptions: we do not expect smaller resource-rich states to attack great powers, as this is entirely irrational. Instead, we merely expect that they will be more likely to initiate conflict in situations where conflict was already somewhat likely.

Kazakhstan is therefore an interesting case. While it is indeed a resource-rich state, possessed of large streams of oil and natural gas revenues, it has not exhibited aggressiveness. The country does have weak institutions: Kazakh bureaucracy is corrupt, paternalistic, and inefficient. Foreign policymaking is also largely personalized, with decisions taken by the President and a small cohort of loyal, appointed advisors. Military spending, while low for a resource-rich state, is also the highest in the region. Despite this, Kazakh foreign policy has been remarkably peaceable. Ultimately, the Kazakh case underlines the fact that conflict does not occur as a result of only one factor. In cases such as this, where there is little potential for conflict (i.e., few border incidents, great power neighbors, etc), state aggressiveness is not likely, even when natural resources are present. Thus the Kazakh case highlights one of this dissertation's key limiting conditions: oil may be a an important factor, but it is individually neither necessary nor sufficient in explaining state aggressiveness.

\footnotetext{
70 Zardykhan (2002): 179.

${ }^{71}$ Hanks (2009): 263.
} 


\subsection{Summary of Findings}

The dissertation's theory has been tested in several ways: a large-n statistical study of the relationship between oil and state aggression, three broad country case-studies (each with three to four individual sub-case analyses), and two minor country case studies. The statistical study focused on assessing Hypotheses One and Two, ascertaining whether there is indeed a strong link between natural resource production and state aggressiveness, using several different measures of natural resources and of aggressive behavior. It also focused on whether the relationship with conflict differs as expected across different types of natural resources. The statistical study showed clear support for the idea that oil-rich states are more aggressive than comparable non-oil states: increased levels of oil revenues are linked with an increase in probability of conflict initiation, especially in those cases (i.e., border disputes) where conflict was already somewhat likely. Increased oil revenues are also linked to non-military aggressiveness, in particular the initiation of threats and sanctions. These findings remained robust in a variety of different tests. The results are also robust to the use of different measures of oil wealth, i.e., both major global suppliers, and those states whose economies are dominated by oil are more aggressive. This implies strongly that there is indeed a domestic link between oil production and aggressive foreign policy. Chapter Three also assessed whether the relationship between oil and aggression was additionally present in states which produced other natural resources. The results were mixed, suggesting that all natural resources are not equivalent, and providing support for Hypothesis Two, which argued that the relationship between resources and aggression is dependent on high levels of revenue, which tend to result only from lucrative resources such as oil.

While the statistical study was broadly supportive of the link between oil and aggressive foreign policy, the dissertation's central focus - on explaining the mechanisms by which oil impacts foreign policy - was assessed in various case studies. Chapters Four, Five and Six presented broad studies of oil-rich states, in addition to process tracing of specific cases of foreign policy formation within that state. Two additional short cases were also presented in this chapter. The results of these cases are presented in Table 7.1; those cells highlighted in grey conformed to our theoretical expectations. 
As the relationship with oil is indirect, relying on several mediating variables, we can assess both whether the states exhibited the institutional and militaristic characteristics predicted by the theory, and whether this then resulted in aggressive behavior.

The case studies provide strong support for Hypothesis Three: that oil-rich states will exhibit weakly institutionalized foreign policy apparatus. In all thirteen specific cases under study, the state experienced some weakness in foreign policy institutions, including elements of weak bureaucracy, overpersonalisation of foreign policy decision-making, or lack of information on foreign policy issues. The case studies also provided strong support for the idea that oil revenues both encourage military expenditure, and increase the attractiveness of military options to leaders as a result (Hypothesis Four). In nine of thirteen specific cases, countries not only experienced high levels of military expenditure, but leaders also exhibited a marked tendency to resort to military solutions before considering other options. Analysis also showed four mixed cases: in each case, the state had high levels of military spending, but did not immediately resort to military action. Saudi Arabia's handling of the Arab Spring crises in both Yemen and Syria did not show an immediate resort to military action. However, in both cases, the Saudi government took other, non-military aggressive action, such as funding and arming rebel groups to do their work. In the case of Kazakhstan, despite military expenditure, there was no armed conflict, but neither was there any crisis likely to precipitate one. In the case of Colombia (under the Punto Fijo), however, leaders actively sought to avoid militaristic actions, a finding at odds with our theory. It should however be noted that the theory is probabilistic, not deterministic: oil simply makes leaders more likely to resort to military action. Thus the absence of aggression in one case does not undermine the theory; instead, other factors may prove to be more important. During Veneuzuela's Punto Fijo period, the regime effectively compensated for weak institutions through a parallel party-based system of deliberative foreign policymaking, which contributed to the lack of aggression in this case. 
Table 7.1: Theoretical Expectations and Findings

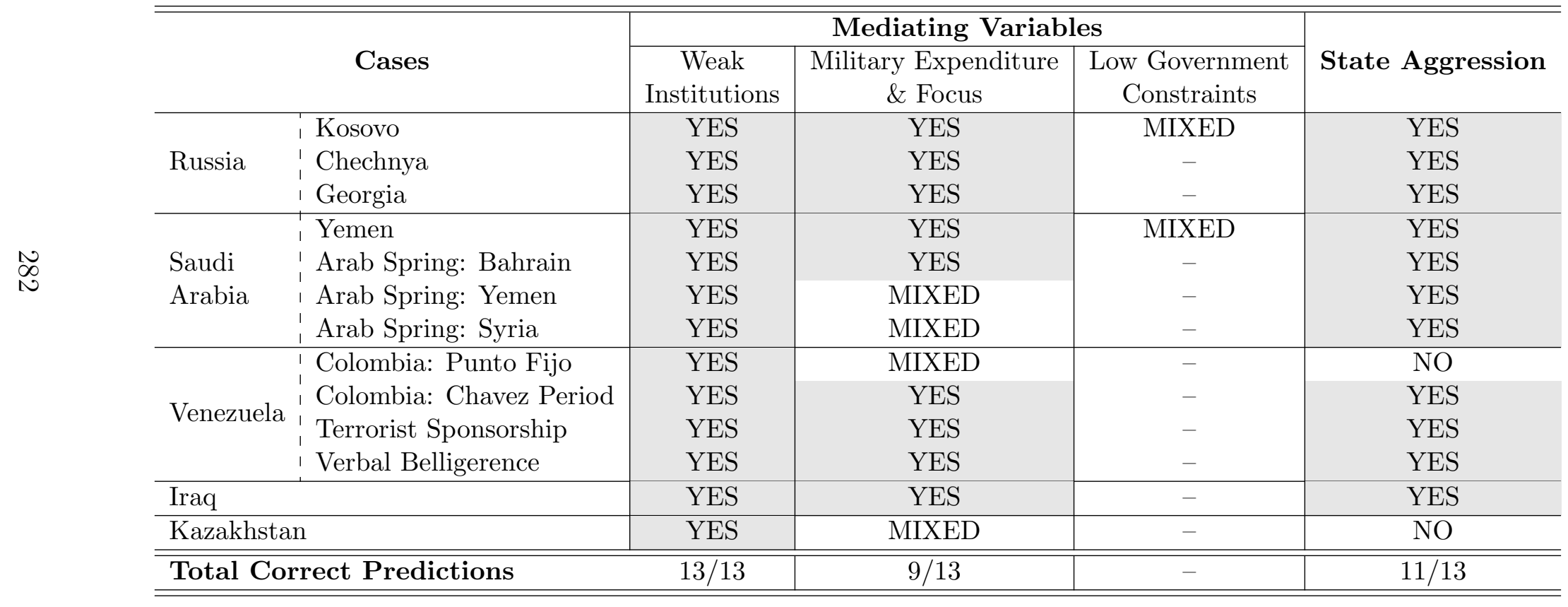


The case studies provided little evidence of low government constraints, and this factor proved effectively impossible to assess in the countries under study. Most of the cases did exhibit some signs that the government had reasonable freedom from constraints in foreign policy. However, the lack of public polling in most cases, the prevalence of authoritarian states among oil producers, and the fact that governments often sought to manipulate public opinion meant that it was rarely possible to ascertain if and when the public and leaders held distinct opinions about foreign policy issues. In addition, this manipulation of the media was often facilitated by oil wealth (i.e., purchasing media outlets). While the mechanism proposed linking oil and government constraints is theoretically viable, the reality is that the relationship between oil, public opinion and government constraints in the cases under study is too convoluted to provide a definitive finding. As a result, the case studies neither confirm nor disprove that oil reduces government constraints in foreign policy. Thus, as no case showed strong evidence of opinion differences between mass publics and leaders, and in the absence of a clear link between oil and government constraints, Hypothesis Six cannot be tested, and should be treated more as a limitation of the study than as a finding.

Thus, although we find limited evidence of low constraints, the cases showed strong evidence that oil weakens foreign policy institutions, impacting both foreign policy formation and implementation. The case studies also illustrate strong support for the theory that oil wealth increases military expenditure and focus. Next, the case studies sought to assess whether these mediating factors ultimately led states to be more aggressive in foreign policy. In eleven of thirteen specific cases, the state exhibited aggressive foreign policy behavior, whether military, covert or verbal. Again, neither Kazakhstan nor Colombia's Punto Fijo regime exhibited aggressive foreign policy. While these cases do not conform to our theory, I argue that there were specific factors in each case which decreased the likelihood of conflict. In the case of Kazakhstan, a combination of great power neighbors and few border conflicts decreased the potential for conflict in general, reducing the likelihood of state aggression. In the case of the Punto Fijo, though bureaucratic institutions were weak, the regime's alternate policymaking system enabled foreign policy to remain more cooperative. Thus the presence or absence of other factors which impact aggression and conflict 
initiation proved to be more important in these cases. Oil is merely one factor which contributes to conflictual foreign policy by states, and it is not always the most important one. Nonetheless, the clear indirect impacts of oil on foreign policy in the other cases highlight that it is indeed an important factor in the formation of foreign policy by resource-rich states.

\subsubsection{Theoretical Implications and Alternate Explanations}

In the only alternate argument linking oil and aggressive state behavior, Colgan argues that oil does not encourage aggressiveness without the simultaneous presence of 'revolutionary governance' within the state. He argues in addition that oil and revolutionary governance interact, so that revolutionary leaders are able to use oil wealth to build a base of support for their foreign policy decisions. However, in all of this, oil is merely the means to permit a leader to pursue an aggressive foreign policy through military expenditure and buildup, while an exogenous factor - the personality traits of a revolutionary leader - provides the impetus for aggression. ${ }^{72}$ Thus, Colgan argues that there is no independent domestic link between oil and foreign policy, and that non-revolutionary oil-states will not be aggressive.

Table 7.2 presents a comparison of this dissertation's institutional theory and Colgan's revolutionary oil theory in terms of the cases studied here. ${ }^{73}$ For the sake of parsimony, the table assesses predicted vs. actual outcomes only in terms of whether the state exhibited aggressive foreign policy. As discussed above, this dissertation's domestic oil-driven theory of conflict performs well in the case studies, correctly predicting eleven of thirteen outcomes. In contrast, Colgan's revolutionary theory correctly predicts only six of thirteen outcomes. The revolutionary oil theory does perform well in the case of Venezuela, where Colgan correctly predicts peaceable foreign policy under the Punto Fijo and conflict in the Bolivarian period. However, our domestic theory of oil and conflict performs far better in the cases of Russia and Saudi Arabia, where Colgan predicts no conflict. Indeed, he argues that Saudi Arabia does not exhibit aggressive foreign policy, focusing primarily

\footnotetext{
${ }^{72}$ In particular, "leaders who take office through a revolution are, on average, more risk-tolerant and politically ambitious than non-revolutionary leaders," predisposing them to conflict. (Colgan (2013): 23.)

${ }^{73}$ For those cases which Colgan does not include in his book, results are extrapolated from his theory based on whether the state under study is revolutionary or not.
} 
Table 7.2: Comparison of Theoretical Explanations for Aggression in Oil-Rich States

\begin{tabular}{|c|c|c|c|c|c|}
\hline & \multirow{2}{*}{ Cases } & \multicolumn{2}{|c|}{$\begin{array}{c}\text { "Revolutionary Oil" } \\
\text { \& Conflict }\end{array}$} & \multicolumn{2}{|c|}{$\begin{array}{l}\text { Domestic Oil- } \\
\text { Driven Conflict }\end{array}$} \\
\hline & & $\begin{array}{l}\text { Predicted } \\
\text { Outcome }\end{array}$ & $\begin{array}{c}\text { Actual } \\
\text { Outcome }\end{array}$ & $\begin{array}{l}\text { Predicted } \\
\text { Outcome }\end{array}$ & $\begin{array}{l}\text { Actual } \\
\text { Outcome }\end{array}$ \\
\hline \multirow{3}{*}{ Russia } & Kosovo & NA & A & A & $\mathrm{A}$ \\
\hline & Chechnya & NA & $\mathrm{A}$ & $\mathrm{A}$ & A \\
\hline & Georgia & NA & A & $\mathrm{A}$ & A \\
\hline \multirow{4}{*}{ Saudi Arabia } & Yemen & NA & $\mathrm{A}$ & $\mathrm{A}$ & $\mathrm{A}$ \\
\hline & Arab Spring: Bahrain & NA & A & A & A \\
\hline & Arab Spring: Yemen & NA & A (Covert) & $\mathrm{A}$ & A (Covert) \\
\hline & Arab Spring: Syria & NA & A (Covert) & $\mathrm{A}$ & A (Covert) \\
\hline \multirow{4}{*}{ Venezuela } & Colombia: Punto Fijo & NA & $\mathrm{NA}$ & $\mathrm{A}$ & NA \\
\hline & Colombia: Chavez Period & $\mathrm{A}$ & A & $\mathrm{A}$ & A \\
\hline & Terrorist Sponsorship & $\mathrm{A}$ & A (Covert) & A & A (Covert) \\
\hline & Verbal Belligerence & $\mathrm{A}$ & A (Verbal) & A & A (Verbal) \\
\hline \multicolumn{2}{|l|}{ Iraq } & $\mathrm{A}$ & $\mathrm{A}$ & $\mathrm{A}$ & $\bar{A}$ \\
\hline \multicolumn{2}{|l|}{ Kazakhstan } & NA & NA & A & NA \\
\hline \multicolumn{2}{|c|}{ Total Correct Predictions } & \multicolumn{2}{|c|}{$6 / 13$} & \multicolumn{2}{|c|}{$11 / 13$} \\
\hline
\end{tabular}

on its relations with the US and ignoring its actions in Yemen and Bahrain, as well as its covert and financial support for conflict elsewhere. In short, by focusing on the potential domestic links between oil and foreign policy, rather than on exogenous factors, this dissertation allows us to explain aggression by non-revolutionary oil states, thereby providing more accurate predictions.

\subsection{Key Observations}

1. Aggression isn't conflict: This dissertation's primary focus has been on explaining why states exhibit aggressive foreign policy behavior, but it is important to note that aggression does not always lead to conflict. Indeed, of the thirteen specific cases studied in this dissertation, eleven showed clear aggression by an oil-rich state, but only five resulted in armed conflict. In contrast to aggression, which is monadic, conflict is dyadic, resulting from the interaction between two states. Venezuela under Hugo Chavez, for example, acted extremely provocatively and aggressively towards Colombia, but Colombian leaders, already struggling with domestic 
conflict, did not respond in kind, and instead sought peace. Thus, although Venezuela acted aggressively, war did not occur. This dissertation has focused on state behavior as our dependent variable, not on conflict itself. Thus, the statistical survey focused on conflict initiation, not on all conflicts, and the cases focused on state behavior as an outcome. In effect, this dissertation presents a theory of foreign policy, focusing on the causes of state aggression, not a systemic theory of conflict.

2. Oil doesn't guarantee aggression: This dissertation has shown a clear link between oil and state aggression, in major oil-producing states, created by oil's distorting domestic effects on institutions and economies. However, it is imperative to note that this theory is not deterministic. Oil impacts foreign policy decision-making indirectly, by weakening institutions and increasing military spending and appeal. These changes can alter leaders' incentives and perceptions in foreign policy decision-making. Thus, each step leading to aggressive foreign policy is probabilistic; weak institutions, for example, increase the likelihood that leaders aren't receiving good information, in turn increasing the likelihood of aggressive behavior. Resource-rich states are not guaranteed to be more aggressive than other states, just more likely to be so. Other factors also continue to be important in the development of state aggression, especially conflict initiation. As demonstrated in the statistical analysis, factors such as distance, capabilities of the opposing state or regime type continue to play a major role in leaders' foreign policy decisions. Oil-rich states are more likely to be aggressive, but their leaders are not irrational. The case of Kazakhstan highlights this discrepancy; even when faced with a border dispute, Kazakh leaders would not have seriously considered military action against China, a state many times larger and better armed; such an action would be suicidal. Oil's effects in changing perceptions, reducing information and altering incentives do not override the national interest, they simply nudge policymakers in the direction of aggression when it was already a viable option. Thus, oil doesn't guarantee state aggression, it simply makes it more likely in cases where it was already possible.

3. Oil, Power and Domestic Distortions: As discussed in Chapter Three, oil impacts aggressiveness 
in two distinct ways, through domestic distortions, and by providing power and influence. This dissertation has focused on the former, in particular by illustrating how oil can undermine domestic institutional development, resulting in poorly formulated, personalistic foreign policy which is more prone to conflict. However, this argument in no way invalidates the long-asserted realist idea that natural resources provide additional leverage to states. In effect, being a large global exporter of natural resources gives additional clout in international affairs. Saudi Arabia, for example, 'punches above its weight' in world affairs, by virtue of supplying fifteen percent or more of the world's oil supply. Its leaders are invited to key summits and consulted on important matters - even by leaders of great power states - as a result of its disproportionate control of the world's oil markets. Our statistical study shows a clear link between a high share of the world's oil export market and aggression. Conversely, this does not undermine the dissertation's theory, as the statistical study also finds a strong link between oil-dominated economies and aggression, and the case studies provide strong support for a domestic link between oil, weak institutions, military expenditure/focus and aggressive foreign policy. In effect, there are two discrete ways in which oil production impacts foreign policy; this dissertation has focused on the domestic links between oil production and foreign policy.

4. Aggression isn't only militaristic: In addition to the initiation of military conflict, the dissertation has also sought to focus on state aggression more broadly. State aggression can take many forms, ranging from military action to economic sanctions, to covert or espionage related actions, to simple verbal belligerence. Of the five countries discussed in this dissertation, Saudi Arabia in particular uses covert means of aggression, for example, the funding and arming of militant groups in neighboring Yemen. Acts like these, while clearly intended to allow plausible diplomatic deniability, are unambiguously aggressive, as they often seek to destabilize other states. Economic sanctions, shown in Chapter Three to be correlated with increased resource revenues, are another form of state aggression. While some sanctions are humanitarian in nature, many are related to trade or diplomatic disputes, and as such have the potential to damage an opponent's economy, an aggressive act. Most statistical studies of state aggression focus entirely on 
conflict initiation, with the result that scholars simply do not analyze a large cross-section of aggressive state actions. As this dissertation's case studies illustrate, aggressive foreign policy is not limited to tanks rolling across the border; it can take many forms.

5. Natural resources and oil aren't equivalent: Unlike previous studies of oil and conflict, this dissertation also sought to assess whether there was a link between non-oil resources and conflict. The theory suggested that there would be a link, but that this would be substantially weaker than that of oil, as oil's key distorting effects are based on high revenues, and other resources are less lucrative than oil. Indeed, statistical analysis showed no significant links between all natural resources and conflict or threat initiation. This is unsurprising, as few countries approach 'petrostate' status solely from other non-oil resources, and the available measures of natural resources are extremely wide, including such commodities as timber. ${ }^{74}$ However, there are some states where natural resources do add substantially to state revenues (particularly natural gas), in addition to moderate or high levels of oil revenues. In 2000, for example, Russia drew $19 \%$ of GDP in revenues from oil, but almost $42 \%$ of GDP in state revenue when natural gas exports are included. Kazakhstan similarly draws moderate levels of state income from oil, but these levels increase dramatically when natural gas is included. Despite the findings of the statistical study, therefore, I argue that other natural resources can in theory distort foreign policy in similar ways to oil. However, there are two caveats: (a) the natural resource in question must provide substantial levels of state income (in practice, only natural gas really meets this requirement), and (b) it is likely that only states with oil in addition to other natural resources will receive enough income to distort foreign policy. Thus, oil is not a unique natural resource in its impact on foreign policy, but the high levels of revenue required for distortion in foreign policy to occur mean that in practice, oil and natural resources do not possess equivalent impact on foreign policy.

\footnotetext{
${ }^{74}$ There are no reliable measures for state income from natural gas, and thus the statistical study was hampered by the need to use a general 'natural resources' metric.
} 


\subsection{Directions for Future Research}

These findings suggest a number of avenues for future research. Firstly, an effort to increase the granularity of natural resource data could provide interesting new conclusions. In addition to the lucrative nature of oil as a resource, one key reason most studies focus on oil wealth is the lack of availability of data on other natural resources. This study suggests that other natural resources, particularly natural gas, have the potential to impact political and economic outcomes, yet the currently available data does not permit individual study, as data is fragmented and only available from national sources. In addition, natural gas production has certain unique features (in particular, differing global prices, and a requirement for standing infrastructure) which may alter incentives for policymakers, and their ability to use such resources as a bargaining tool. Better data on non-oil resources could therefore provide new insights into domestic resource distortions and energy security. Secondly, this dissertation has focused primarily on security studies, and on the incentives of policymakers to initiate conflict or undertake other aggressive foreign policy actions. Yet the process by which oil can undermine foreign policy institutions clearly has the potential to alter decision-making on other factors. The resultant personalized decision-making process and lack of information is also likely to affect decisions on trade and other issues, making foreign policy in general poorly formulated. Broader exploration of policymaking in resource-rich states could yield interesting results. Thirdly, institutional weakness in foreign policy may result from factors other than oil. However, there has been no real study of institutional capacity and foreign policy outcomes, even among developing states. A study of the importance of state capacity for foreign policymaking would have relevance both for academics, and for policymakers. Finally, this study has sought to highlight that aggression is not always overt, and is not limited to the initiation of armed conflicts. Scholars have typically focused on armed conflict as a measure of a state's aggressiveness. Further study of foreign policy decision-making could serve to shed light on why states choose overt or covert aggression options in different situations and on which factors influence this decision. 


\subsection{Policy Implications}

This dissertation's analysis has a number of implications for policymakers. Oil prices have risen exponentially since 2000, with the global financial crisis merely interrupting, not halting, this stratospheric rise. Prices are being driven in particular by growing demand from developing countries such as China which seek natural resources to fuel industrial development. Increased demand is therefore making wealthy resource-producing states wealthier still. Russia, for example, has seen resource revenues rise from around $25 \%$ of GDP to over $50 \%$ of GDP in one decade. This not only increases the leverage possessed by these states, but increases the likelihood that foreign policy formation by these states is being corrupted by oil. The US is largely dependent on oil supplies from Canada and Mexico, while Western European states rely heavily on oil and gas supplies from Russia (although the development of 'fracking' technology has somewhat improved this dependence). In short, for those countries who are dependent on oil- and gas-exporting states, the knowledge that foreign policy decision-making is impacted by resource revenues is important.

Increased aggression among petrostates also has the potential to disrupt energy supplies and to destabilize already difficult regions such as the Middle East. Large US companies such as Shell and Exxon are also heavily exposed to the political risk generated by this relationship. This dissertation's theory describes the ways in which oil can produce sub-optimal foreign policy formation, particularly resulting in aggression. However, understanding this relationship may allow it to be ameliorated to some extent. For example, in oil-rich developing states, developed countries could encourage institutionalization of the foreign policy system through technical assistance. Alternately, such countries could be encouraged to set up Sovereign Wealth Funds to keep revenue flow from resources limited, thereby allowing for the natural development of state capacity. Such solutions have previously been suggested to amend the detrimental economic or political effects of the resource curse, ${ }^{75}$ but also have the potential to improve foreign policy formation and reduce aggression in resource-rich states.

Ultimately, the dissertation's findings suggest that policymakers must be careful when dealing

\footnotetext{
${ }^{75}$ Humphreys, Sachs and Stiglitz (2007).
} 
with oil-rich states, as oil-induced institutional weakness and military expenditure is likely to make these countries less cooperative than other states. This does not mean that these states are entirely unpredictable, but rather that policymakers must be aware that oil-rich states will typically have more personalistic, aggressive foreign policy tendencies. Russia's involvement in the current situation in Ukraine highlights this problem. For example, the inadequacy of information flow to the Kremlin has been a major problem for negotiations. As one article in Kommersant noted, President Putin has been "inundated with unverified information" when making decisions. ${ }^{76}$ Negotiations between Russian diplomats and their European and U.S. counterparts have often seemed tone-deaf, with Russian negotiators insisting that "fascist" groups control Ukraine and that Russia has no troops on the Ukrainian border (despite satellite evidence to the contrary). It is not clear how much of this is standard diplomatic double-talk and how much is truly believed by those in the Kremlin, but Russian policymakers frequently appear insufficiently informed.

This poses problems for US and European negotiators, who often find that the Russian negotiating position seems ill-informed or even illogical. However, this dissertation suggests that there are steps which can be taken to mitigate these weaknesses in Russia's foreign policy process and their impact on other states. For example, U.S. officials can focus on policymakers which the most influence on major decisions, whether or not they hold formal office or titles. Similarly, implementing sanctions on individuals will only work if those targeted are actually involved in the personalized system of decision-making. In addition, western negotiators can keep the U.S. position on key issues clear and consistent, in media interviews as well as negotiations, to reduce the impact of limited information to Russian leaders and potential for misunderstandings.

Ultimately, this dissertation's findings - that oil-rich states are generally more prone to aggression, and that this behavior results from oil-induced institutional weakness and military expenditure - are of importance to policymakers. In providing a vital natural resource, such states are an important cog in the international system. By better understanding the ways in which oil production distorts foreign policy outcomes, policymakers will be better able to respond to resource-rich states,

\footnotetext{
${ }^{76}$ Kommersant-Vlast (March 4, 2014), "Who Influenced the Kremlin's Policy in Ukraine?"
} 
and in so doing, maintain the flow of energy and prevent conflict. 
APPENDICES 


\section{APPENDIX A}

\section{All Militarised Interstate Disputes \\ Initiated by a Petrostate}




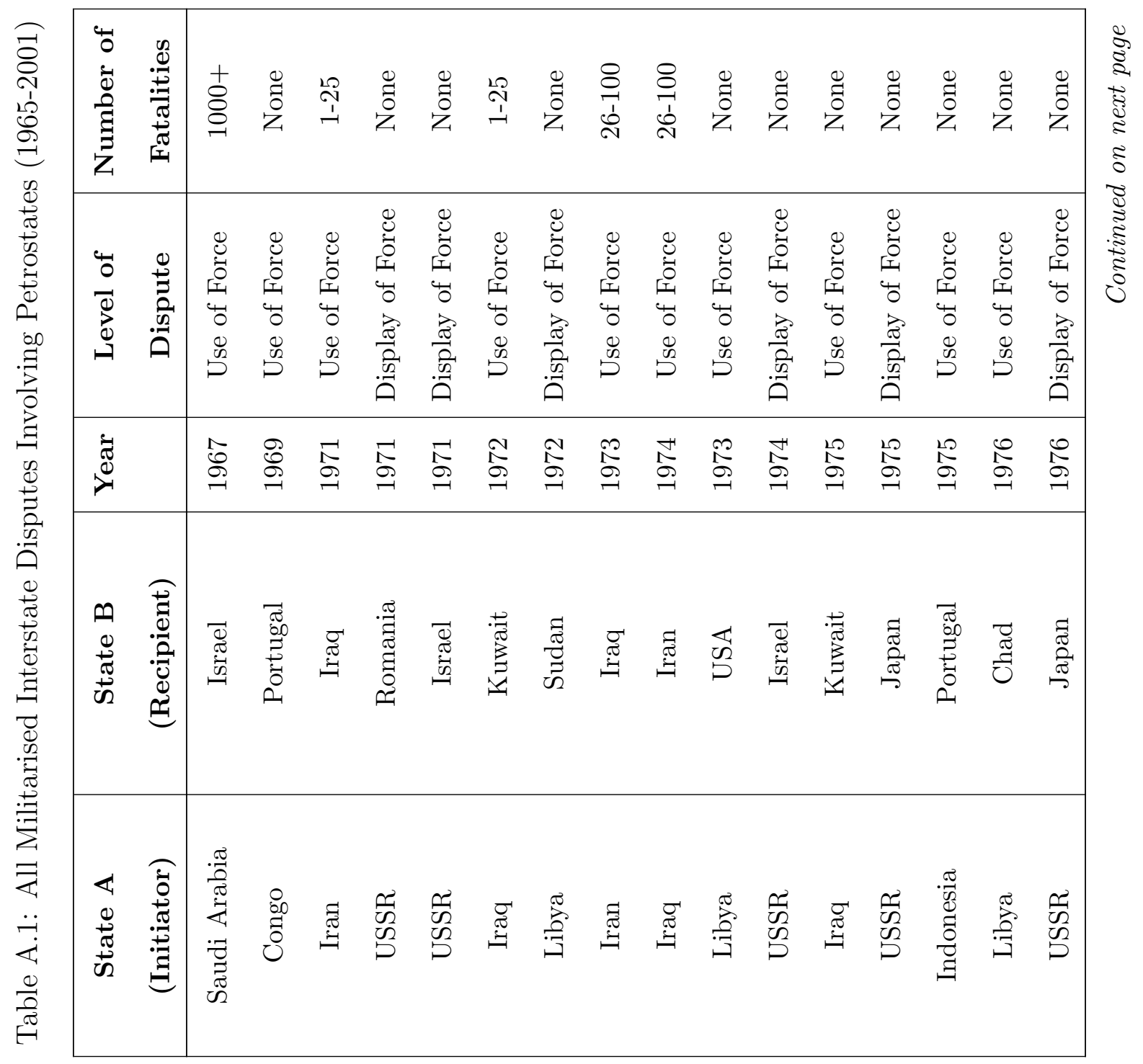




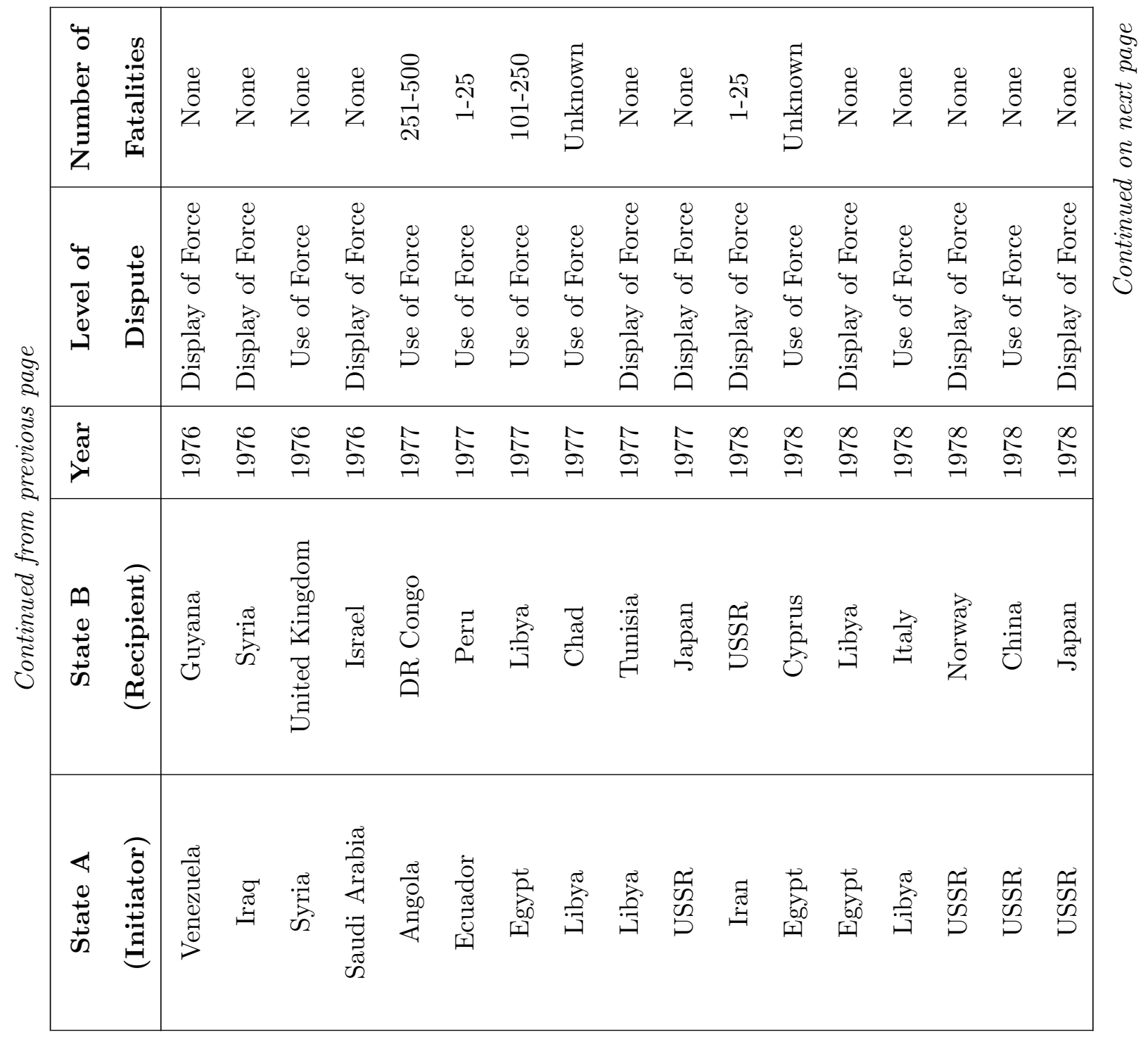




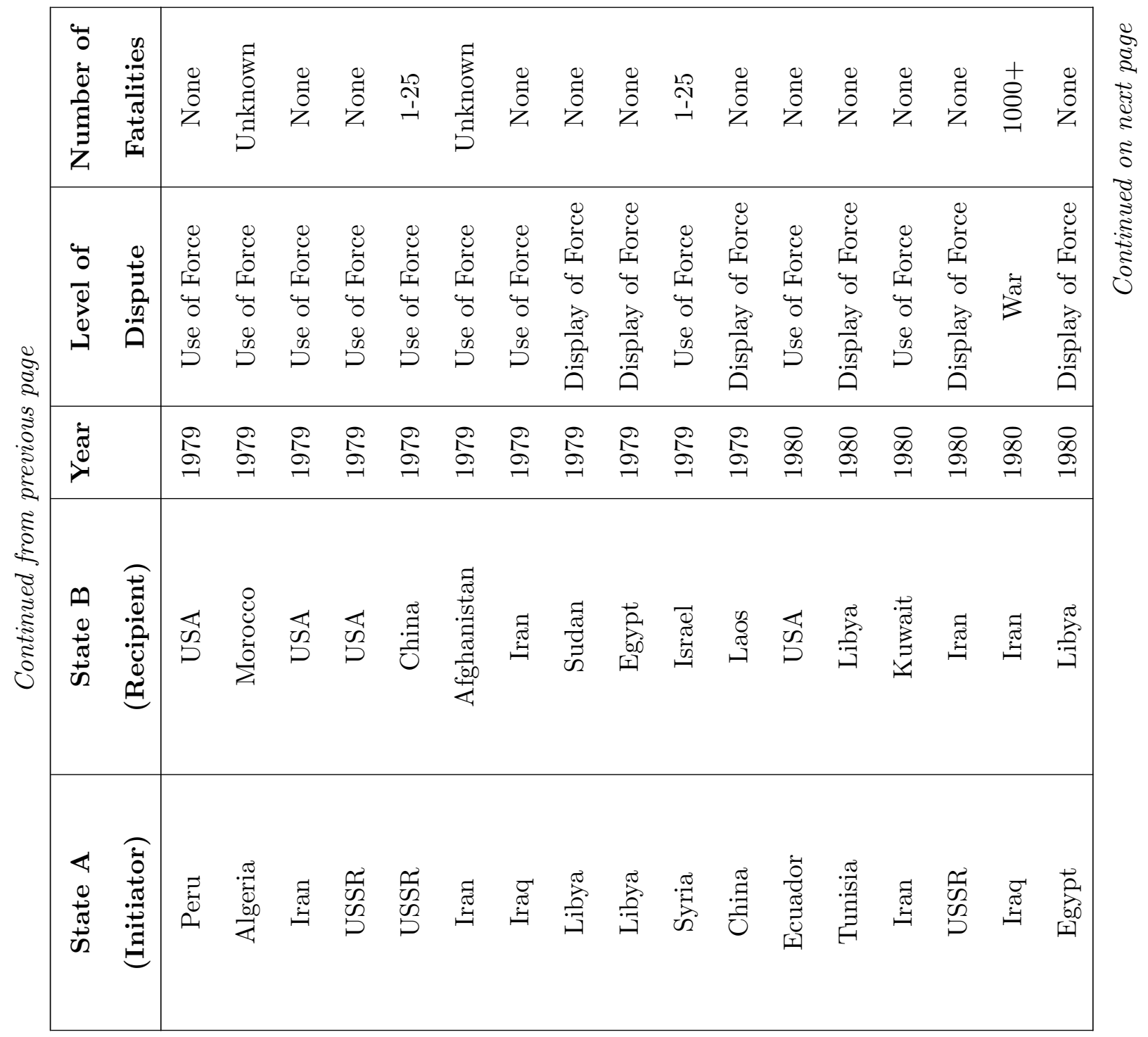




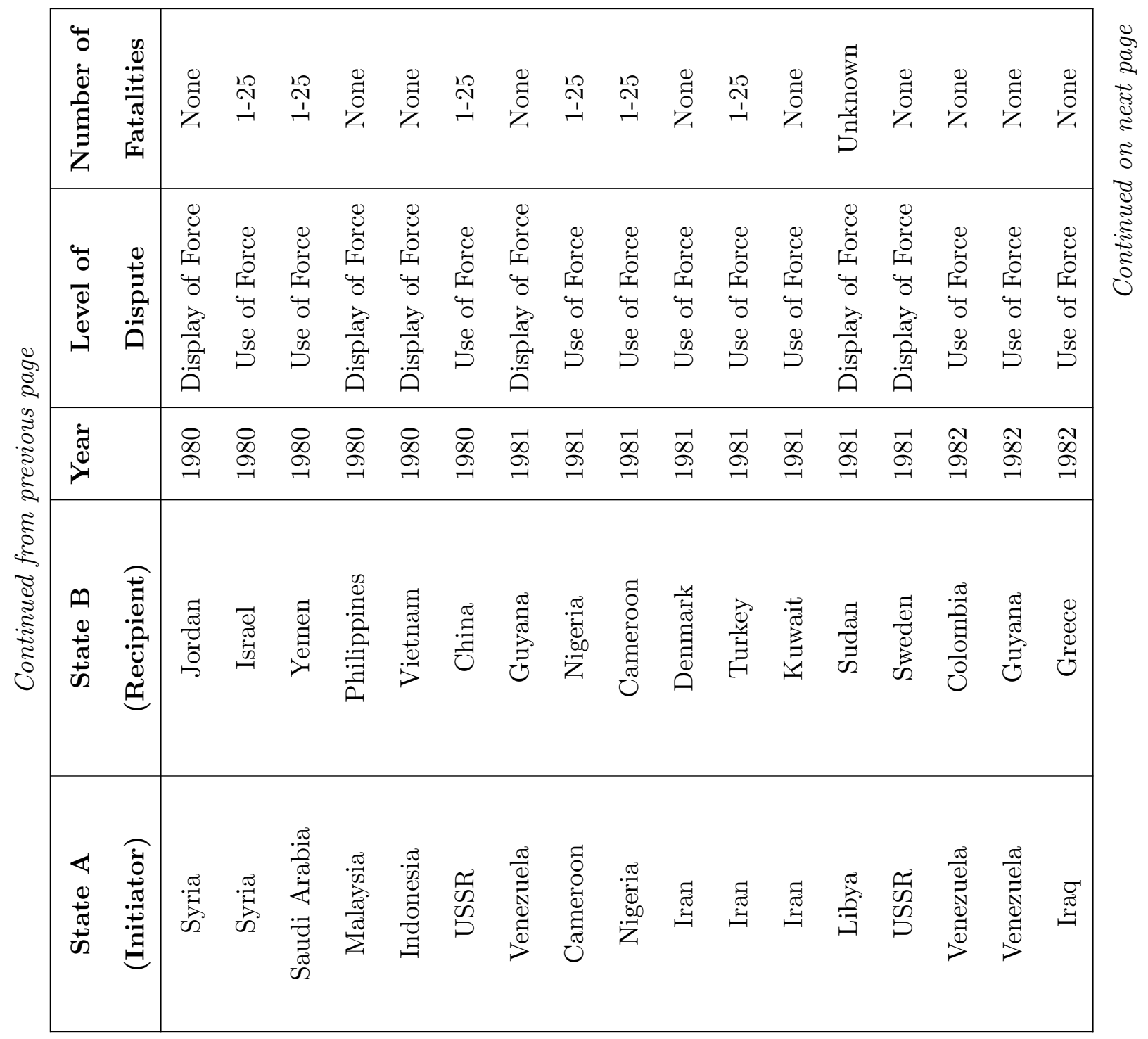




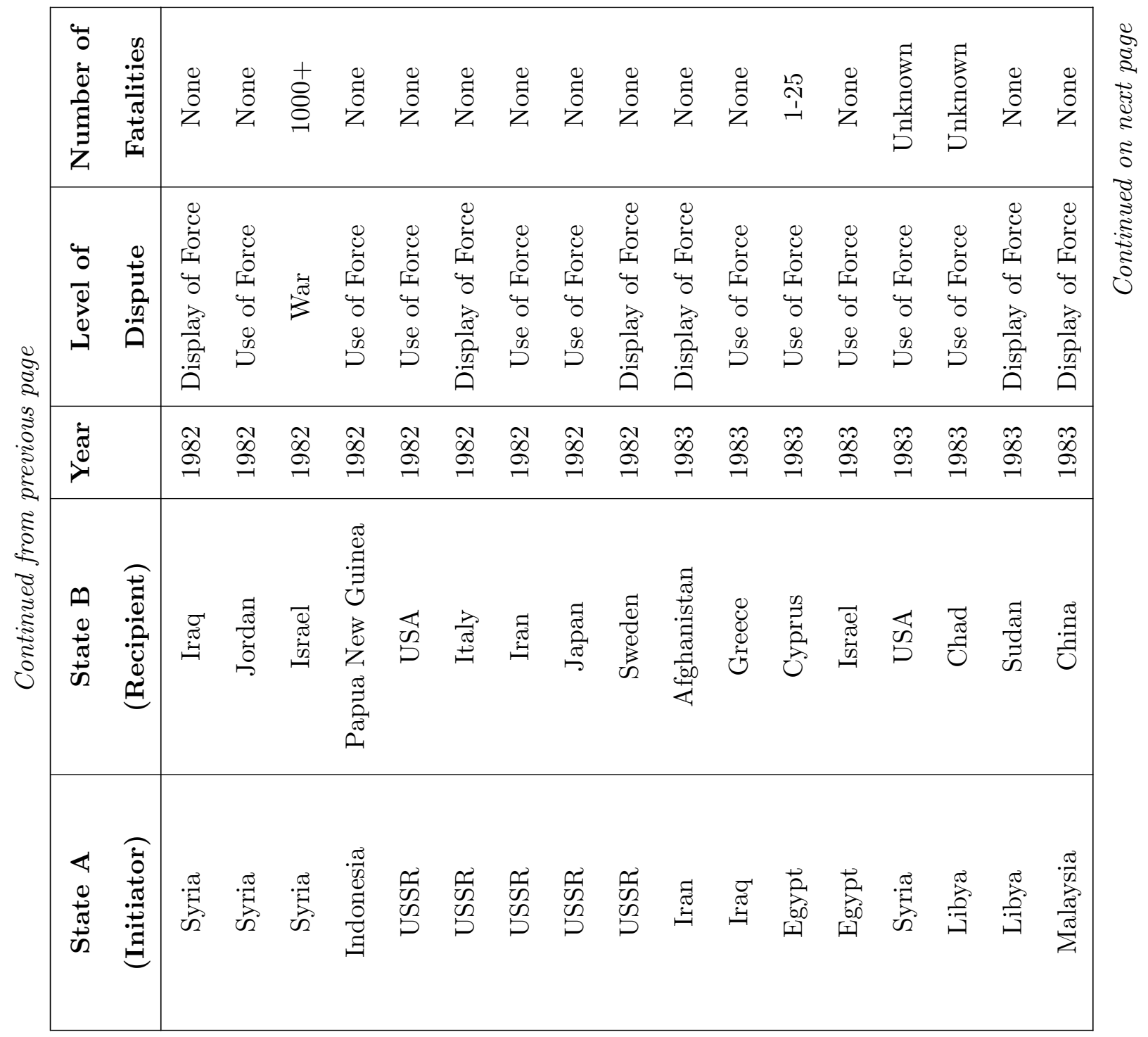




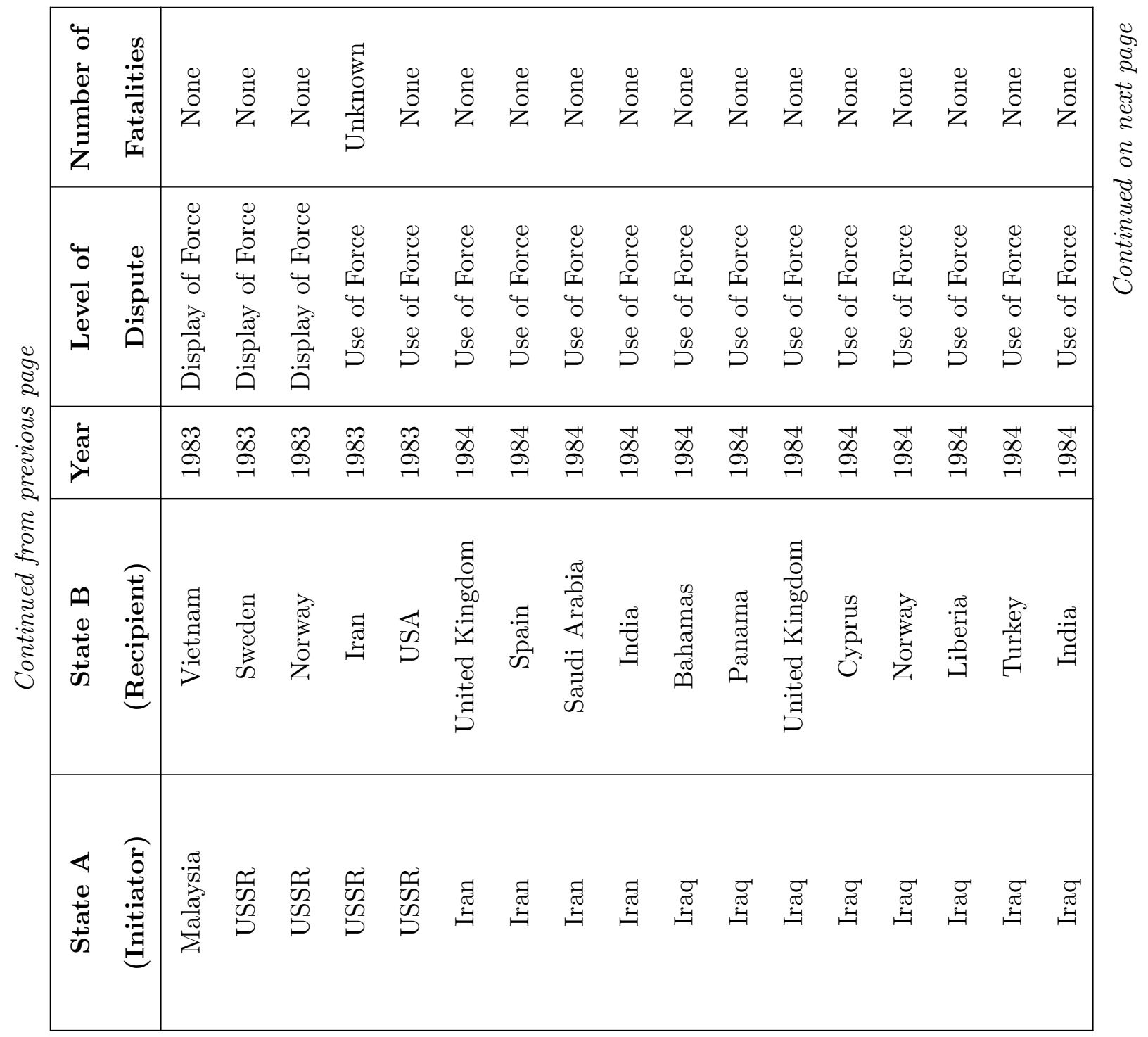




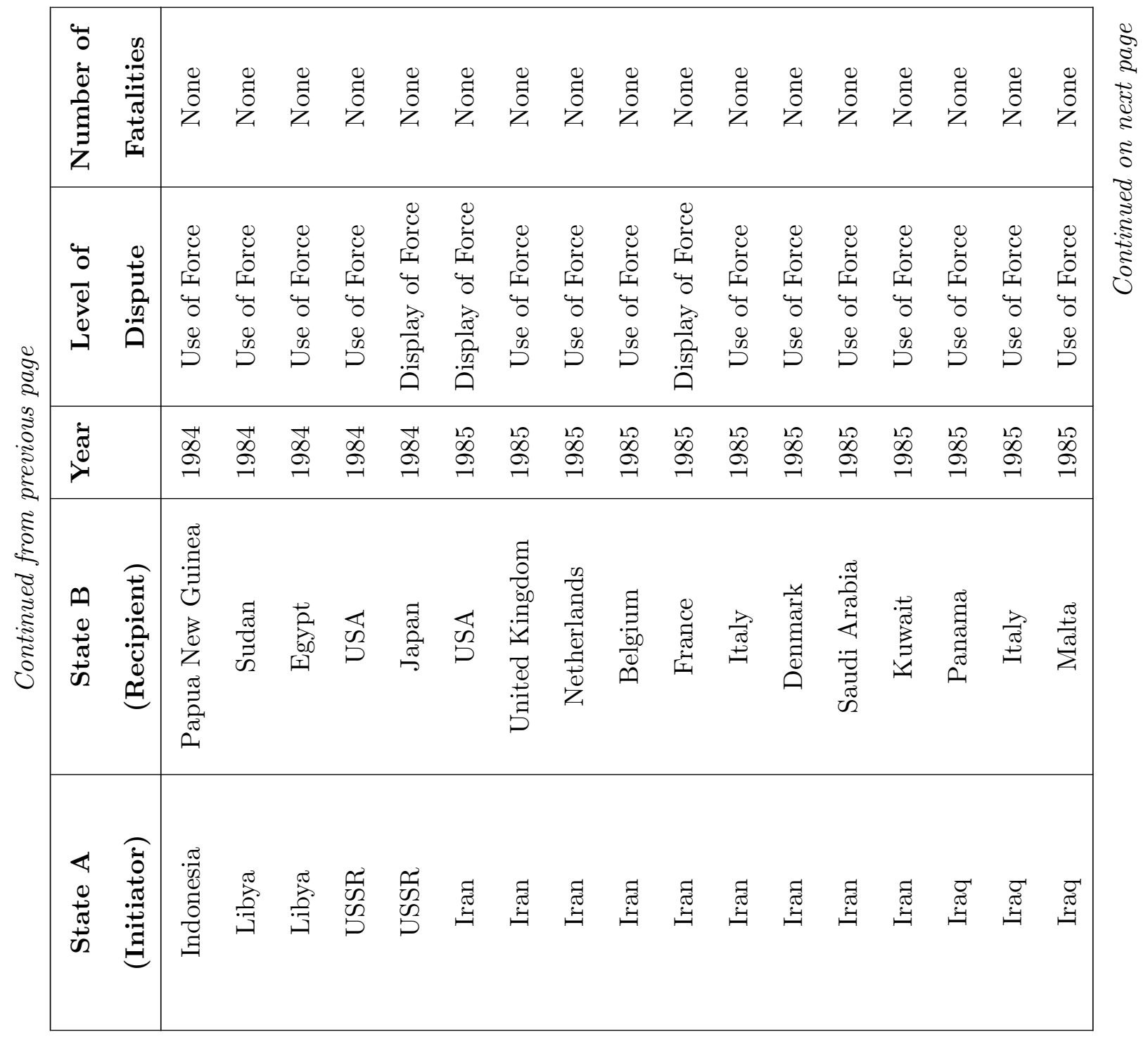




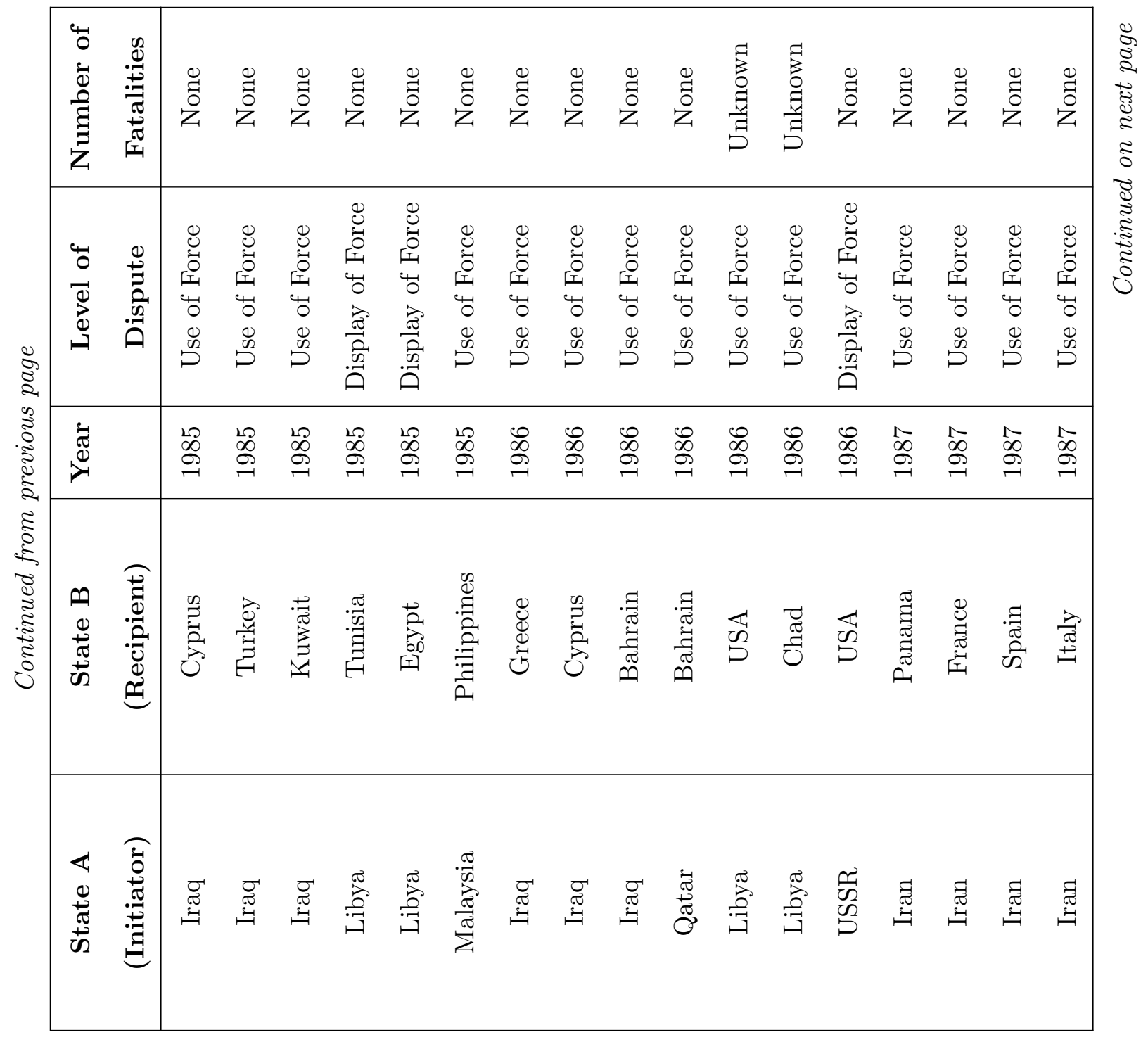




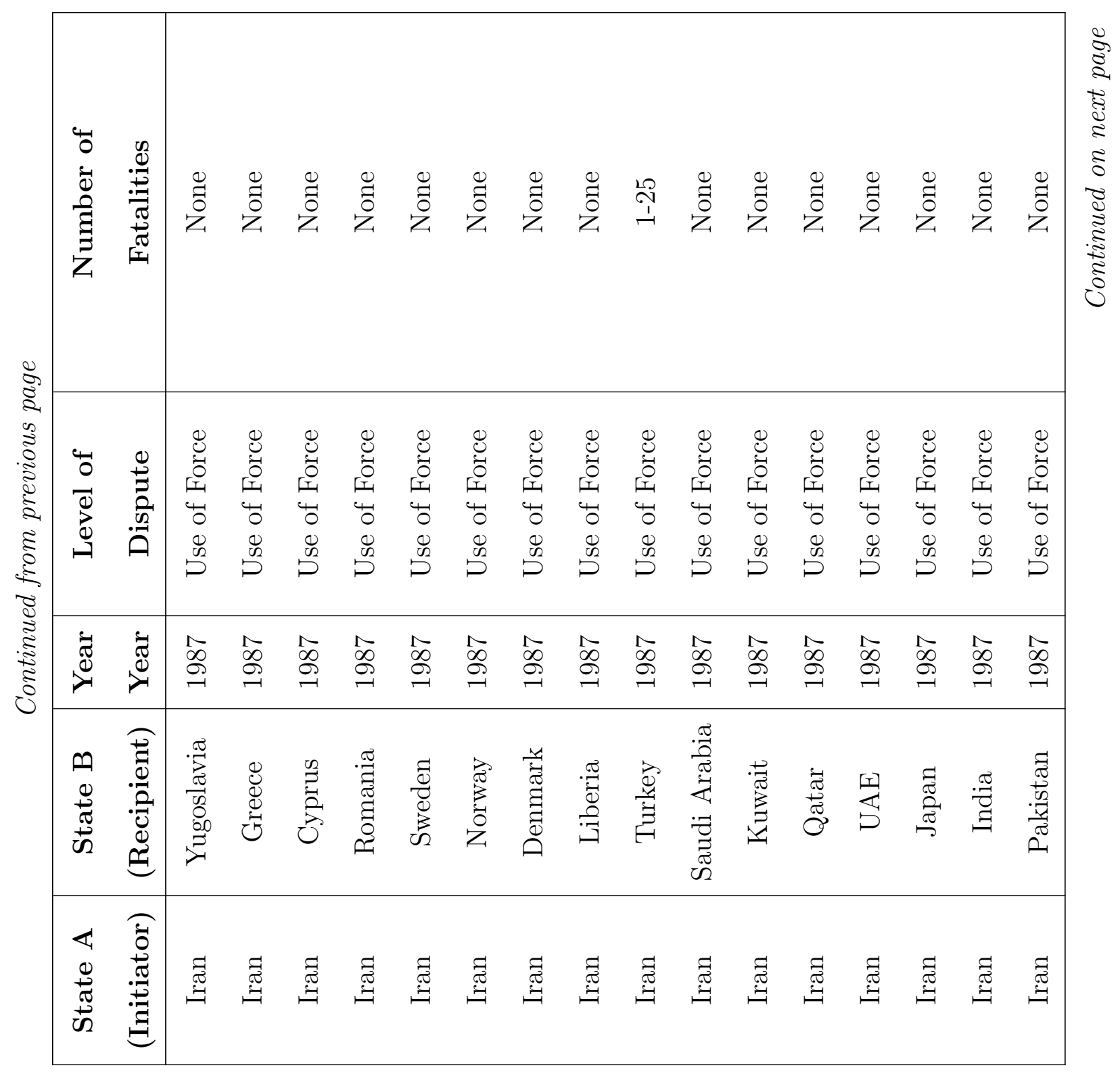




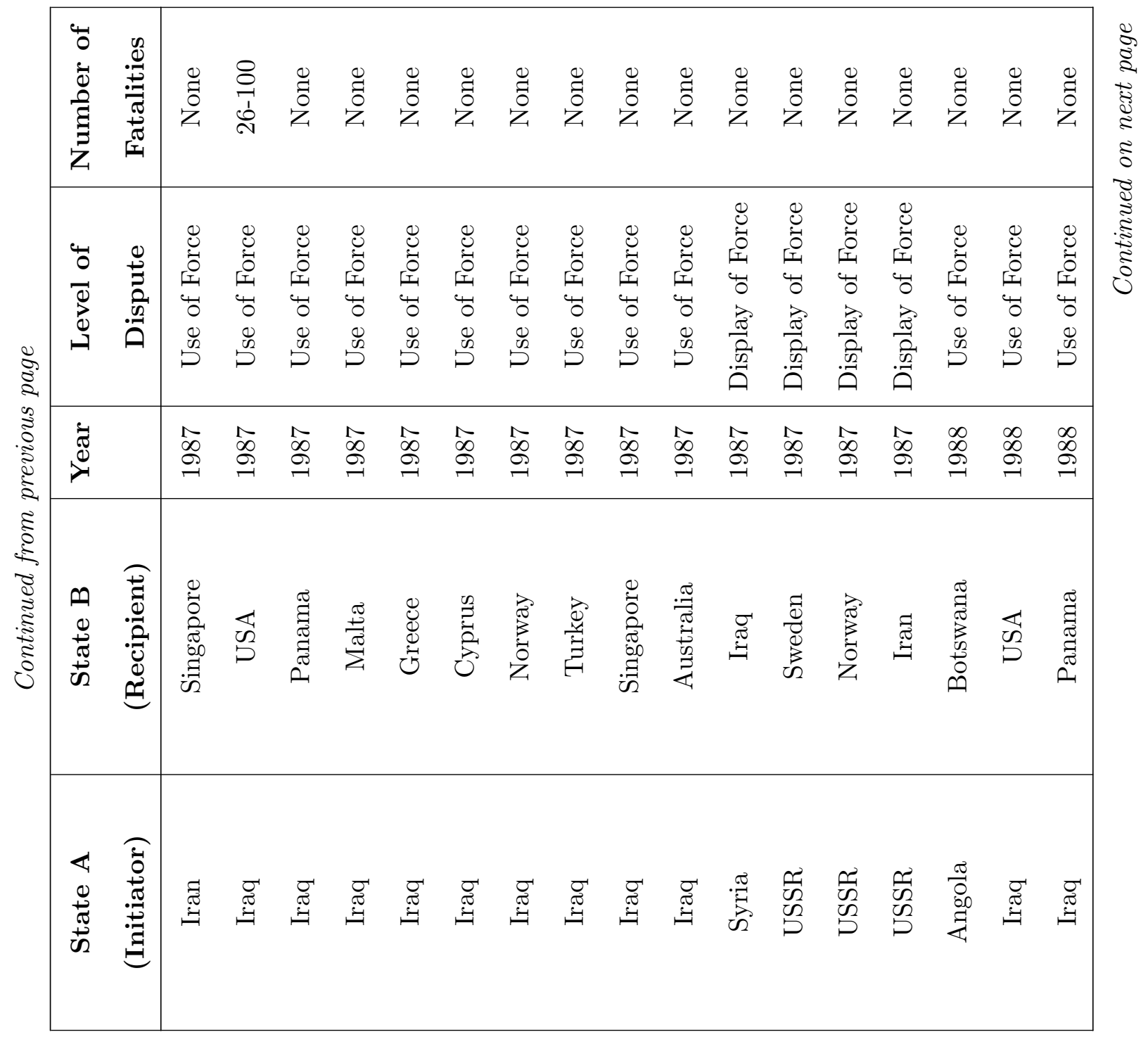




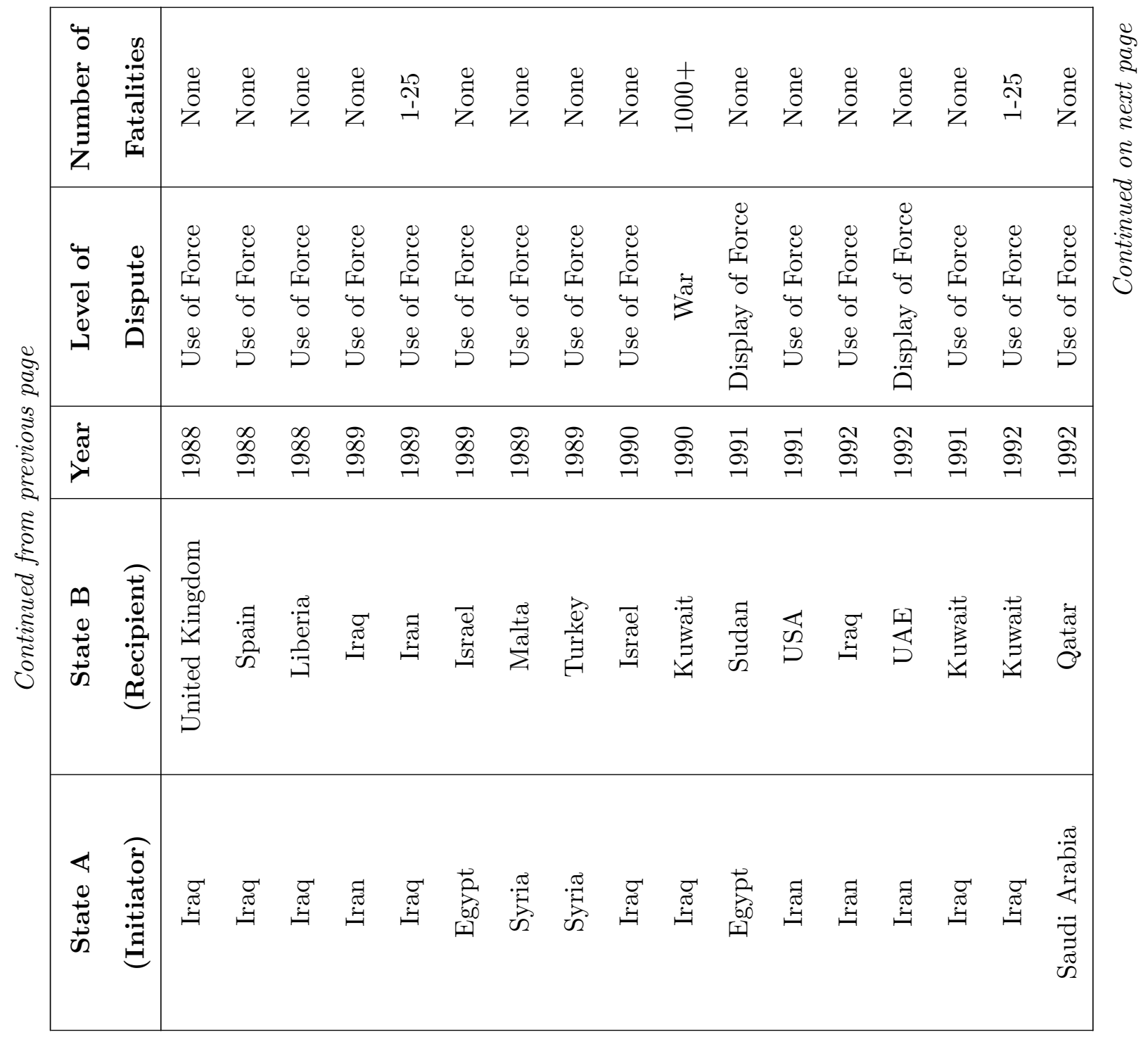




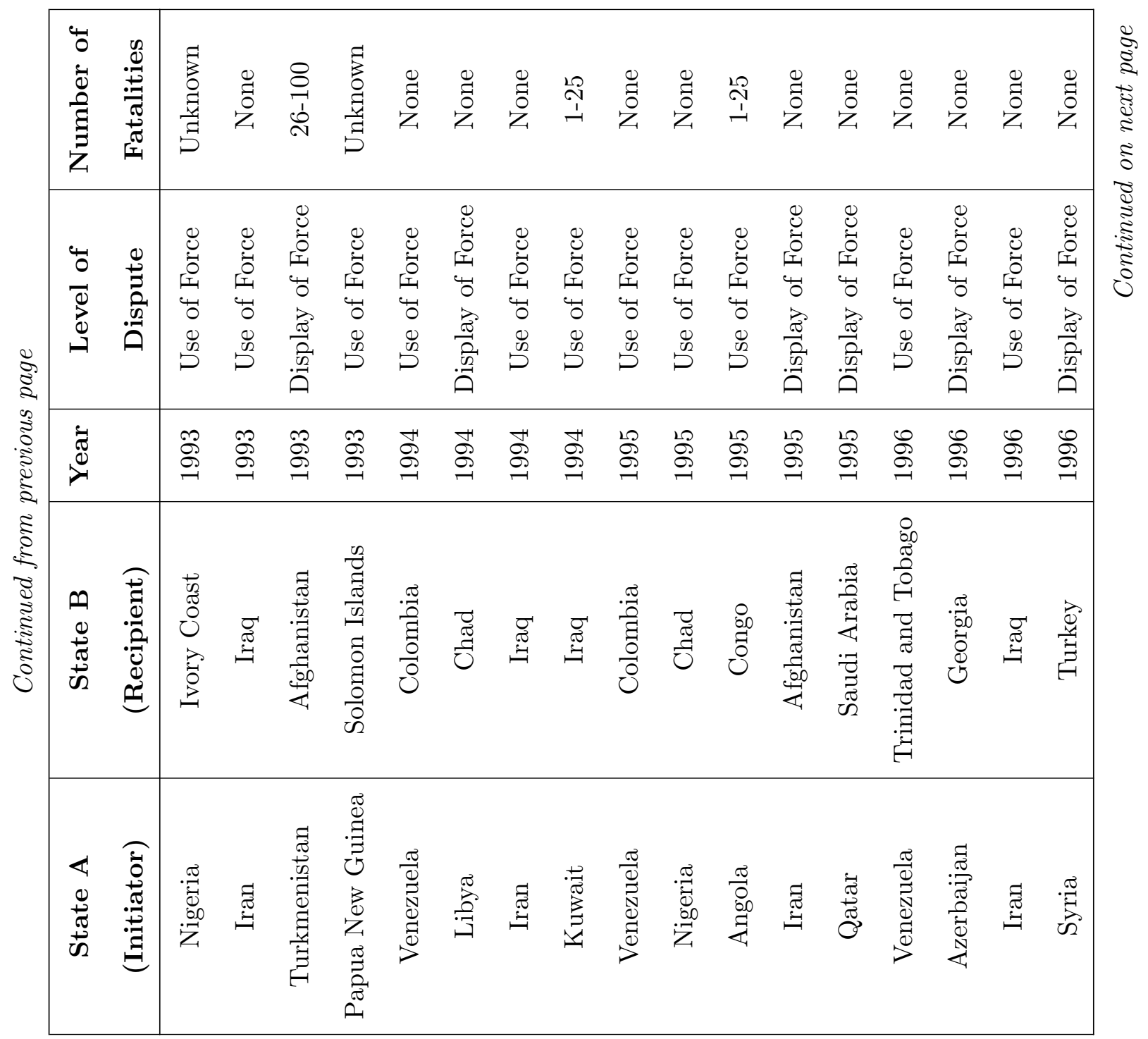




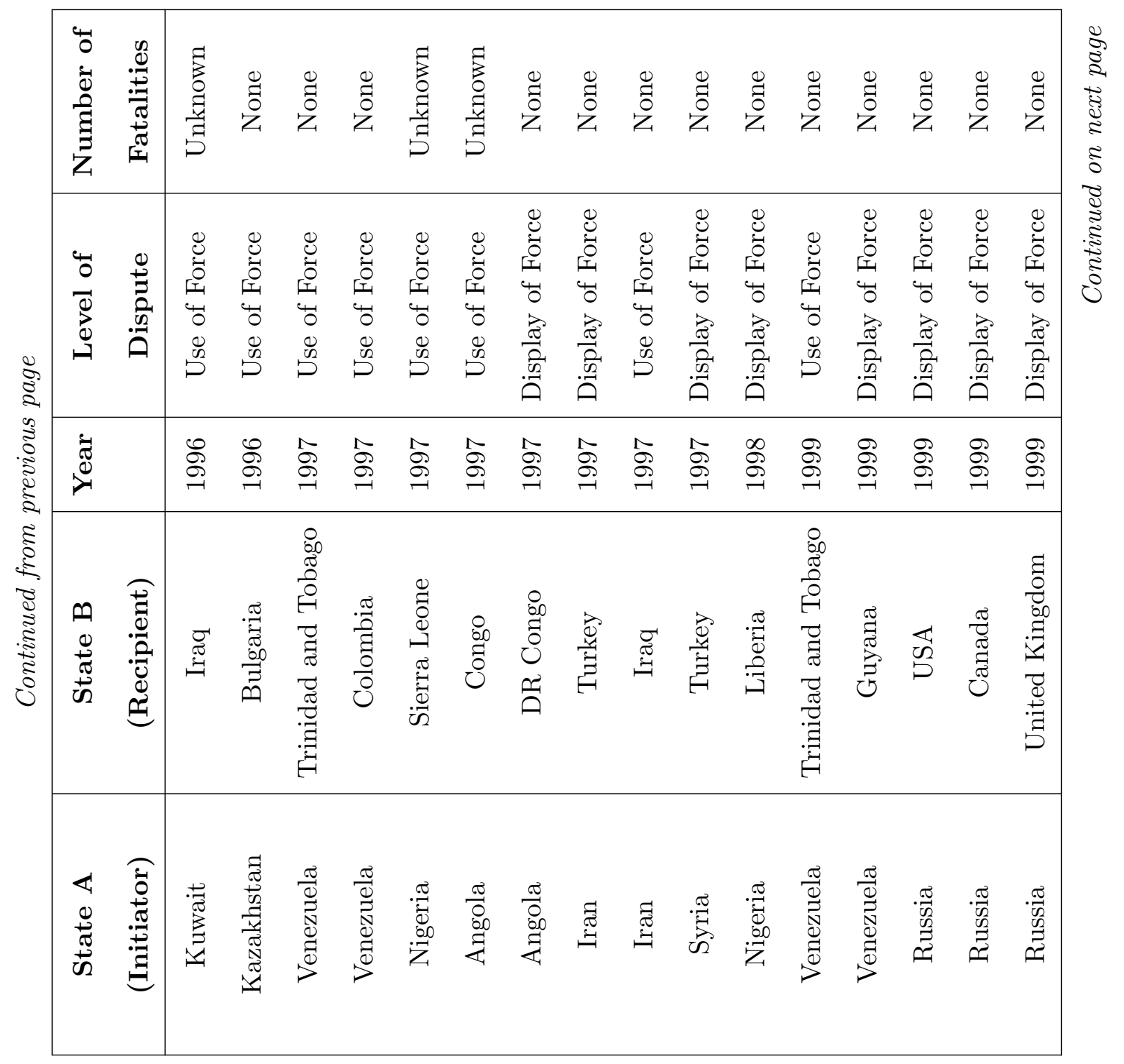




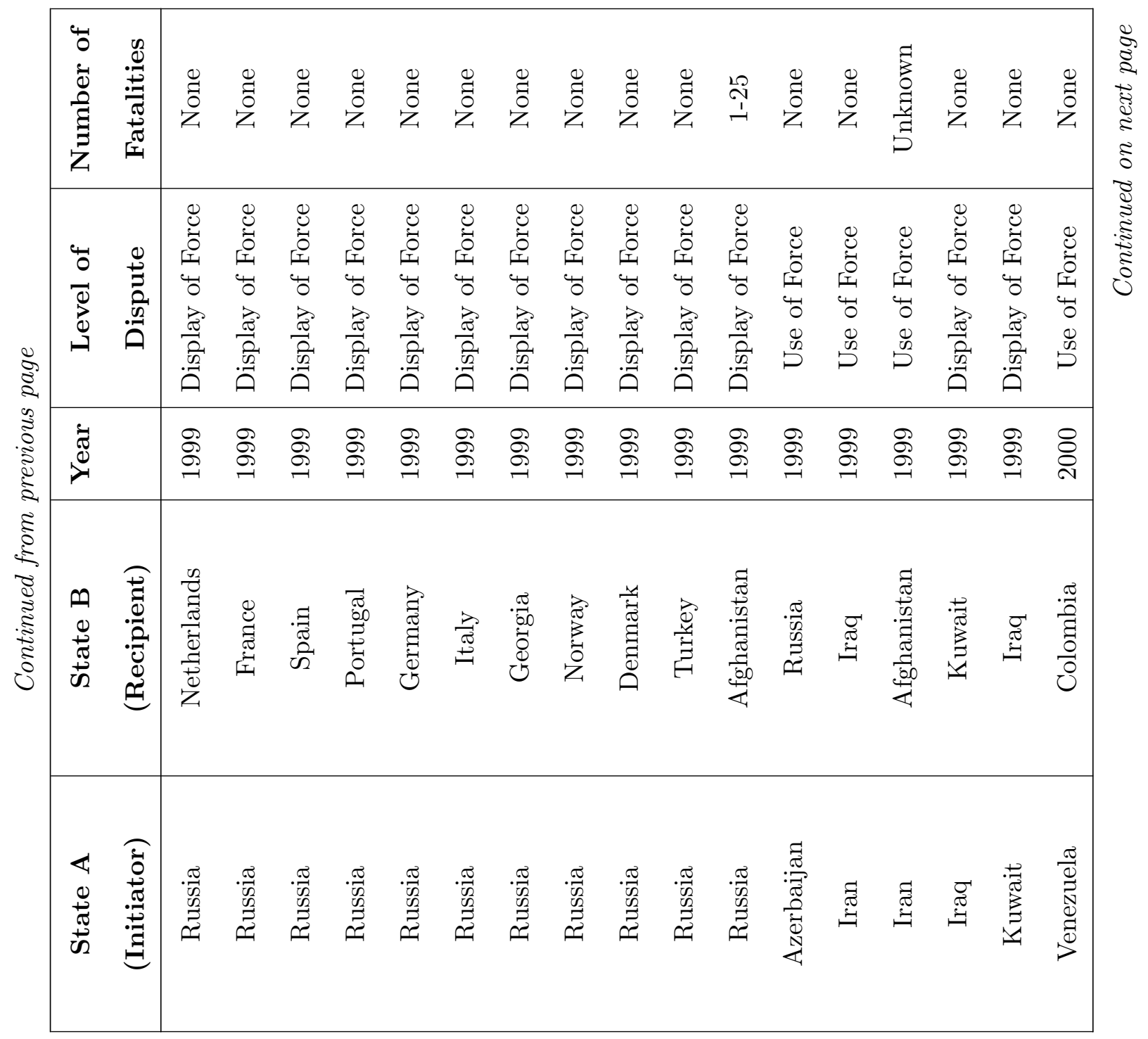




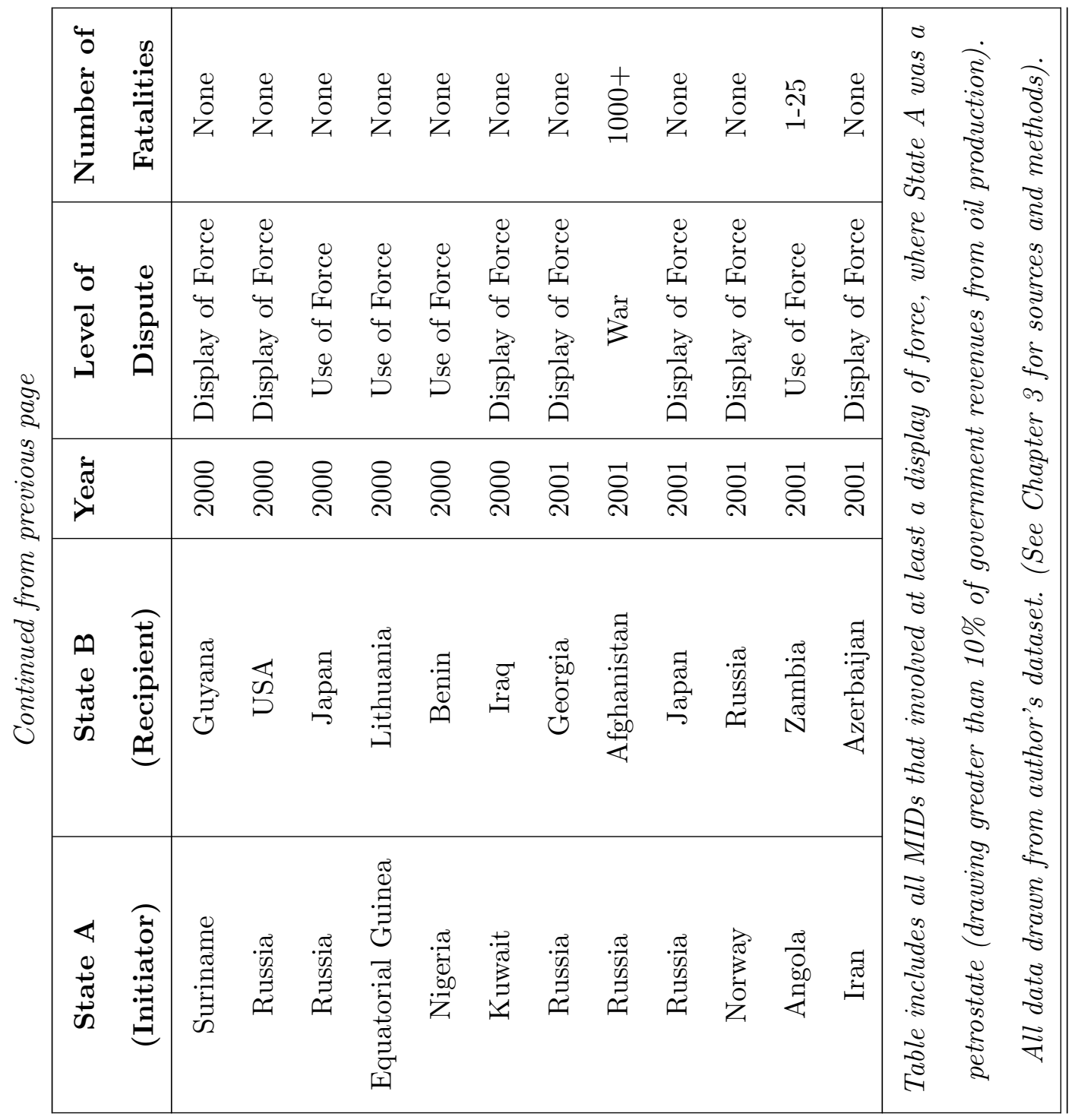




\section{BIBLIOGRAPHY}




\section{BIBLIOGRAPHY}

\section{Books, Monographs and Scholarly Articles}

-. "Assessing Russian foreign policy under Medvedev." International Institute for Strategic Studies Strategic Comments 18, no. 4 (2012).

-. "Syria: Inevitable Descent into Civil War?" International Institution for Strategic Studies Strategic Comments 18, no. 2 (2012): 1.

-. "The Farc Files: Venezuela, Ecuador and the Secret Archive of 'Raúl Reyes." International Institute for Strategic Studies Strategic Dossier (2011).

-. Saudi-Iranian Relations Since the Fall of Saddam: Rivalry, Cooperation, and Implications for US Policy. Rand Corporation, 2009.

Aarts, Paul and Joris Van Duijne. "Saudi Arabia after US-Iranian Dtente: Left in the Lurch?" Middle East Policy 16, no. 3 (2009): 64-78.

Aba-Namay, Rashed. "The New Saudi Representative Assembly." Islamic Law and Society 5, no. 2 (1998): 235-265.

Acemoglu, Daron and James A. Robinson. "Economic Backwardness in Political Perspective." American Political Science Review 100, no. 1 (2006): 115-131.

Adambai, Gulnar. "Kazakhstan: Petty Corruption on a Grand Scale." Transitions Online 5, no. $31(2005)$.

Aguilera, Raul. "Venezuela and Colombia: Border Security Issues." Masters Thesis, Naval Postgraduate School, 1994.

Ahrend, Rudiger and William Tompson. "Unnatural Monopoly: the Endless Wait for Gas Sector Reform in Russia." Europe-Asia Studies 57, no. 6 (2005): 801-821.

Alexeev, Michael, and Robert Conrad. "The Elusive Curse of Oil." The Review of Economics and Statistics 91, no. 3 (2009): 586-598.

Alexperov, Vagit. Oil of Russia: Past, Present and Future. East View Press, 2011. 
Alghanim, Abdullah and Ribhi I. Salhi. "The War on Terror from the Perspective of Indonesia and Saudi Arabia." Digest of Middle East Studies 19, no. 1 (2010): 92-106.

Allison, Roy. "Strategic Reassertion in Russia's Central Asia Policy." International Affairs 80, no. 2 (2004): 277-293.

Al-Marashi, Ibrahim. "Iraq's Security and Intelligence Network: A Guide and Analysis." Gloria Center, 2002.

Anderson, Paul A. "Decision Making by Objection and the Cuban Missile Crisis." Administrative Science Quarterly 28, no. 2 (1983): 201-222.

Al-Hegelan, Abdelrahman and Monte Palmer. "Bureaucracy and Development in Saudi Arabia." The Middle East Journal 39, no. 1 (1985): 48-68.

Allansson, Marie, Jonas Baumann, Samuel Taub, Lotta Themnr and Peter Wallensteen. "The First Year of the Arab Spring." Stockholm International Peace Research Institute, 2012.

Al-Rasheed, Madawi. "Sectarianism as Counter-Revolution: Saudi Responses to the Arab Spring." Studies in Ethnicity and Nationalism 11, no. 3 (2011): 513-526.

Al-Rasheed, Madawi. A History of Saudi Arabia. Cambridge University Press, 2002.

Alsultan, Fahad. "The Saudi King: Power, Limitation and Participation in Saudi Arabian Foreign Policy Making." International Journal of Social Science and Humanity. 3, no. 5 (2013).

Anthony, John Duke. "Saudi Arabian-Yemeni Relations: Implications for US Policy." Middle East Policy 7, no. 3 (2000): 78-96.

Arbatov, Alexei. The Transformation of Russian Military Doctrine: Lessons Learned from Kosovo and Chechnya. The George C. Marshall European Center for Security Studies, 2000.

Arbatov, Alexei. "Russia's Foreign Policy Alternatives." International Security 18, no. 2 (1993): $5-43$.

Auty, Richard M. "The Political State and the Management of Mineral Rents in Capital-Surplus Economies: Botswana and Saudi Arabia." Resources Policy 27, no. 2 (2001): 77-86.

Auty, R. M. and A. H. Gelb. "Political Economy of Resource-Abundant States." Working Paper, World Bank, 2001.

Averre, Derek. "NATO Expansion and Russian National Interests." European Security 7, no. 1 (1998): 10-54.

Aviles, William. "The Democratic-Peace Thesis and US Relations with Colombia and Venezuela." Latin American Perspectives (2005): 33-59.

Aviles, William. "Policy Coalitions, Economic Reform and Military Power in Ecuador and Venezuela." Third World Quarterly 30, no. 8 (2009): 1549-1564. 
Baev, Pavel K. Russian Energy Policy and Military Power: Putin's Quest for Greatness. Routledge, 2008.

Baev, Pavel. "Instrumentalizing Counterterrorism for Regime Consolidation in Putin's Russia." Studies in Conflict and Terrorism 27, no. 4 (2004): 337-352.

Bahgat, Gawdat. "Saudi Arabia and the Arab?Israeli Peace Process." Middle East Policy 14, no. 3 (2007): 49-59.

Baldwin, David. Paradox of Power. Basil Blackwell, 1989.

Balka, Charles E. "The Fate of Saudi Arabia: Regime Evolution in the Saudi Monarchy." Masters thesis, Naval Postgraduate School, 2008.

Baltagi, Badi, Georges Bresson and Alain Pirotte. "Fixed Effects, Random Effects or HausmanTaylor?: A Pretest Estimator." Economics Letters 79, no. 3 (2003): 361-369.

Baltagi, Badi, Georges Bresson, and Alain Pirotte. "Testing the Fixed Effects Restrictions? A Monte Carlo Study of Chamberlain's Minimum Chi-Squared Test." Statistics and Probability Letters 79, no. 10 (2009): 1358-1362.

Barany, Zoltan. Resurgent Russia? A Still-Faltering Military. Hoover Institution, Feb/Mar 2008.

Barany, Zoltan. "The Politics of Russia's Elusive Defense Reform." Political Science Quarterly 121, no. 4 (2006): 597-627.

Basedau, Matthias, and Jann Lay. "Resource Curse or Rentier Peace? The Ambiguous Effects of Oil Wealth and Oil Dependence on Violent Conflict." Journal of Peace Research 46, no. 6 (2009): 757-776.

Beck, Nathaniel, and Jonathan Katz. "Throwing out the Baby with the Bath Water: A Comment on Green, Yoon and Kim." International Organisation 55, no. 2 (2001): 487-495.

Beck, Nathaniel, Jonathan Katz and Richard Tucker. "Taking Time Seriously: Time-Series-CrossSection Analysis with a Binary Dependent Variable." American Journal of Political Science 42, no. 4 (1997): 1260-1288.

Benson, M. "The Relevance of Politically Relevant Dyads in the Study of Interdependence and Dyadic Disputes." Conflict Management and Peace Science 22 (2005): 113-133.

Berenskoetter, F. and M. J. Williams. Power in World Politics. Routledge, 2007.

Besley, Timothy and Torsten Persson. "State Capacity, Conflict, and Development." Econometrica 78, no. 1 (2010): 1-34.

Biberman, Yelena. "Institutional Analysis of the Ministry of Foreign Affairs of Ukraine." International Research and Exchanges Board, 2009.

Blank, Stephen. Perspectives on Russian Foreign Policy. Strategic Studies Institute Monograph, 2012. Nation (2007): 20. 
Blank, Stephen. The NATO-Russia Partnership: A Marriage of Convenience or a Troubled Relationship? Strategic Studies Institute Monography, 2006.

Boucek, Christopher. War in Saada: From Local Insurrection to National Challenge. Carnegie Endowment for International Peace, 2010.

Boucek, Christopher and Marina Ottaway. Yemen on the Brink. Carnegie Endowment for International Peace, 2010.

Bueno de Mesquita, Bruce, Alastair Smith, Randolph M. Siverson and James D. Morrow. The Logic of Political Survival. MIT Press, 2003.

Brautigam, Deborah, Odd Helge Fjeldstad, and Mick Moore. Taxation and State-Building in Developing Countries. Cambridge University Press, 2008.

Bremmer, Ian. "The Saudi Paradox." World Policy Journal 21, no. 3 (2004): 23-30.

Brooks, Stephen G. "Dueling realisms." International Organization 51, no. 3 (1997): 445-477.

Brunnschweiler, C. N. and E. H. Bulte. "The Resource Curse Revisited and Revised: A Tale of Paradoxes and Red Herrings." Journal of Environmental Economics and Management 55, no. 3 (2008): 248-264.

Burges, Sean. "Building a Global Southern Coalition: the Competing Approaches of Brazil's Lula and Venezuela's Chávez." Third World Quarterly 28, no. 7 (2007): 1343-1358.

Burns, Sean. "One Hand: Military Structure and Middle East Revolts." Ph.D. Dissertation, Northwestern University, 2013.

Bridgewater, Elliot. "The Resource Relationship: The Institutional Legacies of Oil in Venezuela." Masters thesis, Dalhousie University, 2010.

Byman, Daniel, Kenneth Pollack and Matthew Waxman. "Coercing Saddam Hussein: Lessons from the Past." Survival 40, no. 3 (1998): 127-151.

Caplan, Richard. "International Diplomacy and the Crisis in Kosovo." International Affairs 74, no. 4 (1998): 745-761.

Carpenter, Ted Galen. "Tangled Web: The Syrian Civil War and its Implications." Mediterranean Quarterly 24, no. 1 (2013): 1-11.

Caselli, Francesco, Massimo Morelli and Dominic Rohner. "The Geography of Inter-state Resource Wars." National Bureau of Economic Research Working Paper No. 18978, 2012.

Champion, Daryl. "The Kingdom of Saudi Arabia: Elements of Instability within Stability." Middle East Review of International Affairs 3, no. 4 (1999): 49-73.

Charap, Samuel. "The Petersburg Experience: Putin's Political Career and Russian Foreign Policy." Problems of Post-Communism 51, no. 1 (2004): 55-62. 
Chaudhry, Kiren Aziz. The Price of Wealth: Economies and Institutions in the Middle East. Cornell University Press, 1997.

Chun, Clayton K. Do Oil Exports Fuel Defense Spending? Strategic Studies Institute, 2010.

Clem, Ralph S. and Anthony P. Maingot. Venezuela's Petro-Diplomacy: Hugo Chávez's Foreign Policy. University Press of Florida, 2011.

Cohen, Ariel and Robert Hamilton. The Russian Military and the Georgia War: Lessons and Implications. Strategic Studies Institute Monograph, 2011.

Colgan, Jeffrey. Petro-Aggression: When Oil Causes War. Cambridge University Press, 2013.

Colgan, Jeffrey. "Oil and Revolutionary Governments: Fuel for International Conflict." International Organization 64, no. 4 (2010): 661-694.

Colgan, Jeff. "Venezuela and Military Expenditure Data." Journal of Peace Research 48, no. 4 (2010a): 547-556.

Collier, Paul and Anke Hoeffler. "Resource Rents, Governance, and Conflict." Journal of Conflict Resolution 49, no. 4 (2005): 625-633.

Collier, P. and Anke Hoeffler. "Greed and Grievance in Civil War." Oxford Economic Papers 56, no. 4 (2004): 563-595.

Conant, M. A. The Oil Factor in US Foreign Policy, 1980-1990. Lexington Books, 1982.

Copeland, Dale. "Economic Interdependence and War: A Theory of Trade Expectations." International Security 20, no. 4 (1996): 5-41.

Coppedge, M. "Thickening Thin Concepts and Theories: Combining Large N and Small in Comparative Politics." Comparative Politics 31, no. 4 (1999): 465-476.

Cordesman, Anthony. The Saudi Arms Sale. Center for Strategic and International Studies, 2010.

Cordesman, Anthony. Saudi Arabia: National Security in a Troubled Region. Center for Strategic and International Studies, 2009.

Cordesman, Anthony H. "Saudi Arabia: Friend or Foe in the War on Terror?" Middle East Policy 13, no. 1 (2006): 28-41.

Cordesman, Anthony. Saudi Arabia Enters the Twenty-First Century: the Military and International Security Dimensions. Volume 1. Greenwood Publishing Group, 2003.

Cordesman, Anthony. Saudi Arabia Enters the Twenty-First Century: the Political, Foreign Policy, Economic, and Energy Dimensions. Volume 2. Greenwood Publishing Group, 2003.

Cordesman, Anthony and Alexander Wilner. The Gulf Military Balance in 2012. Center for Strategic and International Studies, 2012. 
Corrales, Javier and Michael Penfold-Becerra. "Venezuela: Crowding Out the Opposition." Journal of Democracy 18, no. 2 (2007): 99-113.

Corrales, Javier and Carlos A. Romero. United States-Venezuela Relations Since the 1990s. Routledge, 2013.

Crandall, Russell. "Requiem for the FARC?" Survival 53, no. 4 (2011): 233-240.

Crisp, Brian. Democratic Institutional Design: the Powers and Incentives of Venezuelan Politicians and Interest Groups. Stanford University Press, 2000.

Dalacoura, Katerina. "The 2011 Uprisings in the Arab Middle East: Political Change and Geopolitical Implications." International Affairs 88, no. 1 (2012): 63-79.

Danchenko, Igor, Erica Downs and Fiona Hill. "One Step Forward, Two Steps Back? The Realities of a Rising China and Implications for Russia's Energy Ambitions." Brookings Institute Policy Paper 22 (2010): 1-20.

Dawisha, Karen. "Is Russia's Foreign Policy That of a Corporatist-Kleptocratic Regime?" PostSoviet Affairs 27, no. 4 (2011): 331-365.

Deger, Saadet. "Economic Development and Defense Expenditure." Economic Development and Cultural Change (1986): 179-196.

Dekmejian, R. Hrair. "Saudi Arabia's Consultative Council." The Middle East Journal (1998): 204-218.

Denvir, Daniel. "Colombia's Magic Laptops." NACLA Report on the Americas (Nov/Dec 2008).

Deshazo, Peter. "Venezuela Forum: Conclusions and Future Implications." Center for Strategic and International Studies Policy Papers on the Americas 14, no. 1 (2008).

De Soysa, Indra. "Paradise is a Bazaar? Greed, Creed, and Governance in Civil War, 1989-99." Journal of Peace Research 39, no. 4 (2002): 395-416.

De Soysa, Indra, Erik Gartzke and Tove Grete Li. "Blood, Oil, and Strategy: On the Relationship Between Petroleum and Interstate Disputes." Unpublished Paper, Peace Research Institute of Oslo, 2009.

Dixit, Avinash K. "Democracy, Autocracy and Bureaucracy." Journal of Globalization and Development 1 , no. 1 (2010).

Derleth, J. William. "The Evolution of the Russian Polity: The Case of the Security Council." Communist and Post-Communist Studies 29, no. 1 (1996): 43-58.

Dodson, Michael and Manochehr Dorraj. "Populism and Foreign Policy in Venezuela and Iran." Whitehead Journal of Diplomacy and International Relations 9 (2008): 71-87.

Donaldson, Robert. and Joseph Nogee. The Foreign Policy of Russia: Changing Systems, Enduring Interests. M.E. Sharpe, 2005. 
Dunne, Paul and Sam Perlo-Freeman. "The Demand for Military Spending in Developing Countries." International Review of Applied Economics 17, no. 1 (2003): 23-48.

Eilts, Hermann Frederick. "Saudi Arabia's Foreign Policy." In Diplomacy in the Middle East, edited by L. Carl Brown, 219-244. IB Tauris, 2001.

Elass, Jareer and Amy Myers Jaffe. The History of U.S. Relations with OPEC: Lessons to Policymakers. James A. Baker Institute for Public Policy, Rice University, 2010.

Ellner, Steve and Miguel Tinker-Salas. Venezuela: Hugo Chávez and the Decline of an Exceptional Democracy. Rowman and Littlefield Publishers, 2006.

Evans, Peter B. "Predatory, Developmental, and Other Apparatuses: A Comparative Political Economy Perspective on the Third World State." Sociological Forum 4, no. 4 (1989): 561-587.

Farah, Douglas. Transnational Organised Crime, Terrorism and Criminalised States in Latin America: An Emerging Tier-One National Security Priority. Strategic Studies Institute Monograph, 2012.

Fearon, James D. "Rationalist Explanations for War." International Organization 49, no. 3 (1995): $379-414$.

Fearon, James D. "Signaling Versus the Balance of Power and Interests: An Empirical Test of a Crisis Bargaining Model." Journal of Conflict Resolution 38, no. 2 (1994): 236-269.

Fearon, J. D. and D. Laitin. "Ethnicity, Insurgency, and Civil War." American Political Science Review 97, no. 1 (2003): 75-90.

Felgenhauer, Pavel. "After August 7: The Escalation of the Russia-Georgia War." In The Guns of August 2008, edited by Svante Cornell and S. Frederick Starr. M.E. Sharpe, 2009.

Freeman, Chas. "The Arab Reawakening: Strategic Implications." Middle East Policy 18, no. 2 (2011): 29-36.

Freeman, Jack. "The al-Houthi Insurgency in the North of Yemen: An Analysis of the Shabab al-Moumineen." Studies in Conflict and Terrorism 32, no. 11 (2009): 1008-1019.

Freedman, Lawrence and Efraim Karsh. "How Kuwait Was Won: Strategy in the Gulf War." International Security 16, no. 2 (1991): 5-41.

Gaddy, Clifford G. and Barry W. Ickes. "Resource Rents and the Russian Economy." Eurasian Geography and Economics 46, no. 8 (2005): 559-583.

Gaidar, Yegor. The Soviet Collapse: Grain and Oil. American Enterprise Institute for Public Policy Research, 2007.

Gartzke, Erik. "Democracy and the Preparation for War: Does Regime Type Affect States' Anticipation of Casualties?" International Studies Quarterly 45, no. 3 (2001): 467-484. 
Gartzke, Erik, Quan Li, and Charles Boehmer. "Investing in the Peace: Economic Interdependence and International Conflict." International Organization 55, no. 2 (2001): 391-438.

Gause, F. Gregory. Saudi Arabia in the New Middle East. Council on Foreign Relations, 2011.

Gately, Dermot. "A Ten-Year Retrospective: OPEC and the World Oil Market." Journal of Economic Literature 22, no. 3 (1984): 1100-1114.

Gelb, Leslie and Richard K. Betts. The Irony of Vietnam: The System Worked. Brookings Institution Press, 1979.

George, Larry. "Realism and Internationalism in the Gulf of Venezuela." Journal of InterAmerican Studies and World Affairs (1988): 139-170.

Gerber, Theodore and Sarah E. Mendelson. "Russian Public Opinion on Human Rights and the War in Chechnya." Post-Soviet Affairs 18, no. 4 (2002): 271-305.

Gerring, J. "The Mechanismic Worldview: Thinking Inside the Box." British Journal of Political Science 38, no. 1 (2008): 161-179.

Ghosn, F, G. Palmer, and S. Bremer. "The MID Data Set, 1993-2001: Procedures, Coding Rules, and Description." Conflict Management and Peace Science 21 (2004):133-154.

Giacalone, Rita. "Latin American Foreign Policy Analysis: External Influences and Internal Circumstances." Foreign Policy Analysis 8, no. 4 (2012): 335-354.

Ginter, Kevin. "Truth and Mirage: The Cuba-Venezuela Security and Intelligence Alliance." International Journal of Intelligence and CounterIntelligence 26, no. 2 (2013): 215-240.

Gleason, Gregory. "Foreign Policy and Domestic Reform in Central Asia." Central Asian Survey 20, no. 2 (2001): 167-182.

Glosemeyer, Iris. Dancing on Snake Heads in Yemen. Canadian Defence and Foreign Affairs Institute, 2009.

Goemans, Hein Erich. War and Punishment: The Causes of War Termination and the First World War." Princeton University Press, 2000.

Goldman, Marshall. Petrostate: Putin, Power, and the New Russia. Oxford University Press, 2008.

Guo, Rongxing. Territorial Disputes and Conflict Management.' Routledge, 2012.

Guzansky, Yoel. "Saudi Activism in a Changing Middle East." Strategic Assessment 14, no. 3 (2011).

Haber, Stephen and Victor Menaldo. "Do Natural Resources Fuel Authoritarianism? A Reappraisal of the Resource Curse." American Political Science Review 105, no. 1 (2011): 1-26. 
Halliday, Fred. "The Yemens: Conflict and Coexistence." The World Today 40, no. 8/9 (1984): 355-362.

Hamilton, Adrian. Oil: The Price of Power. London: Joseph, 1986.

Hammond, John L. "The Resource Curse and Oil Revenues in Angola and Venezuela." Science and Society 75, no. 3 (2011): 348-378.

Hanks, Reuel R. "Multi-vector Politics and Kazakhstan's Emerging Role as a Geo-Strategic Player in Central Asia." Journal of Balkan and Near Eastern Studies 11, no. 3 (2009): 257-267.

Headley, James. Russia and the Balkans: Foreign Policy from Yeltsin to Putin. Hurst, 2008.

Hellinger, Daniel. "Venezuelan Oil." International Journal 62, no. 1 (2006): 55-67.

Hermann, Charles. F., Charles W. Kegley, and James N. Rosenau. New Directions in the Study of Foreign Policy. HarperCollins Academic, 1987.

Hermann, Margaret G. "Explaining Foreign Policy Behavior using the Personal Characteristics of Political Leaders." International Studies Quarterly 24, no. 1 (1980): 7-46.

Hermann, Margaret G. and Charles F. Hermann. "Who Makes Foreign Policy Decisions and How: An Empirical Inquiry." International Studies Quarterly 33 (1989): 361-387.

Hertog, Steffen. Princes, Brokers, and Bureaucrats: Oil and the State in Saudi Arabia. Cornell University Press, 2011.

Hertog, Steffen. "Petromin: the Slow Death of Statist Oil Development in Saudi Arabia." Business History 50, no. 5 (2008): 645-667.

Hill, Fiona. "Russia: The US Response to Changing Policy Imperatives." The Brookings Review 18, no. 4 (2000): 12-14.

Hill, Fiona and Clifford G. Gaddy. Mr. Putin: Operative in the Kremlin. Brookings Institution Press, 2013.

Hill, Ginny, Gerd Nonneman and Stefan Wolff. Yemen, Saudi Arabia and the Gulf States: Elite Politics, Street Protests and Regional Diplomacy. Chatham House, 2011.

Hoffman, David. "Oil and State-Building in Post-Soviet Azerbaijan and Kazakhstan." Ph.D. Dissertation, University of California Berkeley, 2000.

Hudson, Valerie M. and Christopher S. Vore. "Foreign Policy Analysis: Yesterday, Today, and Tomorrow." Mershon International Studies Review 39 (1995): 209-238.

Hughes, James. "The Chechnya Conflict: Freedom Fighters or Terrorists?" Demokratizatsiya 15, no. 3 (2007): 293-311.

Hughes, James. "The Peace Process in Chechnya." In Chechnya: From the Past to the Future, edited by Richard Sakwa, 265-288. Anthem Press, 2005. 
Humphreys, Macartan. "Natural Resources, Conflict, and Conflict Resolution Uncovering the Mechanisms." Journal of Conflict Resolution 49, no. 4 (2005): 508-537.

Humphreys, Macartan, Jeffrey Sachs and Joseph E. Stiglitz. Escaping the Resource Curse. Columbia University Press, 2007.

Ibrayeva, Aigerim and Tamara Nezhina. "Public Sector Reforms in Kazakhstan." In Public Administration in Post-Communist Countries, edited by Saltanat Liebert, Stephen E. Condrey and Dmitry Goncharov, 45-70. CRC Press, 2013.

Ipek, Pinar. "The Role of Oil and Gas in Kazakhstan's Foreign Policy: Looking East or West?" Europe-Asia Studies 59, no. 7 (2007): 1179-1199.

Jacome, Francine. Petrocaribe: The Current Phase of Venezuela's Oil Diplomacy in the Carribean. Friedrich Ebert Stiftung, 2011.

Jakobson, Linda and Dean Knox. New Foreign Policy Actors in China. Stockholm International Peace Research Institute (SIPRI), 2010.

Jones, Toby Craig. "Saudi Arabia Versus the Arab Spring." Raritan Quarterly Review 31, no. 2 (2011): 43-59.

Jones Luong, Pauline and Erika Weinthal. "Rethinking the Resource Curse: Ownership Structure, Institutional Capacity, and Domestic Constraints." Annual Review of Political Science 9 (2006): 241-263.

Jonson, Lena. "Putin and Chechnya: Is This How to Square a Circle?" Brown Journal of World Affairs 8, no. 1 (2001): 1-15.

Kamrava, Mehran. "The Arab Spring and the Saudi-Led Counterrevolution." Orbis 56, no. 1 (2013): 96-104.

Kanet, Roger and Susanne M. Birgerson. "The Domestic-Foreign Policy Linkage in Russian Politics: Nationalist Influences on Russian Foreign Policy." Communist and Post-Communist Studies 30, no. 4 (1997): 335-344.

Karl, Terry Lynn. The Paradox of Plenty: Oil Booms and Petro-States. University of California Press, 1997.

Karsh, Efraim. "Military Power and Foreign Policy Goals: the Iran-Iraq War Revisited." International Affairs 64, no 1 (1987): 83-95.

Kassenova, Nargis. "Kazakhstan's National Security: Conceptual and Operational Aspects." Central Asian Survey 24, no. 2 (2005): 151-164.

Kasymov, Shavkat. "Statism in Russia: The Implications for US-Russian Relations." The Journal of Slavic Military Studies 24, no. 3 (2011): 529-552.

Katz, Mark. "The Putin-Chávez Partnership." Problems of Post-Communism 53, no. 4 (2006): 3-9. 
Katzenstein, Peter J. Between Power and Plenty: Foreign Economic Policies of Advanced Industrial States. University of Wisconsin Press, 1977.

Katznelson, Ira and Helen V. Milner. Political Science: the State of the Discipline. WW Norton, 2002.

Kechichian, Joseph A. "Trends in Saudi National Security." The Middle East Journal 53, no. 2 (1999): 232-253.

Keohane Robert and J. S. Nye. Power and Interdependence. Longman, 1989

Khong, Yuen Foong. Analogies at War: Korea, Munich, Dien Bien Phu, and the Vietnam Decisions of 1965. Princeton University Press, 1992.

King, Charles. "The Five-Day War: Managing Moscow after the Georgia Crisis." Foreign Affairs 87 (2008): 2-11.

Klare, Michael. Blood and Oil: The Dangers and Consequences of America's Growing Dependency on Imported Petroleum. Macmillan, 2007.

Klare, M. T. Resource Wars: The New Landscape of Global Conflict. Holt Paperbacks, 2002.

Knorr, K. E. The Power of Nations: The Political Economy of International Relations. Basic Books, 1975.

Kotkin, Stephen. "Untitled Review" of Russian Foreign Policy in the Twenty-first Century and the Shadow of the Past, by Robert Legvold. Foreign Affairs, Sept/Oct 2007.

Kramer, Mark. "The Perils of Counterinsurgency: Russia's War in Chechnya." International Security 29, no. 3 (2004-5): 5-63.

Kubicek, Paul. "Russian Energy Policy in the Caspian Basin." World Affairs 166, no. 4 (2004): 207-217.

Kubicek, Paul. "Russian Foreign Policy and the West." Political Science Quarterly 114, no. 4 (1999): 547-568.

Kuboniwa, Masaaki, Shinichiro Tabata and Nataliya Ustinova. "How Large is the Oil and Gas Sector of Russia? A Research Report." Eurasian Geography and Economics 46, no. 1 (2005): 68-76.

Kuchins, Andrew, and Igor A. Zevelev. "Russian Foreign Policy: Continuity in Change." The Washington Quarterly 35, no. 1 (2012): 147-161.

Lacroix, Stéphane. "Is Saudi Arabia Immune?" Journal of Democracy 22, no. 4 (2011): 48-59.

Ladislaw, Sarah and Frank Verrastro. "Post-Chávez Outlook for Venezuelan Oil Production." Center for Strategic and International Studies Commentaries (2013). 
Lam, Ricky and Leonard Wantchekon. "Political Dutch Disease." Unpublished Paper, New York University, 2003.

Lannon, Gregory. "Russia's New Look Army Reforms and Russian Foreign Policy." Journal of Slavic Military Studies 24, no. 1 (2011): 26-54.

Lahn, Glada and Paul Stevens. Burning Oil to Keep Cool: The Hidden Energy Crisis in Saudi Arabia. Chatham House, 2011.

Lapper, Richard. Living with Hugo: US Policy Toward Hugo Chávez's Venezuela. Council on Foreign Relations, 2006.

Lapidus, Gail. "Putin's War on Terrorism: Lessons from Chechnya." Post-Soviet Affairs 18, no. 1 (2002): 41-48.

Legvold, Robert. "Russian Foreign Policy in the 21st Century and the Shadow of the Past." Colombia University Press, 2007.

Levi, Margaret. Of Rule and Revenue. University of California Press, 1988.

Levitin, Oleg. "Inside Moscow's Kosovo Muddle." Survival 42, no. 1 (2000): 130-140.

Levy, Jack S. "Learning and Foreign Policy: Sweeping a Conceptual Minefield." International Organization 48, no. 2 (1994): 279-312.

Lieber, R. J. Will Europe Fight for Oil?: Energy Relations in the Atlantic Area. Praeger Publishers, 1983.

Light, Margot, Neil Malcolm, Alex Pravda and Roy Allison. Internal Factors in Russian Foreign Policy. Oxford University Press, 1996.

Lindsay-Poland, John. "Retreat to Colombia: The Pentagon Adapts its Latin America Strategy." NACLA Report on the Americas 43, no. 1 (2010): 22-26.

Lo, Bobo. Russian Foreign Policy in the Post-Soviet Era: Reality, Illusion and Mythmaking. Palgrave McMillan, 2002.

Lobell, Steven E., Norrin M. Ripsman and Jeffrey W. Taliaferro. Neoclassical Realism, the State, and Foreign Policy. Cambridge University Press, 2009.

Lucas, Russell. Institutions and the Politics of Survival in Jordan. SUNY Press, 2006.

Lynch, Marc. "Beyond the Arab Street: Iraq and the Arab Public Sphere." Politics and Society 31, no. 1 (2003): 55-91.

Macfarlane, S. "The 'R' in BRICs: Is Russia an Emerging Power?" International Affairs 82, no. 1 (2006): 41-57. 
Mahdavy, Hussein. "The Patterns and Problems of Economic Development in Rentier States: The Case of Iran." In Studies in Economic History of the Middle East, edited by MA Cook, 428-267. Oxford University Press, 1970.

Mahoney, J. "Toward a Unified Theory of Causality." Comparative Political Studies 41, no. 4 (2008): 412-436.

Mankoff, Jeffrey. Russian Foreign Policy: The Return of Great Power Politics. Rowman \& Littlefield Publishers, 2009

Mansfield, Edward D., Helen V. Milner, and Peter Rosendorff. "Free to Trade: Democracies, Autocracies, and International Trade." American Political Science Review 94, no. 2 (2000): 305321.

Manwaring, Max G. Venezuela's Hugo Chávez, Bolivarian Socialism, and Asymmetric Warfare. Strategic Studies Institute Monograph, 2007.

Marantz, Paul. "Russian Foreign Policy during Yeltsin's Second Term." Communist and PostCommunist Studies 30, no. 4 (1997): 345-351.

Matthiesen, Toby. Sectarian Gulf: Bahrain, Saudi Arabia, and the Arab Spring That Wasn't. Stanford University Press, 2012.

Matveeva, Anna. "Democratization, Legitimacy and Political Change in Central Asia." International Affairs 75, no. 1 (1999): 23-44.

Maull, Hanns. Oil and Influence: The Oil Weapon Examined. International Institute for Strategic Studies, 1975.

McCarthy-Jones, Anthea. "Origins of Radical Policy-Making: an Analysis of Foreign Policy in the Fifth Republic of Venezuela." Ph.D. Dissertation, University of Canberra, 2010.

McCarthy-Jones, Anthea and Mark Turner. "Explaining Radical Policy Change: the Case of Venezuelan Foreign Policy." Policy Studies 32, no. 5 (2011): 549-567.

McDonald, Patrick J. The Invisible Hand of Peace: Capitalism, the War Machine, and International Relations Theory. Cambridge University Press, 2009.

McFaul, Michael. "A Precarious Peace: Domestic Politics in the Making of Russian Foreign Policy." International Security 22, no. 3 (2012): 5-35.

McHale, T. R. "A Prospect of Saudi Arabia." International Affairs 56, no. 4 (1980): 622-647.

McMillan, Joseph, Anthony H. Cordesman, Mamoun Fandy, and Fareed Mohamedi. "Symposium: The United States and Saudi Arabia, American Interests and Challenges to the Kingdom in 2002." Middle East Policy 9, no. 1 (2002): 1-28.

Medvedev, Roy. Vladimir Putin: Chetiriye Goda v Kremle [Vladimir Putin: Four Years in the Kremlin]. Vremya, 2004. 
Mehlum, H., K. Moene, and R. Torvik. "Institutions and the Resource Curse." The Economic Journal 116, no. 508 (2006): 1-20.

Mendez-Rivera, Marianallet. "Maintaining and Enhancing Political Power via the Mass Media: The Rhetoric of H. R. Chávez, President of Venezuela." Ph.D. Dissertation, University of Minnesota, 2006.

Mendras, Marie. Russian Politics: The Paradox of a Weak State. Columbia University Press, 2012.

Milner, Helen V. Interests, Institutions, and Information: Domestic Politics and International Relations. Princeton University Press, 1997.

Mommer, Bernard. The New Governance of Venezuelan Oil. Oxford Institute for Energy Studies, 1998.

Monaghan, Andrew. "Russia's Energy Diplomacy: A Political Idea Lacking a Strategy?" Southeast European and Black Sea Studies 7, no. 2 (2007): 275-288.

Monaldi, Francisco, Rosa Amelia Gonzlez, Richard Obuchi and Michael Penfold. Political Institutions, Policymaking Processes and Policy Outcomes in Venezuela. Interamerican Development Bank, 2006.

Moore, Mick. "Political Underdevelopment: What Causes 'Bad Governance."' Public Management Review 3, no. 3 (2001): 385-418.

Morandé, José. "Chile: The Invisible Hand and Contemporary Foreign Policy." In Latin American and Caribbean Foreign Policy, edited by Frank Mora and Jeanne Hay, 243-264. Rowman and Littlefield, 2003.

Morgan, T. C, N. Bapat, and V. Krustev. "The Threat and Imposition of Sanctions 1971-2000." Conflict Management and Peace Science 26, no. 1 (2009): 92-110.

Morrison, Kevin M. "Oil, Nontax Revenue, and the Redistributional Foundations of Regime Stability." International Organization 63, no. 1 (2009): 107-138.

Naif, al-Mutairi. "Saudi Governmental Structure and Foreign Policy." Masters Thesis, U.S. War College, 1993.

Naim, Moises. "The Real Story Behind Venezuela's Woes." Journal of Democracy 12, no. 2 (2001): $17-31$.

Niblock, Tim. Saudi Arabia: Power, Legitimacy and Survival. Routledge, 2004.

Nielsen, Jenny. "Inconvenient Thorn or International Security Threat?" Peace Review 21, no. 1 (2009): 95-99.

Nikitin, Alexander. "Russian Foreign Policy in the Fragmented Post-soviet Space." International Journal on World Peace (2008): 7-31. 
Nonneman, Gerd. "Determinants and Patterns of Saudi Foreign Policy: Omnibalancing and Relavtive Autonomy in Multiple Environments." In Saudi Arabia in the Balance: Political Economy, Society, Foreign Affairs, edited by Paul Aarts and Gerd Nonneman, 315-351. New York University Press, 2005.

Norris, John. Collision Course: NATO, Russia, and Kosovo. Greenwood Publishing Group, 2005.

Nuruzzaman, Mohammed. "Politics, Economics and Saudi Military Intervention in Bahrain." Journal of Contemporary Asia 43, no. 2 (2013): 363-378.

Oliker, Olga. Russia's Chechen Wars 1994-2000: Lessons from Urban Combat. Rand Corporation, 2001. Allison (2008).

Oliker, Olga, Keith Crane, Lowell Schwartz and Catherine Yusupov. Russian Foreign Policy: Sources and Implications. Washington, D.C.: RAND Corporation, 2009.

Owen, John. "How Liberalism Produces Democratic Peace." International Security 19, no. 2 (1994): 87-125.

Pachauri, R. K. The Political Economy of Global Energy. Johns Hopkins University Press, 1985.

Padilla, Carlos A. "The FARC and Hugo Chávez: Is Contemporary Venezuela a Threat to Colombia?" Masters Thesis, Naval Postgraduate School, 2010.

Papyrakis, E. and R. Gerlagh. "The Resource Curse Hypothesis and its Transmission Channels." Journal of Comparative Economics 32, no. 1 (2004): 181-193.

Parasiliti, Andrew T. "The Causes and Timing of Iraq's Wars: A Power Cycle Assessment." International Political Science Review 24, no. 1 (2003): 151-165.

Petrova, Maria. "A Formal Theory of Public Opinion in Conflicts." Unpublished Paper. New Economic School, 2008.

Phillip, G. "When Oil Prices Were Low: Petroleos de Venezuela (PdVSA) and Economic PolicyMaking in Venezuela Since 1989." Bulletin of Latin American Research 18, no. 3 (1999): 361-376.

Popjanevski, J. "From Sukhumi to Tskhinvali: the Path to War in Georgia." In The Guns of August 2008, edited by Svante Cornell and S. Frederick Starr. M.E. Sharpe, 2009.

Post, Jerrold M. "Saddam Hussein of Iraq: A Political Psychology Profile." Political Psychology (1991): 279-289.

Quandt, William. Saudi Arabia in the 1980s: Foreign Policy, Security, and Oil. Brookings Institution Press, 1981.

Record, Jeffrey. "Defeating Desert Storm (and Why Saddam Didn't)." Comparative Strategy 12, no. 2 (1993): 125-140.

Reiter, Dan. "Exploring the Bargaining Model of War." Perspective on Politics 1, no. 1 (2003): $27-43$. 
Rios, Xulio. "China and Venezuela: Ambitions and Complexities of an Improving Relationship." East Asia 30, no. 1 (2013): 53-65.

Robinson, James A., Ragnar Torvik and Thierry Verdier. "Political Foundations of the Resource Curse." Journal of Development Economics 79 (2006): 447468.

Rochlin, James. "Who Said the Cold War is Over? The Political Economy of Strategic Conflict between Venezuela and Colombia." Third World Quarterly 32, no. 2 (2011): 237-260.

Rose, Richard and Neil Munro. "Do Russians See Their Future in Europe or the CIS?" EuropeAsia Studies 60, no. 1 (2008): 49-66.

Rosenau, James N. Comparing Foreign Policies: Theories, Findings, and Methods. Halsted Press, 1974.

Rosecrance, Richard N. The Rise of the Trading State: Commerce and Conquest in the Modern World. Basic Books, 1986.

Rosnick, David. "Adjusting for Polling Biases in Venezuela's 2012 Presidential Election." Center for Economic and Policy Research Papers (2012).

Ross, Michael. "Does Oil Hinder Democracy?" World Politics 53 (2001): 325-361.

Ross , Michael. "What Do We Know about Natural Resources and Civil War?" Journal of Peace Research 41(2004): 337-356.

Ross, Michael, and Erik Voeten. "Oil and Unbalanced Globalization." Working Paper, Georgetown University, 2013.

Russett, Bruce and John Oneal. Triangulating peace: Democracy, Interdependence, and International Organizations. Norton, 2001.

Ryan, Curtis. Jordan in Transition: From Hussein to Abdullah. Lynne Rienner Publishers, 2002.

Sachs, J. D. and A. M. Warner. "Natural Resource Abundance and Economic Growth." Harvard Institute for International Development Working Paper 517 (1995).

Sakwa, Richard. "New Cold War or Twenty Years Crisis? Russia and International Politics." International Affairs 84, no. 2 (2008): 241-267.

Sarbu, Bianca. "A Comparative Analysis of Oil-Production Sectors in Saudi Arabia and the United Arab Emirates." EUGOV Working Paper 31, 2011.

Schmidinger, Thomas. "Yemen: State Failure by Regime Support?" Orient 2 (2010): 39-41.

Shakarian, Paulo. "The 2008 Russian Cyber Campaign Against Georgia." Military Review 91, no. 6 (2011): 63-68.

Shelley, Louise. "International Dimensions of Corruption: The Russian Case." Working Paper, Princeton University, 2003. 
Shlapentokh, Dmitry. "The Illusions and Realities of Russian Nationalism." Washington Quarterly 23, no. 1 (2000): 173-186.

Sick, Gary. "Trial by Error: Reflections on the Iran-Iraq War." The Middle East Journal 43, no. 2 (1989): 230-245.

Signorino, C. and J. Ritter. "Tau-b or Not Tau-b: Measuring the Similarity of Foreign Policy Positions." International Studies Quarterly 43, no. 1 (1999): 115-144.

Silva, Patricio. "Technocrats and Politics in Chile: From the Chicago Boys to the CIEPLAN Monks." Journal of Latin American Studies 23, no. 2 (1991): 385-410.

Skocpol, T. "Rentier State and Shi'a Islam in the Iranian Revolution." Theory and Society 11, no. 3 (1982): 265-283.

Soldatov, Andrei and Irina Borogan. The New Nobility: the Restoration of Russia's Security State and the Enduring Legacy of the KGB. Perseus Books, 2011.

Spechler, Dina Rome. "Russian Foreign Policy During the Putin Presidency." Problems of PostCommunism 57, no. 5 (2010): 35-50.

Staar, Richard Felix. "Decision Making in Russia." Mediterranean Quarterly 13, no. 2 (2002): $9-26$.

Staar, Richard Felix, and Corliss A. Tacosa. "Russia's Security Services." Mediterranean Quarterly 15, no. 1 (2004): 39-57.

Stein, Elizabeth A. "The Unraveling of Support for Authoritarianism: The Dynamic Relationship of Media, Elites, and Public Opinion in Brazil, 197282." The International Journal of Press/Politics 2012: 1-23.

Stenslie, Stig. Not Too Strong, Not Too Weak: Saudi Arabia's Policy towards Yemen. Norwegian Peacebuilding Resource Centre, March 2013.

Stevens, P. and E. Dietsche. "Resource Curse: An Analysis of Causes, Experiences and Possible Ways Forward." Energy Policy 36, no. 1 (2008): 56-65.

Strouse, Kevin R. "Russian Natural Gas: Enabler of Uncooperative Foreign Policy." Masters thesis, Georgetown University, 2009.

Strüver, Georg. "Too Many Resources or Too Few? What Drives International Conflicts?" German Institute of Global and Area Studies (GIGA) Working Papers 147 (2010): 1-31.

Szászdi, Lajos F. Russian Civil-Military Relations and the Origins of the Second Chechen War. University Press of America, 2008.

Tabata, Shinichiro. "Russian Revenues from Oil and Gas Exports: Flow and Taxation." Eurasian Geography and Economics 43, no. 8 (2002): 610-627.

Talbott, Strobe. The Russia Hand: A Memoir of Presidential Diplomacy. Random House, 2007. 
Telhami, Shibley. "Arab Public Opinion on the United States and Iraq: Postwar Prospects for Changing Prewar Views." Brookings Review 21, no. 3 (2003): 24-27.

Terrill, W. Andrew. The Conflicts in Yemen and U.S. National Security. Strategic Studies Institute Monograph, 2011.

Tickner, Arlene. "Colombia: An Ambiguous Foreign Policy." Conference Paper, Latin American Studies Association Congress, 2001.

Tilly, Charles. Coercion, Capital, and European States, AD 990-1990. Blackwell, 1990.

Thiel, Tobias. "After the Arab Spring: Power Shift in the Middle East: Yemen's Arab Spring from Youth Revolution to Fragile Political Transition." LSE Ideas, London School of Economics and Political Science, 2012.

Tokatlian, Juan. "Colombia at War: the Search for a Peace Diplomacy." International Journal of Politics, Culture and Society 14, no. 2 (2000): 333-362.

Tomz, M., G. King, and L. Zeng. "ReLogit: Rare Events Logistic Regression." Journal of Statistical Software 8 (2003): 137-163.

Tomz, Michael, and Jessica Weeks. "Public Opinion and the Democratic Peace." American Political Science Review 107, no. 3 (2013).

Trenin, Dmitri. "Russia Reborn: Reimagining Moscow's Foreign Policy." Foreign Affairs 88, no. 6 (2009): 64-78.

Trenin, Dmitri. "Russia's Threat Perception and Strategic Posture." In Russian Security Strategy under Putin: U.S. and Russian Perspectives, by Dmitri Trenin and R. Craig Nation, 35-47. Strategic Studies Institute Monograph, 2007.

Tsygankov, Andrei. "If Not by Tanks, Then by Banks? The Role of Soft Power in Putin's Foreign Policy." Europe-Asia Studies 58, no. 7 (2006): 1079-1099.

Ulfelder, J. "Natural-Resource Wealth and the Survival of Autocracy." Comparative Political Studies 40, no. 8 (2007): 995-1018.

Vatansever, Adnan. Russia's Oil Exports: Economic Rationale Versus Strategic Gains. Carnegie Endowment for International Peace, 2011.

Vom Hau, Matthias. "State Capacity and Inclusive Development: New Challenges and Directions." Effective States and Inclusive Development Research Centre Working Paper, University of Manchester, 2012.

Waldner, David and Benjamin B. Smith. "Rentier States and State Transformations." In Oxford Handbook on Transformations of the State. Oxford University Press, 2014 (Forthcoming).

Walt, Stephen. "Alliance Formation and the Balance of World Power." International Security 9, no. 4 (1985): 3-43. 
Walton, Richard J. The Power of Oil: Economic, Social, and Political. Seabury Press, 1977.

Waltz, Kenneth. Theory of International Relations. Addison-Webley, 1979.

Waisberg, Tatiana. "The Colombia-Ecuador Armed Crisis of March 2008: The Practice of Targeted Killing and Incursions against Non-State Actors Harbored at Terrorist Safe Havens in a Third Party State." Studies in Conflict and Terrorism 32, no. 6 (2009): 476-488.

Weeks, Jessica L. "Strongmen and Straw Men: Authoritarian Regimes and the Initiation of International Conflict." American Political Science Review 106, no. 2 (2012): 326-347.

Weeks, Jessica L. "Autocratic Audience Costs: Regime Type and Signaling Resolve." International Organization 62, no. 1 (2008): 35-64.

Westing, A. H. Global Resources and International Conflict: Environmental Factors in Strategic Policy and Action. Stockholm International Peace Research Institute, 1986.

Williams, A. "Shining a Light on the Resource Curse: An Empirical Analysis of the Relationship between Natural Resources, Transparency, and Economic Growth." World Development 39, no. 4 (2011): 490-505.

Wilpert, Gregory. "Making Sense of Colombia-Venezuela Relations." NACLA Report on the Americas (May/June 2011).

Wilpert, Gregory. "A New Turn in Colombia-Venezuela Relations." NACLA Report on the Americas (Sept/Oct 2010).

Wiseman, Colin and Daniel Beland. "Change in Venezuela: Oil Policy During the Presidency of Hugo Chávez." Canadian Journal of Latin American and Caribbean Studies 35 (2010): 141-164.

Yergin, Daniel. The Prize: The Epic Quest for Oil, Money and Power. Simon and Schuster, 2003.

Yergin, Daniel. The Quest: Energy, Security, and the Remaking of the Modern World. Penguin Books, 2011.

Zardykhan, Zharmukhamed. "Kazakhstan and Central Asia: Regional Perspectives." Central Asian Survey 21, no. 2 (2002): 167-183.

Zimmerman, William. The Russian People and Foreign Policy: Russian Elite and Mass Perspectives, 1993-2000. Princeton University Press, 2001.

Zimmerman, William. "Survey Research and Russian Perspectives on NATO Expansion." PostSoviet Affairs 17, no. 3 (2001): 235-261. 


\section{Data Sources}

Bennett, D. Scott, and Allan Stam. EUGene Software. "EUGene: A Conceptual Manual." International Interactions 26:179-204. Available from: http://eugenesoftware.org.

British Petroleum. Statistical Review of World Energy 2011. Available from: http://www.bp.com/en/global/corporate/about-bp/energy-economics/statistical-review-ofworld-energy/statistical-review-downloads.html.

Gazprom. Annual Financial Report 2009. Available from http://www.gazprom.com/investors/reports/2009.

Ghosn, Faten, and Scott Bennett. Codebook for the Dyadic Militarized Interstate Incident Data Version 3.10 (2003). Available from: http://correlatesofwar.org.

Haber, Stephen and Victor Menaldo. Replication Data. "Do Natural Resources Fuel Authoritarianism? A Reappraisal of the Resource Curse." American Political Science Review 105, no. 1 (2011): 1-26. Data obtained directly from author.

Latinobarometró. Latinobarometer Survey Data 2013. Available from http://www.latinobarometro.org.

Levada Analytical Center. Russian Public Opinion Survey Booklet 2012-2013. Moscow: Levada Center (2013). Available from http://www.levada.ru/books/obshchestvennoe-mnenie-2012-eng.

Lujala, Päivi, Jan Ketil Rød and Nadia Thième. "Fighting over Oil: Introducing A New Dataset." Conflict Management and Peace Science (2007) 24, no. 3: 239-256.

Marshall, Monty and Keith Jaggers. Polity IV Project: Political Regime Characteristics and Transitions, 1800-2002. Version 2002. Available from: http://www.systemicpeace.org/inscrdata.html.

Morgan, T. C, N. Bapat, and V. Krustev. Threat and Imposition of Sanctions (TIES) Data Users Manual. Version 3.5 (2006). Available from: http://www.unc.edu/ bapat/TIES.htm.

Pew Research Center. Global Attitudes Project Data 2013. Available from http://www.pewglobal.org/category/datasets.

Russett, Bruce and John Oneal. Replication Data. Triangulating Peace: Democracy, Interdependence, and International Organizations. W.W. Norton (2001). Available from: http://pantheon.yale.edu/ brusset/PeaceStata.zip.

Stockholm International Peace Research Institute. SIPRI Yearbook 2013. Sweden: Stockholm International Peace Research Institute (2013). Available from http://www.sipri.org/yearbook/2013.

Stockholm International Peace Research Institute. Trends in World Military Expenditure 2013. Sweden: Stockholm International Peace Research Institute (2013). Available from http://books.sipri.org/product_info?c_product_id $\overline{4} 76$.

Stockholm International Peace Research Institute. International Arms Transfers Database (2013). Sweden: Stockholm International Peace Research Institute (2010). Available from: http://www.sipri.org/research/armaments/transfers. 
Stockholm International Peace Research Institute. SIPRI Yearbook 2010. Sweden: Stockholm International Peace Research Institute (2010). Available from: http://www.sipri.org/yearbook/2010.

U.S. Energy Information Administration. International Energy Statistics 2012. Available from: http://www.eia.gov/countries/data.cfm.

World Bank. World Development Indicators 2013. Washington, DC: World Bank. doi: 10.1596/978-0-8213-9824-1. Available from: http://data.worldbank.org/data-catalog/worlddevelopment-indicators. 


\section{News Articles and Sources}

Agence-France Presse (August 8, 2013), "Moscow Rejects Saudi Offer to Drop Assad for Arms Deal."

Agence-France Presse (May 5, 2013), "Venezuelan President Nicolás Maduro Blasts 'Devil' Obama."

Agence-France Presse (March 17, 2012), "Saudi Sends Military Gear to Syria Rebels: Diplomat." Agence-France Presse (June 8, 2011), "Saudis May be Key to a Yemen Solution."

Agence-France Presse (November 10, 2009), "Saudi to Bomb Until Yemen Rebels Back Off: Minister."

Agence-France Presse (March 13, 2008), "Bush Lashes Out At Chávez."

Al Jazeera (May 22, 2011), "Yemen Transition Deal Collapses."

Al Jazeera (November 11, 2009), "Saudis 'to Keep up Houthi Campaign."”

Aló Presidente Broadcast (December 9, 2010). Aló Presidente with Hugo Chávez. Caracas: Venezolana de Televisin.

Aló Presidente Broadcast (January 1, 2007). Aló Presidente with Hugo Chávez. Caracas: Venezolana de Televisin.

Aló Presidente Broadcast (March 2006). Aló Presidente with Hugo Chávez. Caracas: Venezolana de Televisin.

American Enterprise Institute. "Tracker: Saudi Arabia's Military Operations Along Yemeni Border." Washington DC: American Enterprise Institute (January 4, 2010). Available from: http://www.criticalthreats.org/yemen/tracker-saudi-arabia\%E2\%80\%99s-militaryoperations-along-yemeni-border.

Associated Press International (January 23, 2010), "Saudi: Bodies of 20 Soldiers Found on Yemen Border."

Associated Press International (November 5, 2009), "Diplomats: Saudi Bombs Yemen Rebels Across Border."

Associated Press International (August 15, 2008), "War Shows Putin Still in Charge."

Associated Press International (June 2, 2006), "Saudi, Yemeni Ministers Sign Border Demarcation Agreement in Southeast Yemen."

Associated Press International (January 31, 2000), "Albright in Moscow To Size Up Putin." BBC News (17 August, 2008). "Russia pledge on Georgia pull-out." 
BBC Worldwide Monitoring (November 12, 2009), "Qatari Paper says Saudi Attack on Huthists 'Sharp Change' in Foreign Policy."

BBC Worldwide Monitoring (July 23, 2010). "Venezuela Severs Ties with Colombia."

BBC Worldwide Monitoring (February 7, 2008). "Venezuelan Retired General says Chávez Wants to Create FARC Border State."

Comins-Richmond, Walter. "The Second Chechnya War." Los Angeles, CA: Occidental College, 2007. Available from: http://faculty.oxy.edu/richmond/csp8/second_chechen_war.htm.

CNN (February 23, 2011), "Saudi King Returns Home to Shaken Mideast."

Council on Foreign Relations. "Venezuela's Oil-Based Economy." Washington D.C: Council on Foreign Relations Backgrounder (February 9, 2009). Available from: http://www.cfr.org/world/venezuelas-oil-based-economy/p12089.

Council on Foreign Relations. "Iraq: Oil for Food Scandal." Washington D.C: Council on Foreign Relations Backgrounder (October 28, 2005). Available from: http://www.cfr.org/iraq/iraq-oilfood-scandal/p7631.

Defense Industry Daily (July 18, 2013), "The Saudis' American Shopping Spree." Available from: http://www.defenseindustrydaily.com/a-2010-saudi-shopping-spree-06520.

The Diplomat (February 8, 2013), "Did Russian Jets Violate Japanese Airspace?" Available from: http://thediplomat.com/flashpoints-blog/2013/02/08/did-russian-jets-violate-japanese-airspace.

El Universal (December 27, 2007), "Envoy to Venezuela says Colombia ready "to turn the page" on recent impasse."

Eurasia Daily Monitor (August 9, 2012), "Putin Confirms the Invasion of Georgia Was Preplanned."

Financial Times (March 5, 2008), "Uribe accuses Venezuela of backing Farc 'Genocide'."

Financial Times (March 4, 2008), "Venezuelan Action Falls Short of Chávez's Bellicose Bluster."

Financial Times (January 20, 2005), "Lula Acts to Broker End to Standoff over Farc 'arrest'."

Financial Times (November 27, 2000), "The Americas: Colombia recalls its ambassador."

Forbes (January 10, 2012), "Oil and Natural Gas Prices Get Divorced." Available from: http://www.forbes.com/sites/energysource/2012/01/10/oil-and-natural-gas-prices-get-divorced.

Foreign Affairs (September 7, 2011), "Pushing for Reform in Bahrain."

Foreign Affairs (May/June 2006), "Saddam's Delusions: The View From the Inside."

Foreign Affairs (March/April 2005), "Ukraine's Orange Revolution." 
Foreign Affairs (Jan/Feb 2004), "The Saudi Paradox."

Foreign Affairs (Jul/Aug 1999), "Colombia on the Brink: There Goes the Neighborhood."

Foreign Policy (November 8, 2013), "Saudi Arabia's Shadow War."

Foreign Policy (August 26, 2013), "CIA Files Prove America Helped Saddam as he Gassed Iran."

Foreign Policy (July 17, 2013), "Egypt's Wide State Reassembles Itself."

Foreign Policy (March 16, 2011), "The GCC Shows its True Colors."

Foreign Policy (March 14, 2011), "Saudi Arabia Strikes Back."

Foreign Policy (July 24, 2010), "The Prince and the Revolution."

Foreign Policy (February 12, 2010), "What do Saudis Want?"

Foreign Policy (Sept/Oct 2009), "A Diplomatic Mystery."

Foreign Policy (Jan 4, 2006), "Hugo Boss."

Gallup World. "Colombians and Venezuelans at Odds on Leadership." Washington, D.C: Gallup (November 24, 2009). Available from: http://www.gallup.com/poll/124478/colombiansvenezuelans-odds-leadership.aspx.

The Guardian (November 7, 2013), "Syria Crisis: Saudi Arabia to Spend Millions to Train New Rebel Force."

The Guardian (April 8, 2011), "WikiLeaks: Yemen Tricked Saudis into Nearly Bombing President's Rival."

The Guardian (November 20, 2009), "Venezuela Blows Up Border Bridges With Colombia."

Heritage Foundation. "State Sponsors of Terrorism: Time to Add Venezuela to the List." Washington, D.C: Heritage Foundation Backgrounder (January 20, 2010). Available from: http://www.heritage.org/research/reports/2010/01/state-sponsors-of-terrorism-timeto-add-venezuela-to-the-list.

Independent International Fact-Finding Mission on the Conflict in Georgia (IIFFMCG CEIIG). "Report on the Conflict in Georgia Volume I." Brussels, Belgium: Independent International Fact-Finding Mission on the Conflict in Georgia (2009). Available from: http://www.ceiig.ch/Report.html.

Independent International Fact-Finding Mission on the Conflict in Georgia (IIFFMCG CEIIG). "Report on the Conflict in Georgia Volume II." Brussels, Belgium: Independent International Fact-Finding Mission on the Conflict in Georgia (2009). Available from: http://www.ceiig.ch/Report.html.

Intelligence Online (June 30, 2011), "CIA relies on Riyadh in Yemen." 
Intelligence Online (March 31, 2011), "Princes Try to Extinguish Arab Revolts; Saudi Arabia." Interfax (November 13, 2007), "Adapted CFE Treaty A Yoke For Russia - Chief Of The Staff." International Crisis Group. "Central Asia: Border Disputes and Conflict Potential." Washington, D.C: International Crisis Group (2002). Available from: http://www.crisisgroup.org/en/regions/asia/central-asia/033-central-asia-border-disputes-andconflict-potential.aspx.

International Herald Tribune (May 13, 2011), "Dear Comrade... The Farc files lift the lid on Hugo Chvez's Venezuela."

International Herald Tribune (March 15, 2011), "Strain Tugs at Ties with a Key U.S. Ally; Saudis Taking a Dim View of American Stances from Mubarak to Bahrain."

Izvestia (24 February, 1998), "Untitled."

Kommersant (July 6, 1999), "Secret Airport in Pristina."

Kommersant-Vlast (March 4, 2014), "Who Influenced the Kremlin's Policy in Ukraine?"

Memorial Human Rights Center. "From Chechenization to Palestinization: The Human Rights Situation in Chechnya and North Caucasus in 2004." Moscow, Russia: Memorial Human Rights Center (2004). Available from: http://www.memo.ru/eng/memhrc/texts/5palest.shtml.

McLatchy Washington Bureau (June 22, 2011), "Wikileaks: Saudi Crackdown on Shi'ites has Echoes in Bahrain."

McLatchy Washington Bureau (October 18, 2010), "Spain-Venezuela Ties Strained as Hugo Chávez Stonewalls ETA Investigation."

Mideast Mirror (June 8, 2011), "Buying Loyalty in Yemen."

Moscow Times (August 1, 2000), "Putin Sacks 6 of Sergeyev's Generals."

The Nation (August 13, 2012), "Colombia Keyword: Insurgency."

Nezavismaya Gazeta (December 1, 2000), "Russian Security Council Secretary Interviewed."

New York Times (September 9, 2013), "Tracking the Syrian Crisis and the International Response."

New York Times (May 4, 2012), "The Realest Reality Show in the World."

New York Times (February 10, 2012), "In Rare, Blunt Speech, Saudi King Criticizes Syria Vetoes."

New York Times (August 11, 2010), "Leaders Repair Ties Between Colombia and Venezuela."

New York Times (January 12, 2010), "Saudi and Yemeni Forces Fight Rebels on 2 Fronts." 
New York Times (May 10, 2011), "Venezuela Asked Colombian Rebels to Kill Opposition Figures, Analysis Shows."

New York Times (August 20, 2008), "West Baffled by 2 Heads for Russian Government."

New York Times (March 6, 2008), "Regional Bloc Says Ecuador's Sovereignty Was Violated."

New York Times (March 3, 2008), "Troops Mass at Colombian Borders in Crisis Over Killing of Rebel."

New York Times (November 29, 2007), "Chávez Says He’ll Cut Ties With Colombia And Its Leader."

New York Times (February 25, 2007), "Venezuela Spending on Arms Soars to World's Top Ranks."

New York Times (February 1, 2000), "A Look at How the Kremlin Slid Into the Chechen War."

New York Times (September 10, 1999), "U.S. General Was Overruled in Kosovo."

New York Times (September 9, 1995), "No Title."

New York Times (March 17, 1995), "Nationalist Fever Helps Heat Up Another Latin Border."

New York Times (August 24, 1987), "Two Claims of Territory Roil Waters in Gulf of Venezuela."

NPR (October 22, 2010), "Foreign Policy: A Prince's Mysterious Disappearance."

Putin, Vladimir. "Speech at the Valdai Discussion Club," (October 25, 2012). Available from: http://eng.kremlin.ru/news/4564.

Putin, Vladimir. "Speech at the Munich Security Conference," (February 12, 2007). Available from: http://archive.kremlin.ru/eng/speeches/2007/02/10/0138_type82912type82914type82917type84779_11812

Reuters (March 11, 2014), "From loyal aides and 'inner voice', Putin hears no Crimea Dissent."

Reuters (September 29, 2011), "Frail Saudi Royals Face Hard Diplomatic Choices."

Reuters (July 14, 2011), "Saudi Policy on Yemen and Syria seen Floundering."

Reuters (December 2, 2010), "Saudis Think Yemen is a Failed State - Leaked US Cable."

Reporters Sans Frontiéres. "World Press Freedom Index." Paris, France: Reporters Sans Frontiéres (2013). Available from: http://rsf.org/index2014/en-index2014.php.

RIA Novosti (February 22, 2012), "Saudi Arabia King: Current Dialogue on Syria 'Useless'."

RIA Novosti (March 25, 2010), "Russian Air Force Denies it Violated British Airspace."

Rossisskaya Gazeta (1 October 1999), "No Title." 
Russian Federation. "Foreign Policy Concept of the Russian Federation." Moscow, Russia: Russian Federation (1993). Available from: http://www.mid.ru/ns-osndoc.nsf/osnddeng.

Russian Federation. "Military Strategy Document of the Russian Federation." Moscow, Russia: Russian Federation (2003). Available from: http://www.mid.ru/ns-osndoc.nsf/osnddeng.

Sevodnya (June 18, 1999), "The Window of Opportunity in Pristina Slams Shut."

STRATFOR (April 18, 2010), "Hezbollah is Radical but Rational." Available from: http://www.stratfor.com/weekly/20100811_hezbollah_radical_rational.

Sunday Times (April 11, 1999): "Enter the Bear."

United Nations Security Council. "UN Security Council Resolution 1199." New York, NY: United Nations (September 23, 1998).

Univision (April 11, 2013), "Los secretos de las FARC sobre Nicolás Maduro."

U.S. Central Intelligence Agency. Prewar Status of Iraq's Weapons of Mass Destruction. McLean, VA: Central Intelligence Agency, 2002. Available from: http://fas.org/irp/gulf/cia/961102/72247_01.htm.

U.S. Congressional Research Service. Iraq: Former and Recent Military Confrontations With the United States. Washington, D.C: Congressional Research Service, 2002.

U.S. Congressional Research Service. Iraq: Post-War Challenges and U.S. Responses, 1991-1998. Washington, D.C: Congressional Research Service, 1999.

U.S. Congressional Research Service. Country Profile: Venezuela. Washington, D.C: Congressional Research Service, 1990.

U.S. Congressional Research Service. Country Profile: Yemen. Washington, D.C: Congressional Research Service, 2008.

U.S. Congressional Research Service. Country Profile: Soviet Union. Washington, D.C: Congressional Research Service, 1989.

U.S. Energy Information Administration. Russia Country Report. Washington, D.C: Energy Information Administration, 2014.

U.S. Energy Information Administration. Iraq Country Report. Washington, D.C: Energy Information Administration, 2013.

U.S. Energy Information Administration. Saudi Arabia Country Report. Washington, D.C: Energy Information Administration, 2013.

U.S. Energy Information Administration. Venezuela Country Report. Washington, D.C: Energy Information Administration, 2012. 
U.S. Department of State. US-Saudi Technical Cooperation Agreement. Washington D.C: Department of State, 2008. Available from http://www.state.gov/documents/organization/109344.pdf.

U.S. Senate Committee on Foreign Relations. Hearing Before the Committee on Foreign Relations of the United States Senate. Washington D.C, November 4, 1999. Available from http://www.gpo.gov/fdsys/pkg/CHRG-106shrg61866/html/CHRG-106shrg61866.htm.

U.S. Senate Committee on Foreign Relations. Hearing Before the Committee on Foreign Relations of the United States Senate, Subcommittee on the Western Hemisphere. Washington D.C, July 17, 2008. Available from http://www.democrats.foreignaffairs.house.gov/110/cor071708.pdf.

US News (April 24, 2013), "Iranian-Sponsored Narco-Terrorism in Venezuela: How Will Maduro Respond?"

Washington Institute. "Saudi Arabia's Oil Policy Vacancies." Washington, D.C: Washington Institute (January 7, 2011). Available from: http://www.washingtoninstitute.org/policyanalysis/view/saudi-arabias-oil-policy-vacancies.

Washington Post (October 8, 2012), "Saudis Line Up Against Syrian Regime."

Washington Post (July 30, 2006), "Hugo Chávez Receives Iran’s Highest Honor."

Washington Post (June 13, 1999), "NATO Occupies Tense Kosovo Capital."

The Washington Times (December 10, 2009), "Colombia Faces Border Tensions with Venezuela."

Window on Eurasia (Paul Goble) (May 13, 2014), "Budget Figures Show Putin has Been Preparing for War for Four Years, Nemtsov Says."

World Tribune (August 12, 2013), "Ailing Saudi Crown Prince Suddenly Takes 'Special Leave'." 